UNIVERSIDADE FEDERAL DE GOIÁS

ESCOLA DE ENGENHARIA CIVIL E AMBIENTAL

PROGRAMA DE PÓS-GRADUAÇÃO EM GEOTECNIA

ESTRUTURAS E CONSTRUÇÃO CIVIL

\title{
ANÁLISE ESTÁTICA NÃO-LINEAR DE CASCAS CONOIDAIS
}

\section{DANIELLY LUZ ARAÚJO DE MORAIS}

D0153E17

GOIÂNIA

2017 


\section{TERMO DE CIÊNCIA E DE AUTORIZAÇÃO PARA DISPONIBILIZAR VERSÕES ELETRÔNICAS DE TESES E DISSERTAÇÕES NA BIBLIOTECA DIGITAL DA UFG}

$\mathrm{Na}$ qualidade de titular dos direitos de autor, autorizo a Universidade Federal de Goiás (UFG) a disponibilizar, gratuitamente, por meio da Biblioteca Digital de Teses e Dissertações (BDTD/UFG), regulamentada pela Resolução CEPEC no 832/2007, sem ressarcimento dos direitos autorais, de acordo com a Lei no 9610/98, o documento conforme permissões assinaladas abaixo, para fins de leitura, impressão e/ou download, a título de divulgação da produção científica brasileira, a partir desta data.

\section{Identificação do material bibliográfico: [x] Dissertação [ ] Tese}

\section{Identificação da Tese ou Dissertação:}

Nome completo do autor: Danielly Luz Araújo de Morais

Título do trabalho: Análise Estática Não-linear de Cascas Conoidais

\section{Informações de acesso ao documento:}

Concorda com a liberação total do documento [ $x$ ] SIM

[ ] NÃO

Havendo concordância com a disponibilização eletrônica, torna-se imprescindível o envio do(s) arquivo(s) em formato digital PDF da tese ou dissertação.

Ciente e de acordo:

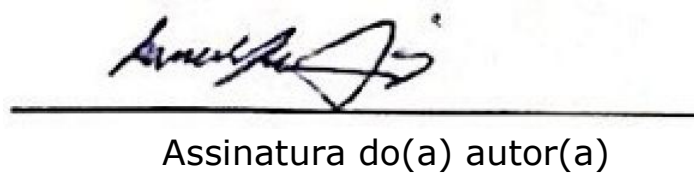




\section{ANÁLISE ESTÁTICA NÃO-LINEAR DE CASCAS CONOIDAIS}

Dissertação apresentada ao Programa de Pós Graduação em Geotecnia, Estruturas e Construção Civil da Universidade Federal de Goiás para a obtenção do título de Mestre em Engenharia Civil.

Área de concentração: Mecânica das estruturas.

Orientadora: Prof ${ }^{a}$. D. Sc. Renata Machado Soares

Co-orientador: Prof. D. Sc. Frederico Martins Alves da Silva

D0153E17

GOIÂNIA

2017 
Dados Internacionais de Catalogação na Publicação na (CIP)

\section{GPT/BC/UFG}

Morais, Danielly Luz Araújo de.

Análise estática não-linear de cascas conoidais [dissertação] / Danielly Luz Araújo de Morais - 2017. $\mathrm{xv}, 113 \mathrm{f}$. : il., figs, tabs.

Orientadora: Prof ${ }^{a}$. Dr ${ }^{\mathrm{a}}$. Renata Machado Soares; Coorientador: Prof. Dr. Frederico Martins Alves da Silva

Dissertação (Mestrado) - Universidade Federal de Goiás, Escola de Engenharia Civil e Ambiental, 2017.

Bibliografia.

Inclui lista de figuras, abreviaturas, siglas e tabelas.

1. Carga crítica 2. Casca conoidal 3. Método dos elementos finitos 4. Trajetória não-linear de equilíbrio 
Ata de $N^{0} 0153$ da sessão de julgamento de Dissertaçăo da aluna Danielly Luz Araújo de Morais da área de concentraçăo Mecânica das Estruturas do PPG em Geotecnia, Estruturas e Construçào Civil

Aos 27 dias do mes de junho de 2017, às 09h00, no Auditório Biolkino Pereira, da Escola de Engenharia Civil e Ambiental da Universidade Federal de Goiás, reuniu-se a banca examinadora designada na forma regimental pela Coordenaçâo do Curso de Pós-Graduaçăo em Geotecnia, Estruturas e Construção Civil para julgar a Dissertaçăo intitulada "Análise Estática Não-Linear do Cascas Conoidais", apresentada pela aluna Danielly Luz Araújo de Morais, como parte dos requisitos necessários à obtençâo do grau de MESTRE, área de concentração Mecânica das Estruturas A Banca Examinadora foi Presidida pela Prof ${ }^{\circ} \mathrm{Dr}{ }^{\circ}$ Renata Machado Soares (GECON/UFG), tendo como membros o Prol. Dr. Zenón José Guzmán N. del Prado (GECON/UFG) e o Prof. Dr. Eulher Chaves Carvalho (IFG - Jatai). Aberta a sessão pública, a candidata teve a oportunidade de expor o trabalho Após a exposição, a aluna foi arguida oralmente pelos membros da Banca, os quais concluiram pelos seguintes resultados:

Membro

Renata Machado Soares

Zenón José Guzmán N. del Prado

Eulher Chaves Carvalho

$$
\text { Instituiçăo }
$$

GECON/UFG

GECON/UFG

IFG - Jataí

\section{Função}

Presidente

Examinador Interno

Examinador Externo
Resultado

\section{APROVADA}

\section{APROVADA}

Aprovede

(N) Tendo demonstrado suficiéncia de conhecimento e capacidade de sistematizaçăo no tema de sua Dissertaçăo, a Banca Examinadora concluiu pela aprovação da candidata sem restriçōes.

( ) Não tendo demonstrado suficiéncia de conhecimento e capacidade de sistematização no tema de sua Dissertação, a Banca Examinadora concluiu pela reprovação da candidata, conforme as seguintes justificativas

Nos termos do Regulamento Geral dos Cursos de Pós-Graduação desta Universidade, foi lavrada a presente ata que, lida e julgada conforme, segue assinada pelos membros da Banca Examinadora e pela candidata.

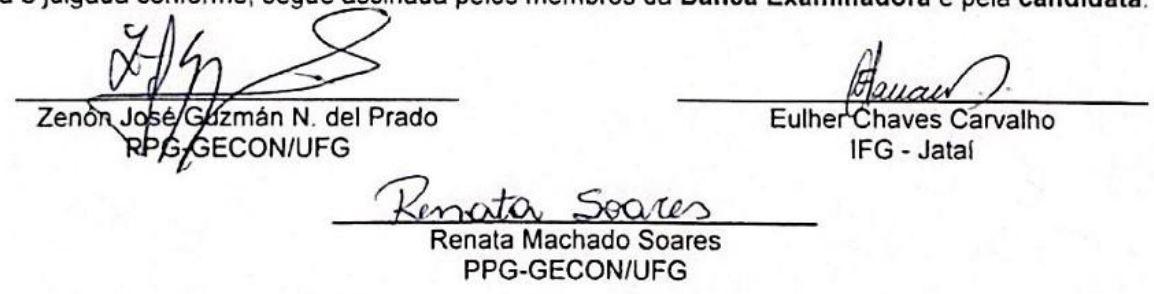

Candidata: Danielly Luz Araújo de Morais

$$
\text { sumes } 75^{\circ}
$$




\section{AGRADECIMENTOS}

Com muita gratidão, agradeço àqueles que me apoiaram, ajudaram e acompanharam tornando possível a produção desta dissertação.

Primeiramente a Deus, por sua graça e bondade eterna na minha vida, guiando-me em cada passo e dando-me a força necessária para seguir o caminho.

Aos meus queridos familiares, um agradecimento especial aos meus pais Ivan e Fátima, por me amarem e fazerem o possível para que meus sonhos se realizem sem nunca esperar qualquer vantagem para si e nem pedirem nada em troca. Por acreditarem e incentivarem o meu desejo de obter mais esta conquista dou-lhes meu mais profundo respeito, amor e consideração. Às minhas irmãs, Franciellen e Juliana, por me encorajarem e incentivarem, desejando-me sempre sucesso mesmo nas mais difíceis decisões. Ao meu amado, Eduardo, que apareceu em minha vida para me fazer feliz e estando sempre ao meu lado nas dificuldades com toda sua paciência, amor e amizade, se tornou parte integrante do resto de minha vida. À Madalena por seu apoio, dedicação e, principalmente, ter dado à luz a meu amado.

Não posso deixar de citar os professores do mestrado, peço-lhes licença para chamá-los pelo primeiro nome, Renata, Frederico, Sylvia, Daniel, Marcos, Júlio e Zenón, pois se não fosse por eles este mestrado não seria possível.

Aos professores orientadores Renata e Frederico, pela sabedoria, paciência, prontidão e dedicação ao longo do desenvolvimento desta dissertação.

Agradeço ao Programa de Pós Graduação em Geotecnia, Estruturas e Construção Civil da Universidade Federal de Goiás e também à CAPES pelo apoio financeiro.

Obrigado. 


\section{RESUMO}

No estudo analítico de cascas conoidais abatidas, tem-se a dificuldade de representar analiticamente os seus campos de deslocamentos. Dessa forma a análise numérica, como por exemplo, via Método dos Elementos Finitos (MEF), vem sendo utilizada no estudo desse tipo de estrutura. Neste trabalho, elabora-se uma análise estática de cascas conoidais abatidas de bordas curvas parabólicas, ou cilíndricas, de material elástico linear, homogêneo e isotrópico, submetidas a um carregamento transversal uniformemente distribuído ao longo da superfície. Com a formulação para placas finas derivada das hipóteses de Kirchhoff e a teoria desenvolvida por Marguerre para cascas finas, determinam-se as equações não-lineares de equilíbrio que regem o comportamento da casca conoidal, considerando que esta seja uma placa com um deslocamento inicial. Faz-se uma análise paramétrica linear das cargas críticas e modos de flambagem através do MEF utilizando o programa ABAQUS 6.11®, variando-se as condições de contorno e altura das bordas curvas. Avalia-se, analiticamente, a complexidade das componentes dos campos de deslocamentos do modo de flambagem de uma dada geometria através de sua decomposição em séries duplas de Fourier. Com a análise não-linear via MEF, obtêm-se as trajetórias não-lineares de equilíbrio dos deslocamentos da casca e obtêm-se os primeiros pontos limites de carregamento não-lineares. Comparam-se também as trajetórias não-lineares de equilíbrio de conóides de geometrias parabólicas, ou cilíndricas, com apoios indeslocáveis em suas quatro bordas, avaliando como as nãolinearidades geométricas influenciam nos modos dos campos de deslocamentos durante o carregamento. Por fim, efetua-se uma análise paramétrica não-linear da influência da variação das alturas das bordas curvas nas trajetórias de equilíbrio dos esforços de membrana e resultantes de momentos internos dos conóides. Verifica-se, com este trabalho, que análises lineares podem subestimar, ou superestimar, o comportamento não-linear do conóide. Sendo que a análise paramétrica influencia o comportamento do conóide frente ao carregamento, seja no âmbito da análise linear, resultando em diferentes cargas críticas e modos de flambagem, seja na análise não-linear, resultando em cargas limites e trajetórias não-lineares de equilíbrio dos deslocamentos e dos esforços de membrana e momentos, diferenciados.

Palavras-chave: Carga crítica, Casca conoidal, Método dos elementos finitos, Modo de flambagem, Trajetória não-linear de equilíbrio. 


\begin{abstract}
In the analytical study of conoidal shallow shells, one has the difficulty in analytically representing their displacement fields. In this way a numerical analysis, such as the Finite Element Method (MEF), has been used in the study of this type of structure. In this work, a static analysis of conoidal shallow shells from curved parabolic or cylindrical edges of linear, homogeneous and isotropic elastic material is performed, subjected to a transversal uniformly load distributed along the surface. With the thin-plate formulation derived from Kirchhoff's hypotheses and the theory developed by Marguerre for thin shells, the non-linear equilibrium equations that govern the behavior of the conoidal shell were determined, considering that this is a plate with an initial displacement. A linear parametric analysis of the critical loads and of buckling modes through the MEF is performed using ABAQUS $6.11 \circledR$ program, varying the contour and height conditions of the curved edges. Analytically, a complexity of the components of the buckling mode displacement fields of a given geometry is evaluated by its decomposition into double Fourier series. With the non-linear analysis via MEF, the nonlinear equilibrium trajectories of the displacements are obtained and the first non-linear loading limit points are obtained. Nonlinear parabolic or cylindrical geometric parabolic geometry trajectories with describable supports at their four edges are also compared, evaluating how the geometric non-linearities influence the modes of the displacement fields during loading. Finally, a non-linear parametric analysis of the influence of the variation of the curved edge heights on the equilibrium trajectories of the membrane stresses and resulting from internal moments of the conoidal shell is carried out. It is verified, with this work, that linear analyzes can underestimate, or overestimate, the nonlinear behavior of the conoid. As the parametric analysis influences the behavior of the conoid in front of the load, either in the linear analysis, resulting in different critical loads and modes of buckling, or in the nonlinear analysis, resulting in differentiated limits loads and nonlinear equilibrium trajectories of the displacements and membrane stresses and moments.
\end{abstract}

Key words: Critical load, Conoidal Shell, Finite element method, Buckling mode, Non-linear equilibrium trajectory. 


\section{LISTA DE FIGURAS}

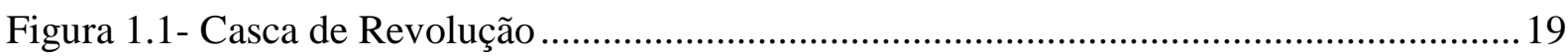

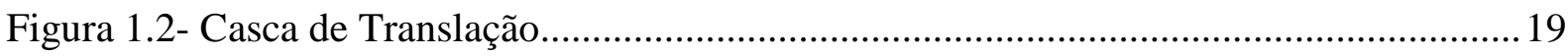

Figura 1.3- Algeciras Market- Espanha 1935 (Fonte: PLAZA, 2011) .................................... 20

Figura 1.4- Anahuac Market Hall and Annex- México 1957 (Fonte: STRUCTURAE, 2016)

Figura 1.5- Bacardi Rum Factory- México 1960 (Fonte: STRUCTURAE, 2016) ................. 20

Figura 1.6- Fundação Getúlio Vargas (Fonte: FGV, 2016).................................................. 21

Figura 1.7- Congresso Nacional- 1960 (Fonte: ZIGONI, 2014) ..........................................2

Figura 1.8- Paróquia Universitária João Evangelista- 2009 ...................................................21

Figura 1.9- Igreja de Lindéia- Minas Gerais (Fonte: FONTES, 2005) ..................................22

Figura 1.10- Memorial da América Latina (Fonte: DINIS; MEDRANO; MEIRELLES, 2009)

Figura 2.1- Geometria, campos de deslocamentos e sistema de eixos da casca conoidal........27

Figura 2.2- Variações geométricas da função de superfície da casca conoidal........................ 30

Figura 2.3- Convenção de sinais para o elemento infinitesimal $d x d y$ na configuração

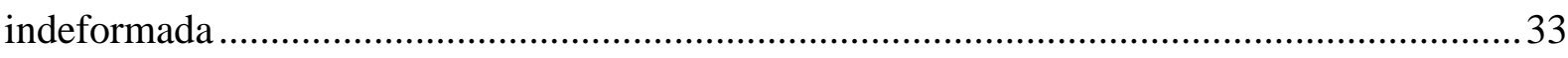

Figura 2.4- Graus de liberdade, adaptado pelo autor (ABAQUS 6.11, 2011) ...........................37

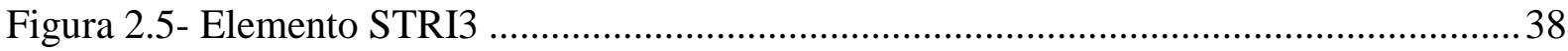

Figura 3.1- Malha de elementos finitos STRI3 modelada com o ABAQUS 6.11®................. 39

Figura 3.2- Representação em planta da casca conoidal com as condições de contorno e as bordas curvas e retas

Figura 3.3- Análise de convergência da malha de elementos finitos (caso parabólico de Geometria $3 \mathrm{~A}_{1} \mathrm{~A}_{1} \mathrm{~A}_{1} \mathrm{~A}_{1}$ )

Figura 3.4- Modo de flambagem do conóide parabólico para diferentes condições de contorno

(Geometria 1). 45

Figura 3.5- Modo de flambagem do conóide cilíndrico para diferentes condições de contorno (Geometria 1)

Figura 3.6- Modo de flambagem do conóide parabólico para diferentes condições de contorno

(Geometria 4). 
Figura 3.7- Modo de flambagem do conóide cilíndrico para diferentes condições de contorno (Geometria 4).

Figura 3.8- Modo de flambagem do conóide parabólico com condição de contorno $\mathrm{A}_{2} \mathrm{~A}_{2} \mathrm{~A}_{2} \mathrm{~A}_{2}$ para diferentes geometrias 52

Figura 3.9- Modo de flambagem do conóide cilíndrico com condição de contorno $\mathrm{A}_{2} \mathrm{~A}_{2} \mathrm{~A}_{2} \mathrm{~A}_{2}$ para diferentes geometrias 52

Figura 3.10- Modo de flambagem do conóide parabólico com condição de contorno $\mathrm{A}_{2} \mathrm{~A}_{2} \mathrm{LL}$ para diferentes geometrias

Figura 3.11- Modo de flambagem do conóide cilíndrico com condição de contorno $\mathrm{A}_{2} \mathrm{~A}_{2} \mathrm{LL}$ para diferentes geometrias

Figura 3.12- Modo de flambagem do conóide de bordas curvas parabólicas, Geometria 3 e

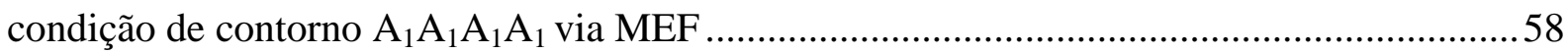

Figura 3.13- Representação dos cortes realizados para o estudo das decomposições..............58

Figura 3.14- Solução modal $W_{3,5}$ para os cortes transversais ( $x$ fixo) .....................................60

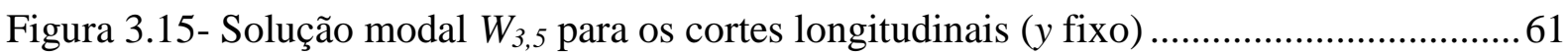

Figura 3.16- Solução modal $V_{3,5}$ para os cortes transversais ( $x$ fixo) .....................................63

Figura 3.17- Solução modal $V_{3,5}$ para os cortes longitudinais ( $y$ fixo) ....................................64

Figura 3.18- Solução modal $U_{3,5}+u_{c t e}$ para os cortes transversais ( $x$ fixo) ...........................65

Figura 3.19- Solução modal $U_{3,5}+u_{c t e}$ para os cortes longitudinais ( $y$ fixo) ..........................66

Figura 3.20- Deslocamentos obtidos via MEF e por decomposição modal ..............................68

Figura 4.1- Representação em planta dos pontos de observação da casca conoidal com as condições de contorno e as bordas curvas e retas.

Figura 4.2- Análise paramétrica das condições de contorno no conóide de Geometria 1 (parabólico)

Figura 4.3- Análise paramétrica das condições de contorno no conóide de Geometria 2

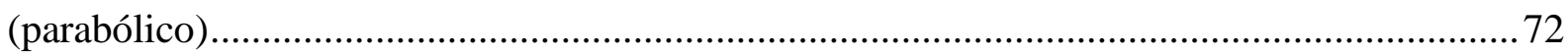

Figura 4.4- Análise paramétrica das condições de contorno no conóide de Geometria 3 (parabólico)

Figura 4.5- Análise paramétrica das condições de contorno no conóide de Geometria 4 (parabólico).

Figura 4.6- Análise paramétrica das geometrias para a mesma condição de contorno fixa (parabólico)

Figura 4.7- Análise paramétrica das geometrias para a mesma condição de contorno fixa (cilíndrico) 78 
Figura 4.8- Trajetória não-linear de equilíbrio dos conóides de Geometria $1\left(\mathrm{~A}_{2} \mathrm{~A}_{2} \mathrm{~A}_{2} \mathrm{~A}_{2}\right.$ parabólico $x$ cilíndrico)

Figura 4.9- Modos de deslocamentos $w$ ao longo das trajetórias não-lineares de equilíbrio da Geometria 1 submetida ao apoio $\mathrm{A}_{2} \mathrm{~A}_{2} \mathrm{~A}_{2} \mathrm{~A}_{2}$ 84

Figura 4.10- Modos de deslocamentos $u$ ao longo das trajetórias não-lineares de equilíbrio da Geometria 1 submetida ao apoio $\mathrm{A}_{2} \mathrm{~A}_{2} \mathrm{~A}_{2} \mathrm{~A}_{2}$ 85

Figura 4.11- Modos de deslocamentos $v$ ao longo das trajetórias não-lineares de equilíbrio da Geometria 1 com apoio $\mathrm{A}_{2} \mathrm{~A}_{2} \mathrm{~A}_{2} \mathrm{~A}_{2}$. 86

Figura 4.12- Trajetória não-linear de equilíbrio dos conóides de Geometria $4\left(\mathrm{~A}_{2} \mathrm{~A}_{2} \mathrm{~A}_{2} \mathrm{~A}_{2}\right.$ parabólico x cilíndrico)

Figura 4.13- Modos de deslocamentos $w$ ao longo das trajetórias não-lineares de equilíbrio da Geometria 4 submetida ao apoio $\mathrm{A}_{2} \mathrm{~A}_{2} \mathrm{~A}_{2} \mathrm{~A}_{2}$ 88

Figura 4.14- Modos de deslocamentos $u$ ao longo das trajetórias não-lineares de equilíbrio da Geometria 4 submetida ao apoio $\mathrm{A}_{2} \mathrm{~A}_{2} \mathrm{~A}_{2} \mathrm{~A}_{2}$

Figura 4.15- Modos de deslocamentos $v$ ao longo das trajetórias não-lineares de equilíbrio da Geometria 4 submetida ao apoio $\mathrm{A}_{2} \mathrm{~A}_{2} \mathrm{~A}_{2} \mathrm{~A}_{2}$

Figura 4.16- Influência da variação das Geometrias na condição de contorno $\mathrm{A}_{2} \mathrm{~A}_{2} \mathrm{~A}_{2} \mathrm{~A}_{2}$ do conóide parabólico.

Figura 4.17- Modo de flambagem Influência da variação das Geometrias na condição de contorno $\mathrm{A}_{2} \mathrm{~A}_{2} \mathrm{~A}_{2} \mathrm{~A}_{2}$ do conóide cilíndrico 92

Figura 4.18- Influência da imperfeição geométrica inicial (Modelo parabólico com apoios $\mathrm{A}_{2} \mathrm{~A}_{2} \mathrm{~A}_{2} \mathrm{~A}_{2}$ ).

Figura 4.19- Influência da imperfeição geométrica inicial (Modelo cilíndrico com apoios $\left.\mathrm{A}_{2} \mathrm{~A}_{2} \mathrm{~A}_{2} \mathrm{~A}_{2}\right)$

Figura 4.20- Trajetória não-linear de $\mathrm{M}_{\mathrm{xy}}$ dos conóides parabólicos de condição de contorno $\mathrm{A}_{2} \mathrm{~A}_{2} \mathrm{~A}_{2} \mathrm{~A}_{2}$ 96

Figura 4.21- Trajetória não-linear de $\mathrm{M}_{\mathrm{xy}}$ do conóide cilíndrico de condição de contorno $\mathrm{A}_{2} \mathrm{~A}_{2} \mathrm{~A}_{2} \mathrm{~A}_{2}$ 97

Figura 4.22- Trajetória não-linear de $\mathrm{M}_{\mathrm{x}}$ do parabólico de condição de contorno $\mathrm{A}_{2} \mathrm{~A}_{2} \mathrm{~A}_{2} \mathrm{~A}_{2} .98$ Figura 4.23- Trajetória não-linear de $\mathrm{M}_{\mathrm{x}}$ do conóide cilíndrico de condição de contorno $\mathrm{A}_{2} \mathrm{~A}_{2} \mathrm{~A}_{2} \mathrm{~A}_{2}$ 100

Figura 4.24- Trajetória não-linear de $\mathrm{M}_{\mathrm{y}}$ do conóide parabólico de condição de contorno $\mathrm{A}_{2} \mathrm{~A}_{2} \mathrm{~A}_{2} \mathrm{~A}_{2}$ 101 
Figura 4.25- Trajetória não-linear de $\mathrm{M}_{\mathrm{y}}$ do conóide cilíndrico de condição de contorno $\mathrm{A}_{2} \mathrm{~A}_{2} \mathrm{~A}_{2} \mathrm{~A}_{2}$

Figura 4.26- Trajetória não-linear de $\mathrm{N}_{\mathrm{x}}$ do conóide parabólico de condição de contorno $\mathrm{A}_{2} \mathrm{~A}_{2} \mathrm{~A}_{2} \mathrm{~A}_{2}$

Figura 4.27- Trajetória não-linear de $\mathrm{N}_{\mathrm{x}}$ do conóide cilíndrico de condição de contorno $\mathrm{A}_{2} \mathrm{~A}_{2} \mathrm{~A}_{2} \mathrm{~A}_{2}$ 104

Figura 4.28- Trajetória não-linear de $\mathrm{N}_{\mathrm{y}}$ do conóide parabólico de condição de contorno $\mathrm{A}_{2} \mathrm{~A}_{2} \mathrm{~A}_{2} \mathrm{~A}_{2}$ 105

Figura 4.29- Trajetória não-linear de $\mathrm{N}_{\mathrm{y}}$ do conóide cilíndrico de condição de contorno $\mathrm{A}_{2} \mathrm{~A}_{2} \mathrm{~A}_{2} \mathrm{~A}_{2}$ 106

Figura 4.30- Trajetória não-linear de $\mathrm{N}_{\mathrm{xy}}$ do conóide parabólico de condição de contorno $\mathrm{A}_{2} \mathrm{~A}_{2} \mathrm{~A}_{2} \mathrm{~A}_{2}$ 107

Figura 4.31- Trajetória não-linear de $\mathrm{N}_{\mathrm{xy}}$ do conóide cilíndrico de condição de contorno $\mathrm{A}_{2} \mathrm{~A}_{2} \mathrm{~A}_{2} \mathrm{~A}_{2}$ 108 


\section{LISTA DE TABELAS}

Tabela 3.1- Características geométricas, condições de contorno e nomenclatura adotada .......40 Tabela 3.2- Carga crítica $\left(\mathrm{P}_{\mathrm{cr}}\right)$ da casca conoidal para diferentes condições de apoio e de geometria $\left(\mathrm{kN} / \mathrm{m}^{2}\right)$ 42

Tabela 3.3- Decomposição dos campos de deslocamentos para a casca conoidal de bordas curvas parabólicas, Geometria 3 e condição de apoio $\mathrm{A}_{1} \mathrm{~A}_{1} \mathrm{~A}_{1} \mathrm{~A}_{1}$ 59

Tabela 4.1- Carga limite não-linear $\left(\mathrm{P}_{\mathrm{nl}}\right)$ da casca conoidal para diferentes condições de apoio e de geometria $\left(\mathrm{kN} / \mathrm{m}^{2}\right)$ 


\section{LISTA DE ABREVIATURAS}

CAPES Coordenação de Aperfeiçoamento de Pessoal de Nível Superior

MEF Método dos elementos finitos

PPG- GECON Programa de Pós-Graduação em Geotecnia, Estruturas e Construção Civil 


\section{LISTA DE SÍMBOLOS}

\section{Símbolos Romanos:}

\begin{tabular}{|c|c|}
\hline$A_{m n}$ & Amplitude modal da expansão para o campo de deslocamentos axiais \\
\hline$A_{i j}$ & Coeficiente analítico da decomposição do campo de deslocamentos axiais \\
\hline$a$ & Comprimento axial da casca \\
\hline$B_{m n}$ & $\begin{array}{l}\text { Amplitude modal da expansão para o campo de deslocamento } \\
\text { circunferencial }\end{array}$ \\
\hline$B_{i j}$ & $\begin{array}{l}\text { Coeficiente analítico da decomposição do campo de deslocamento } \\
\text { circunferencial }\end{array}$ \\
\hline$b$ & Largura em planta da casca \\
\hline$C$ & Coeficiente de rigidez de membrana \\
\hline$C_{m n}$ & Amplitude modal da expansão para o campo de deslocamentos transversais \\
\hline$C_{i j}$ & $\begin{array}{l}\text { Coeficiente analítico da decomposição do campo de deslocamentos } \\
\text { transversais }\end{array}$ \\
\hline$C A$ & Condição de apoio \\
\hline$D$ & Coeficiente de rigidez à flexão \\
\hline$E$ & Módulo de elasticidade \\
\hline$F$ & Funcional de energia \\
\hline$h$ & Espessura da conóide \\
\hline$H_{1}$ e $H_{2}$ & Máximas Alturas das bordas curvas \\
\hline$I$ & Número de parcelas axiais da decomposição \\
\hline$i$ & Número de semi-ondas axiais da decomposição \\
\hline$J$ & Número de parcelas circunferenciais da decomposição \\
\hline$j$ & Número de semi-ondas circunferenciais da decomposição \\
\hline$m$ & Número de semi-ondas axiais da expansão modal \\
\hline$M_{x}$ & Momento fletor axial \\
\hline$M_{y}$ & Momento fletor circunferencial \\
\hline$M_{x y}$ & Momento torçor \\
\hline$n$ & Número de semi-ondas circunferenciais da expansão modal \\
\hline$N_{x}$ & Esforço de membrana axial \\
\hline
\end{tabular}




\begin{tabular}{|c|c|}
\hline$N_{y}$ & Esforço de membrana circunferencial \\
\hline$N_{x y}$ & Esforço de membrana cisalhante \\
\hline$P_{c r}$ & Carga crítica \\
\hline$P_{n l}$ & Carga limite não-linear \\
\hline$Q_{x}$ e $Q_{y}$ & Forças transversais cisalhantes \\
\hline $\bar{q}$ & Carga vertical por unidade de área horizontal da superfície da casca \\
\hline$u$ & Campo de deslocamento axial (eixo $\mathrm{x}$ ) \\
\hline $\bar{u}$ & Campo de deslocamento axial (eixo x) no plano médio da casca \\
\hline$u_{M E F}$ & Deslocamento $u$ obtido via MEF \\
\hline$u_{c t e}$ & Parcela adicional da expansão $U_{i, j}$ \\
\hline$U$ & Energia interna de deformação \\
\hline$U_{i, j}$ & Expansão modal da decomposição dos deslocamentos $u$ \\
\hline$U_{m}$ & Energia interna de membrana \\
\hline$U_{f}$ & Energia interna de flexão \\
\hline$v$ & Campo de deslocamento circunferencial (eixo y) \\
\hline $\bar{v}$ & Campo de deslocamento circunferencial (eixo y) no plano médio da casca \\
\hline$v_{M E F}$ & Deslocamento $v$ obtido via MEF \\
\hline$V$ & Energia potencial total \\
\hline$V_{i, j}$ & Expansão modal da decomposição dos deslocamentos $v$ \\
\hline$w$ & Campo de deslocamento transversal (eixo $z$ ) \\
\hline $\bar{w}$ & Campo de deslocamento transversal (eixo z) no plano médio da casca \\
\hline$w_{M E F}$ & Deslocamento $w$ obtido via MEF \\
\hline$W_{i, j}$ & Expansão modal da decomposição dos deslocamentos $w$ \\
\hline$x$ & Coordenada cartesiana relativa ao eixo $x$ \\
\hline$x_{i}$ & Coordenadas $x$ dos nós da malha de elementos finitos \\
\hline$\Delta x_{i}$ & Distâncias $x$ entre os nós da malha de elementos finitos \\
\hline$y$ & Coordenada cartesiana relativa ao eixo $y$ \\
\hline$y_{i}$ & Coordenadas $y$ dos nós da malha de elementos finitos \\
\hline$\Delta y_{i}$ & Distâncias $y$ entre os nós da malha de elementos finitos \\
\hline$Z$ & Coordenada cartesiana relativa ao eixo $z$ \\
\hline $\bar{z}(x, y)$ & Função de superfície da casca \\
\hline
\end{tabular}

\section{Símbolos Gregos:}

$\beta_{x}, \beta_{y} \quad$ Rotações da superfície média 
$\varepsilon_{x} \quad$ Deformação específica da superfície média da casca na direção axial

d Diferenciação parcial

$\Delta \quad$ Delta de Dirac

$\varepsilon_{y} \quad$ Deformação específica da superfície média da casca na direção circunferencial

$\overline{\varepsilon_{x}} \quad$ Deformação específica de um ponto qualquer da casca na direção axial

$\overline{\varepsilon_{y}} \quad$ Deformação específica de um ponto qualquer da casca na direção circunferencial

$\rho \quad$ Densidade do material da casca conoidal

$\sigma_{x} \quad$ Tensão normal axial no ponto médio

$\overline{\sigma_{x}} \quad$ Tensão normal axial em qualquer ponto

$\sigma_{y} \quad$ Tensão normal circunferencial no ponto médio

$\overline{\sigma_{y}} \quad$ Tensão normal circunferencial em qualquer ponto

$\sigma_{z} \quad$ Tensão transversal no ponto médio

$\overline{\sigma_{z}} \quad$ Tensão transversal em qualquer ponto

$\overline{\tau_{x y}}, \overline{\tau_{y x}}, \overline{\tau_{x z}}, \overline{\tau_{z x}} \quad$ Tensões cisalhantes em qualquer ponto

$v \quad$ Coeficiente de Poisson

$\Omega \quad$ Trabalho realizado pelas forças externas

$\kappa_{x} \quad$ Mudança de curvatura da superfície média da casca na direção axial

$\kappa_{y} \quad$ Mudança de curvatura da superfície média da casca na direção circunferencial

$\kappa_{x y} \quad$ Mudança da distorção angular da superfície média da casca

$\gamma_{x y} \quad$ Distorção angular

$\overline{\gamma_{x y}} \quad$ Distorção angular de um ponto qualquer da casca 


\section{SUMÁRIO}

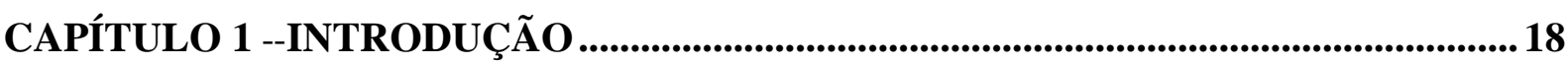

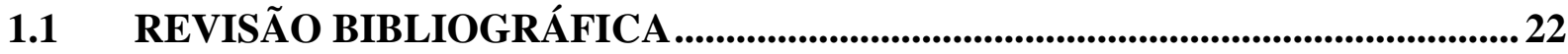

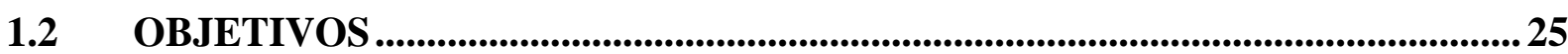

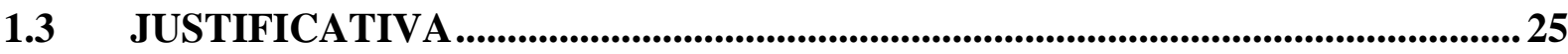

1.4 ORGANIZAÇÃO DO TEXTO ...............................................................................26

CAPÍTULO 2 --FORMULAÇÃO MATEMÁTICA DA CASCA CONOIDAL .................27

2.1 CAMPO DE DEFORMAÇÕES.........................................................................30

2.2 ESFORÇOS INTERNOS DE MEMBRANA E MOMENTOS................................. 33

2.3 FUNCIONAIS DE ENERGIA POTENCIAL ESTACIONÁRIA .............................35

2.4 SISTEMA DE EQUAÇÕES NÃO-LINEARES ………………………........................ 35

2.5 MODELAGEM COMPUTACIONAL VIA MEF ...................................................... 37

CAPÍTULO 3 --ANÁLISE ESTÁTICA LINEAR ............................................................39

3.1 ANÁLISE PARAMÉTRICA DA CARGA CRÍTICA .....................................................42

3.2 MODO DE FLAMBAGEM...............................................................................44

3.3 DECOMPOSIÇÃO DOS CAMPOS DE DESLOCAMENTOS EM SÉRIES DUPLAS

DE FOURIER ........................................................................................................................................ 56

CAPÍTULO 4 --ANÁLISE ESTÁTICA NÃO-LINEAR....................................................... 69

4.1 ANÁLISE PARAMÉTRICA DAS CONDIÇÕES DE CONTORNO .....................70

4.2 INFLUÊNCIA DA FORMA DA BORDA CURVA ................................................. 81

4.3 INFLUÊNCIA DA IMPERFEIÇÃO GEOMÉTRICA INICIAL ............................93

4.4 VARIAÇÃO DOS EFEITOS DE MEMBRANA E DE FLEXÃO AO LONGO

DA TRAJETÓRIA DE EQUILÍBRIO....................................................................................95

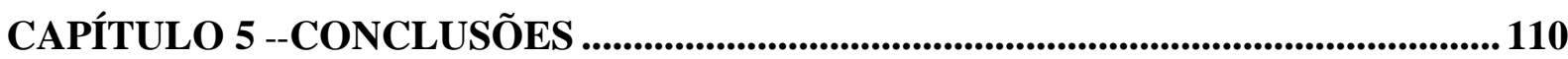

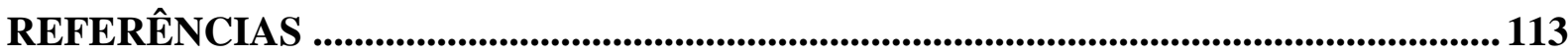




\section{CAPÍTULO 1 INTRODUÇÃO}

O engenheiro estrutural procura associar às formas a menor quantidade possível de material, visando obter resistência e estabilidade no sistema estrutural. Chakravorty e Das (2009) especificam que a casca conoidal tem grande aplicação para coberturas que necessitam de grandes vãos. Dentro deste pensamento, as cascas são eficientes elementos estruturais, podendo ser utilizadas em coberturas, atribuindo leveza e arrojo às edificações, economia de material devido às espessuras reduzidas e boa resistência mecânica.

Almroth e Brush (1975) definem o elemento estrutural de casca esbelta como um corpo no qual a distância de qualquer ponto desse corpo à superfície média, geralmente tomada como superfície de referência, seja pequena em comparação aos raios de curvatura que definem a superfície média. A maior parte das formas utilizadas nas estruturas do tipo casca é gerada a partir da revolução ou translação de uma reta ou curva. Algumas formas são citadas neste trabalho pela grande utilização nas construções.

Algumas características de cascas são descritas por Vizotto (1993), tais como:

- Casca de Revolução: uma curva plana é rotacionada em torno de uma reta fixa contida no mesmo plano, caso apresentado na Figura 1.1 e que tem como exemplo a cobertura do Congresso Nacional, Figura 1.7.

- Casca de Translação: uma curva contida num plano é transladada sobre outra curva fixa ou reta, contida em outro plano perpendicular ao primeiro, caso apresentado na Figura 1.2 da casca conoidal.

- Casca de forma livre: tem sua geometria selecionada por critérios arbitrários.

O engenheiro Eduardo Torroja (1899-1961) foi um dos precursores do que se chama hoje arte estrutural. Segundo Fontes (2005), o Eduardo Torroja tinha a convicção de que a estrutura depende da forma mais do que do material empregado. Dentro desta concepção, desde que estejam sob estado de tensões de membrana com as tensões de flexão minimizadas, a casca conoidal é uma ótima alternativa, já que sua forma gerada por uma malha de retas torna sua construção fácil e economiza fôrmas, um elemento crucial no orçamento de obras em 
concreto armado. O processo executivo apresenta vantagens como a execução por camadas, permitindo a utilização de cimbramento leve e introdução gradual de cargas na estrutura. Por mais que tenham comportamento eficiente como membrana, estão sujeitas ao fenômeno da flambagem, principalmente nos apoios onde existe a maior concentração de esforços de compressão.

Figura 1.1- Casca de Revolução

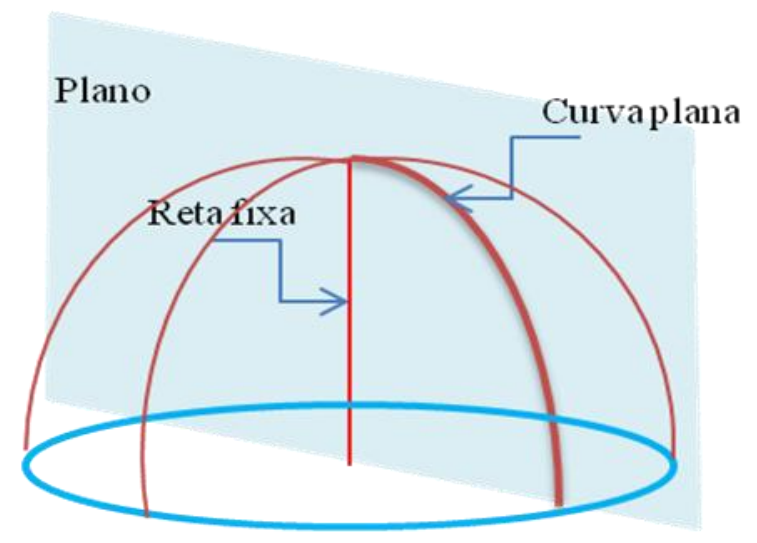

Figura 1.2- Casca de Translação

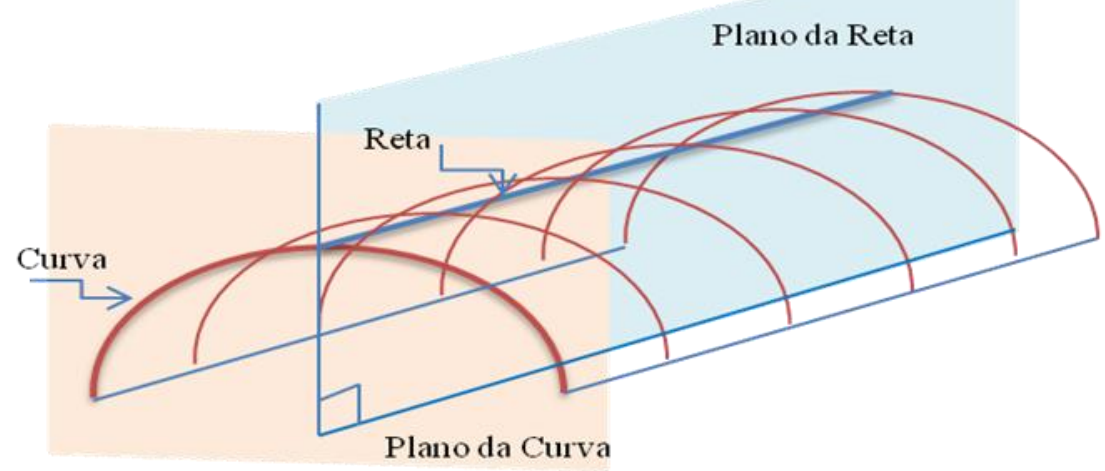

Segundo Plaza (2011), Eduardo Torroja projetou algumas de suas cascas de concreto armado mais famosas e notáveis por volta de 1930 na Espanha, ganhou renome internacional por sua obra denominada de Algeciras Market (1935), Figura 1.3, tendo como cobertura uma casca esférica. $\mathrm{O}$ uso da casca como cobertura para grandes vãos também foi empregado em meados de 1950 pelo arquiteto espanhol Félix Candela (1910-1997), que trabalhou com o projeto, cálculo e execução de coberturas com formato de parabolóides hiperbólicos, conóides e cascas de revolução constituídas de concreto armado. Félix Candela chamou atenção pela obra onde ousou com o parabolóide hiperbólico, o Anahuac Market Hall and Annex de 1957 
ilustrado na Figura 1.4, e pela construção da cobertura em conóide parabólico do Bacardi Rum Factory de 1960, Figura 1.5.

Figura 1.3- Algeciras Market- Espanha 1935 (Fonte: PLAZA, 2011)

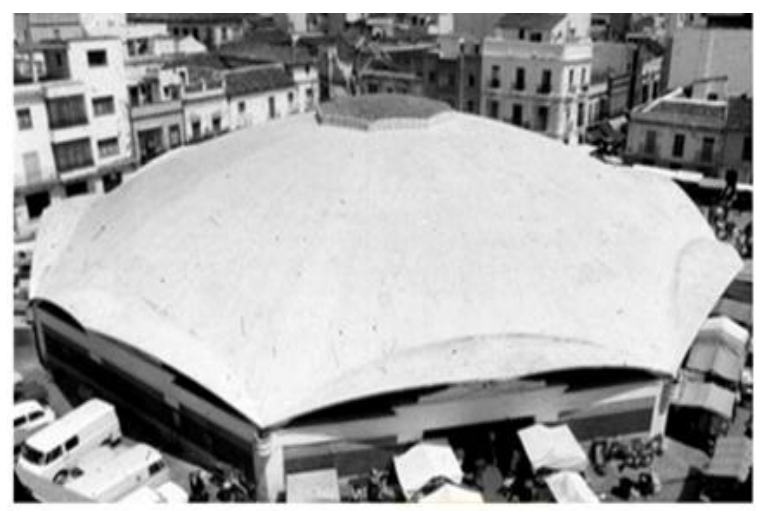

Figura 1.4- Anahuac Market Hall and Annex- México 1957 (Fonte: STRUCTURAE, 2016)

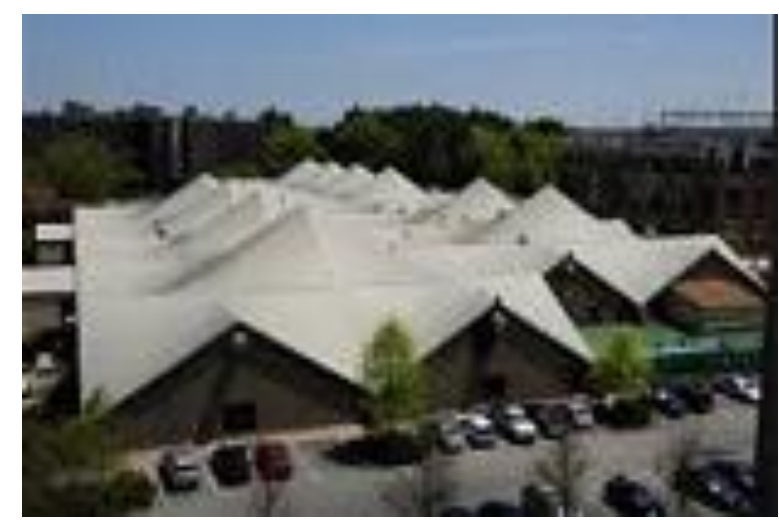

Figura 1.5- Bacardi Rum Factory- México 1960 (Fonte: STRUCTURAE, 2016)

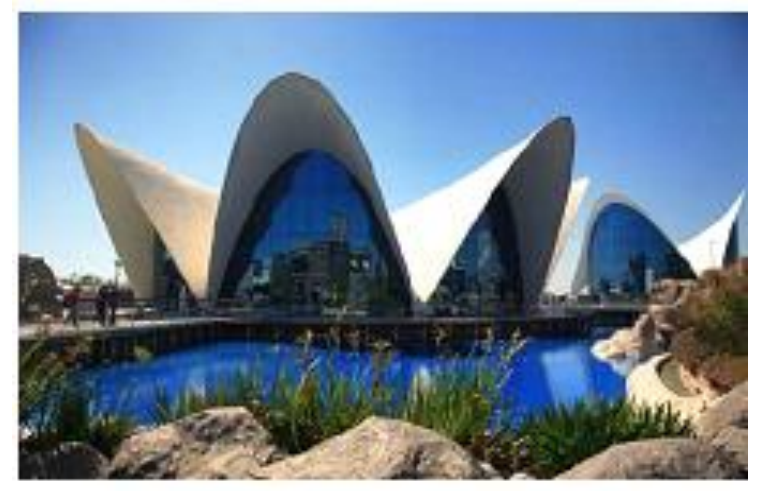

No Brasil, muitas coberturas com estrutura em forma de casca têm sido projetadas e construídas. Na Figura 1.6 é ilustrada a cobertura em forma de cilindróide da Fundação Getúlio Vargas no Rio de Janeiro enquanto na Figura 1.7 é ilustrado o Congresso Nacional em Brasília, ambas as obras são importantes na história do uso de cascas como cobertura 
projetadas pelo renomado arquiteto Oscar Niemeyer, arquiteto cuja maioria de suas obras tiveram como calculistas estruturais os engenheiros Joaquim Cardoso e José Carlos Sussekind. Outra obra que pode ser citada é a Capela Universitária João Evangelista (Figura 1.8), projetada pelo arquiteto Pedro Ernesto Gualberto. Esta está localizada em Goiânia e seu objeto de inspiração foram as catacumbas cristãs.

Figura 1.6- Fundação Getúlio Vargas- São Paulo (Fonte: FGV, 2016)

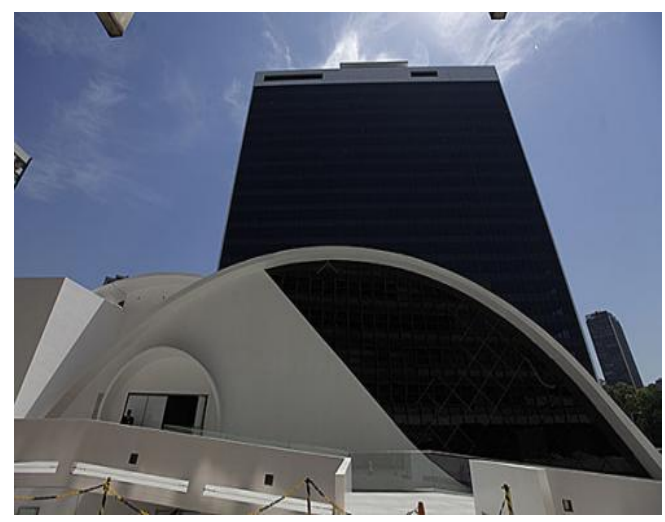

Figura 1.7- Congresso Nacional- Brasília 1960 (Fonte: ZIGONI, 2014)

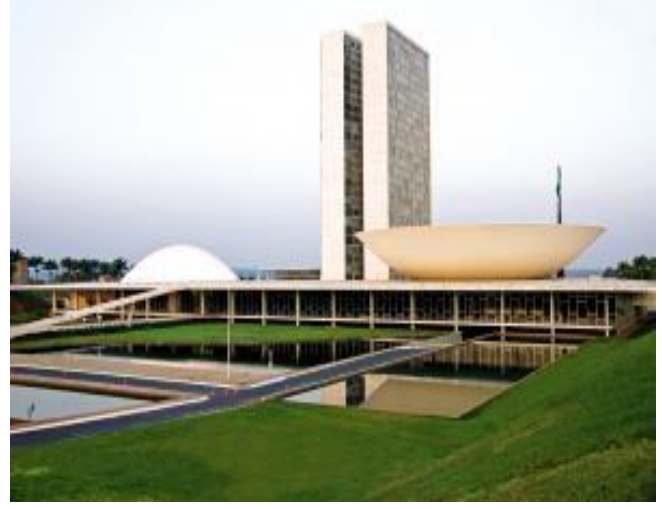

Figura 1.8- Paróquia Universitária João Evangelista- Goiânia 2009

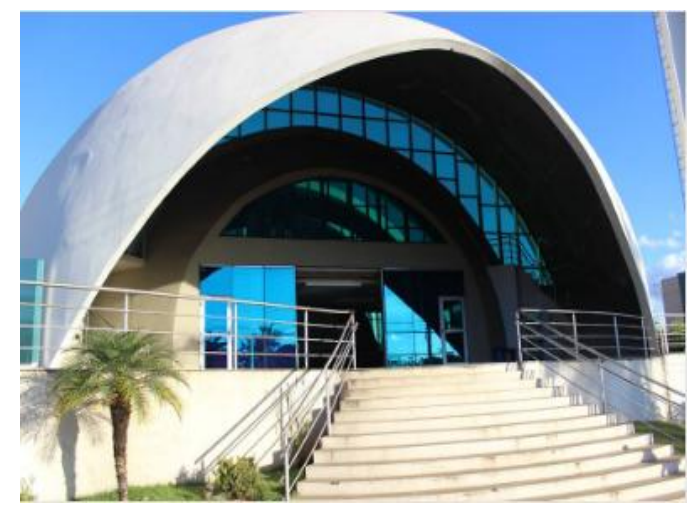




\subsection{REVISÃO BIBLIOGRÁFICA}

Esta seção apresenta a revisão bibliográfica realizada para embasamento teórico da dissertação, para isso, são referenciados alguns trabalhos que versam sobre o estudo e aplicação de cascas como coberturas.

A citação "Força através da forma", de Bandyopadhyay e Ghosh (1990, p. 801), descreve com clareza o motivo da utilização de cascas com geometria conoidal serem cada vez mais presente nas construções de coberturas de grandes vãos. Apesar da sua extensa aplicabilidade, esse assunto ainda é pouco abordado por pesquisadores, principalmente tratando-se de estudos analíticos, devido à dificuldade de se obterem funções que descrevam corretamente os campos de deslocamentos da casca conoidal.

Bandyopadhyay e Ghosh (1990) fizeram uma análise dos esforços de flexão de uma casca conoidal, engastada nas quatro bordas, de dupla curvatura, sendo que suas curvaturas eram negativas. Para a análise, os autores utilizaram as equações de equilíbrio da teoria de flexão de cascas conoidais de Vlasov's com a solução dos campos de deslocamentos descrita por funções algébricas. A manipulação destas equações é complexa devido a presença de constantes arbitrárias de difícil definição. O método de Galerkin foi aplicado pelos autores para discretizar as equações de equilíbrio sendo dois problemas resolvidos e comparados aos resultados via MEF, pré-existentes, de Brebbia e Hadid (1975 ${ }^{1}$ apud BANDYOPADHYAY; GHOSH, 1990). Os autores analisaram os deslocamentos e as tensões ao longo da casca e concluíram que as equações de equilíbrio podem ser utilizadas para o estudo do comportamento de maneira segura, pois os resultados das análises são aproximados e o tempo requerido para alcançar a solução foi menor quando comparados com os resultados obtidos via MEF.

Bandyopadhyay, Chakravorty e Sinha (1995) investigaram o comportamento dinâmico da casca com o intuito de conhecer a sua frequência natural, através de uma variação paramétrica das condições de contorno, das espessuras, das alturas das bordas curvas e dos comprimentos da geometria em planta. Os autores utilizaram o elemento isoparamétrico de oito nós e cinco graus de liberdade por nó, obtiveram as frequências fundamentais via MEF e apresentaramnas de forma não dimensional validando os resultados comparando-os aos de Kadi e Leissa

\footnotetext{
${ }^{1}$ Brebbia. C. A.; Hadid. H. A. A review of different methods of shell analysis. J. struct. Eng 3, I-16, 1975.
} 
(1971 ${ }^{2}$ apud BANDYOPADHYAY; CHAKRAVORTY; SINHA, 1995). Os autores avaliaram que as cascas cujas bordas foram engastadas obtiveram valores de frequência fundamental acima das mesmas geometrias de cascas simplesmente apoiadas, esta última, por sua vez, obteve frequência maior que a mesma geometria com apoios pontuais em suas extremidades.

Stavridis (1998) apresentou um procedimento analítico sistemático para estudos de cascas abatidas finas de projeção retangular no plano, cujo método de discretização das equações de equilíbrio é uma solução aproximada utilizando o método de Galerkin. Através de um programa computacional, especialmente desenvolvido com esta formulação, fez-se uma investigação dinâmica obtendo-se os autovalores da frequência não-dimensional para cascas que são utilizadas como coberturas de concreto em forma de parabolóides hiperbólicos e elípticos, hipérboles, conóides parabólicos e cascas em forma de bolha variando-se parâmetros de geometria e as condições de contorno. Os autores concluíram que a avaliação de uma análise dinâmica para as cascas citadas é possível desde que se considere, além das condições de contorno apropriadas, apenas algumas variáveis não dimensionais relativas à geometria da casca.

Hanai e Teixeira (2002) propuseram definir a forma da superfície média da casca por analogia com membranas suspensas e obter uma configuração deformada tal que conseguisse equilibrar o carregamento apenas com esforços de compressão, ou apenas tração. Os autores encontraram a superfície procurada escolhendo o estado de tensões desejado e definindo o carregamento que atuaria na cobertura e obtiveram a estrutura definitiva a partir de uma inversão da forma da membrana suspensa submetida à ação de cargas. Analisando-se esta estrutura via MEF, os autores verificaram que a hipótese da estrutura funcionar apenas sob compressão, ou tração, estava incorreta, pois surgiram além de esforços de compressão, esforços de tração e momento fletor de valores significativos na casca de forma livre.

Fontes (2005) avaliou, em sua dissertação, aspectos de projeto e construção da alvenaria como solução construtiva. Analisou a cobertura em forma de casca parabolóide hiperbólica tipo sela da Igreja de Lindéia apresentada na Figura 1.9, sendo composta de alvenaria cerâmica armada como material. $\mathrm{O}$ autor fez uma análise linear e não-linear via MEF com apoio do programa computacional DIANA, versão 8, e comparou com o dimensionamento original do projetista feito pela teoria de membrana com auxílio de um programa construído em linguagem FORTRAN. Verificou-se que a solução estrutural adotada pelo projetista se mostrou eficiente.

${ }^{2}$ Kadi A. S.; Leissa A. W. Curvature effects on shallow shell vibrations. J. Sound Vibr. 16, 173-187, 1971. 
Figura 1.9- Igreja de Lindéia- Minas Gerais (Fonte: FONTES, 2005)

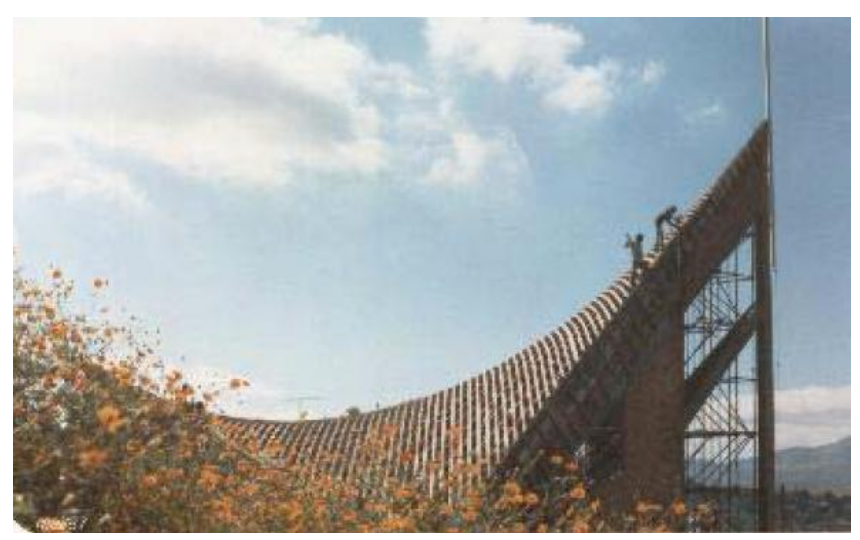

(a) Cobertura em forma de casca parabolóide hiperbólica

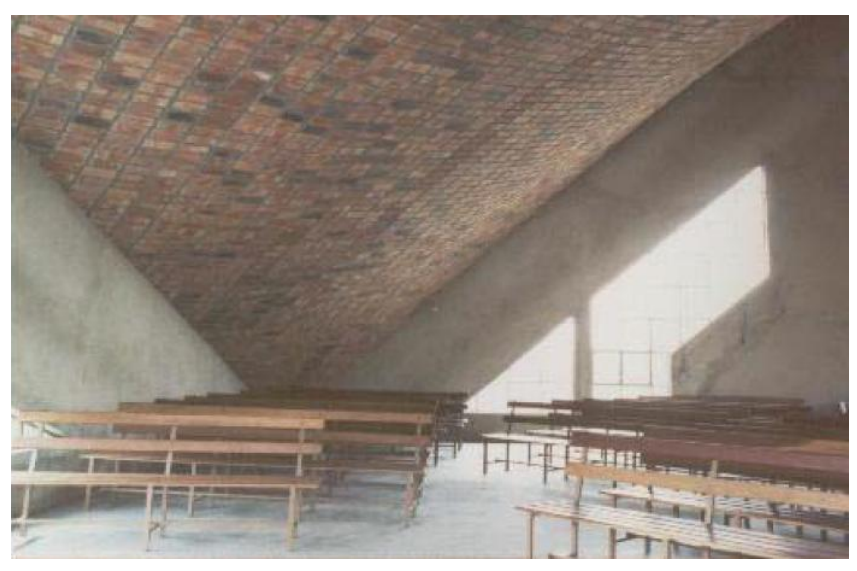

(b) Parte interna da igreja

Chakravorty e Das (2009) aplicaram o MEF para analisar o comportamento de flexão de cascas conoidais de material composto submetidos a apoios pontuais ao longo de suas bordas. Considerando o problema estático, criaram um código computacional para calcular a matriz de rigidez da casca conoidal considerando o elemento finito isoparamétrico quadrático curvo de oito nós e cinco graus de liberdade. Os autores analisaram a performance da casca conoidal à flexão com diferentes combinações de suporte e de laminações do material composto comparando-a a uma placa. Observaram que a deflexão tornou-se menor, no conóide, utilizando-se bloqueio em mais pontos de apoios, o que acrescentou reações na casca exigindo-se maior esforço computacional. Observaram que nas cascas com condição de apoio pontuais em suas extremidades geraram-se deslocamentos não só na superfície central, mas também se notaram deslocamentos ao longo das extremidades nos intervalos entre os apoios. Em comparação à placa plana, notou-se um desempenho superior da casca conoidal com menores deslocamentos, maiores esforços de membrana e reduzidos efeitos de flexão. 
Dinis, Medrano e Meirelles (2009), estudaram a aplicação da modelagem via MEF na concepção de cascas de concreto armado. Para demonstrar o potencial desta ferramenta, realizaram a modelagem das cascas de cobertura da biblioteca do Memorial da América Latina (Figura 1.10) pelo programa ANSYS ®. Os autores verificaram uma alta concentração de tensões de compressão próximas a região dos apoios e também surgiu flexão nos apoios, devido à forma assimétrica da cobertura.

Figura 1.10- Memorial da América Latina (Fonte: DINIS; MEDRANO; MEIRELLES, 2009)

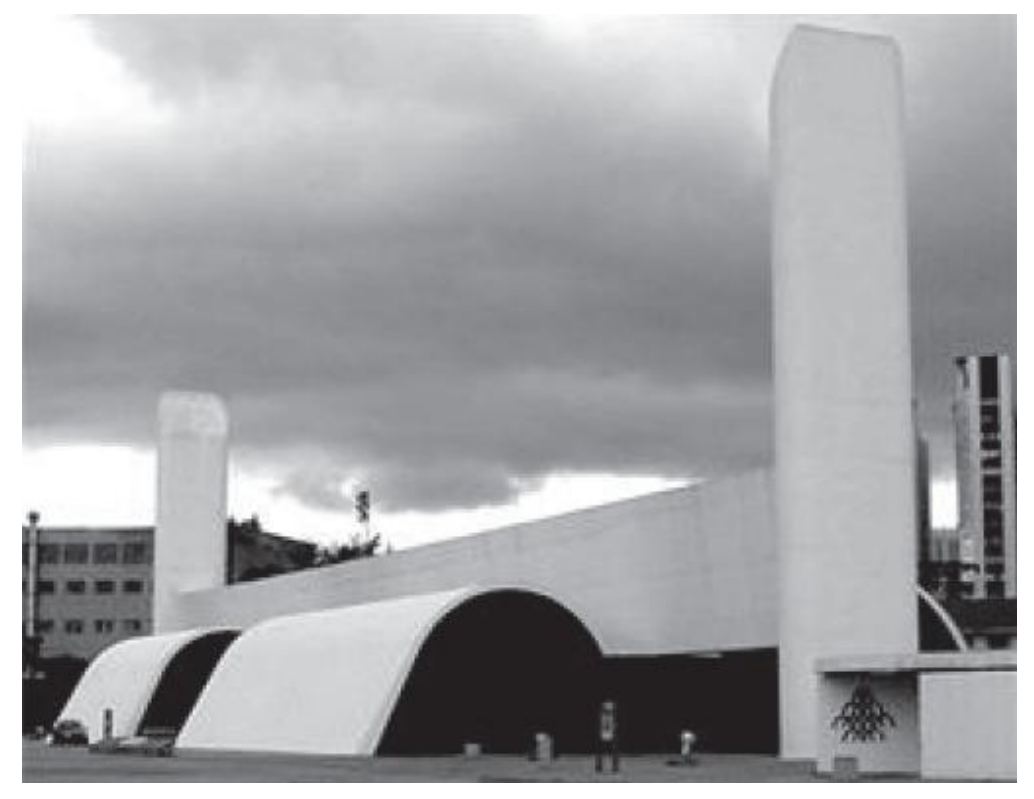

Sahoo (2013) estudou as características dinâmicas de cascas conoidais feitas de material composto determinando-se as frequências naturais e modos de vibração via MEF. Verificouse a influência de aberturas, presentes à superfície, no comportamento estrutural para diferentes condições de contorno e diferentes formatos das cascas conoidais compostas. Desenvolveu-se um código em MEF que, combinava um elemento isoparamétrico curvo de casca de oito nós com um elemento de viga curva de três nós para simular as aberturas presentes à superfície. Gerou-se uma malha de elementos finitos não uniforme ao longo da superfície da casca cujo tamanho dos elementos foram reduzidos nas proximidades da abertura. Concluiu-se que os recortes, para requisitos funcionais, podem ser feitos com segurança quando suas margens forem construídas de forma rígida.

Cavalcanti (2015) apresentou uma formulação matemática para cascas abatidas a partir da teoria de placas retangulares, considerando-se que esta geometria de casca é uma placa retangular com um deslocamento inicial na forma da superfície conoidal desejada, segundo 
um procedimento matemático similar ao desenvolvido por Marguerre (CIARLET; PAUMIER, 1986³ ; MARGUERRE, $1938^{4}$; VOROVICH, $1999^{5}$ apud CAVALCANTI, 2015). Debongnie (1978) fez uma interpretação lógica das equações de equilíbrio da teoria de Marguerre para cascas abatidas, com a ideia de utilizar o sistema de coordenadas cartesiano não envolvendo os raios de curvaturas da superfície curva, mas somente a inclinação da superfície em relação aos eixos cartesianos.

Com auxílio do programa ROBOT®, Cavalcanti (2015) comparou os esforços na casca conoidal parabólica com os de uma placa plana via método dos elementos finitos (MEF). Observou-se um decréscimo acentuado nos esforços de flexão devido à curvatura inicial da estrutura, o aparecimento dos esforços de membrana, que se tornam dominantes na casca, maior rigidez, capacidade de carga e melhor comportamento dinâmico com o aumento da curvatura.

Recentemente, Gonçalves e Soares (2015) estudaram a influência da variação de parâmetros geométricos no comportamento pós-crítico não-linear, nos carregamentos de flambagem e nas frequências naturais da casca conoidal. Já Gonçalves e Soares (2016) estudaram o comportamento não-linear da casca conoidal engastada nas bordas retas e livres nas bordas curvas utilizando o programa comercial de elementos finitos ABAQUS®. A partir de um estudo paramétrico detalhado, os autores verificaram a influência da variação da geometria nas cargas limites, frequências naturais e no comportamento não-linear das trajetórias de equilíbrio.

O estado da arte mostrou que o desempenho da casca conoidal, comparado à placa, é maior em questões de deflexão. Enquanto na placa o esforço dominante é o de flexão, na casca conoidal predomina-se o esforço de membrana. Notou-se nos trabalhos apresentados sobre cascas uma grande utilização de análises via MEF. Devido às novas propostas arquitetônicas, as estruturas têm exigido dos projetistas avanços nos procedimentos dos cálculos estruturais. Com este fator, juntamente ao comportamento não-linear geométrico das cascas conoidais ainda não estarem bem definidos, precisam-se de estudos que solidifiquem o conhecimento do

3 Ciarlet, P.G.; Paumier, J. C. A justification of the Marguerre-von Karman equations. Computational Mechanics 1, 177-202, 1986.

4 Marguerre, K. Zur Theorie der gekrummten Platte grosser Formanderun. In: 5th INTERNACIONAL CONGRESS FOR APPLIED MECHANICS. Proceeding... 93-10, 1938.

${ }^{5}$ Vorovich, I.I. Nonlinear Theory of Shallow Shells, Applied Mathematical Sciences. Vol.133, Springer-Verlag, New York, 1999. 
comportamento deste tipo de elemento estrutural, motivando o desenvolvimento desta pesquisa.

\subsection{OBJETIVOS}

Esta dissertação de mestrado está inserida na linha de pesquisa de mecânica aplicada e computacional de estruturas do PPG-GECON e visa contribuir para a difusão do conhecimento acerca da não-linearidade geométrica das cascas conoidais atendendo não somente o meio acadêmico como também os profissionais relacionados ao projeto desse tipo de estrutura. Objetiva-se contribuir com o estudo analítico não-linear da casca conoidal abatida, inicialmente obtendo-se as equações não-lineares de equilíbrio a partir da teoria de placas retangulares e considerando-se que esta geometria de casca é uma placa retangular com um deslocamento inicial na forma da superfície conoidal desejada.

Objetiva-se realizar um estudo numérico estático não-linear utilizando o programa comercial ABAQUS 6.11®, no qual é possível realizar análises lineares simples à análises não-lineares complexas via MEF. Para isso, primeiramente faz-se uma análise linear paramétrica comparativa das cargas críticas de conóides de diferentes condições de contorno e altura das bordas curvas parabólicas, ou cilíndricas, e uma análise modal das componentes do campo de deslocamentos dos modos de flambagem. Investiga-se a complexidade do modo de flambagem avaliando-se, analiticamente, as componentes dos campos de deslocamentos de uma casca conoidal a partir da decomposição dos campos de deslocamentos em séries duplas de Fourier.

Através da análise não-linear pretende-se apresentar o comportamento não-linear das trajetórias de equilíbrio dos deslocamentos transversais de conóides com diferentes condições de contorno e alturas das curvas das bordas parabólicas, ou cilíndricas, e identificar nas trajetórias os pontos limites de carregamento. Objetiva-se ainda avaliar a influência da variação das alturas das curvas parabólicas, ou cilíndricas, nas trajetórias não-lineares dos efeitos de membrana e momentos dos conóides.

\subsection{JUSTIFICATIVA}

O interesse no estudo da casca conoidal abatida se justifica pelo fato de seu comportamento não-linear não ser totalmente compreendido, além das novas propostas arquitetônicas 
exigirem cada vez mais avanços nos procedimentos de cálculo estrutural, havendo inúmeras abordagens para seu estudo.

\subsection{ORGANIZAÇÃO DO TEXTO}

O trabalho é constituído deste capítulo introdutório e mais quatro capítulos, organizados da seguinte maneira:

- Capítulo 2: apresenta a formulação matemática para obtenção das equações de equilíbrio da casca conoidal a partir da teoria de placas finas e teoria de Marguerre. É explanado sobre a modelagem computacional via MEF com algumas particularidades do programa ABAQUS $6.11 \circledR$ relativas ao problema numérico proposto;

- Capítulo 3: são apresentados os resultados da análise estática linear via MEF, bem como a investigação analítica da complexidade de um modo de flambagem utilizando-se o princípio do somatório duplo de Fourier;

- Capítulo 4: apresentam-se os resultados da análise estática não-linear;

- Capítulo 5: contém as conclusões desta dissertação, além de algumas sugestões para trabalhos futuros.

Finaliza-se esta dissertação de mestrado com as referências utilizadas na produção do trabalho. 


\section{CAPÍTULO 2 \\ FORMULAÇÃO MATEMÁTICA DA CASCA CONOIDAL}

Este capítulo apresenta a formulação matemática para modelagem da casca conoidal parabólica, ou cilíndrica, de parâmetros geométricos, campos de deslocamentos e sistema de eixos apresentados na Figura 2.1. Considera-se uma casca conoidal sujeita a um carregamento uniformemente distribuído $\bar{q}$ ao longo de sua superfície feita com material elástico-linear, homogêneo e isotrópico com módulo de elasticidade $E$, coeficiente de Poisson $v$ e densidade $\rho$. A geometria é definida a partir da espessura $h$, do comprimento no plano $a$, da largura no plano $2 b$ e das alturas máximas dos arcos parabólicos, ou cilíndricos, $H_{2}$ e $H_{l}$. Os campos de deslocamentos $u, v$ e $w$ referem-se às direções $x, y$ e $z$, respectivamente.

Figura 2.1- Geometria, campos de deslocamentos e sistema de eixos da casca conoidal

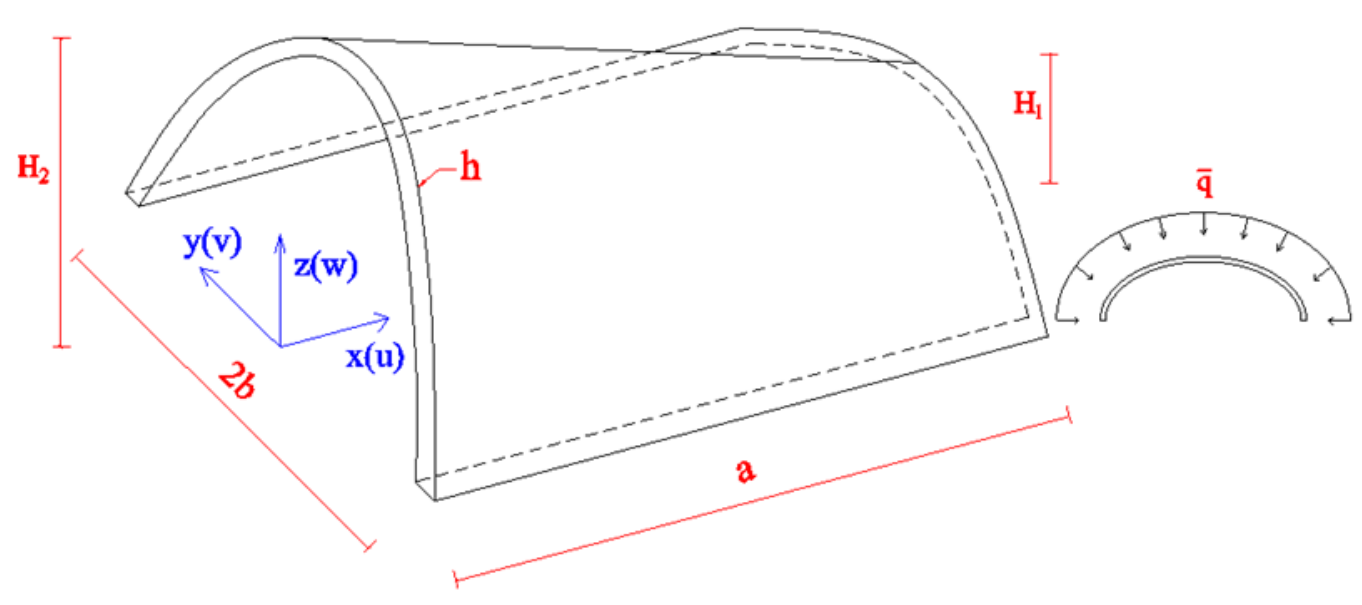

Segundo Bandyopadhyay e Ghosh (1990) a equação (2.1) representa a superfície $\bar{z}(x, y)$ da casca conoidal parabólica e para descrever a superfície da casca conoidal cilíndrica, utiliza-se a equação (2.2). É interessante ressaltar que dependendo dos valores assumidos para as alturas das curvas das bordas parabólicas, ou cilíndricas, obtêm-se variações geométricas distintas que são encontradas em arquiteturas existentes e exemplificadas na Figura 2.2.

$$
\bar{z}(x, y)=-\left(H_{2}+\frac{\left(H_{1}-H_{2}\right)}{a} x\right)\left(1-\frac{y^{2}}{b^{2}}\right)
$$




$$
\bar{z}(x, y)=-\left(H_{2}+\frac{\left(H_{1}-H_{2}\right)}{a} x\right) \sqrt{1-\frac{y^{2}}{b^{2}}}
$$

Figura 2.2- Variações geométricas da função de superfície da casca conoidal

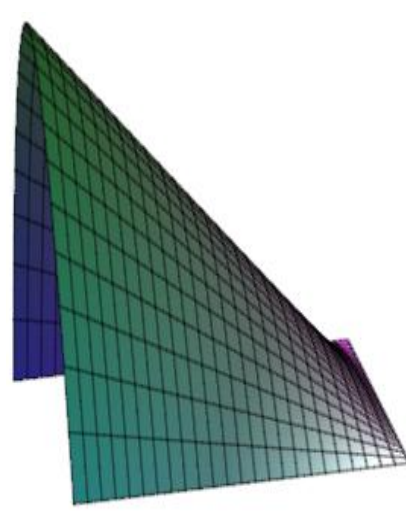

(a) $H_{2}>0$ e $H_{1}=0$

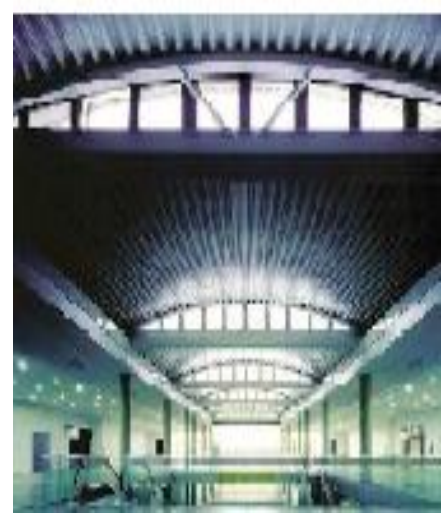

(d) Centro de Exposições de Valência (Fonte: CAVALCANTI, 2015)

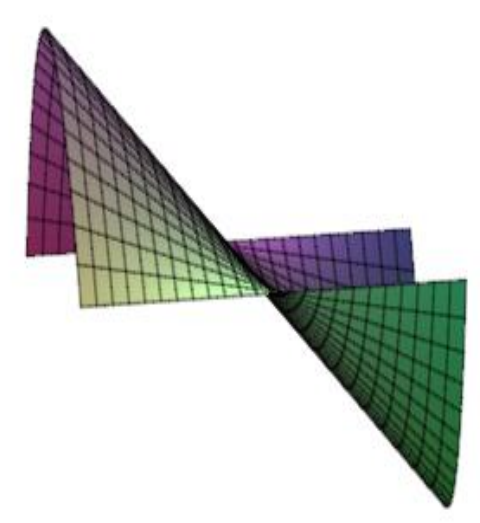

(b) $H_{2}>0$ e $H_{1}<0$

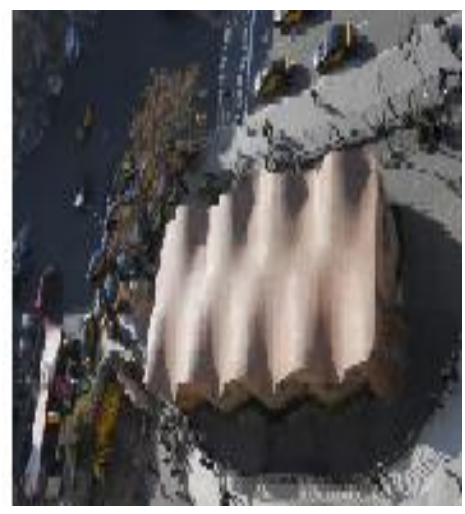

(e) Sagrada Família (Fonte: CAVALCANTI, 2015)

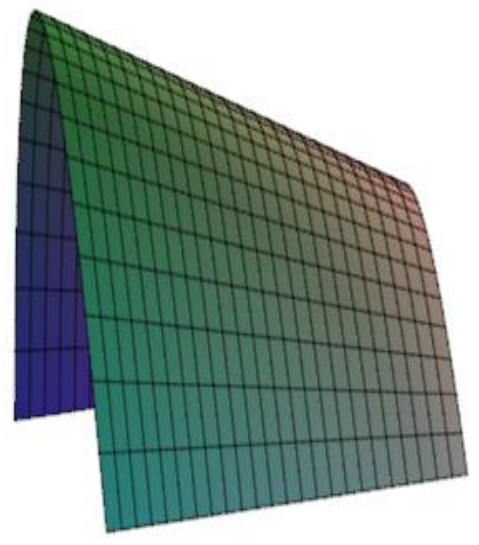

(c) $H_{2}>H_{1}>0$

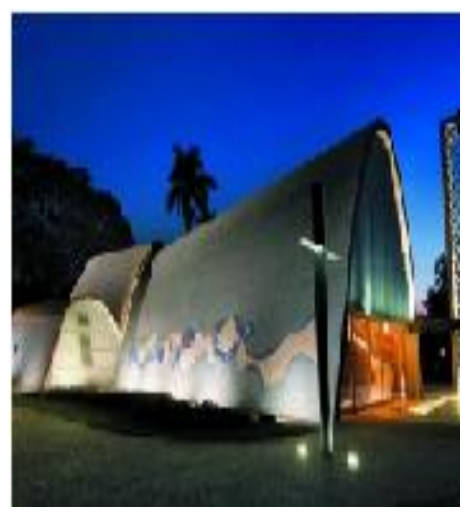

(f) Igreja de São Francisco, Pampulha- Minas Gerais (Fonte: ROSA, 2016)

Bandyopadhyay e Ghosh (1990) definem a representação da carga vertical por unidade de área horizontal da superfície da casca pela equação (2.3):

$\bar{q}=q\left[1+\left(\frac{\partial \bar{z}(x, y)}{\partial x}\right)^{2}+\left(\frac{\partial \bar{z}(x, y)}{\partial y}\right)^{2}\right]^{1 / 2}$

\subsection{CAMPO DE DEFORMAÇÕES}

A formulação analítica para cascas abatidas neste trabalho é obtida a partir da teoria de placas (ALMROTH; BRUSH, 1975) considerando a hipótese de que a casca conoidal seja uma placa 
retangular com um deslocamento inicial na forma da casca conoidal. Utiliza-se aqui o procedimento de Marguerre para cascas abatidas considerando a curvatura da superfície no sistema de coordenadas cartesianas não envolvendo o raio de curvatura (CAVALCANTI, 2015; CRISFIELD, 1991; DEBONGNIE, 1978; GONÇALVES; SOARES, 2016).

Segundo Almroth e Brush (1975), a teoria de placas finas é derivada das seguintes simplificações de Kirchhoff-Love:

- Os planos normais ao plano médio indeformado da placa permanecem normais, retos e com o comprimento inicial durante a deformação. Desta maneira, as deformações transversais normais e cisalhantes podem ser desprezadas nas relações cinemáticas da placa;

- Como a espessura da placa é pequena, pode-se admitir como aproximação que as tensões $\sigma_{z}, \tau_{x z}$ e $\tau_{y z}$ assumem um valor muito pequeno comparado com as outras componentes de tensão, podendo ser desprezadas nas relações de tensão-deformação da placa.

Como consequência da primeira hipótese de Kirchhoff-Love, as componentes dos campos de deslocamento em qualquer ponto de uma placa $\bar{u}, \bar{v}$ e $\bar{w}$ podem ser expressas em termos dos deslocamentos $u, v$ e $w$ do plano médio a partir das seguintes relações:

$$
\bar{u}=u+z \beta_{x} \quad \bar{v}=v+z \beta_{y} \quad \bar{w}=w
$$

Onde $\beta_{x}=w_{, x}$ e $\beta_{y}=w_{, y}$ são as rotações da superfície média em relação aos eixos $x$ e $y$, respectivamente.

As componentes da relação deformação-deslocamento $\bar{\varepsilon}_{x}, \bar{\varepsilon}_{y}$ (extensões) e $\bar{\gamma}_{x y}$ (distorção) em qualquer ponto da espessura da placa podem ser expressas através das equações:

$$
\bar{\varepsilon}_{x}=\bar{u}_{, x}+\frac{1}{2} \bar{w}_{, x}^{2} \quad \bar{\varepsilon}_{y}=\bar{v}_{, y}+\frac{1}{2} \bar{w}_{, y}{ }^{2} \quad \bar{\gamma}_{x y}=\bar{u}_{, x}+\bar{v}_{, y}+\bar{w}_{, x} \bar{w}_{, y}
$$

As relações cinemáticas para placas dadas pela teoria de Von Kárman encontram-se nas equações: 


$$
\begin{array}{lll}
\varepsilon_{x}=u_{, x}+\frac{1}{2} \beta_{x}{ }^{2} & \beta_{x}=-w_{, x} & \kappa_{x}=\beta_{x, x} \\
\varepsilon_{y}=v_{, y}+\frac{1}{2} \beta_{y}{ }^{2} & \beta_{y}=-w_{, y} & \kappa_{y}=\beta_{y, y} \\
\gamma_{x y}=\left(u_{, y}+v_{, x}\right)+\beta_{x} \beta_{y} & \kappa_{x y}=\frac{1}{2}\left(\beta_{x, y}+\beta_{y, x}\right)
\end{array}
$$

Onde $\varepsilon_{x}, \varepsilon_{y}$ e $\gamma_{x y}$ são as deformações no plano médio e $\kappa_{x}, \kappa_{y}$ e $\kappa_{x y}$ constituem as mudanças de curvatura da superfície média.

Substituindo-se as equações (2.4) em (2.5) e assumindo as relações dadas em (2.6), obtêm-se as equações (2.7) que fornecem as deformações em qualquer ponto da placa a partir das deformações no plano médio e das mudanças de curvatura.

$$
\bar{\varepsilon}_{x}=\varepsilon_{x}+z \kappa_{x} \quad \bar{\varepsilon}_{y}=\varepsilon_{y}+z \kappa_{y} \quad \bar{\gamma}_{x y}=\gamma_{x y}+2 z \kappa_{x y}
$$

A estrutura em forma de casca conoidal possui uma curvatura inicial e a componente de deslocamento transversal em qualquer ponto é dada em função do deslocamento transversal inicial:

$$
\bar{w}=w+\bar{z}(x, y)
$$

Stavridis (1998) caracteriza a casca como abatida se qualquer linha infinitesimal pertencente ao plano médio puder ser aproximada pelo comprimento de sua projeção ao plano $x y$, isso implica em:

$$
\left[\frac{\partial \overline{\mathbf{z}}(x, y)}{\partial x}\right]^{2} \quad \ll 1 \quad\left[\frac{\partial \overline{\mathbf{z}}(x, y)}{\partial y}\right]^{2} \quad \ll 1 \quad \frac{\partial \overline{\mathbf{z}}(x, y)}{\partial x} \frac{\partial \overline{\mathbf{z}}(x, y)}{\partial y} \quad \ll 1
$$

Sendo assim, as equações (2.10) fornecem os campos de deformações não-lineares no plano médio da casca conoidal em função das deformações do plano médio e da superfície inicial $\bar{z}(x, y)$, ou seja: 


$$
\begin{aligned}
& \varepsilon_{x}=u_{, x}+\frac{1}{2}\left(w_{, x}{ }^{2}+2 w_{, x} \bar{z}(x, y)_{, x}\right) \\
& \varepsilon_{y}=v_{, y}+\frac{1}{2}\left(w_{, y}{ }^{2}+2 w_{, y} \bar{z}(x, y)_{, y}\right) \\
& \gamma_{x y}=u_{, y}+v_{, x}+w_{, x} w_{, y}+w_{, x} \bar{z}(x, y)_{, y}+w_{, y} \bar{z}(x, y)_{, x}
\end{aligned}
$$

Considerando que a casca conoidal do presente trabalho é constituída por um material linear, elástico, isotrópico e homogêneo, as relações tensão-deformação são dadas por:

$$
\bar{\sigma}_{x}=\frac{E}{1-v^{2}}\left(\bar{\varepsilon}_{x}+v \bar{\varepsilon}_{y}\right) \quad \bar{\sigma}_{y}=\frac{E}{1-v^{2}}\left(\bar{\varepsilon}_{y}+v \bar{\varepsilon}_{x}\right) \quad \bar{\tau}_{x y}=\frac{E}{2(1+v)} \bar{\gamma}_{x y}
$$

\subsection{ESFORÇOS INTERNOS DE MEMBRANA E MOMENTOS}

A teoria de placas esbeltas reduz o problema tridimensional a um problema bidimensional aproximado. Forças e momentos internos agem nos extremos de um elemento de placa $d x d y$ como ilustra a Figura 2.3, expressos em termos de forças e momentos por unidade de comprimento.

Figura 2.3- Convenção de sinais para o elemento infinitesimal $d x d y$ na configuração indeformada

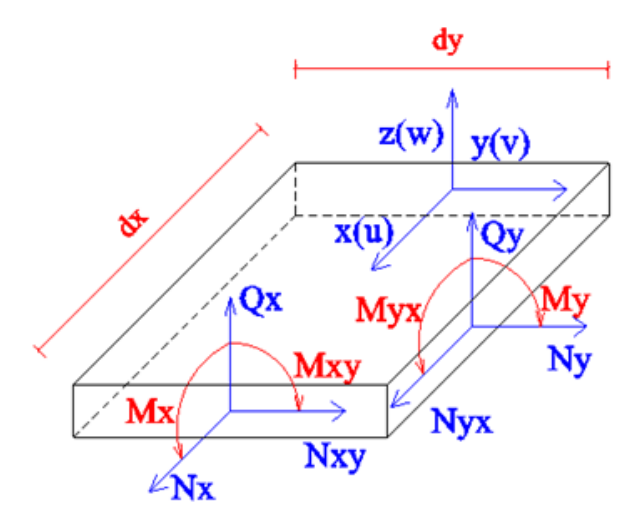

A intensidade da força e do momento são funções das tensões internas e são obtidas através das equações: 


$$
\begin{array}{lll}
N_{x}=\int_{-\frac{h}{2}}^{\frac{h}{2}} \bar{\sigma}_{x} d z & N_{y}=\int_{-\frac{h}{2}}^{\frac{h}{2}} \bar{\sigma}_{y} d z & N_{x y}=\int_{-\frac{h}{2}}^{\frac{h}{2}} \bar{\tau}_{x y} d z \quad N_{y x}=\int_{-\frac{h}{2}}^{\frac{h}{2}} \bar{\tau}_{y x} d z \\
Q_{x}=\int_{-\frac{h}{2}}^{\frac{h}{2}} \bar{\tau}_{x z} d z & Q_{y}=\int_{-\frac{h}{2}}^{\frac{h}{2}} \bar{\tau}_{y z} d z \\
M_{x}=\int_{-\frac{h}{2} z \bar{\sigma}_{x} d z}^{\frac{h}{2}} & M_{y}=\int_{-\frac{h}{2}}^{\frac{h}{2}} z \bar{\sigma}_{y} d z & M_{x y}=\int_{-\frac{h}{2}}^{\frac{h}{2}} z \bar{\tau}_{x y} d z \quad M_{y x}=\int_{-\frac{h}{2}}^{\frac{h}{2}} z \bar{\tau}_{y x} d z
\end{array}
$$

Onde $N_{x}, N_{y}, N_{x y}$ e $N_{y x}$ são as intensidades das forças normais e cisalhantes no plano, $Q_{x}$ e $Q_{y}$ são as intensidades das forças transversais cisalhantes, $M_{x}$ e $M_{y}$ são as resultantes do momento fletor e, por fim, $M_{x y}$ e $M_{y x}$ são as intensidades dos momentos torçores.

As componentes de tensão $\bar{\sigma}$ e $\bar{\tau}$ em qualquer ponto ao longo da espessura da placa diferem de $\sigma$ e $\tau$ que correspondente exclusivamente aos valores no plano médio. Considerando que $\bar{\tau}_{x y}=\bar{\tau}_{y x}$, pode-se dizer que $N_{x y}=N_{y x}$ e $M_{y x}=M_{x y}$, no geral as forças e momentos são funções das coordenadas $x$ e $y$.

Introduzindo-se as equações de (2.7) a (2.11) em (2.12) e integrando-se ao longo da espessura da casca conoidal, obtêm-se as relações constitutivas apresentadas nas equações (2.13). O termo $C$ que acompanha as forças normais e cisalhantes no plano, e $D$, que acompanha os momentos fletores e torçor, são referentes a rigidez de membrana e de flexão, respectivamente.

$$
\begin{array}{ll}
N_{x}=C\left(\varepsilon_{x}+v \varepsilon_{y}\right) & M_{x}=D\left(k_{y} v+k_{x}\right) \\
N_{y}=C\left(\varepsilon_{y}+v \varepsilon_{x}\right) & M_{y}=D\left(k_{x} v+k_{y}\right) \\
N_{x y}=C \frac{1-v}{2} \gamma_{x y} \quad C=\frac{E h}{1-v^{2}} & M_{x y}=D(1-v) k_{x y} \quad D=\frac{E h^{3}}{12\left(1-v^{2}\right)}
\end{array}
$$




\subsection{FUNCIONAIS DE ENERGIA POTENCIAL ESTACIONÁRIA}

As equações não-lineares de equilíbrio podem ser obtidas partindo-se do critério de energia potencial estacionária. Uma placa está em equilíbrio se a energia potencial total $V$, formada pela energia interna de deformação $U$ e pelo trabalho realizado pelas forças externas $\Omega$, for estacionária:

$V=U+\Omega$

A energia interna de deformação é obtida a partir da integração volumétrica do somatório do produto das tensões pelas suas respectivas deformações, que para um meio isotrópico tridimensional no sistema de coordenadas ortogonais é dada por:

$U=\frac{1}{2} \iiint\left(\bar{\sigma}_{x} \bar{\varepsilon}_{x}+\bar{\sigma}_{y} \bar{\varepsilon}_{y}+\bar{\sigma}_{z} \bar{\varepsilon}_{z}+\bar{\tau}_{x y} \bar{\gamma}_{x y}+\bar{\tau}_{y z} \bar{\gamma}_{y z}+\bar{\tau}_{x y} \bar{\gamma}_{x y}\right) d x d y d z$

De acordo com as hipóteses da teoria de placas esbeltas, os termos $\bar{\sigma}_{z}, \bar{\gamma}_{z x}$ e $\bar{\gamma}_{y z}$ são desprezíveis. Introduzindo as equações (2.7) e (2.11) em (2.15) e integrando a expressão ao longo da espessura, obtém-se a energia interna de deformação que é separada em duas parcelas de energia: membrana $\left(U_{m}\right)$ e flexão $\left(U_{f}\right)$, a saber:

$$
\begin{aligned}
& U_{m}=\frac{C}{2} \iint\left[\varepsilon_{x}{ }^{2}+\varepsilon_{y}{ }^{2}+2 v \varepsilon_{x} \varepsilon_{y}+\frac{1-v}{2} \gamma_{x y}{ }^{2}\right] d x d y \\
& U_{f}=\frac{D}{2} \iint\left[\kappa_{x}{ }^{2}+\kappa_{y}{ }^{2}+2 v \kappa_{x} \kappa_{y}+2(1-v) \kappa_{x y}{ }^{2}\right] d x d y
\end{aligned}
$$

O trabalho devido ao carregamento externo distribuído na direção transversal $z$, é dado por:

$$
\Omega=-\iint \bar{q} w d x d y
$$

\subsection{SISTEMA DE EQUAÇÕES NÃO-LINEARES}

As equações não-lineares de equilíbrio da casca conoidal permitem a análise não-linear do sistema. A equação (2.19) mostra que a energia potencial total $V$ pode ser escrita em termos 
de um funcional $F$ (equação (2.20)) formado pela energia potencial total em termos dos campos de deslocamentos $u, v, w$ que são dependentes de $x$ e $y$ e de suas respectivas derivadas.

$$
\begin{aligned}
& V=\iint F\left(x, y, u, v, w, u_{x}, u_{, y}, v_{, x}, v_{, y}, w_{, x}, w_{, y}, w_{, x x}, w_{, y y}, w_{, x y}\right) d x d y \\
& F=\frac{C}{2}\left(\varepsilon_{x}{ }^{2}+\varepsilon_{y}{ }^{2}+2 v \varepsilon_{x} \varepsilon_{y}+\frac{1-v}{2} \gamma_{x y}{ }^{2}\right)+\frac{D}{2}\left[{\kappa_{x}}^{2}+\kappa_{y}{ }^{2}+2 v \kappa_{x} \kappa_{y}+2(1-v) \kappa_{x y}{ }^{2}-\bar{q} w\right.
\end{aligned}
$$

Aplicando-se o cálculo variacional e fazendo-se as devidas simplificações, resultam-se nas seguintes equações não-lineares de equilíbrio para cascas conoidais abatidas em termos dos campos de deslocamentos $u, v$ e $w$ e do deslocamento inicial da superfície conoidal $\bar{z}(x, y)$.

$$
\begin{aligned}
& \mathrm{C}\left[\left\{\left(u_{, x}+\frac{1}{2}\left(w_{, x}{ }^{2}+2 w_{, x} \bar{z}(x, y)_{, x}\right)\right)+v\left(v_{, y}+\frac{1}{2}\left(w_{, y}{ }^{2}+2 w_{, y} \bar{z}(x, y)_{, y}\right)\right)\right\}_{, x}\right. \\
& \left.+\frac{1-v}{2}\left\{\left(u_{, y}+v_{, x}+w_{, x} w_{, y}+w_{, x} \bar{z}(x, y)_{, y}+w_{, y} \bar{z}(x, y)_{, x}\right)\right\}_{, y}\right]=0 \\
& \mathrm{C}\left[\frac{1-v}{2}\left\{\left(u_{, y}+v_{, x}+w_{, x} w_{, y}+w_{, x} \bar{z}(x, y)_{, y}+w_{, y} \bar{z}(x, y)_{, x}\right)\right\}_{, x}\right. \\
& \left.+\left\{\left(v_{, y}+\frac{1}{2}\left(w_{, y}^{2}+2 w_{, y} \bar{z}(x, y)_{, y}\right)\right)+v\left(u_{, x}+\frac{1}{2}\left(w_{, x}{ }^{2}+2 w_{, x} \bar{z}(x, y)_{, x}\right)\right)\right\}_{, y}\right]=0 \\
& -D\left[\left\{w_{, x x}+v w_{, y y}\right\}_{, x x}+2(1-v)\left(\frac{1}{2}\left(w_{, x y}+w_{, y x}\right)\right)_{, x y}+\left(w_{, y y}+v w_{, x x}\right)_{, y y}\right] \\
& -\mathrm{C}\left[\left(\left(u_{, x}+\frac{1}{2}\left(w_{, x}{ }^{2}+2 w_{, x} \bar{z}(x, y)_{, x}\right)\right)+v\left(v_{, y}+\frac{1}{2}\left(w_{, y}{ }^{2}+2 w_{, y} \bar{z}(x, y)_{, y}\right)\right)\right) w_{, \mathrm{x}}\right. \\
& \left.+\frac{1-v}{2}\left(u_{, y}+v_{, x}+w_{, x} w_{, y}+w_{, x} \bar{z}(x, y)_{, y}+w_{, y} \bar{z}(x, y)_{, x}\right) w_{, y}\right]_{, \mathrm{x}} \\
& -\mathrm{C}\left[\left(\left(v_{, y}+\frac{1}{2}\left(w_{, y}{ }^{2}+2 w_{, y} \bar{z}(x, y)_{, y}\right)\right)+v\left(u_{, x}+\frac{1}{2}\left(w_{, x}{ }^{2}+2 w_{, x} \bar{z}(x, y)_{, x}\right)\right)\right) w_{, \mathrm{y}}\right. \\
& \left.+\frac{1-v}{2}\left(u_{, y}+v_{, x}+w_{, x} w_{, y}+w_{, x} \bar{z}(x, y)_{, y}+w_{, y} \bar{z}(x, y)_{, x}\right) w_{, \mathrm{x}}\right]_{, \mathrm{y}}=\bar{q}
\end{aligned}
$$

Verifica-se a presença dos deslocamentos $u, v$ e $w$ em cada uma das equações sugerindo-se a influência e o acoplamento de todos os campos de deslocamentos. As não-linearidades cúbicas e quadráticas, além da função de forma $\bar{z}(x, y)$ e suas derivadas, aparecem como termos lineares e não-lineares influenciando de forma significativa no comportamento da estrutura. 


\subsection{MODELAGEM COMPUTACIONAL VIA MEF}

O MEF é um método numérico originado da necessidade de se obter soluções aproximadas de problemas onde a solução exata, advinda de métodos analíticos, é trabalhosa ou não é conhecida devido à sua complexidade. O programa comercial utilizado para a modelagem computacional por elementos finitos neste trabalho é o $A B A Q U S$ 6.11®, pois possui uma extensa biblioteca de elementos e de materiais que permite modelar diversas geometrias, resolvendo problemas que necessitem análises lineares simples até simulações não-lineares complexas.

Alguns aspectos da formulação dos elementos finitos influenciam no comportamento do problema apresentado. Os graus de liberdade são as variáveis fundamentais de análise e, dependendo do tipo de problema, podem se referir a variáveis como, por exemplo, a deformação, potencial elétrico, temperatura, translação e também a rotação. Corriqueiramente nos problemas de engenharia os graus de liberdade utilizados nas análises são os de translação e de rotação, cuja convenção positiva pode ser visualizada na Figura 2.4. Neste trabalho, os graus de liberdade 1 e 4, são referentes, respectivamente, a translação e rotação em torno do eixo $x$, os graus de liberdade 2 e 5 , são referentes, respectivamente, a translação e rotação em torno do eixo $y$ e os graus 3 e 6 , referentes, respectivamente, a translação e rotação em torno do eixo $z$.

Figura 2.4- Graus de liberdade, adaptado pelo autor $(A B A Q U S$ 6.11, 2011)

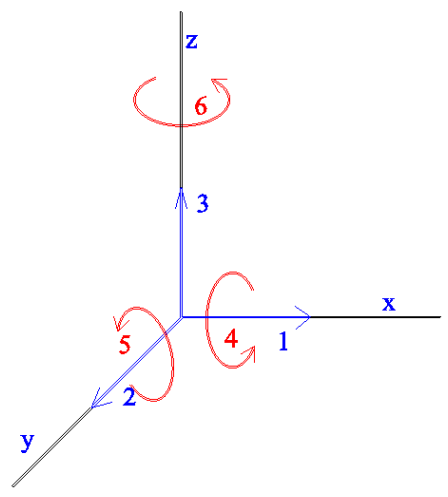

Os elementos finitos disponíveis no programa ABAQUS 6.11®, possuem na sua nomenclatura a referência da quantidade de nós e a família de geometria que pertence para melhor identificação. O elemento utilizado nesta dissertação é o STRI3, ilustrado na Figura 2.5, que é um elemento cuja formulação satisfaz a teoria de Kirchhoff, considerando somente pequenas 
deformações. Para o STRI3, não há alterações nas análises com relação à mudança da espessura do elemento durante a deformação.

Figura 2.5- Elemento STRI3

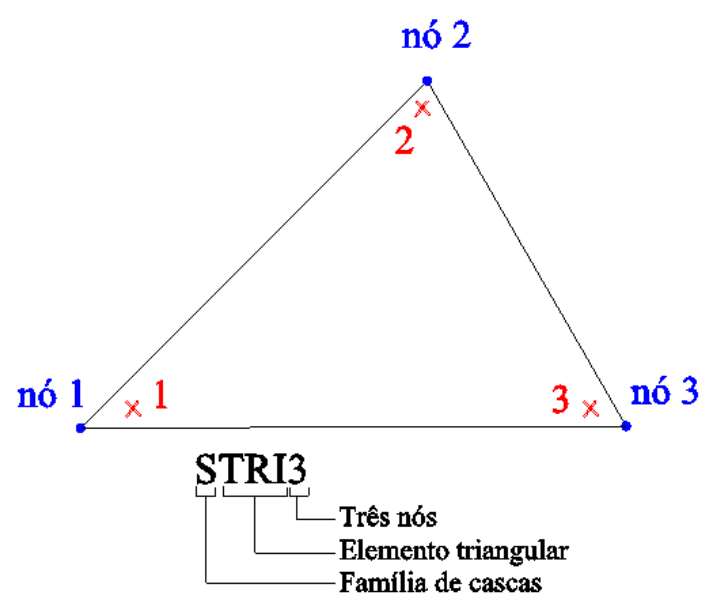

O elemento STRI3 é um elemento de casca, indicado pela letra "S", triangular, indicado pelo termo "TRI", contendo três nós sem existência de nós intermediários, resultando em interpolação linear, ou de primeira ordem. O ABAQUS 6.11® aplica técnicas numéricas para integrar ao longo do volume de cada elemento usando quadratura Gaussiana para a maioria dos casos e avaliando a resposta do material em cada ponto de integração. Os três pontos de integração, ou pontos de Gauss, são ilustrados na Figura 2.5 pelo símbolo "X".

Os nós são os pontos onde são aplicadas as condições de contorno, carregamentos e são calculados os graus de liberdade dos elementos. Nos demais pontos, as variáveis são obtidas por interpolação a partir das informações obtidas no nó. 


\section{CAPÍTULO 3 \\ ANÁLISE ESTÁTICA LINEAR}

Neste capítulo apresenta-se uma análise paramétrica estática linear de cascas conoidais utilizando o MEF a partir do programa computacional ABAQUS 6.11®. Avaliaram-se e compararam-se cascas conoidais abatidas de bordas curvas parabólicas, ou cilíndricas, submetidas a um carregamento transversal uniformemente distribuído ao longo da superfície da casca. O material é considerado como sendo elástico linear, homogêneo, coeso e isotrópico com módulo de elasticidade E $=14 \mathrm{GPa}$, coeficiente de Poisson $v=0,3$ e densidade $\rho$ $=2548,42 \mathrm{~kg} / \mathrm{m}^{3}$. As cascas conoidais avaliadas apresentam uma espessura $h=0,06 \mathrm{~m}$ e geometria em planta de comprimento $a=6 \mathrm{~m}$ e largura $2 b=8 \mathrm{~m}$, sendo que as malhas de elementos finitos utilizadas, Figura 3.1, são constituídas de elementos de casca fina, triangulares de três nós, de denominação STRI3 no ABAQUS 6.11® e os campos de deslocamentos $U 1$ no sentido do eixo $x, U 2$ no sentido de $y$ e $U 3$ no sentido do eixo $z$.

Figura 3.1- Malha de elementos finitos STRI3 modelada com o ABAQUS 6.11®

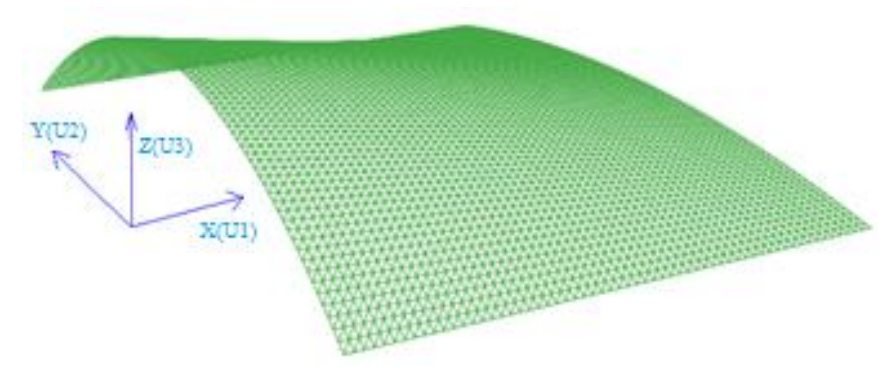

(a) Geometria parabólica

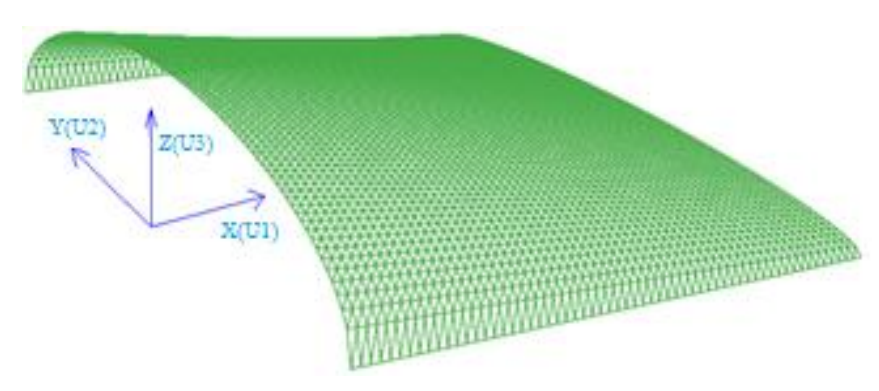

(b) Geometria cilíndrica 
$\mathrm{Na}$ análise estática linear utilizaram-se os parâmetros ilustrados na Figura 3.2, variaram-se as condições de contorno, representadas por $\mathrm{CA}$, e a altura da menor borda curva, $\mathrm{H}_{1}$, mantendose a altura da maior borda curva, $\mathrm{H}_{2}$. Os valores utilizados na geometria da casca bem como as condições de apoio utilizadas são apresentados na Tabela 3.1, onde a Geometria 1 é ilustrada na Figura 2.2 (a) e as Geometrias 2, 3 e 4 são ilustradas na Figura 2.2 (c). É importante destacar que as bordas posicionadas em $(x=0, y)$ e $(x=a, y)$ da Figura 3.2 são curvas, podendo ser parabólicas ou cilíndricas, conforme as equações (2.1) e (2.2), respectivamente, a exceção na Geometria 1 na qual a borda $\mathrm{H}_{1}$ é reta. Já as bordas da Figura 3.2 posicionadas em $(x, y=-\mathrm{b}) \mathrm{e}(x, y=\mathrm{b})$ são retas.

Figura 3.2- Representação em planta da casca conoidal com as condições de contorno e as bordas curvas e retas

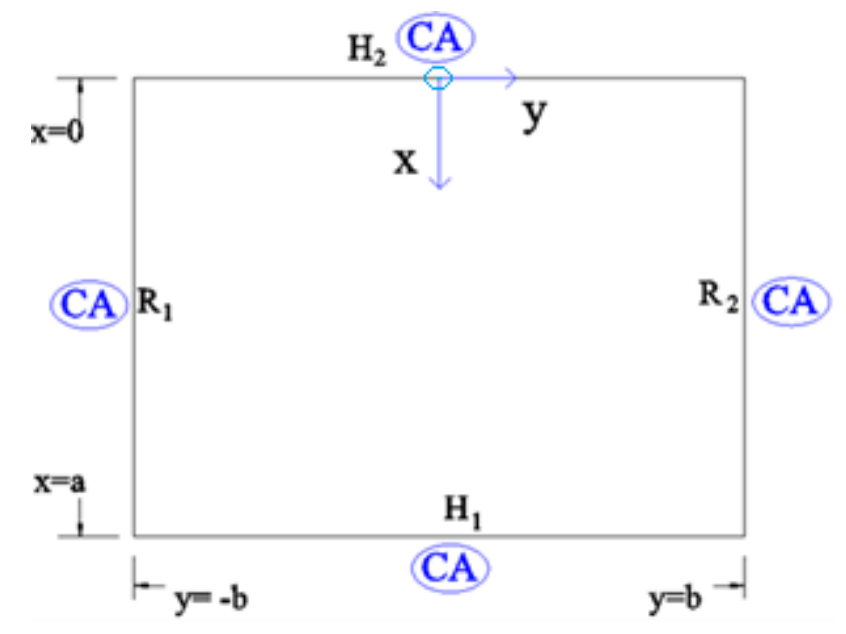

Tabela 3.1- Características geométricas, condições de contorno e nomenclatura adotada

\begin{tabular}{|c|c|c|}
\hline CASO & $\mathrm{H}_{2}(\mathrm{~m})$ & $\mathrm{H}_{1}(\mathrm{~m})$ \\
\hline Geometria 1 & 1,500 & 0 \\
\hline Geometria 2 & 1,500 & 0,375 \\
\hline Geometria 3 & 1,500 & 0,750 \\
\hline Geometria 4 & 1,500 & 1,500 \\
\hline CA & \multicolumn{2}{|c|}{ Legenda } \\
\hline Referência: $\mathrm{R}_{1} \mathrm{R}_{2} \mathrm{H}_{2} \mathrm{H}_{1}$ & \multicolumn{2}{|c|}{$\mathrm{R}_{1}$ : borda reta, $y=-b ; \mathrm{R}_{2}$ : borda reta, $y=b$} \\
\hline $\mathrm{A}_{1} \mathrm{~A}_{1} \mathrm{~A}_{1} \mathrm{~A}_{1} ; \mathrm{A}_{2} \mathrm{~A}_{2} \mathrm{~A}_{2} \mathrm{~A}_{2}$ & \multicolumn{2}{|c|}{$\mathrm{H}_{2}:$ borda curva, $x=0 ; \mathrm{H}_{1}$ : borda curva, $x=a$} \\
\hline $\mathrm{A}_{2} \mathrm{~A}_{2} \mathrm{LA}_{2} ;$ EELE & \multirow{2}{*}{\multicolumn{2}{|c|}{$\begin{array}{l}\left.\mathrm{A}_{1} \text { : apoio deslocável ( } 1^{\circ} \text { gênero }\right) ; \mathrm{A}_{2} \text { : apoio indeslocável ( } 2^{\circ} \\
\left.\text { gênero); L: borda livre; E: borda engastada ( } 3^{\circ} \text { gênero }\right)\end{array}$}} \\
\hline $\mathrm{A}_{2} \mathrm{~A}_{2} \mathrm{LL} ; \mathrm{EELL}$ & & \\
\hline
\end{tabular}


Para atingir a precisão desejada dos resultados numéricos, realizou-se uma análise de convergência da malha de elementos finitos. Para isso, a malha de elementos finitos foi refinada e os diferentes elementos do tipo casca disponíveis no programa de MEF foram analisados. Observa-se, na Figura 3.3, a convergência da carga crítica linear com o incremento do número de elementos finitos STRI3 para uma casca conoidal com bordas curvas parabólicas, de Geometria 3 e condição de apoio $\mathrm{A}_{1} \mathrm{~A}_{1} \mathrm{~A}_{1} \mathrm{~A}_{1}$.

Figura 3.3- Análise de convergência da malha de elementos finitos (caso parabólico de Geometria 3 $\mathrm{A}_{1} \mathrm{~A}_{1} \mathrm{~A}_{1} \mathrm{~A}_{1}$ )

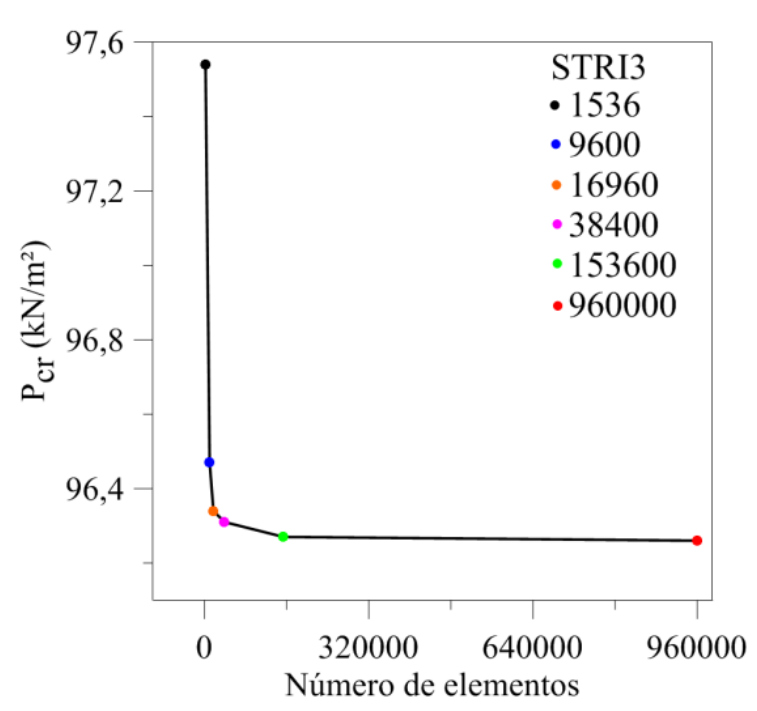

A partir da análise da carga crítica do primeiro modo flambagem, observou-se que à medida que se aumenta o número de elementos finitos a carga crítica converge em 96,26 kN/m². Com o intuito de reduzir o esforço computacional nas futuras análises lineares e não-lineares, utilizou-se, neste trabalho, a malha de elementos finitos com 9600 elementos STRI3. Considerando-se o valor de carga crítica da malha com 960000 elementos como a solução exata do problema verificou-se que o grau de aproximação à malha de 9600 elementos é altíssimo, com valor apenas $0,2 \%$ inferior, não havendo a necessidade de representar o problema com uma malha que demande um tempo de cálculo tão superior.

A escolha do elemento foi feita buscando-se a maior proximidade possível à formulação matemática apresentada no Capítulo 2. O elemento escolhido, STRI3, apresenta uma formulação que satisfaz a teoria de Kirchhoff, os planos normais ao plano da casca permanecem ortogonais à superfície de referência e as tensões transversais de cisalhamento são negligenciadas. Este elemento considera pequenas deformações não havendo alterações na análise com relação à mudança da espessura durante a deformação. 


\subsection{ANÁLISE PARAMÉTRICA DA CARGA CRÍTICA}

Segundo Gonçalves e Soares (2016), na análise estática linear da casca conoidal, submetida a um carregamento uniformemente distribuído na direção transversal é possível obter a carga crítica através da resolução do problema de autovalor, sendo este ponto definido na análise de estabilidade de carga crítica. As cargas críticas dos conóides parabólicos e cilíndricos são apresentadas na Tabela 3.2 para diferentes condições de apoio e de geometrias em planta.

Tabela 3.2- Carga crítica $\left(\mathrm{P}_{\mathrm{cr}}\right)$ da casca conoidal para diferentes condições de apoio e de geometria $\left(\mathrm{kN} / \mathrm{m}^{2}\right)$

\begin{tabular}{|c|c|c|c|c|c|c|}
\hline \multirow{2}{*}{ Geometria } & \multicolumn{6}{|c|}{$\mathrm{CA}$} \\
\hline & $\mathrm{A}_{1} \mathrm{~A}_{1} \mathrm{~A}_{1} \mathrm{~A}_{1}$ & $\mathrm{~A}_{2} \mathrm{~A}_{2} \mathrm{~A}_{2} \mathrm{~A}_{2}$ & $\mathrm{~A}_{2} \mathrm{~A}_{2} \mathrm{LA}_{2}$ & EELE & $\mathrm{A}_{2} \mathrm{~A}_{2} \mathrm{LL}$ & EELL \\
\hline \multicolumn{7}{|c|}{ Casca conoidal parabólica (Figura 3.1 (a)) } \\
\hline 1 & 42,609 & 81,909 & 85,392 & 106,954 & 20,765 & 27,747 \\
\hline 2 & 67,423 & 121,558 & 103,588 & 122,932 & 31,297 & 39,769 \\
\hline 3 & 96,466 & 145,681 & 106,163 & 130,343 & 28,398 & 42,915 \\
\hline 4 & 139,491 & 178,606 & 99,750 & 121,700 & 22,044 & 48,582 \\
\hline \multicolumn{7}{|c|}{ Casca conoidal cilíndrica (Figura 3.1 (b)) } \\
\hline 1 & 28,736 & 41,147 & 47,400 & 56,058 & 17,054 & 16,995 \\
\hline 2 & 44,096 & 58,197 & 52,778 & 62,624 & 20,026 & 23,009 \\
\hline 3 & 63,876 & 78,004 & 60,719 & 69,025 & 20,312 & 30,270 \\
\hline 4 & 99,076 & 116,897 & 73,142 & 78,976 & 21,876 & 38,739 \\
\hline
\end{tabular}

Observou-se, a partir da Tabela 3.2, que na análise estática linear as bordas curvas parabólicas conferem a casca conoidal maior carga crítica do que as bordas cilíndricas, considerando-se as mesmas condições de contorno e de geometria. Pensando-se em projetar a favor da segurança, seria interessante a adoção do conóide cilíndrico, pois possui menores cargas críticas. Verificou-se que, dentre os casos analisados, as situações com as maiores cargas críticas ocorreram para as cascas conoidais dadas pela Geometria 4 e apoiadas em todas as bordas, independentemente das bordas curvas serem parabólicas ou cilíndricas, ou seja, quanto mais graus de liberdade restringidos, maiores foram as cargas críticas atingidas pelos conóides. Notou-se que a Geometria 4 apresenta altura das bordas curvas iguais, levando a casca conoidal a um típico caso de painel parabólico ou cilíndrico. As maiores cargas críticas da casca conoidal com apoios indeslocáveis e com bordas curvas cilíndricas apresenta um valor 
de 34,55\% menor que a mesma casca com bordas curvas parabólicas, e 28,97\% menor para o caso com apoios deslocáveis.

Em todas as condições de contorno e geometrias analisadas na Tabela 3.2, a menor carga crítica ocorreu na casca conoidal de Geometria 1, na qual apenas a borda $\mathrm{H}_{2}$ é curva. As menores cargas críticas obtidas, para a casca com variação cilíndrica das bordas curvas livres, tem diferença 38,77\% menor do que a casca com variação parabólica da borda e bordas retas engastadas e $17,87 \%$ menor se tratando das bordas retas com apoios indeslocáveis, como apresentado na Tabela 3.2.

Ainda a partir da Tabela 3.2, notou-se tanto nos casos parabólicos quanto nos casos cilíndricos que cada geometria de conóide tem sua maior e sua menor carga crítica considerando a mesma condição de contorno. A exceção é a Geometria 1 na qual sua menor carga crítica no caso cilíndrico ocorre no caso de apoio EELL enquanto que para o caso parabólico ocorre no caso de apoio $\mathrm{A}_{2} \mathrm{~A}_{2} \mathrm{LL}$. Porém, um fator construtivo interessante é que ainda na Geometria 1 com bordas cilíndricas, o valor da carga crítica da casca com apoio $\mathrm{A}_{2} \mathrm{~A}_{2} \mathrm{LL}$ é $0,3 \%$ superior à carga crítica da casca com apoio EELL, ou seja, uma diferença pequena de valores então pode-se escolher qualquer desses apoios para a construção da Geometria 1.

A carga crítica encontrada através do estudo estático linear pode acarretar em respostas inadequadas à realidade do problema, pois o comportamento linear dos conóides está baseado na condição que o material trabalhe no regime elástico-linear e não considera os efeitos de segunda ordem que dependem das características geométricas dos conóides assim como das propriedades do seu material constituinte. Gonçalves e Soares (2016) afirmam que a análise estática linear da carga crítica pode subestimar, ou superestimar, a capacidade de carga da casca conoidal, sendo assim, o estudo da trajetória de equilíbrio estático não-linear deste tipo de estrutura se faz necessário e será apresentado no Capítulo 4 desta dissertação. 


\subsection{MODO DE FLAMBAGEM}

O modo de flambagem da casca conoidal apresenta a forma dos campos de deslocamentos da estrutura ao atingir a carga crítica. Os resultados apresentados nesta seção não representam a magnitude real dos deslocamentos ao atingir a carga crítica, pois se trata de um autovetor associado ao autovalor (carga crítica) do problema. Os resultados obtidos são apresentados com o campo de deslocamento máximo normalizado com a unidade, sendo os demais campos de deslocamentos proporcionais à unidade.

Apresentam-se nas Figuras 3.4 e 3.5 o primeiro modo de flambagem dos campos de deslocamentos para as cascas conoidais com Geometria 1 e bordas curvas parabólicas (Figura 3.4), ou cilíndricas, (Figura 3.5). Nesta geometria existe apenas uma borda curva $\left(\mathrm{H}_{2}\right)$ e está submetida à variação paramétrica das condições de contorno apresentadas na Tabela 3.2 e seu estudo é justificado por apresentar as menores cargas críticas obtidas na análise estática linear.

A partir dos modos de flambagem apresentados nas Figuras 3.4 e 3.5, percebeu-se que a variação da condição de apoio, ou da geometria, alterou as disposições e os números das semi-ondas dos campos de deslocamentos, levando seus máximos a se localizarem em diferentes coordenadas da casca. As semi-ondas dispostas em relação ao eixo $x$ são denominadas de semi-ondas longitudinais e as semi-ondas dispostas em relação ao eixo $y$ são denominadas de semi-ondas circunferenciais.

Observou-se, nas Figuras 3.4 e 3.5, que ao utilizar apoios simétricos, deslocáveis ou indeslocáveis, na casca conoidal parabólica, ou cilíndrica, os campos de deslocamentos $w$ e $u$ têm a forma de três semi-ondas circunferenciais distribuídas ao centro da casca conoidal de forma simétrica em torno do eixo $x$, sendo os seus valores máximos localizados próximos a borda $\mathrm{H}_{1}$, como ilustram as Figuras 3.4 (a), (c), (d) e (f) e 3.5 (a), (c), (d) e (f).

Para os casos de condição de contorno com apenas uma borda curva livre e as demais com apoios indeslocáveis, ou engastados, Figuras 3.4 (g), (i), (j), (l) e 3.5 (g), (i), (j), (1), há uma distribuição simétrica em torno do eixo $x$ das semi-ondas circunferenciais dos campos de deslocamentos $w$ e $u$ ao longo da borda curva livre como era esperado. Ressalta-se que a condição de contorno com as três bordas retas engastadas e a borda curva livre obteve as maiores cargas críticas nos conóides de Geometria 1. 
Figura 3.4- Modo de flambagem do conóide parabólico para diferentes condições de contorno (Geometria 1)

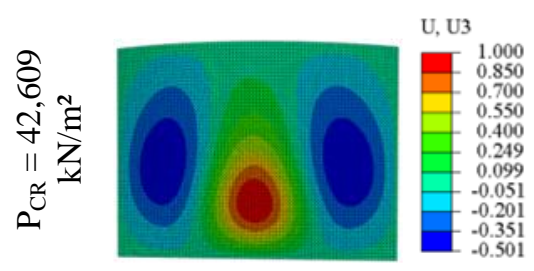

(a) $w: \mathrm{A}_{1} \mathrm{~A}_{1} \mathrm{~A}_{1} \mathrm{~A}_{1}$

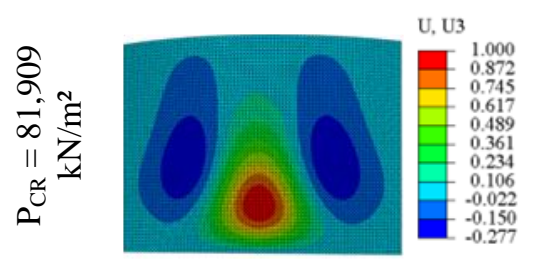

(d) $w: \mathrm{A}_{2} \mathrm{~A}_{2} \mathrm{~A}_{2} \mathrm{~A}_{2}$

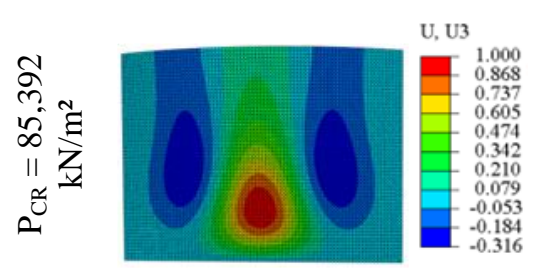

(g) $w: \mathrm{A}_{2} \mathrm{~A}_{2} \mathrm{LA}_{2}$

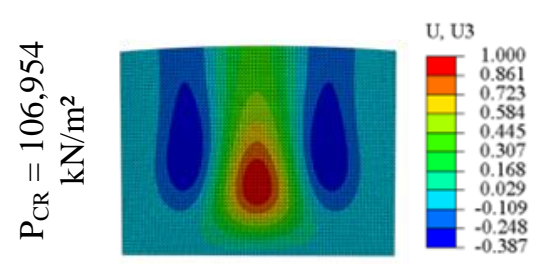

(j) $w$ : EELE

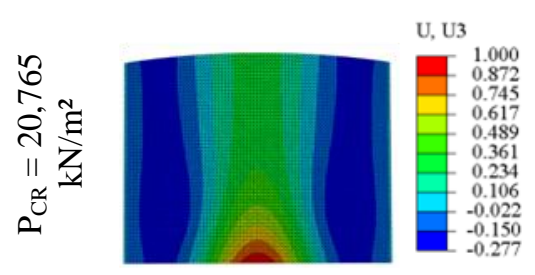

(m) $w: \mathrm{A}_{2} \mathrm{~A}_{2} \mathrm{LL}$

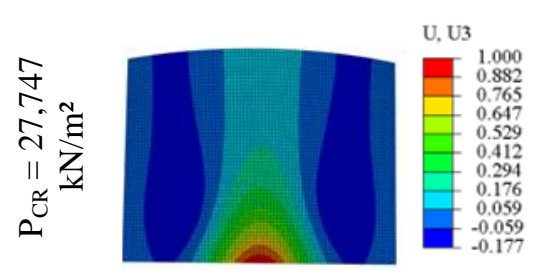

(p) $w$ : EELL

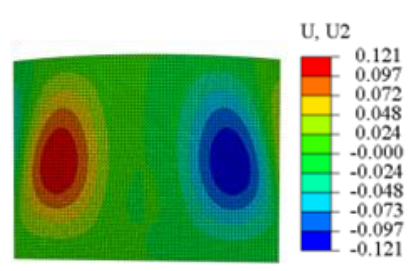

(b) $v: \mathrm{A}_{1} \mathrm{~A}_{1} \mathrm{~A}_{1} \mathrm{~A}_{1}$

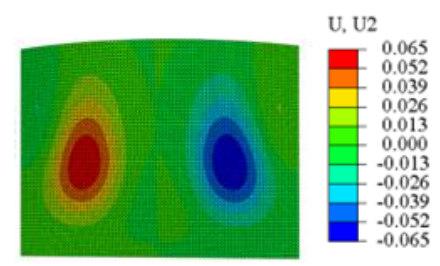

(e) $v: \mathrm{A}_{2} \mathrm{~A}_{2} \mathrm{~A}_{2} \mathrm{~A}_{2}$

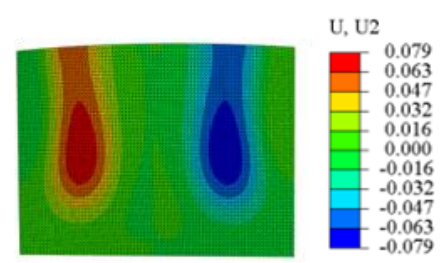

(h) $v: \mathrm{A}_{2} \mathrm{~A}_{2} \mathrm{LA}_{2}$

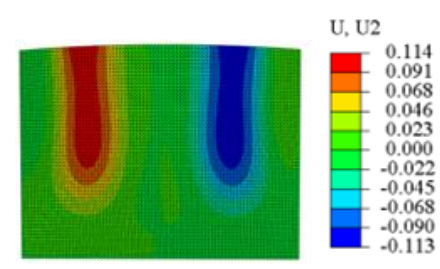

(k) $v$ : EELE

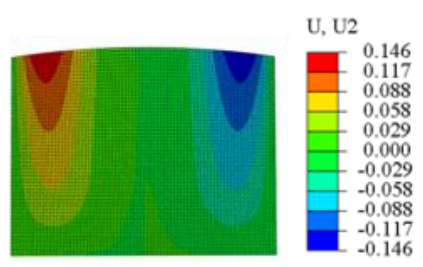

(n) $v: \mathrm{A}_{2} \mathrm{~A}_{2} \mathrm{LL}$

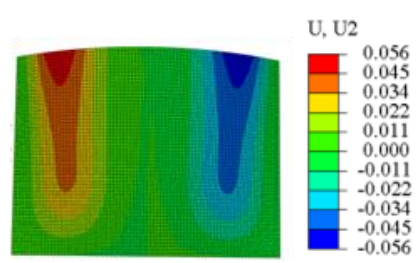

(q) $v$ : EELL

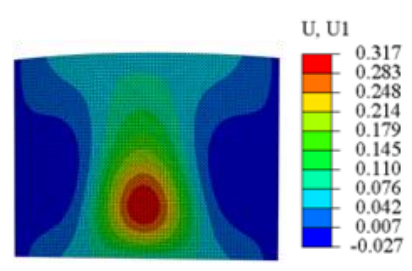

(c) $u: \mathrm{A}_{1} \mathrm{~A}_{1} \mathrm{~A}_{1} \mathrm{~A}_{1}$

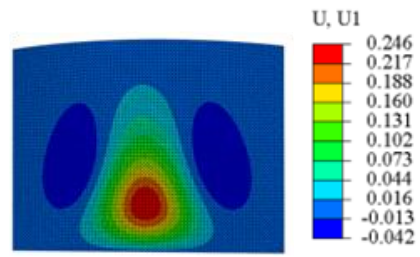

(f) $u: \mathrm{A}_{2} \mathrm{~A}_{2} \mathrm{~A}_{2} \mathrm{~A}_{2}$

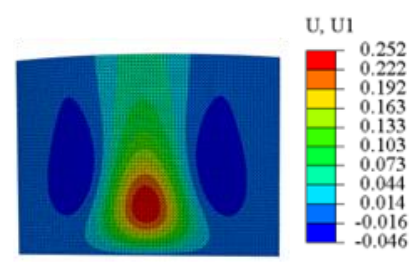

(i) $u: \mathrm{A}_{2} \mathrm{~A}_{2} \mathrm{LA}_{2}$

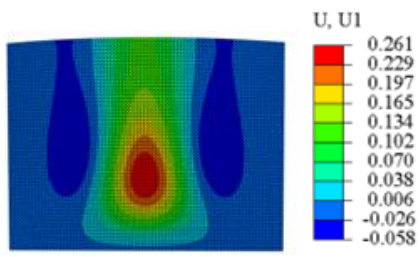

(1) $u$ : EELE

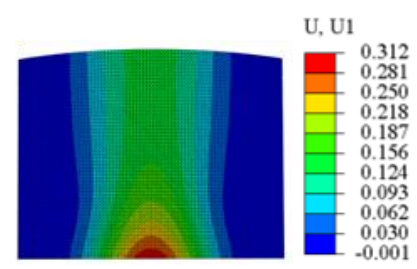

(o) $u: \mathrm{A}_{2} \mathrm{~A}_{2} \mathrm{LL}$

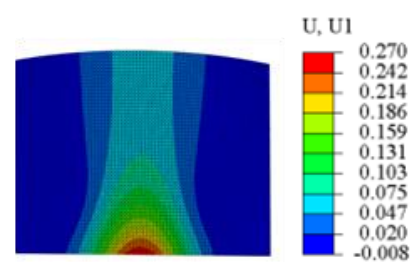

(r) $u$ : EELL 
Figura 3.5- Modo de flambagem do conóide cilíndrico para diferentes condições de contorno (Geometria 1)

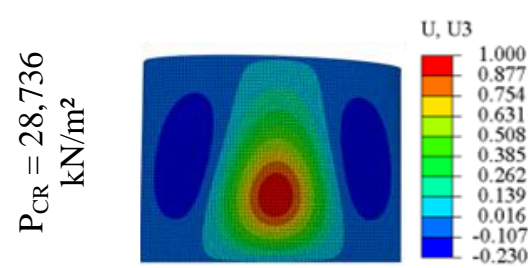

(a) $w: \mathrm{A}_{1} \mathrm{~A}_{1} \mathrm{~A}_{1} \mathrm{~A}_{1}$

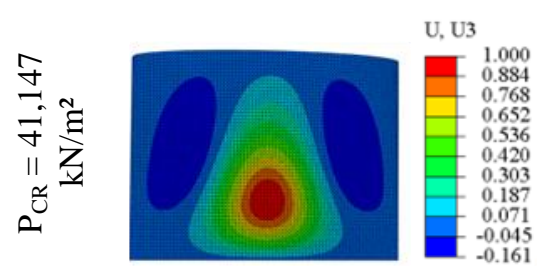

(d) $w: \mathrm{A}_{2} \mathrm{~A}_{2} \mathrm{~A}_{2} \mathrm{~A}_{2}$

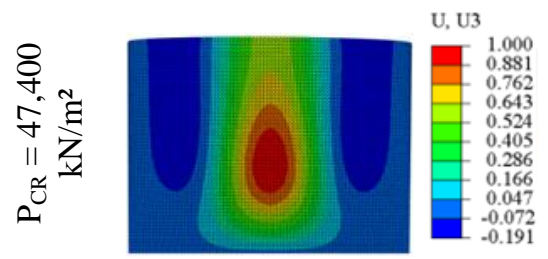

(g) $w: \mathrm{A}_{2} \mathrm{~A}_{2} \mathrm{LA}_{2}$

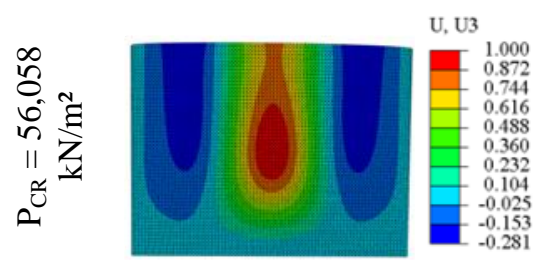

(j) $w$ : EELE

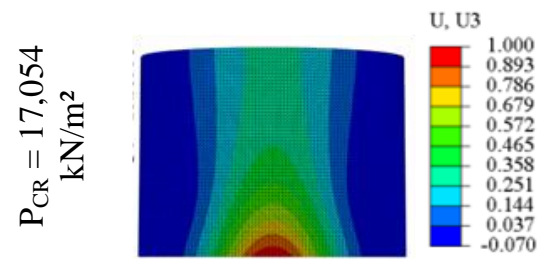

(m) $w: \mathrm{A}_{2} \mathrm{~A}_{2} \mathrm{LL}$

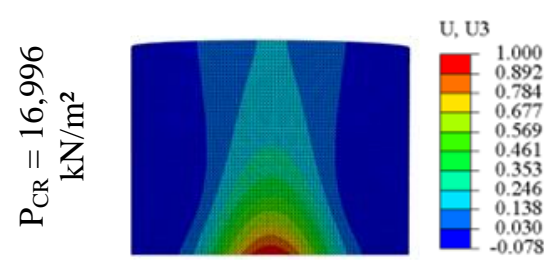

(p) $w$ : EELL

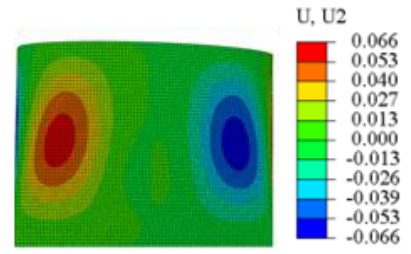

(b) $v: \mathrm{A}_{1} \mathrm{~A}_{1} \mathrm{~A}_{1} \mathrm{~A}_{1}$

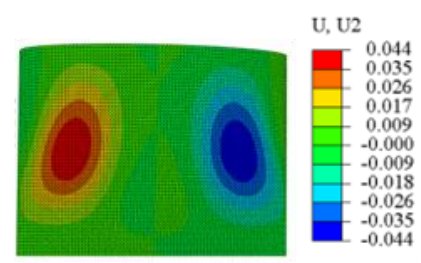

(e) $v: \mathrm{A}_{2} \mathrm{~A}_{2} \mathrm{~A}_{2} \mathrm{~A}_{2}$

U, U2

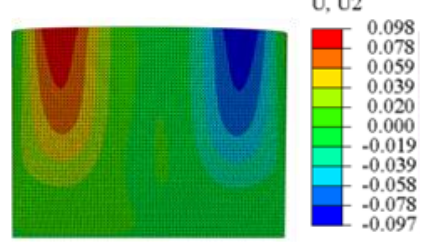

(h) $v: \mathrm{A}_{2} \mathrm{~A}_{2} \mathrm{LA}_{2}$

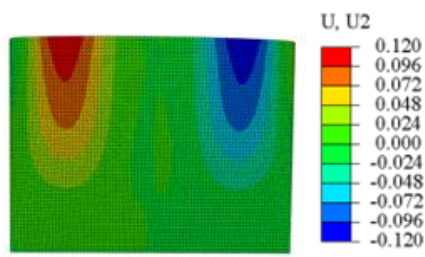

(k) $v$ : EELE

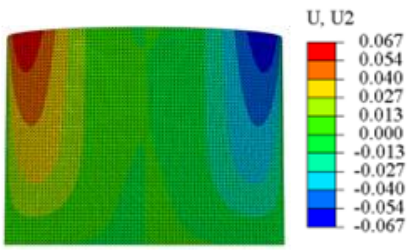

(n) $v: \mathrm{A}_{2} \mathrm{~A}_{2} \mathrm{LL}$
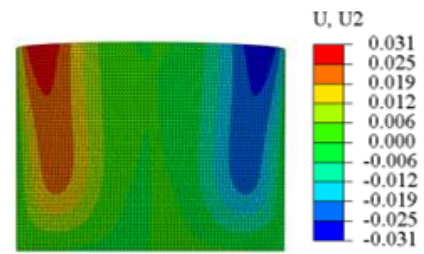

(q) $v$ : EELL

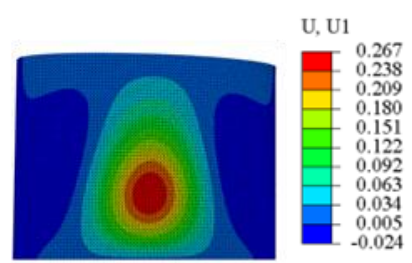

(c) $u: \mathrm{A}_{1} \mathrm{~A}_{1} \mathrm{~A}_{1} \mathrm{~A}_{1}$

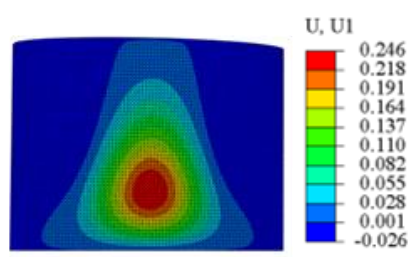

(f) $u: \mathrm{A}_{2} \mathrm{~A}_{2} \mathrm{~A}_{2} \mathrm{~A}_{2}$

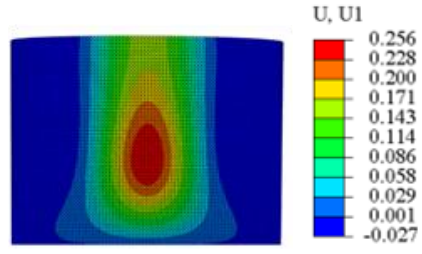

(i) $u: \mathrm{A}_{2} \mathrm{~A}_{2} \mathrm{LA}_{2}$

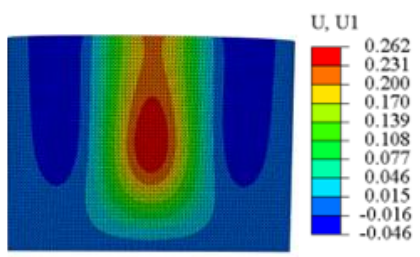

(1) $u$ : EELE

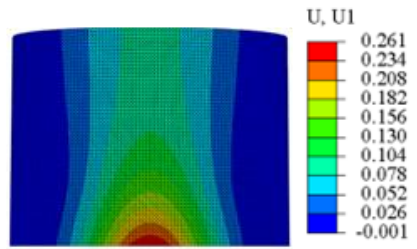

(o) $u: \mathrm{A}_{2} \mathrm{~A}_{2} \mathrm{LL}$

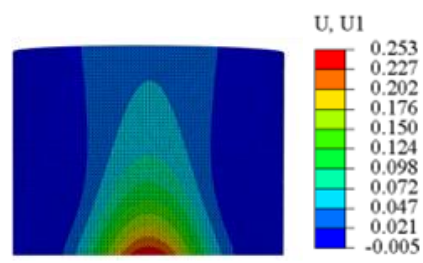

(r) $u$ : EELL 
As cascas conoidais de Geometria $1 \mathrm{com}$ as bordas $\mathrm{H}_{1}$ e $\mathrm{H}_{2}$ livres e as demais com apoios indeslocáveis, Figuras 3.4 (m), (o), (p) e (r), ou com as outras engastadas, Figuras 3.5 (m), (o), (p) e (r), possuem as menores cargas críticas da Tabela 3.2. Verificou-se que a inserção de duas bordas livres modificou a configuração da distribuição das semi-ondas ao longo do eixo axial, $x$, sendo que as semi-ondas circunferenciais dos campos de deslocamentos $w$ e $u$ passaram a se distribuir em faixas de uma borda curva a outra, com máximos localizados na borda curva $\mathrm{H}_{1}$ e simetria em torno do eixo $x$.

Para os campos de deslocamento $v$, os modos de flambagem dos conóides parabólicos, ou cilíndricos, apresentados nas Figuras 3.4 e 3.5, observou-se a existência de duas semi-ondas circunferenciais, anti-simétricas em torno do eixo $x$, independentemente das condições de contorno da casca conoidal e da forma das bordas curvas. Esse campo de deslocamento tem sua distribuição preferencialmente no centro dos conóides apoiados em todas as bordas, Figuras 3.4 (b) e (e) e 3.5 (b) e (e), e ao longo da borda curva de maior altura nas cascas que possuem pelo menos uma das bordas curvas livre, Figuras 3.4 (h), (k), (n) e (q) e 3.5 (h), (k), (n) e (q).

Por fim, destaca-se, a partir das Figuras 3.4 e 3.5, a existência de uma semelhança na topologia dos campos de deslocamentos para os conóides de Geometria 1 com bordas curvas parabólicas, ou cilíndricas, com três semi-ondas circunferenciais em $w$ e $u$ e apenas duas semi-ondas em $v$.

Considerando-se a variação paramétrica das condições de contorno dos conóides com altura das bordas curvas iguais, Geometria 4, as componentes dos campos de deslocamento do primeiro modo de flambagem dos casos parabólicos, ou cilíndricos, são apresentados nas Figuras 3.6 e 3.7, respectivamente. Esta geometria apresenta as maiores cargas críticas obtidas na análise estática linear, Tabela 3.2.

Observou-se para as cascas conoidais com apoios simétricos $\left(\mathrm{A}_{1} \mathrm{~A}_{1} \mathrm{~A}_{1} \mathrm{~A}_{1}\right.$ e $\left.\mathrm{A}_{2} \mathrm{~A}_{2} \mathrm{~A}_{2} \mathrm{~A}_{2}\right)$ que as semi-ondas circunferenciais dos deslocamentos $w$ e $v$, Figuras 3.6 (b) e (d) e 3.7 (b) e (d), se distribuem preferencialmente ao centro das cascas e de forma simétrica em torno do eixo $x$. Já nas Figuras 3.6 (a) e (e) e 3.7 (a) e (e) os campos de deslocamentos $w$ e $v$ assumem uma distribuição anti-simétrica em torno do eixo $x$. Para os campos de deslocamentos em $u$, as semi-ondas se desenvolvem de forma anti-simétrica em torno do eixo $x$, Figuras 3.6 (c) e 3.7 (c), enquanto nas Figuras 3.6 (f) e 3.7 (f) os campos de deslocamentos em $u$ se organizam 
simetricamente em torno do eixo $x$, porém há uma duplicação das ondas na direção de $x$, levando a uma distribuição anti-simétrica ao longo do eixo $x$.

Observou-se que o número de semi-ondas circunferenciais do campo de deslocamento $w$ do caso parabólico,

Figura 3.6 (a), aumentou em relação ao número de semi-ondas do caso cilíndrico,

Figura 3.7 (a), isto também ocorreu no número de semi-ondas dos campos de deslocamentos $u, v$ e $w$ do caso parabólico, Figuras 3.6 (d)-(f), em relação ao caso cilíndrico, Figuras 3.7 (d)(f). Esta casca conoidal de bordas curvas parabólicas é a que apresenta as maiores cargas críticas das duas condições de apoio $\mathrm{A}_{1} \mathrm{~A}_{1} \mathrm{~A}_{1} \mathrm{~A}_{1}$ e $\mathrm{A}_{2} \mathrm{~A}_{2} \mathrm{~A}_{2} \mathrm{~A}_{2}$.

Nas cascas conoidais com apoios assimétricos entre as bordas curvas $\left(\mathrm{A}_{2} \mathrm{~A}_{2} \mathrm{LA} \mathrm{A}_{2}\right.$ e EELE), Figuras 3.6 (g)-(l) e 3.7 (g)-(l), notaram-se combinações de semi-ondas semelhantes, onde os máximos deslocamentos das semi-ondas circunferenciais ocorreram nas bordas curvas livres, $\mathrm{H}_{2}$. Observou-se uma anti-simetria nos campos de deslocamentos $w$ e $u$ e simetria nos campos de deslocamentos $v$ em torno do eixo $x$ nos conóides cilíndricos de apoios $\mathrm{A}_{2} \mathrm{~A}_{2} \mathrm{LA}_{2}$, EELE e no conóide parabólico de apoio $\mathrm{A}_{2} \mathrm{~A}_{2} \mathrm{LA}_{2}$, além de anti-simetria no campo de deslocamento $v$ e simetria nos campos de deslocamentos $w$ e $u$ em relação ao eixo $x$ no conóide parabólico de apoio EELE.

Tratando-se das cascas conoidais com apoios simétricos e com duas bordas curvas livres, Figuras $3.6(\mathrm{~m})-(\mathrm{r})$ e $3.7(\mathrm{~m})-(\mathrm{r})$, nos campos de deslocamentos $w$ e $v$ as semi-ondas circunferenciais foram distribuídas de uma borda curva a outra borda curva de forma simétrica em torno do eixo $x$. Para os campos de deslocamento $u$ as semi-ondas longitudinais se dividiram em dois seguimentos cada um perto de uma das bordas curvas, Figuras 3.6 (o) e (r) e 3.7 (o) e (r), como já identificado para as condições de apoio $\mathrm{A}_{1} \mathrm{~A}_{1} \mathrm{~A}_{1} \mathrm{~A}_{1}$ e $\mathrm{A}_{2} \mathrm{~A}_{2} \mathrm{~A}_{2} \mathrm{~A}_{2}$, Figuras 3.6 (c) e (f) e 3.7 (c) e (f).

De forma geral, observou-se que os campos de deslocamentos $u, v$ e $w$ nas cascas conoidais com somente uma borda curva livre tendem a se apresentar com semi-ondas circunferenciais nesta borda livre para todas as geometrias avaliadas. 
Figura 3.6- Modo de flambagem do conóide parabólico para diferentes condições de contorno (Geometria 4)

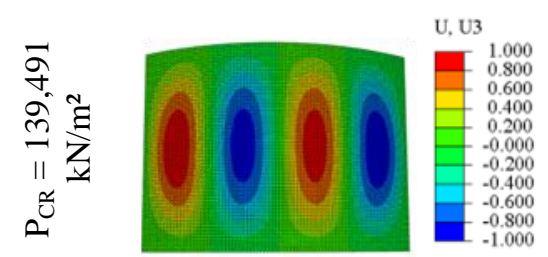

(a) $w: \mathrm{A}_{1} \mathrm{~A}_{1} \mathrm{~A}_{1} \mathrm{~A}_{1}$

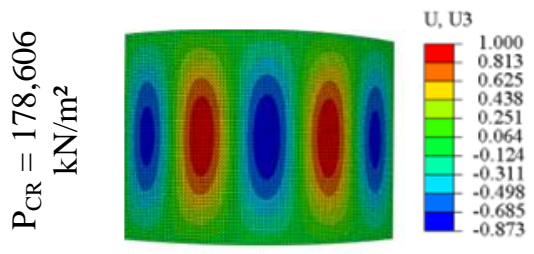

(d) $w: \mathrm{A}_{2} \mathrm{~A}_{2} \mathrm{~A}_{2} \mathrm{~A}_{2}$

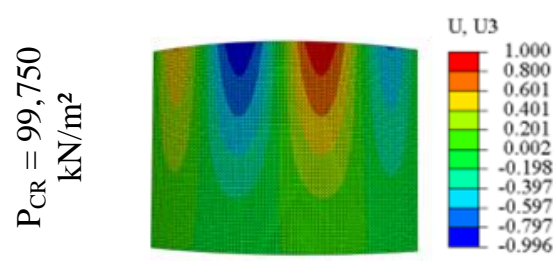

(g) $w: \mathrm{A}_{2} \mathrm{~A}_{2} \mathrm{LA}_{2}$

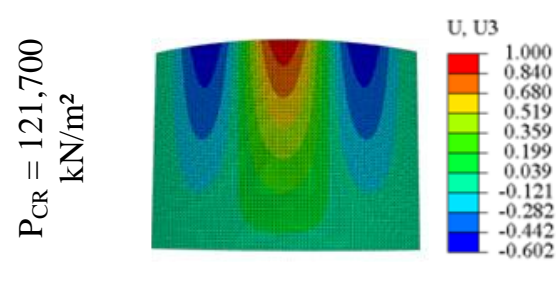

(j) $w$ : EELE

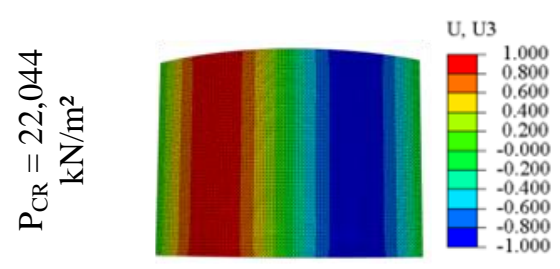

(m) $w: \mathrm{A}_{2} \mathrm{~A}_{2} \mathrm{LL}$

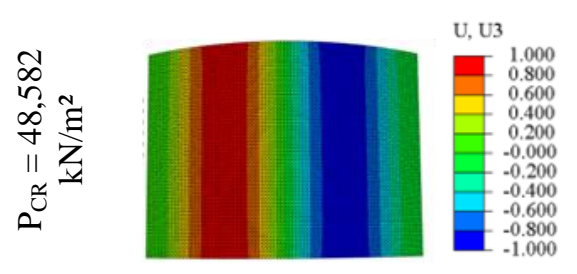

(p) $w$ : EELL

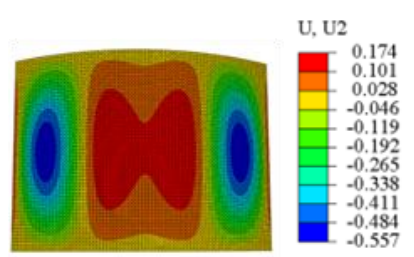

(b) $v: \mathrm{A}_{1} \mathrm{~A}_{1} \mathrm{~A}_{1} \mathrm{~A}_{1}$

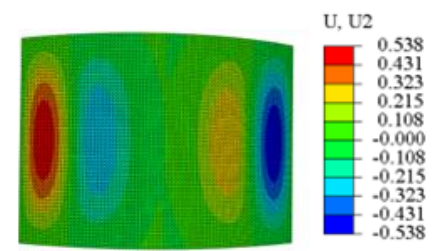

(e) $v: \mathrm{A}_{2} \mathrm{~A}_{2} \mathrm{~A}_{2} \mathrm{~A}_{2}$

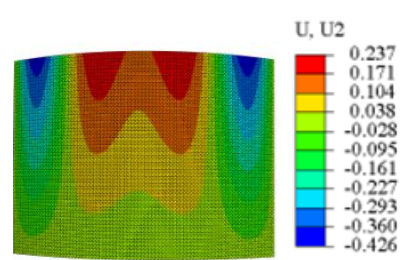

(h) $v: \mathrm{A}_{2} \mathrm{~A}_{2} \mathrm{LA}_{2}$

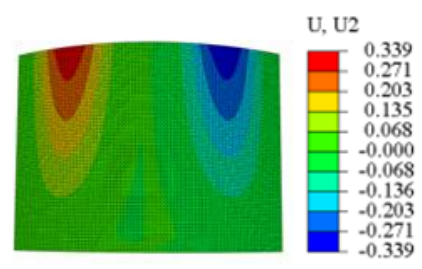

(k) $v$ : EELE

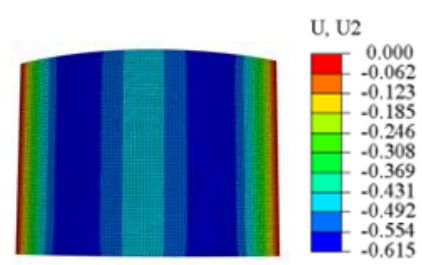

(n) $v: \mathrm{A}_{2} \mathrm{~A}_{2} \mathrm{LL}$

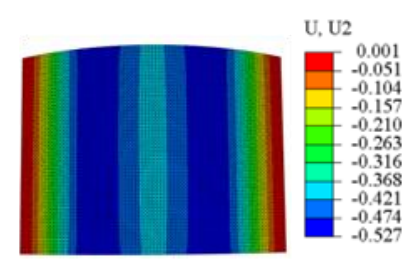

(q) $v$ : EELL

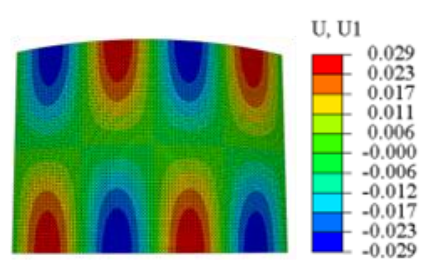

(c) $u: \mathrm{A}_{1} \mathrm{~A}_{1} \mathrm{~A}_{1} \mathrm{~A}_{1}$

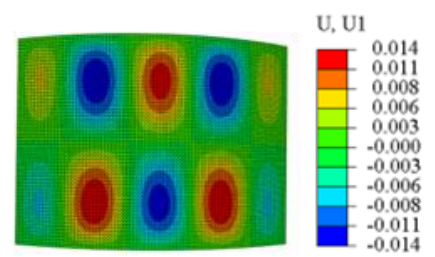

(f) $u: \mathrm{A}_{2} \mathrm{~A}_{2} \mathrm{~A}_{2} \mathrm{~A}_{2}$

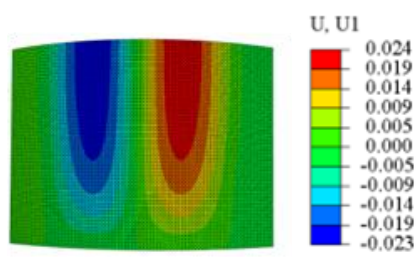

(i) $u: \mathrm{A}_{2} \mathrm{~A}_{2} \mathrm{LA}_{2}$

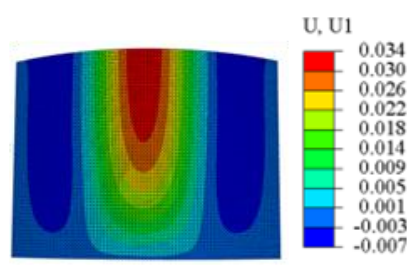

(1) $u$ : EELE

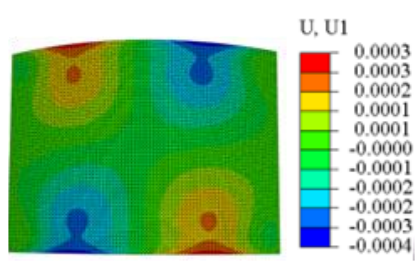

(o) $u: \mathrm{A}_{2} \mathrm{~A}_{2} \mathrm{LL}$

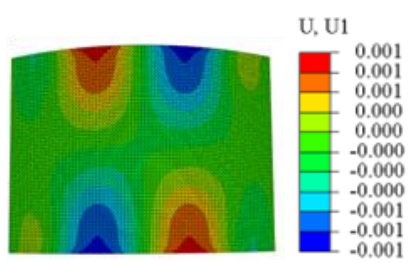

(r) $u$ : EELL 
Figura 3.7- Modo de flambagem do conóide cilíndrico para diferentes condições de contorno (Geometria 4)

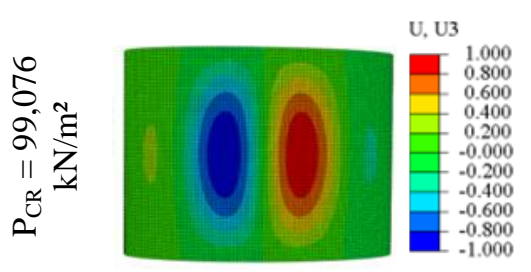

(a) $w: \mathrm{A}_{1} \mathrm{~A}_{1} \mathrm{~A}_{1} \mathrm{~A}_{1}$

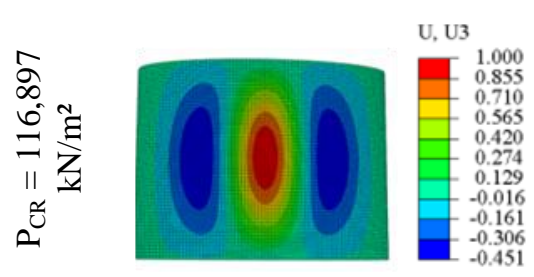

(d) $w: \mathrm{A}_{2} \mathrm{~A}_{2} \mathrm{~A}_{2} \mathrm{~A}_{2}$

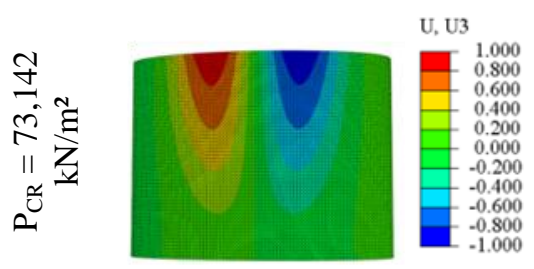

(g) $w: \mathrm{A}_{2} \mathrm{~A}_{2} \mathrm{LA}_{2}$

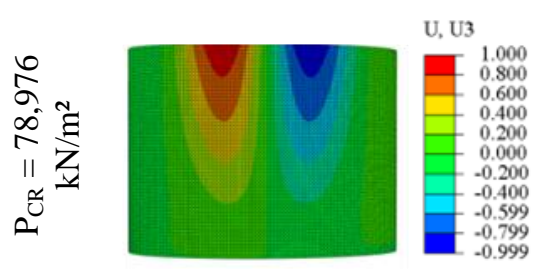

(j) $w$ : EELE

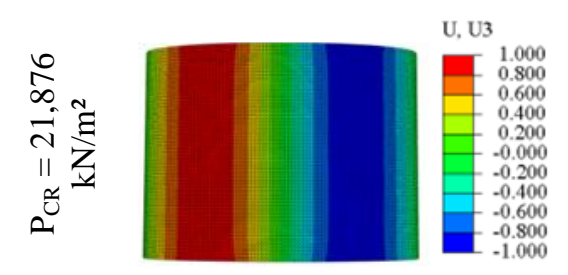

(m) $w: \mathrm{A}_{2} \mathrm{~A}_{2} \mathrm{LL}$

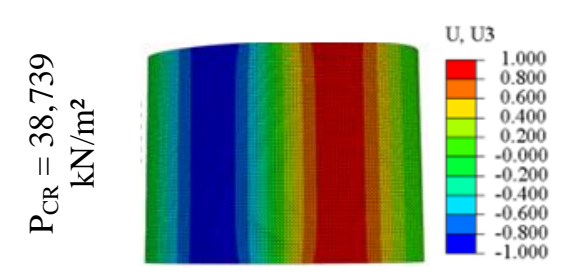

(p) $w$ : EELL

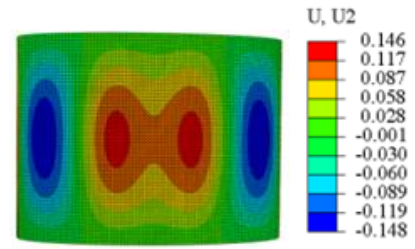

(b) $v: \mathrm{A}_{1} \mathrm{~A}_{1} \mathrm{~A}_{1} \mathrm{~A}_{1}$

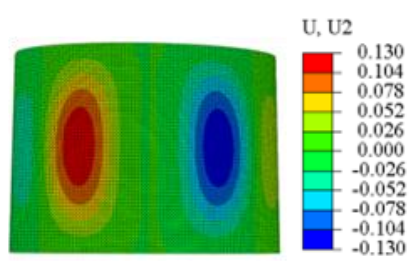

(e) $v: \mathrm{A}_{2} \mathrm{~A}_{2} \mathrm{~A}_{2} \mathrm{~A}_{2}$ U, U2

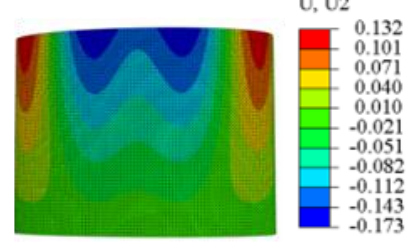

(h) $v: \mathrm{A}_{2} \mathrm{~A}_{2} \mathrm{LA}_{2}$

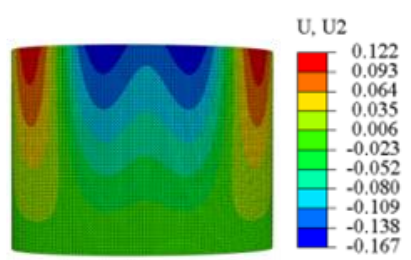

(k) $v$ : EELE

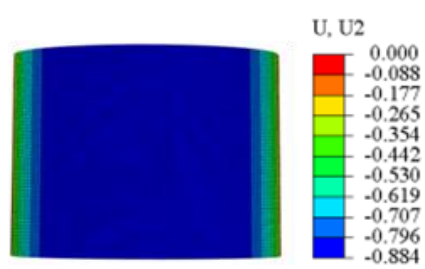

(n) $v: \mathrm{A}_{2} \mathrm{~A}_{2} \mathrm{LL}$

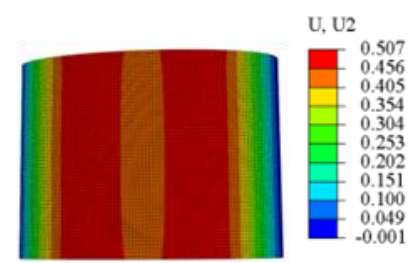

(q) $v$ : EELL

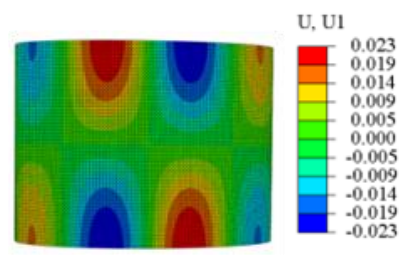

(c) $u: \mathrm{A}_{1} \mathrm{~A}_{1} \mathrm{~A}_{1} \mathrm{~A}_{1} \mathrm{P}$

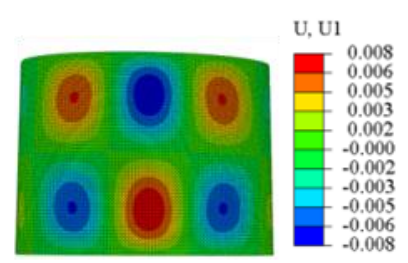

(f) $u: \mathrm{A}_{2} \mathrm{~A}_{2} \mathrm{~A}_{2} \mathrm{~A}_{2}$

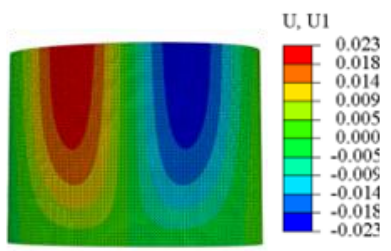

(i) $u: \mathrm{A}_{2} \mathrm{~A}_{2} \mathrm{LA}_{2}$

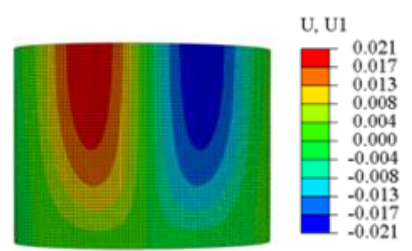

(1) $u$ : EELE

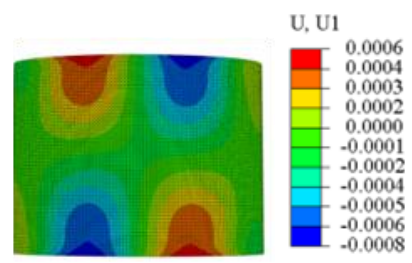

(o) $u: \mathrm{A}_{2} \mathrm{~A}_{2} \mathrm{LL}$

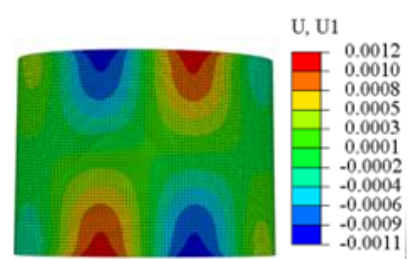

(r) $u$ : EELL 
Nas cascas com apoios simétricos com as quatro bordas apoiadas em primeiro, ou segundo gêneros, os campos de deslocamentos $w$ e $v$ possuem semi-ondas circunferenciais dispostas preferencialmente ao centro das cascas quando as alturas das bordas curvas são iguais. Quando a borda curva $\mathrm{H}_{1}$ tem a menor altura, há uma leve aproximação das semi-ondas para esta borda. O mesmo ocorre para o campo de deslocamento $u$ nas cascas conoidais de Geometria 1 com esses apoios simétricos, Figuras 3.4 (c) e (f) e 3.5 (c) e (f), exceto quando as duas bordas curvas tem a mesma altura, onde os campos de deslocamentos $u$ se dividem em duas faixas de semi-ondas longitudinais, sendo cada faixa próxima à uma borda curva da casca.

Ressalta-se que a maior carga crítica registrada para o conóide parabólico de Geometria 4, na qual houve um aumento no número de semi-ondas do campo de deslocamento $w$, com ilustra a Figuras 3.6 (a) e (d). Verificou-se também que as cascas conoidais com apoios simétricos e com duas bordas livres possuem as menores cargas críticas com a distribuição dos campos de deslocamento $w$ em faixas de uma borda curva a outra, Figuras $3.6(\mathrm{~m})$ e (p) e $3.7(\mathrm{~m})$ e (p). Por fim, quando a borda $\mathrm{H}_{1}$ apresenta a menor altura, Geometria 1, notou-se que os máximos das semi-ondas ocorrem nas proximidades da borda curva de menor altura, Figuras 3.4 (m) e (p) e $3.5(\mathrm{~m})$ e (p).

Em todos os casos analisados nas Figuras 3.4 a 3.7, notaram-se que as amplitudes dos campos de deslocamentos transversais $w$, são superiores as amplitudes dos campos de deslocamentos $u$ e $v$. Considerando fixa a altura da borda $\mathrm{H}_{2}$ e aumentando-se a altura da borda $\mathrm{H}_{1}$, as magnitudes dos campos de deslocamentos $u$ passam de superiores a inferiores às magnitudes dos campos de deslocamentos $v$.

Por fim, analisou-se a influência da variação das geometrias nas componentes dos campos de deslocamentos dos primeiros modos de flambagem das cascas conoidais com as condições de apoio que obtiveram as maiores e as menores cargas críticas, $\mathrm{A}_{2} \mathrm{~A}_{2} \mathrm{~A}_{2} \mathrm{~A}_{2}$ e $\mathrm{A}_{2} \mathrm{~A}_{2} \mathrm{LL}$. $\mathrm{A}$ variação do modo de flambagem com a geometria do conóide com apoios indeslocáveis nas quatro bordas, $\mathrm{A}_{2} \mathrm{~A}_{2} \mathrm{~A}_{2} \mathrm{~A}_{2}$, pode ser visualizada nas Figuras 3.8 (parabólico) e 3.9 (cilíndrico). 
Figura 3.8- Modo de flambagem do conóide parabólico com condição de contorno $\mathrm{A}_{2} \mathrm{~A}_{2} \mathrm{~A}_{2} \mathrm{~A}_{2}$ para diferentes geometrias

W

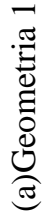

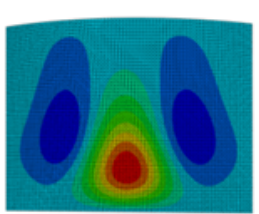

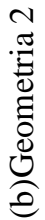

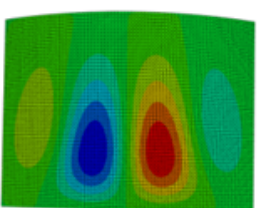

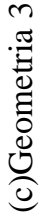

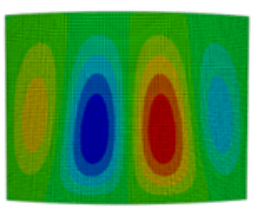

苞

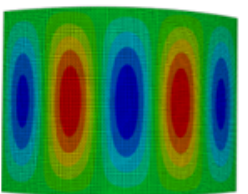

$v$
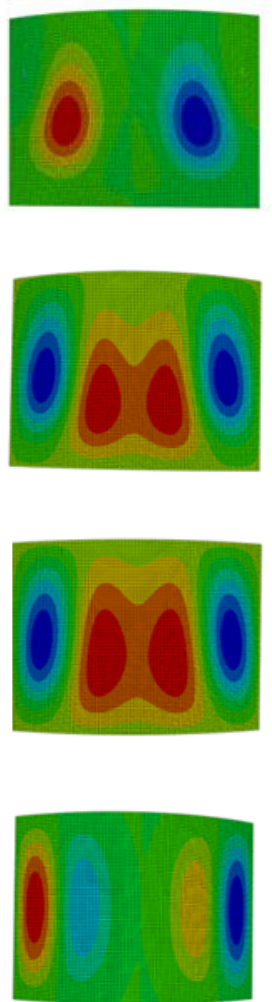

u
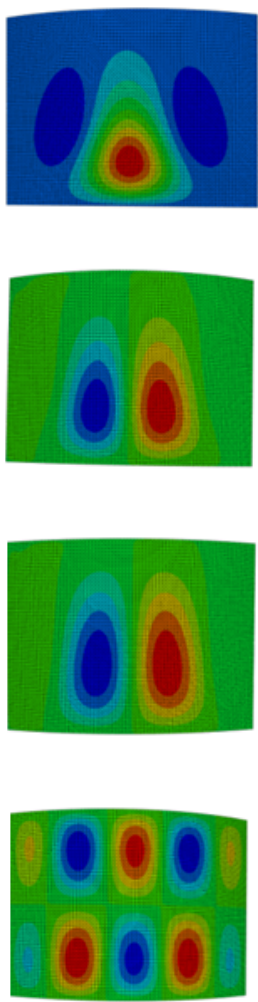

Figura 3.9- Modo de flambagem do conóide cilíndrico com condição de contorno $\mathrm{A}_{2} \mathrm{~A}_{2} \mathrm{~A}_{2} \mathrm{~A}_{2}$ para diferentes geometrias

$W$

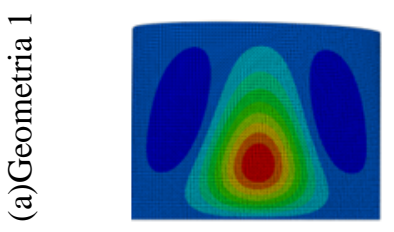

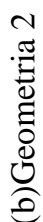

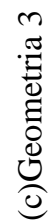
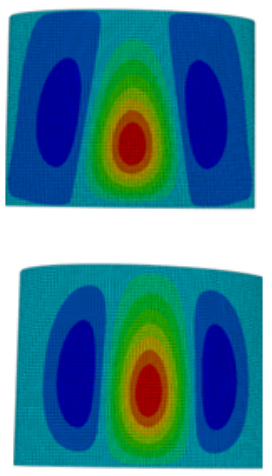

v

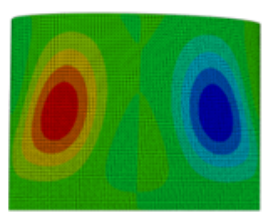

$u$
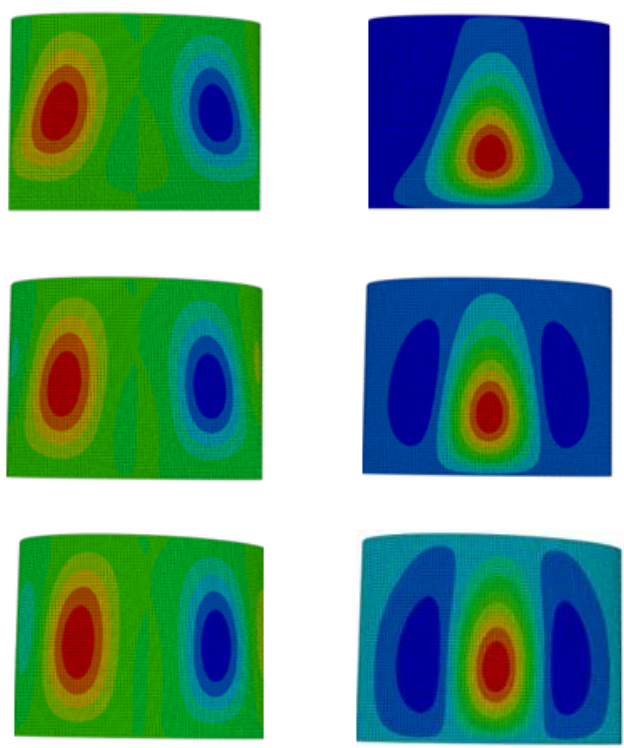

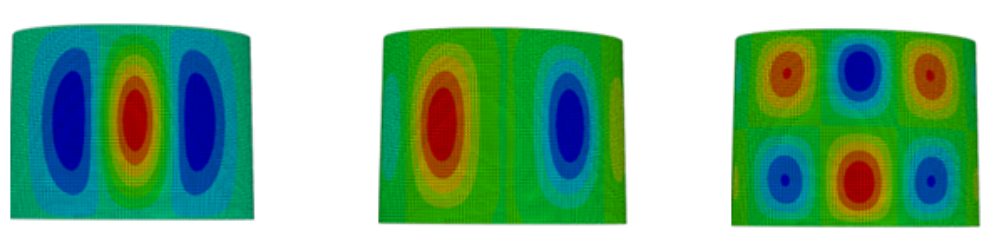

As Geometrias 1, 2 e 3 cilíndricas, Figuras 3.9 (a)-(c), têm modos de flambagem semelhantes aos modos de flambagem do caso parabólico quando há somente uma borda curva, Figura 3.8 (a), com três semi-ondas circunferenciais dispostas ao centro das cascas conoidais com o máximo deslocado para próximo da borda $\mathrm{H}_{1}$ nos campos de deslocamentos $w$ e $u$, sendo que para o campo de deslocamento $v$ há apenas duas semi-ondas circunferenciais dispostas ao centro. Quando se trata dos conóides de Geometrias 2, 3 e 4 e de bordas curvas parabólicas, Figuras 3.8 (b)-(d), a topologia dos modos de flambagem diverge da casca conoidal cilíndrica, apresentando números diferentes de semi-ondas circunferenciais.

As cascas com as duas bordas curvas livres e apoios indeslocáveis nas duas bordas retas, $\mathrm{A}_{2} \mathrm{~A}_{2} \mathrm{LL}$, tiveram as menores cargas críticas em todas as geometrias analisadas. Verificou-se, a partir das Figuras 3.10 (parabólico) e 3.11 (cilíndrico), a influência da variação das geometrias nas componentes dos campos de deslocamento dos modos de flambagem dos conóides com esta condição de contorno.

No conóide de Geometria 1, Figuras 3.10 (a) e 3.11 (a), verificou-se que os campos de deslocamentos $w$ e $u$ possuem a mesma topologia tanto no caso parabólico quanto no cilíndrico, apresentando duas faixas de semi-ondas circunferenciais simétricas em torno do eixo $x$ dispostas de uma borda curva a outra com o máximo de deslocamento próximo a borda $\mathrm{H}_{1}$.

O campo de deslocamento $v$ do modo de flambagem também possui a mesma topologia tanto no caso parabólico quanto no cilíndrico do conóide de Geometria 1, apresentando duas semiondas circunferenciais próximas a borda curva com maior altura. Observou-se no campo de deslocamento do conóide de Geometria 1, a dependência da coordenada $x$ devido a diferença entre as alturas das bordas curvas $\mathrm{H}_{1}$ e $\mathrm{H}_{2}$, bem como a simetria, em $w$ e $u$ e anti-simetria, em $v$, em torno do eixo $x$. 
Figura 3.10- Modo de flambagem do conóide parabólico com condição de contorno $\mathrm{A}_{2} \mathrm{~A}_{2} \mathrm{LL}$ para diferentes geometrias

$w$
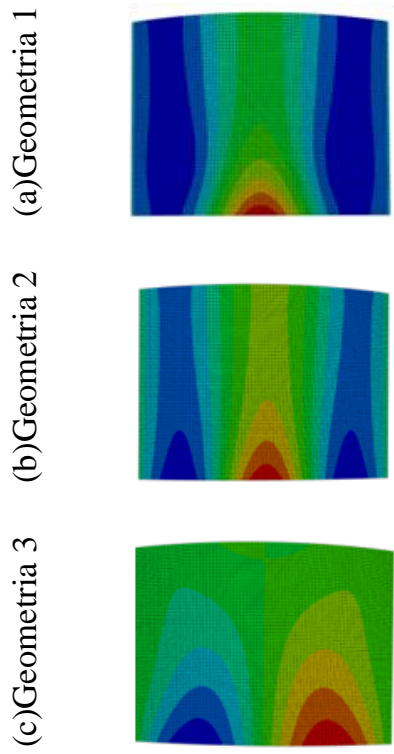

サ্ত

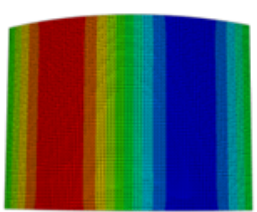

$v$
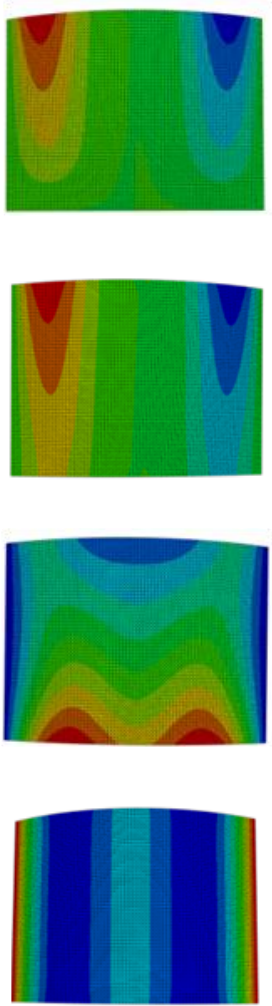

$u$
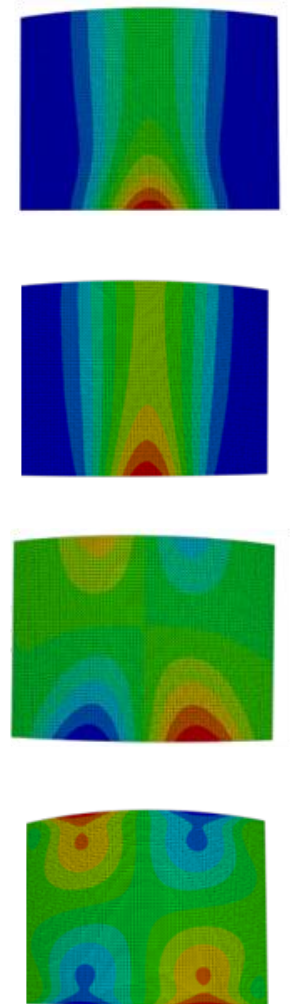

Figura 3.11- Modo de flambagem do conóide cilíndrico com condição de contorno $\mathrm{A}_{2} \mathrm{~A}_{2} \mathrm{LL}$ para diferentes geometrias

w

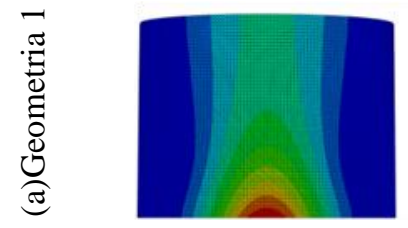

ֻ

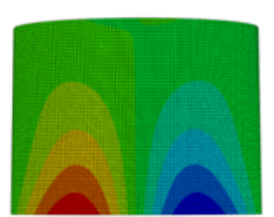

苞

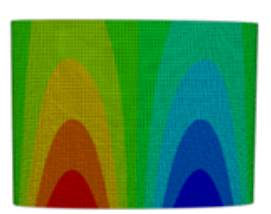

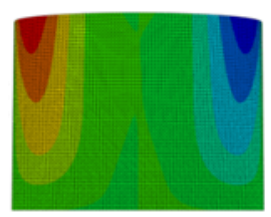
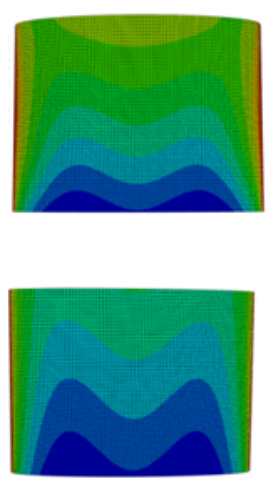

$u$
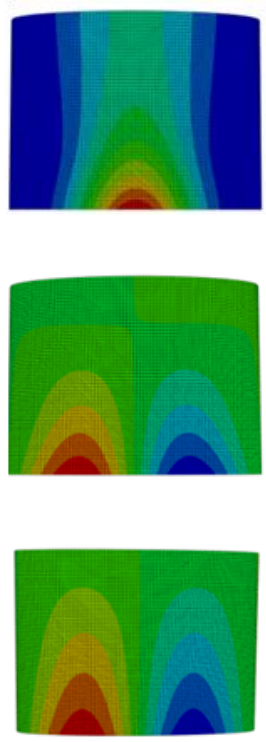

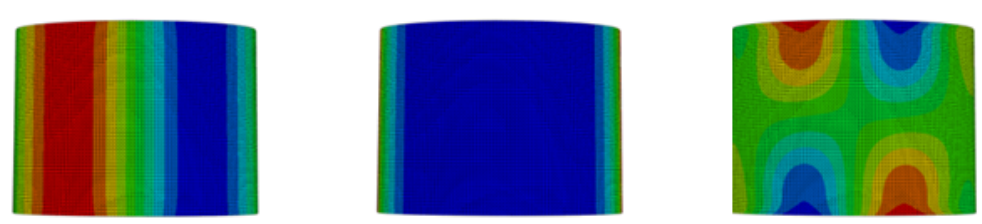

Para o conóide de Geometria 2, observou-se nas componentes dos campos de deslocamento dos seus modos de flambagem, Figuras 3.10 (b) e 3.11 (b), a diferença entre as topologias do modo de flambagem para as considerações parabólicas e cilíndricas. No caso parabólico os campos de deslocamentos $u, v$ e $w$, Figura 3.10 (b), a mesma forma identificada no conóide parabólico de Geometria 1. Já no caso cilíndrico, Figura 3.11 (b), há duas semi-ondas circunferenciais próximas à borda curva com menor altura. A dependência da coordenada axial está presente nos campos de deslocamentos $u, v$ e $w$ do caso cilíndrico, sendo que há simetria no campo de deslocamento $v$, e anti-simetria em $w$ e $u$, em torno do eixo $x$.

A forma do modo de flambagem do conóide de Geometria 2 e de bordas curvas cilíndricas, se repete nos conóides de Geometria 3 com bordas curvas parabólicas, ou cilíndricas, como pode ser visualizado nas Figuras 3.10 (c) e 3.11 (c). Apenas no campo de deslocamento $v$ do caso parabólico, Figura 3.10 (c), apareceram duas faixas de deslocamento circunferenciais próximos aos apoios indeslocáveis, além de uma semi-onda próxima a borda $\mathrm{H}_{2}$, apresentando ainda simetria em torno do eixo axial.

Por fim, verificou-se nas Figuras 3.10 (d) e 3.11 (d), que nos conóides de Geometria 4 e de bordas curvas parabólicas, ou cilíndricas, há simetria nos campos de deslocamentos $w$ e $v$, e anti-simetria no modo de deslocamento $u$ em relação ao eixo $x$. Isto se deve às alturas das bordas curvas serem iguais nesta geometria. Notou-se ainda que os campos de deslocamento $w$ possuem a mesma topologia no caso parabólico e cilíndrico com duas faixas de semi-ondas circunferenciais, anti-simétricas em torno do eixo $x$, dispostas de uma borda curva a outra de forma paralela ao eixo $x$. O campo de deslocamento $u$ apresentou duas semi-ondas longitudinais anti-simétricas em relação ao eixo $x$ e duas semi-ondas circunferenciais no caso parabólico e no cilíndrico. Já o campo de deslocamentos $v$, possui faixas de semi-ondas circunferenciais de uma borda curva a outra de forma paralela e simétrica ao eixo $x$.

É importante dizer que devido à diferença entre as alturas das bordas curvas, $\mathrm{H}_{1}$ e $\mathrm{H}_{2}$, e devido a presença de apoios assimétricos na casca conoidal (Figuras 3.4-3.11) a configuração das semi-ondas longitudinais e circunferenciais, apesar de serem simétricas, ou antisimétricas, em torno do eixo axial $x$, é fortemente dependente da coordenada axial, indicando 
que há um modo complexo proveniente da composição de outros modos com outras configurações em seu número de semi-ondas. Essa questão será apresentada na próxima seção.

\subsection{DECOMPOSIÇÃO DOS CAMPOS DE DESLOCAMENTOS EM SÉRIES DUPLAS DE FOURIER}

Esta seção tem como objetivo avaliar, analiticamente, as componentes dos campos de deslocamentos da casca conoidal, investigando, principalmente, a complexidade dos modos de flambagem e as limitações para obtenção das cargas críticas e caminhos não-lineares de equilíbrio a partir de uma abordagem analítica. Um esforço muito válido pensando na economia de esforço computacional que um estudo analítico confere às análises.

Inicialmente, para o estudo analítico do modo de flambagem da casca conoidal é necessário determinar os campos de deslocamento através de expansões modais que atendam as condições de contorno do problema. O presente trabalho apresenta três expansões modais que representam uma aproximação em séries duplas trigonométricas para os campos de deslocamentos $u, v$ e $w$. A casca conoidal considerada nessa seção apresenta bordas curvas parabólicas, Geometria 3 e condição de contorno $\mathrm{A}_{1} \mathrm{~A}_{1} \mathrm{~A}_{1} \mathrm{~A}_{1}$, ou seja, os apoios são prescritos da seguinte maneira:

$$
\begin{aligned}
& w(0, y)=w(a, y)=w(x,-\mathrm{b})=w(x, b)=0 \\
& u(x,-b)=u(x, b)=0 \\
& v(0, y)=v(a, y)=0
\end{aligned}
$$

As expansões modais para os campos de deslocamentos de painéis cilíndricos dadas em Alijani e Amabili (2012) e Amabili (2004) são as descritas nas equações (3.2) a (3.4), as quais foram utilizadas neste trabalho para representar uma aproximação para o campo de deslocamentos da casca conoidal parabólica. Essas equações são constituídas de séries duplas de Fourier compostas por um somatório de termos do tipo:

$$
u=\sum_{m=1,2,3 \ldots n=1,3,5 \ldots}^{\infty} \sum_{m n}^{\infty} \cos \frac{m \pi x}{a} \cos \frac{n \pi y}{2 b}
$$




$$
\begin{aligned}
& v=\sum_{m=1,2,3 \ldots n=1,3,5 \ldots}^{\infty} \sum_{m n}^{\infty} \operatorname{sen} \frac{m \pi x}{a} \operatorname{sen} \frac{n \pi y}{2 b} \\
& w=\sum_{m=1,2,3 \ldots n=1,3,5 \ldots}^{\infty} \sum_{m n}^{\infty} \operatorname{sen} \frac{m \pi x}{a} \cos \frac{n \pi y}{2 b}
\end{aligned}
$$

Onde $A_{m n}, B_{m n}$ e $C_{m n}$ são as amplitudes modais, $m$ o número de semi-ondas na direção $x$ e $n$ o número de semi-ondas na direção $y$.

Segundo Alijani e Amabili (2012), a convergência e precisão da solução podem ser estudadas usando diferentes números de termos na expansão das equações (3.2) a (3.4). Através do princípio do duplo somatório de Fourier, limita-se o número de termos das expansões modais $U_{i, j}, V_{i, j}$ e $W_{i, j}$ a partir das equações (3.5) a (3.7) que expressam que a solução analítica deve se igualar a solução obtida via MEF. São utilizadas para expandir as componentes dos campos de deslocamentos do primeiro modo de flambagem da casca parabólica, obtendo-se uma solução analítica do modo de flambagem.

$$
\begin{aligned}
& U_{i, j}: \int_{i}^{I} \int_{j}^{j} A_{i j}\left[\cos \left(\frac{i \pi x}{a}\right)\right]^{2}\left[\cos \left(\frac{j \pi y}{2 b}\right)\right]^{2}= \\
& \sum_{i=1}^{I} \sum_{j=1}^{J} u_{M E F} \cos \left(\frac{i \pi x_{i}}{a}\right) \cos \left(\frac{j \pi y_{j}}{2 b}\right) \Delta x_{i} \Delta y_{j} \\
& V_{i, j}: \int_{i}^{I} \int_{j}^{J} B_{i j}\left[\operatorname{sen}\left(\frac{i \pi x}{a}\right)\right]^{2}\left[\operatorname{sen}\left(\frac{j \pi y}{2 b}\right)\right]^{2}= \\
& \sum_{i=1}^{I} \sum_{j=1}^{J} v_{M E F} \operatorname{sen}\left(\frac{i \pi x_{i}}{a}\right) \operatorname{sen}\left(\frac{j \pi y_{j}}{2 b}\right) \Delta x_{i} \Delta y_{j} \\
& W_{i, j}: \int_{i}^{I} \int_{j}^{J} C_{i j}\left[\operatorname{sen}\left(\frac{i \pi x}{a}\right)\right]^{2}\left[\cos \left(\frac{j \pi y}{2 b}\right)\right]^{2}= \\
& \sum_{i=1}^{I} \sum_{j=1}^{J} w_{M E F} \operatorname{sen}\left(\frac{i \pi x_{i}}{a}\right) \cos \left(\frac{j \pi y_{j}}{2 b}\right) \Delta x_{i} \Delta y_{j}
\end{aligned}
$$

Onde $u_{M E F}, v_{M E F}$ e $w_{M E F}$ são as componentes dos campos dos deslocamentos do primeiro modo de flambagem obtidos via MEF, $\Delta x_{i}$ e $\Delta y_{i}$ são as distâncias entre os nós, $x_{i}$ e $y_{i}$ são as 
coordenadas dos nós da casca perfeita, $i$ e $j$ o número de semi-ondas, $I$ e $J$ o número de parcelas a serem definidas que garantem a aproximação da série dupla trigonométrica.

Na parcela a esquerda da igualdade das equações (3.5)-(3.7), encontram-se as expressões analíticas e à direita, os dados obtidos via MEF. Decompõe-se os campos de deslocamentos em séries duplas de Fourier, calculando-se os coeficientes analíticos $A_{i j}, B_{i j}, C_{i j}$ e variando-se os números de semi-ondas $i$ e $j$ até atingir a convergência dos resultados. As componentes dos campos de deslocamentos de elementos finitos foram obtidos a partir de cortes na configuração do modo de flambagem, Figura 3.12, e as posições dos cortes para verificação da precisão da série dupla obtida estão ilustrados na Figura 3.13.

Figura 3.12- Modo de flambagem do conóide de bordas curvas parabólicas, Geometria 3 e condição de contorno $\mathrm{A}_{1} \mathrm{~A}_{1} \mathrm{~A}_{1} \mathrm{~A}_{1}$ via $\mathrm{MEF}$

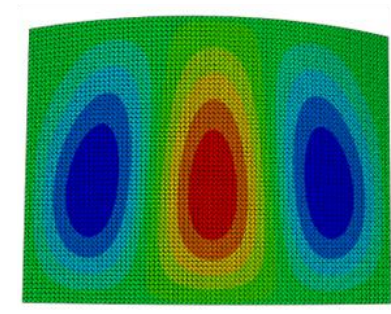

(a) w

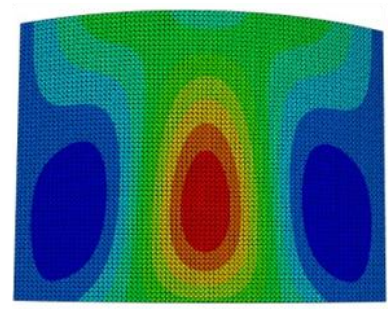

(b) $\mathrm{u}$

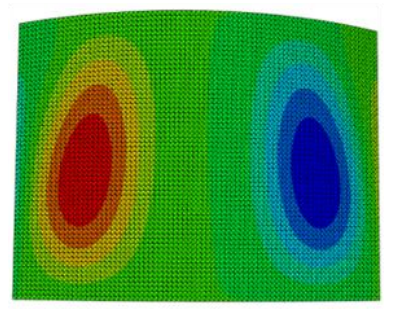

(c) $\mathrm{V}$

Figura 3.13- Representação dos cortes realizados para o estudo das decomposições

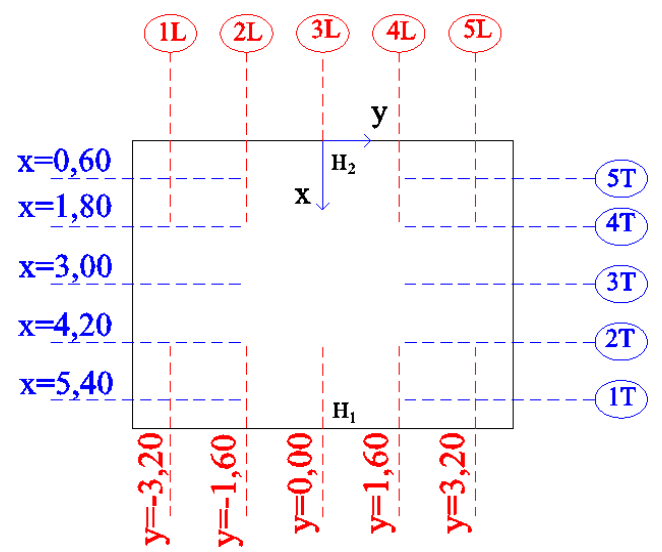

Para cada deslocamento $u_{M E F}, v_{M E F}$ e $w_{M E F}$ determinou-se a expansão modal através das séries duplas de Fourier, equações (3.5)-(3.7), variando-se o número de semi-ondas $i$ e $j$ conforme indicado nas expansões modais sumarizadas na Tabela 3.3. Várias expansões modais foram estudadas obtendo-se os coeficientes analíticos apresentados nas decomposições da Tabela 3.3. Nas Figuras 3.14 e 3.15 são apresentados as resultantes da expansão modal $W_{i, j}$ avaliada para o campo de deslocamento $w_{M E F}$. 
Tabela 3.3- Decomposição dos campos de deslocamentos para a casca conoidal de bordas curvas parabólicas, Geometria 3 e condição de apoio $\mathrm{A}_{1} \mathrm{~A}_{1} \mathrm{~A}_{1} \mathrm{~A}_{1}$

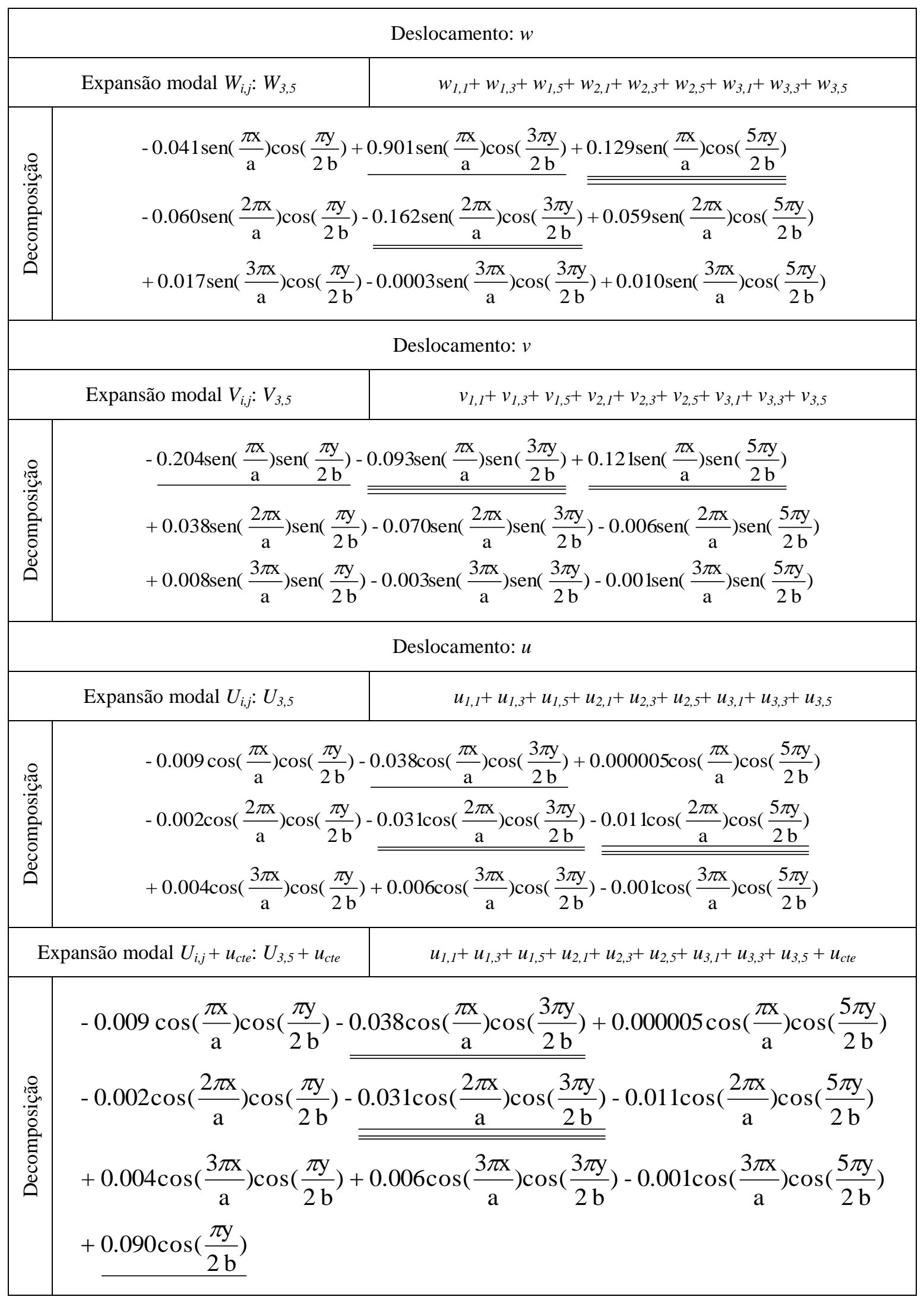


Figura 3.14- Solução modal $W_{3,5}$ para os cortes transversais ( $x$ fixo)

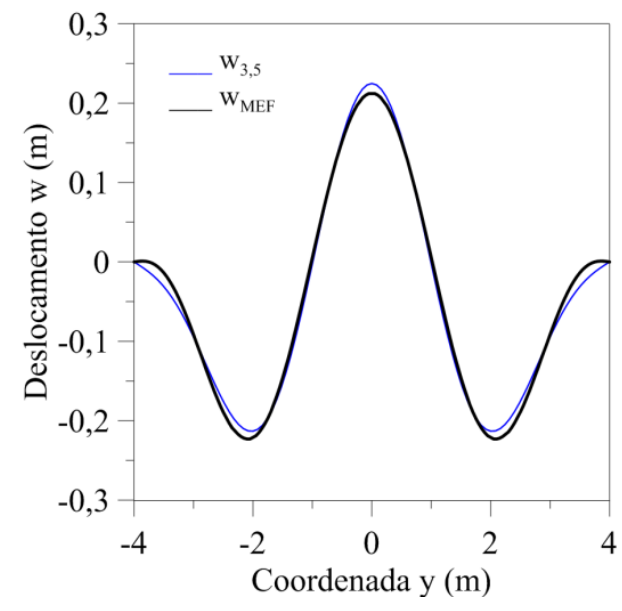

(a) Corte 5T: $x=0,60 \mathrm{~m}$

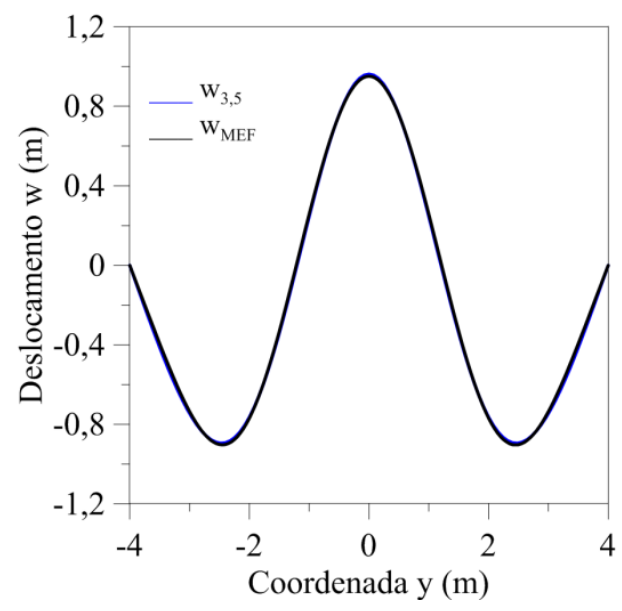

(c) Corte 3T: $x=3,00 \mathrm{~m}$

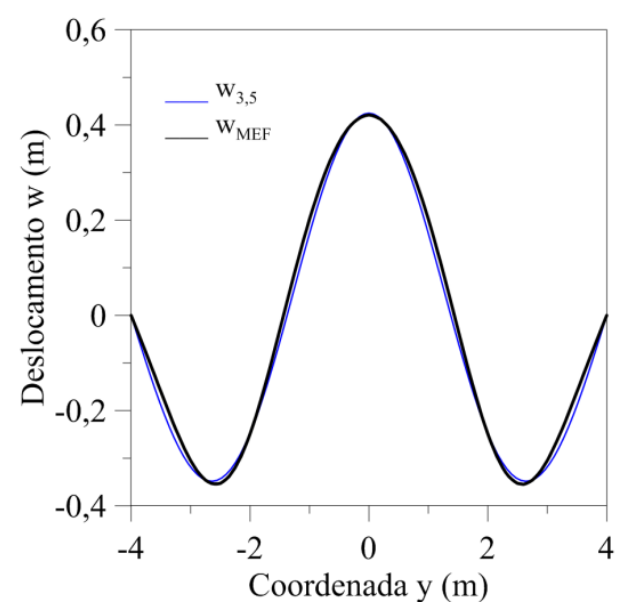

(e) Corte 1T: $x=5,40 \mathrm{~m}$

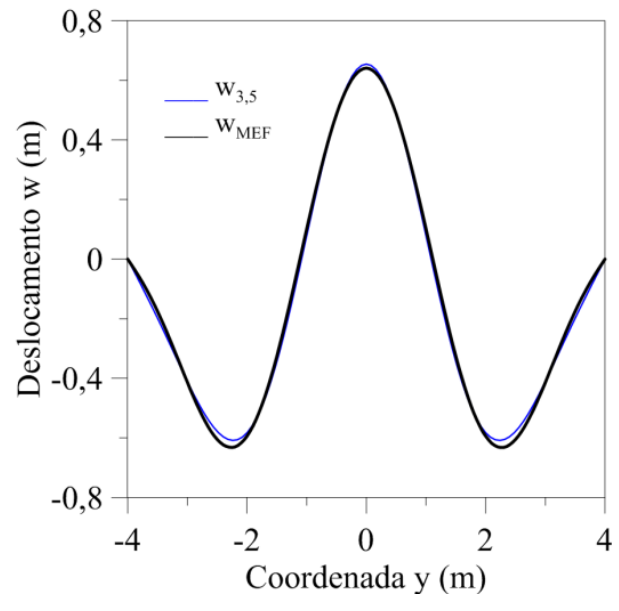

(b) Corte 4T: $x=1,80 \mathrm{~m}$

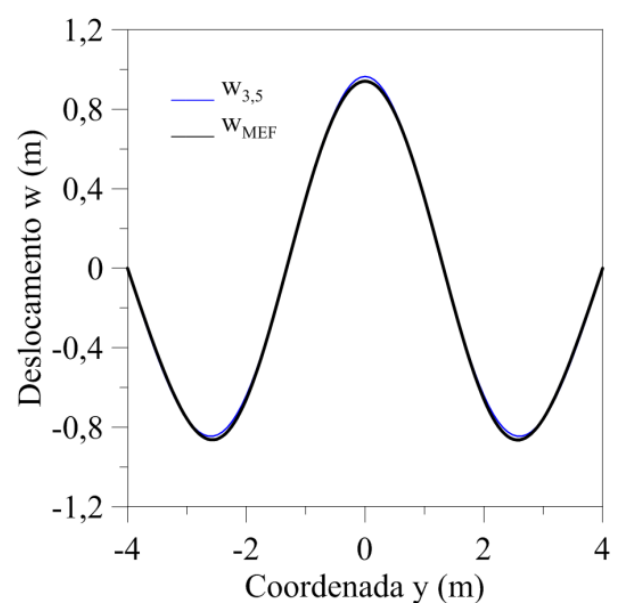

(d) Corte 2T: $x=4,20 \mathrm{~m}$

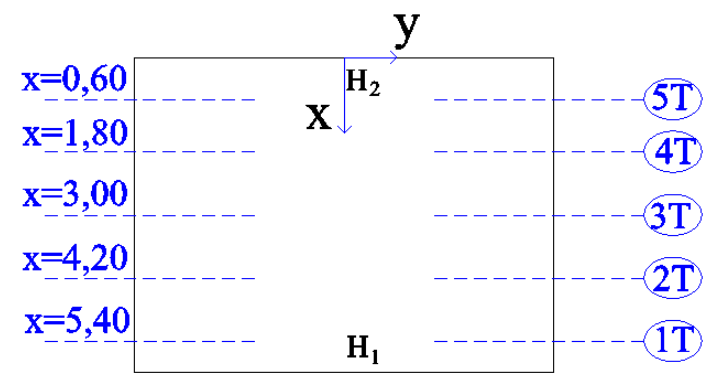


Figura 3.15- Solução modal $W_{3,5}$ para os cortes longitudinais ( $y$ fixo)

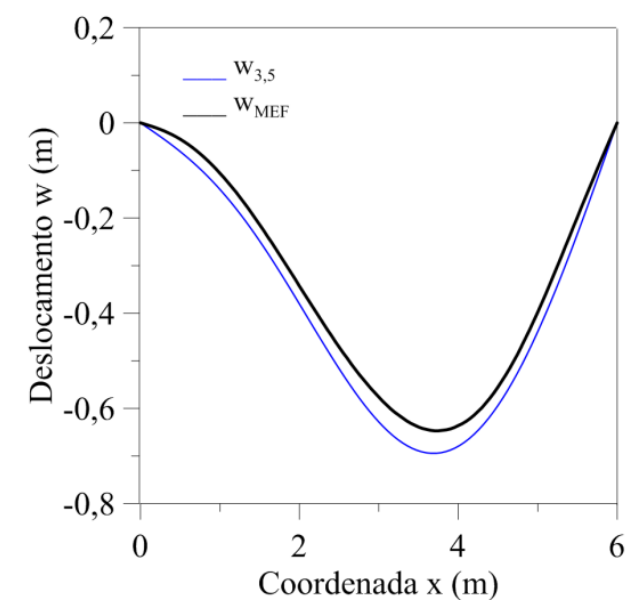

(a) Corte 5L: $y=-3,20 \mathrm{~m}$

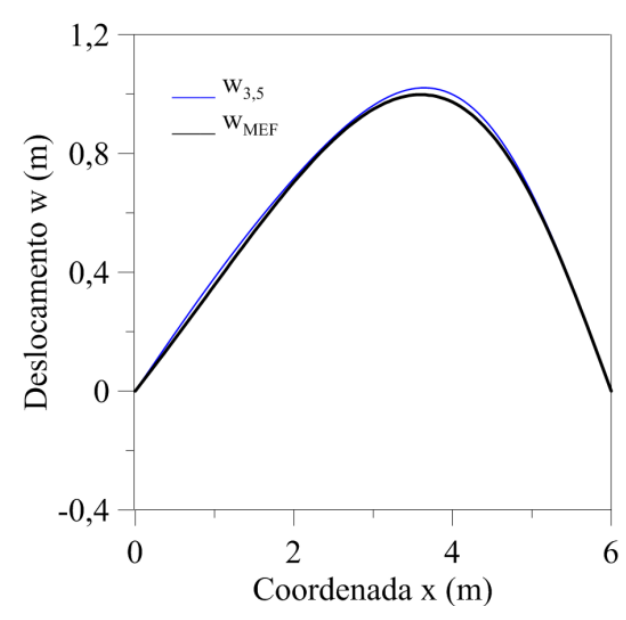

(c) Corte 3L: $y=0,00 \mathrm{~m}$

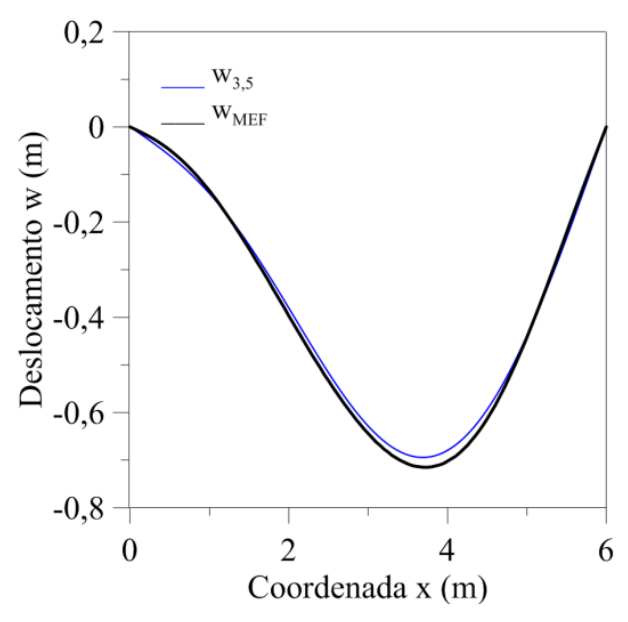

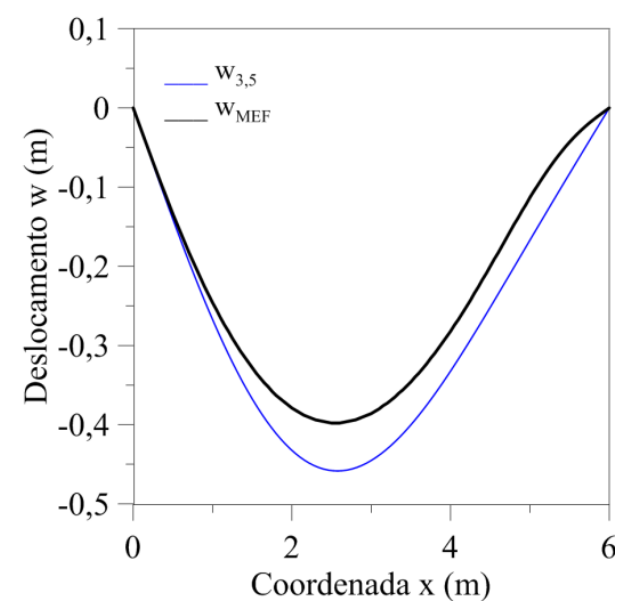

(b) Corte 4L: $y=-1,60 \mathrm{~m}$

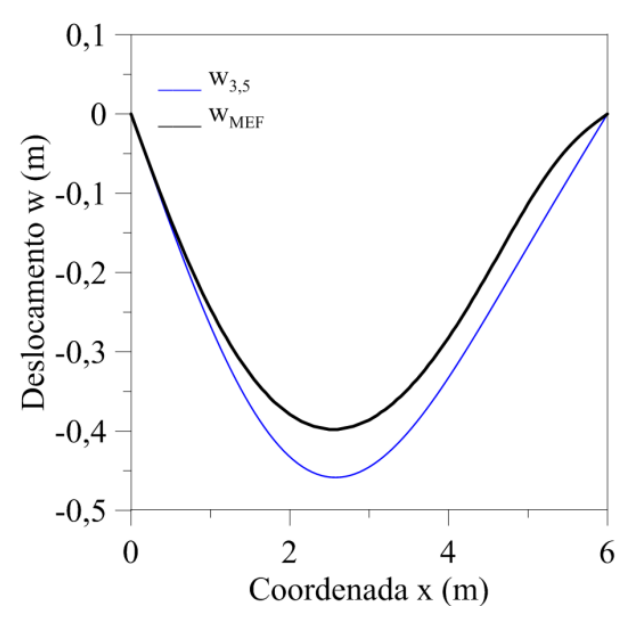

(d) Corte 2L: $y=1,60 \mathrm{~m}$

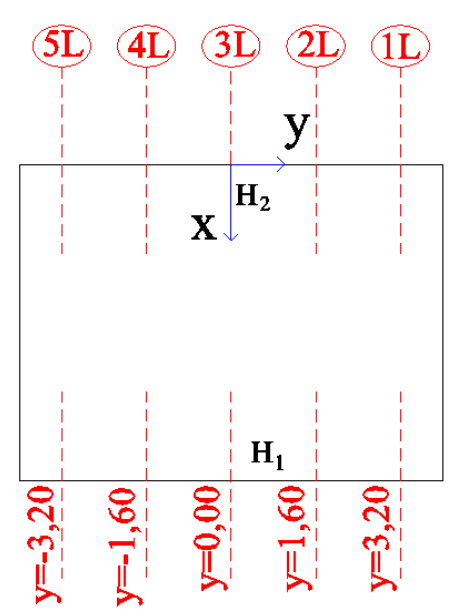

(e) Corte 1L: $y=3,20 \mathrm{~m}$ 
Na decomposição dos deslocamentos $w_{M E F}$ estudaram-se cinco cortes transversais mantendose a coordenada $x$ fixa e variando-se $y$, Figura 3.14, e cinco cortes longitudinais mantendo-se a coordenada $y$ fixa e variando-se $x$, Figura 3.15. Verificou-se que a decomposição $W_{3,5}$ da Tabela 3.3, obtida para os deslocamentos $w$, apresenta uma aproximação com uma boa precisão quando comparada com os resultados obtidos via MEF.

A expansão modal para os campos de deslocamentos transversais, $w$, apresenta uma forte influência do modo $(i, j)=(1,3)$, sublinhado por um traço na Tabela 3.3, juntamente com os modos $(i, j)=(2,3)$ e $(i, j)=(1,5)$, sublinhados duplamente e triplamente na Tabela 3.3, respectivamente, além de outras parcelas com menor influência. Isto demonstra a necessidade de um modo complexo para descrever o modo de flambagem da casca conoidal.

Nos cortes transversais realizados, tanto nas extremidades quanto na região central da casca conoidal parabólica, a decomposição usada converge para os resultados obtidos via MEF. Nos cortes longitudinais a decomposição usada tem uma menor convergência no corte da região central que nos demais cortes. Nesses termos, a expansão modal da equação (3.4), composta apenas por funções harmônicas, é conveniente para a decomposição do campo de deslocamento $w$.

Nas Figuras 3.16 e 3.17 são apresentadas as aproximações no sentido transversal e longitudinal, respectivamente, resultantes da expansão modal $V_{i, j}$ avaliada para o deslocamento $v_{M E F}$. Verificou-se para a expansão resultante $V_{3,5}$, decomposta na Tabela 3.3, que a convergência em séries harmônicas para os resultados obtidos via MEF é melhor no sentido transversal do que no sentido longitudinal como observado para o campo de deslocamento $w$.

Várias parcelas foram necessárias para decompor com uma boa aproximação as componentes do campo de deslocamentos $v$ da casca conoidal. Observou-se na Tabela 3.3 a maior influência do modo sublinhado com um traço $(i, j)=(1,1)$ seguido do modo duplamente sublinhado $(i, j)=(1,5)$ e do modo triplamente sublinhado $(i, j)=(1,3)$. Assim, notou-se através desses cortes que a expansão modal da equação (3.3) constitui uma aproximação conveniente para a decomposição do campo de deslocamento $v$, mas com menor precisão em relação ao obtido para o campo de deslocamento $w$. 
Figura 3.16- Solução modal $V_{3,5}$ para os cortes transversais ( $x$ fixo)

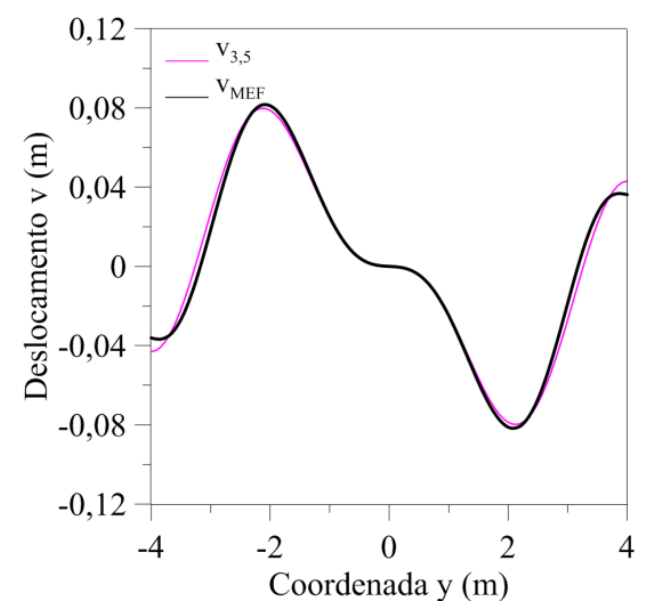

(a) Corte 5T: $x=0,60 \mathrm{~m}$

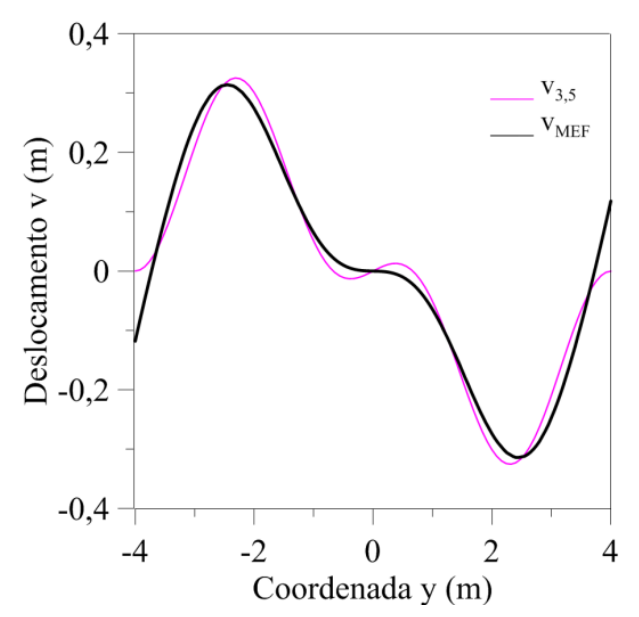

(c) Corte 3T: $x=3,00 \mathrm{~m}$

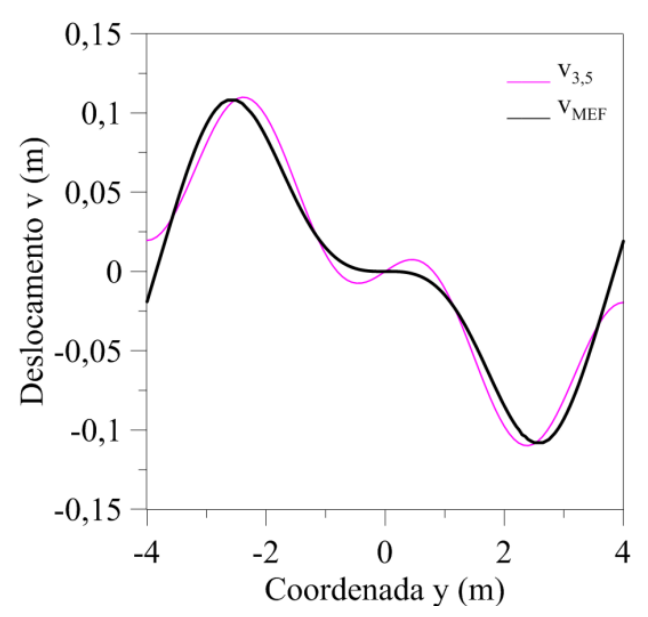

(e) Corte 1T: $x=5,40 \mathrm{~m}$

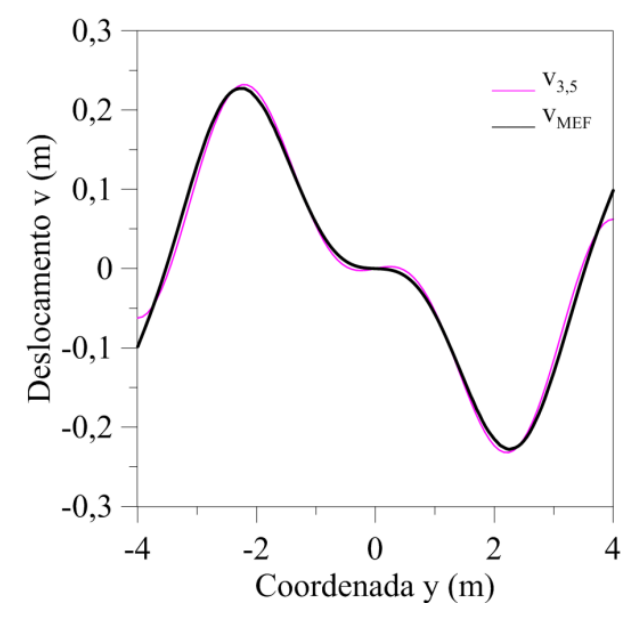

(b) Corte 4T: $x=1,80 \mathrm{~m}$

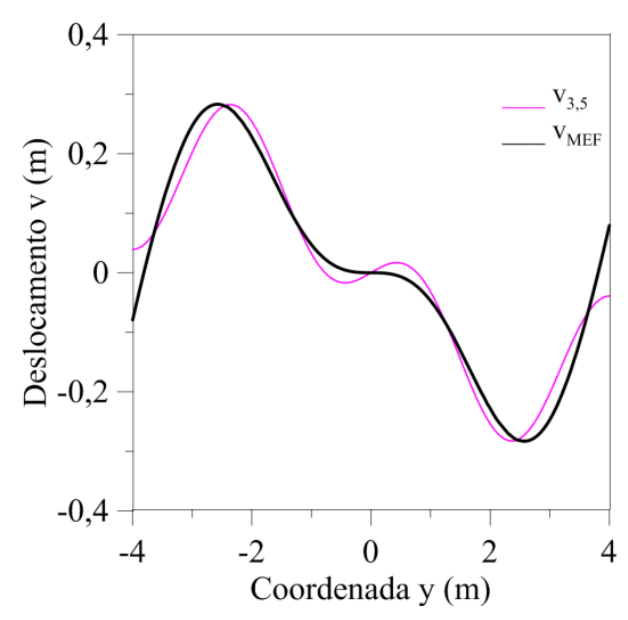

(d) Corte 2T: $x=4,20 \mathrm{~m}$

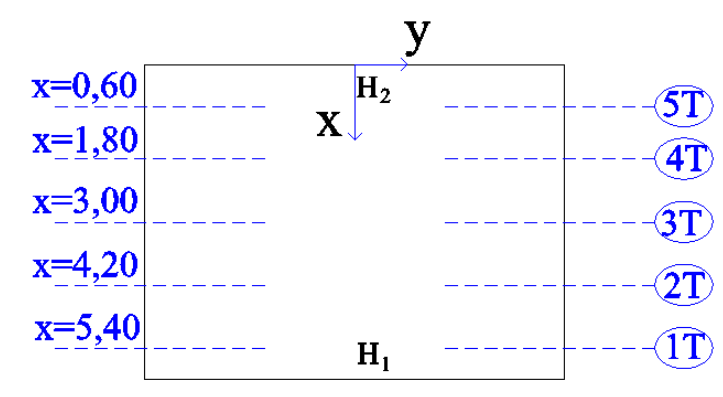


Figura 3.17- Solução modal $V_{3,5}$ para os cortes longitudinais ( $y$ fixo)

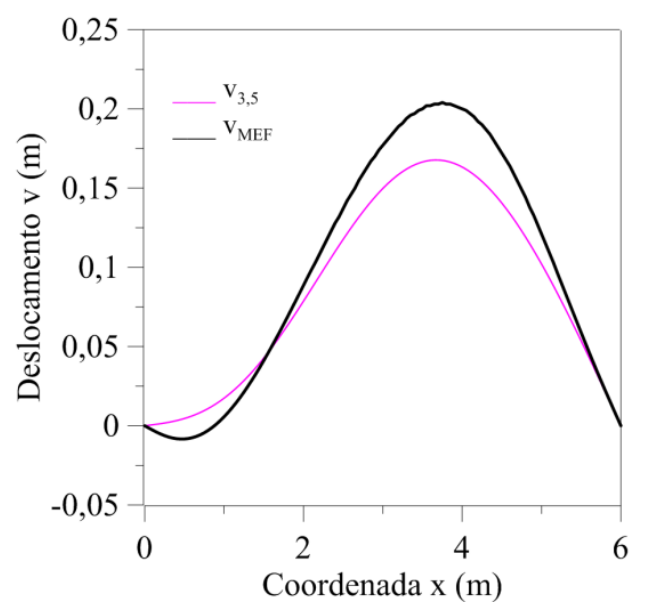

(a) Corte 5L: $y=-3,20 \mathrm{~m}$

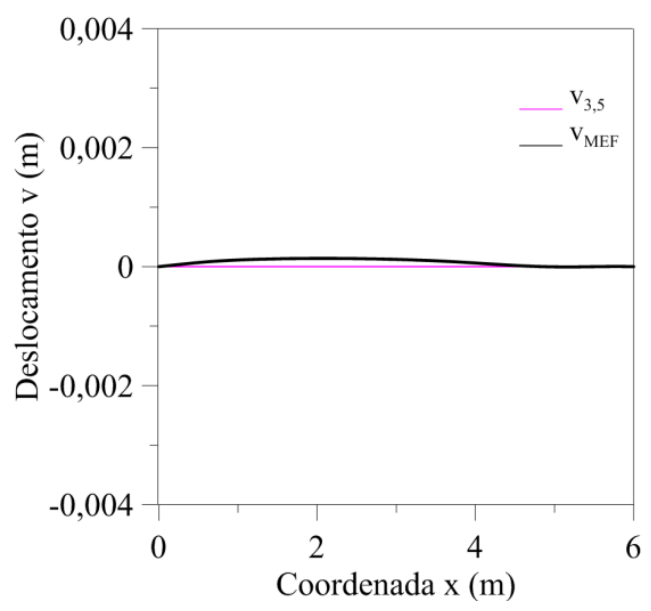

(c) Corte 3L: $y=0,00 \mathrm{~m}$

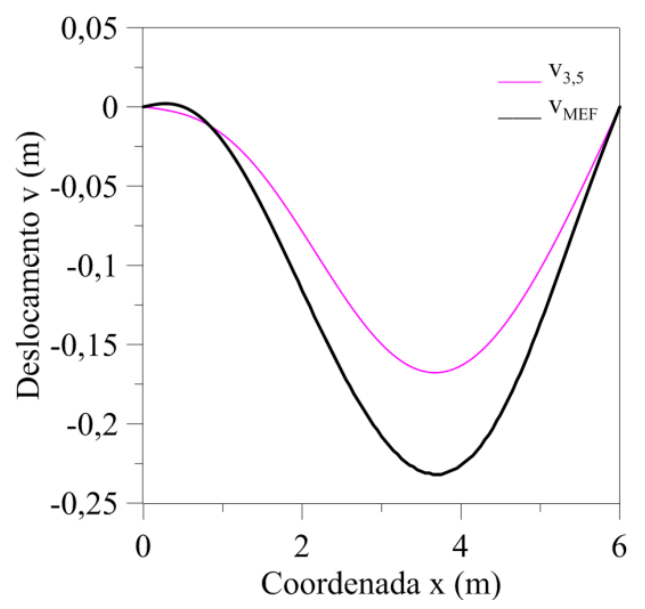

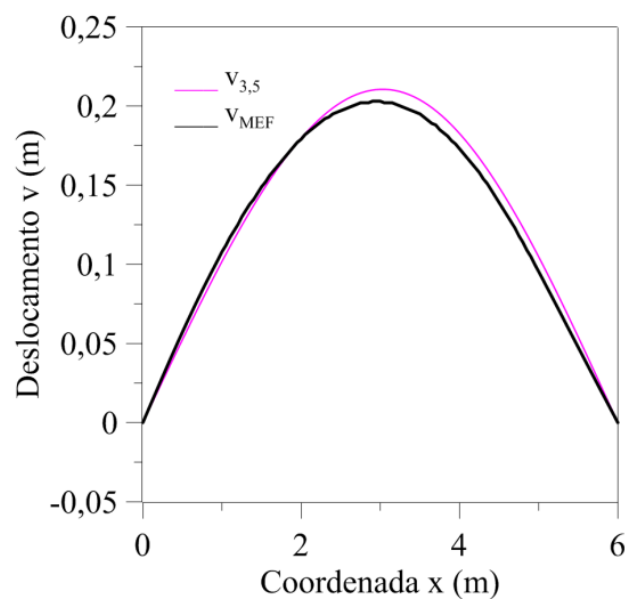

(b) Corte 4L: $y=-1,60 \mathrm{~m}$

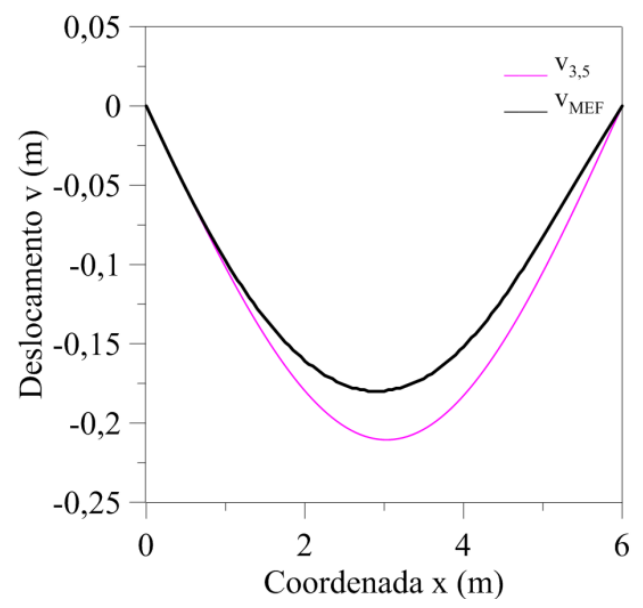

(d) Corte 2L: $y=1,60 \mathrm{~m}$

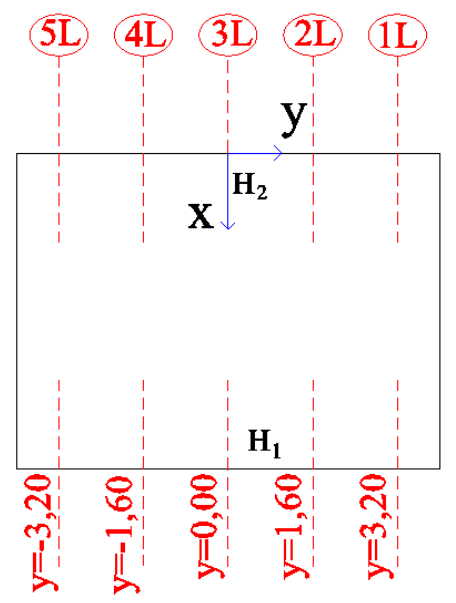

(e) Corte 1L: $y=3,20 \mathrm{~m}$

Nas Figuras 3.18 e 3.19 são apresentadas as curvas de aproximação no sentido transversal e longitudinal resultantes da expansão modal $U_{i, j}$ avaliada para o campo de deslocamento $u_{M E F}$. 
Figura 3.18- Solução modal $U_{3,5}+u_{c t e}$ para os cortes transversais ( $x$ fixo)

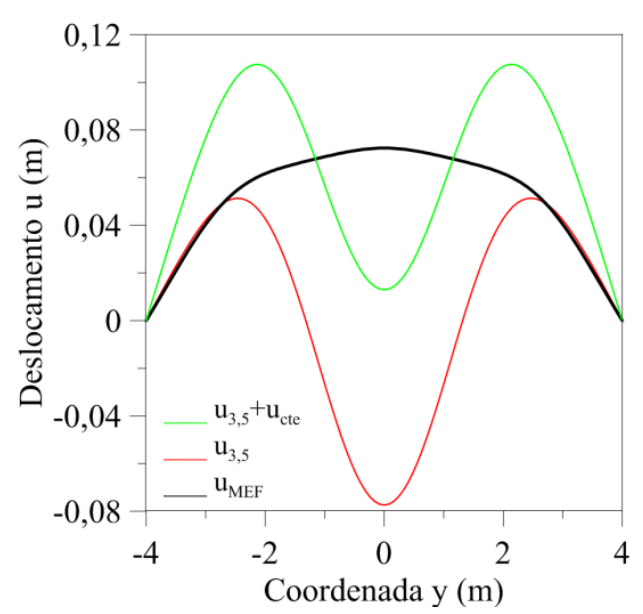

(a) Corte 5T: $x=0,60 \mathrm{~m}$

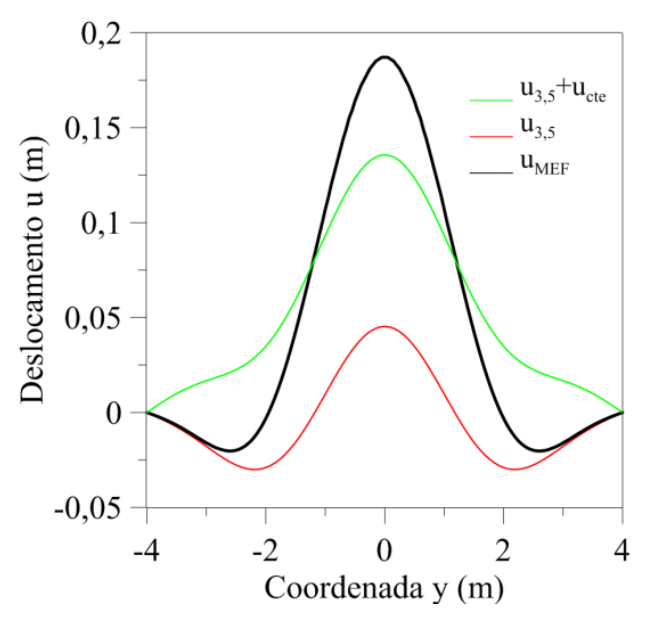

(c) Corte 3T: $x=3,00 \mathrm{~m}$

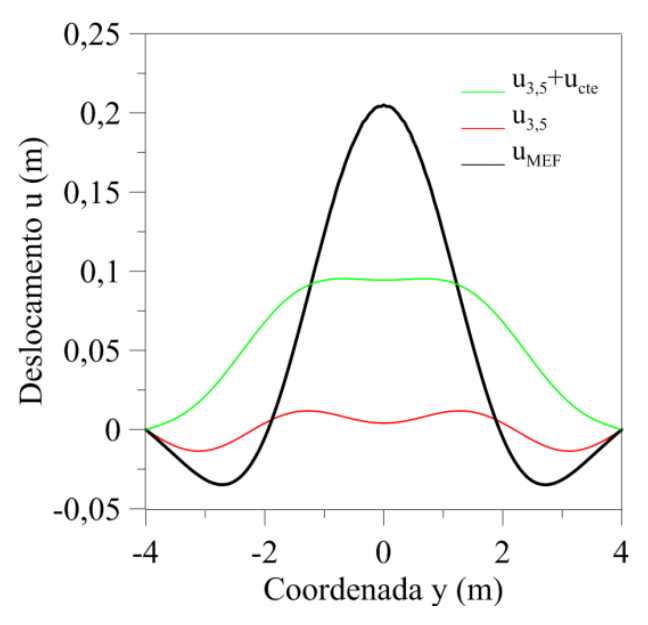

(e) Corte 1T: $x=5,40 \mathrm{~m}$

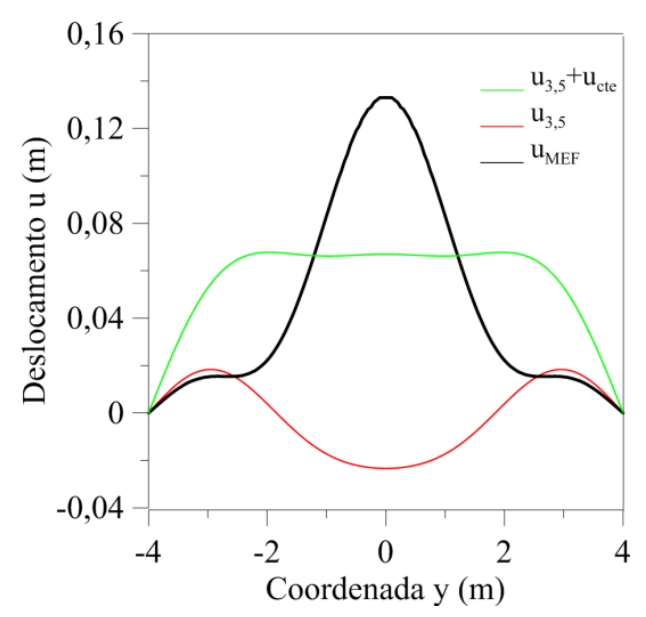

(b) Corte 4T: $x=1,80 \mathrm{~m}$

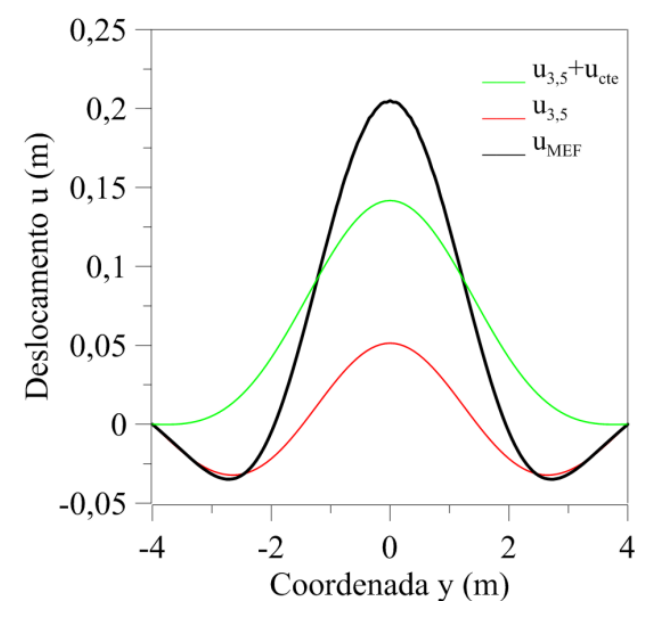

(d) Corte 2T: $x=4,20 \mathrm{~m}$

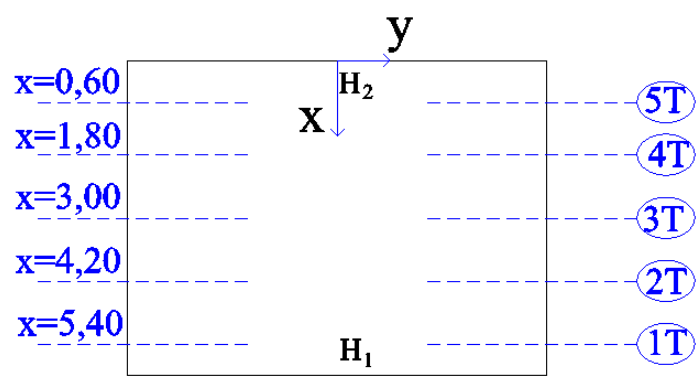


Figura 3.19- Solução modal $U_{3,5}+u_{c t e}$ para os cortes longitudinais ( $y$ fixo)

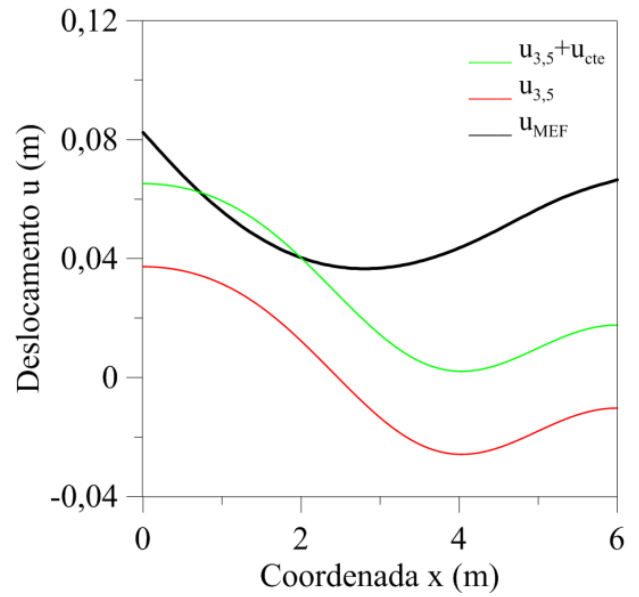

(a) Corte 5L: $y=-3,20 \mathrm{~m}$

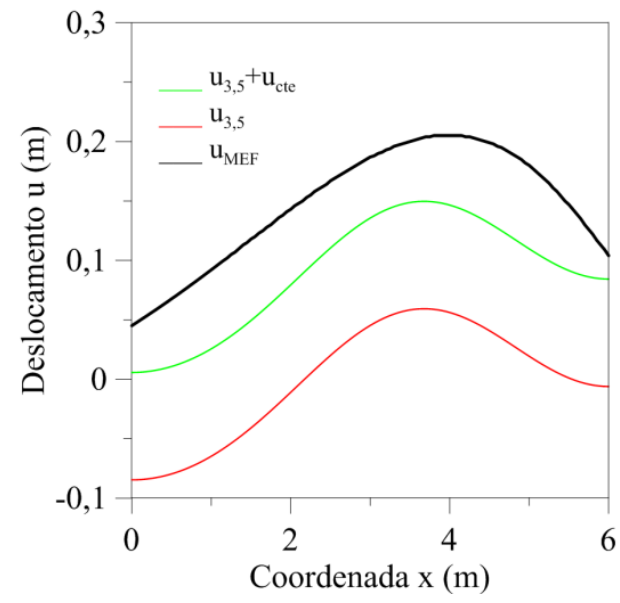

(c) Corte 3L: $y=0,00 \mathrm{~m}$

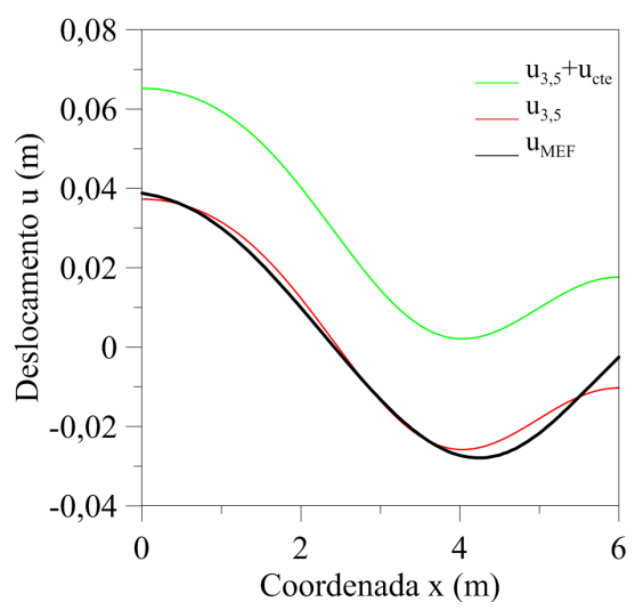

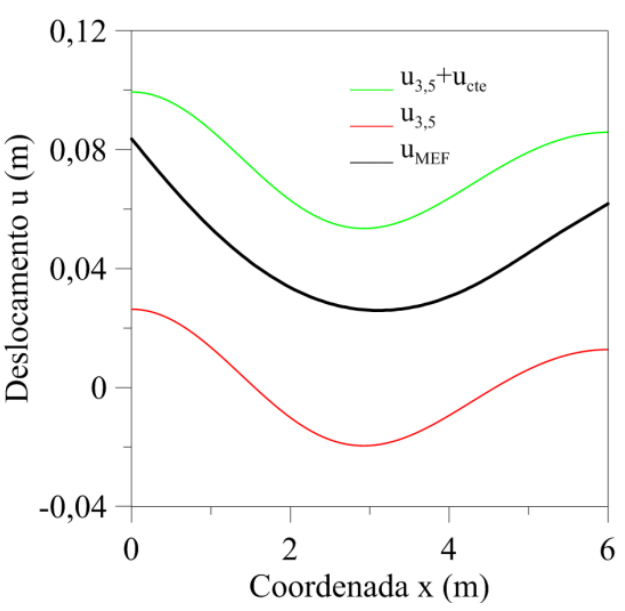

(b) Corte 4L: $y=-1,60 \mathrm{~m}$

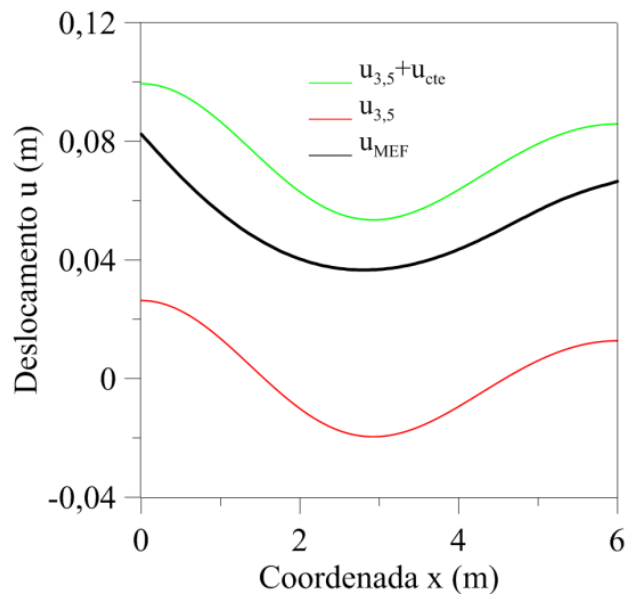

(d) Corte 2L: $y=1,60 \mathrm{~m}$

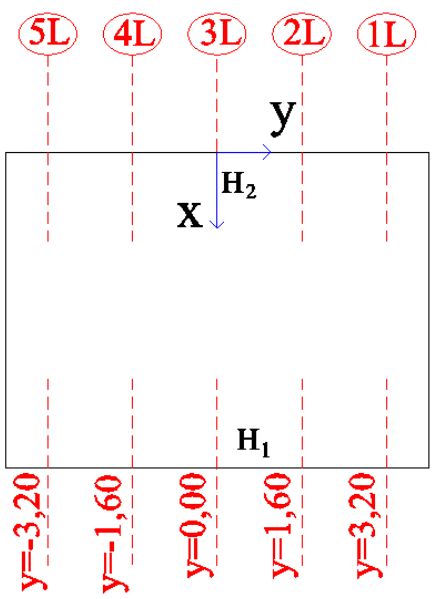

(e) Corte 1L: $y=3,20 \mathrm{~m}$

Observou-se na Figura 3.18 que a expansão $U_{3,5}$, da Tabela 3.3, é uma aproximação com a precisão desejada nas regiões próximas as bordas apoiadas nos cortes transversais, mas na 
região central os deslocamentos não apresentam boa convergência. A decomposição usada convergiu para os resultados obtidos via MEF somente no corte longitudinal 1L, Figura 3.19 (e). Nesses termos, a expansão modal da equação (3.2) não é suficiente para a decomposição do campo de deslocamento $u$, indicando a necessidade de uma expansão modal capaz de adicionar magnitude a esse campo de deslocamento com atendimento às condições de contorno do problema.

Devido ao deslocamento $u$ ter a particularidade de liberdade de se deslocar nas bordas curvas parabólicas, adiciona-se a parcela, denominada $u_{c t e}$, à expansão $U_{3,5}$ considerando-se a série em $x$ da expansão modal da equação (3.2) como sendo uma constante unitária, mas garantindo a presença da série em y para atendimento das condições de contorno do problema resultando na expansão $U_{3,5}+u_{c t e}$ discretizada na Tabela 3.3. Observou-se nos cortes transversais apresentados na Figura 3.18 que essa nova expansão modal produziu uma aproximação mais conveniente no centro, mas reduziu a precisão nas extremidades da casca. Já nos cortes longitudinais, Figura 3.19, verificou-se que a decomposição se aproxima dos resultados obtidos via MEF, mas nenhum dos cortes converge para o resultado de elementos finitos, constituindo-se uma solução com pouca precisão.

A parcela de maior influência na expansão modal $U_{3,5}$ apresentada na Tabela 3.3 é referente ao modo $(i, j)=(1,1)$ que foi sublinhado para destacá-lo, além desta parcela também existem outras parcelas que influenciam na resposta, dentre eles foi evidenciado o modo $(i, j)=(2,3)$ com sublinhado duplo e o modo $(i, j)=(2,5)$, sublinhado triplamente. Com a adição da componente constante $u_{c t e}$, sublinhado na Tabela 3.3, verificou-se que esta passa a ser a parcela de maior influência na decomposição do campo de deslocamento $u$.

Uma comparação dos modos de flambagem obtidos via MEF com os deslocamentos provenientes das decomposições das expansões estudadas é apresentada na Figura 3.20. Verificou-se que a expansão modal $W_{3,5}$ apresentou boa convergência, pois há semelhança dos modos dos deslocamentos $w$, Figuras 3.20 (a) e (d), com três semi-ondas circunferenciais dispostas no centro do conóide. Observou-se ainda nas Figuras 3.20 (c) e (f), que os campos dos deslocamentos $v$ bem como o campo de deslocamentos $u$, Figuras 3.20 (b) e (e), divergem em várias regiões da casca conoidal parabólica constituindo aproximações de menor precisão. 
Figura 3.20- Deslocamentos obtidos via MEF e por decomposição modal

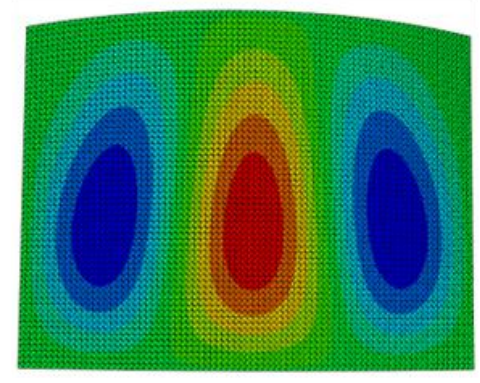

(a) $w$ via MEF

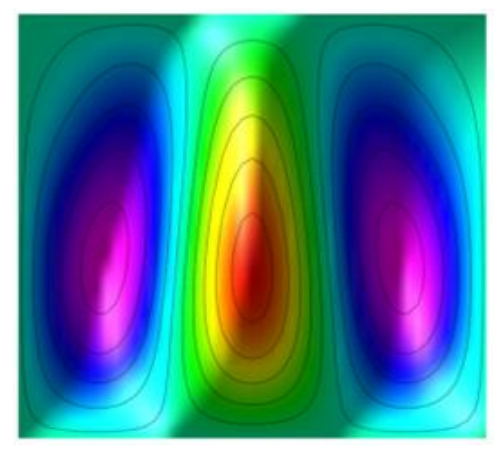

(d) $W_{3,5}$

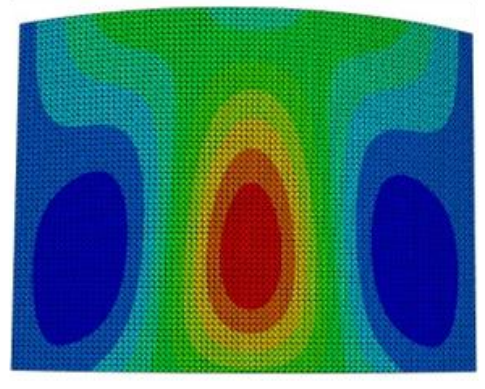

(b) $u$ via MEF

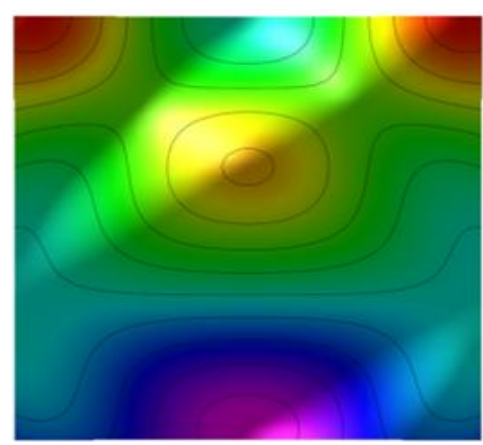

(e) $U_{3,5}+u_{c t e}$

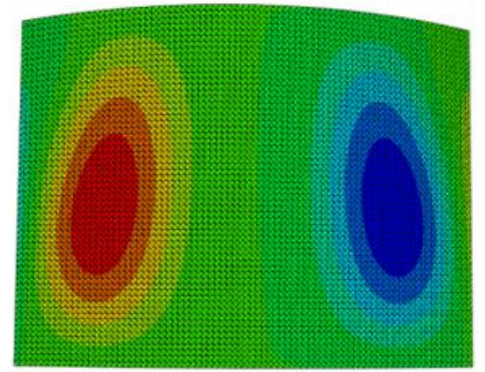

(c) $v$ via MEF

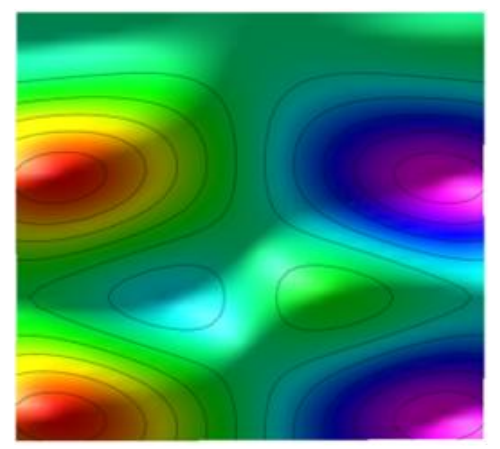

(f) $V_{3,5}$

Para construir uma análise analítica da casca conoidal é necessário obter uma solução modal que considere os acoplamentos e as interações modais que decorrem das não-linearidades geométricas presentes nas equações de equilíbrio. Uma das técnicas analíticas para a obtenção consistente dessas expansões modais é o método da perturbação (DEL PRADO, 2008; GONÇALVES; SATTLER; SILVA, 2015; SILVA, 2008) que é capaz de descrever os modos não-lineares que se acoplarão aos campos de deslocamentos $u, v$ e $w$. A dificuldade de obtenção de soluções analíticas para esse problema é acrescida quando as soluções básicas para a obtenção da solução modal são compostas por vários modos básicos, como os descritos na Tabela 3.3, o que eleva o número de graus de liberdade do problema. Nesse sentido, as análises estáticas não-lineares, que serão apresentadas no próximo capítulo, se darão somente a partir dos resultados obtidos via método dos elementos finitos. 


\section{CAPÍTULO 4 \\ ANÁLISE ESTÁTICA NÃO-LINEAR}

Neste capítulo são analisadas as trajetórias não-lineares de equilíbrio da casca conoidal a partir de uma análise não-linear obtida via MEF com o auxílio do programa ABAQUS 6.11®. Compararam-se cascas de bordas curvas parabólicas, ou cilíndricas, tendo como referência os parâmetros geométricos e condições de contorno que foram apresentados na Tabela 3.1. Para a geração dos resultados, tomaram-se como pontos de observação os pontos indicados na Figura 4.1, onde o primeiro ponto, P1, possui as coordenadas $(x=1,50 \mathrm{~m}, y=-2,00 \mathrm{~m}), \mathrm{P} 2$ está localizado em $(x=1,50 \mathrm{~m}, y=2,00 \mathrm{~m}), \mathrm{P} 3$ no centro $(x=3,00 \mathrm{~m}, y=0,00 \mathrm{~m}), \mathrm{P} 4 \mathrm{em}$ $(x=4,5 \mathrm{~m}, y=-2,00 \mathrm{~m})$ e P5 situa-se em $(x=4,50 \mathrm{~m}, y=2,00 \mathrm{~m})$.

Figura 4.1- Representação em planta dos pontos de observação da casca conoidal com as condições de contorno e as bordas curvas e retas

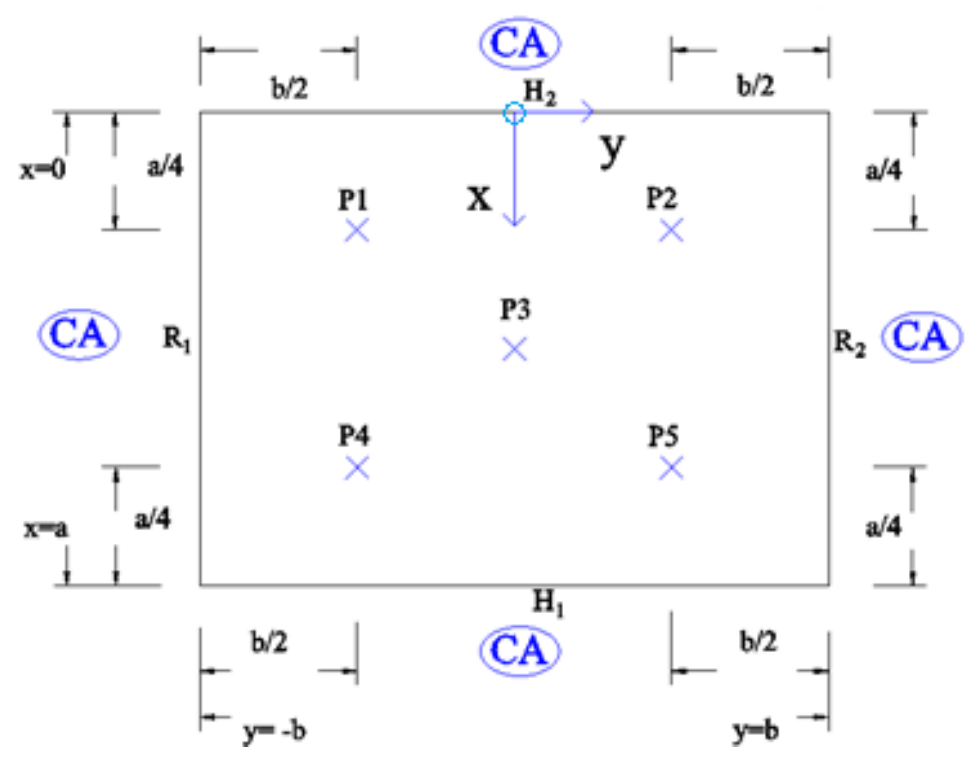

Em um problema que considera a não-linearidade geométrica, a rigidez da estrutura modificase à medida que ela se desloca. Neste trabalho, consideraram-se os efeitos das nãolinearidades provenientes da geometria da casca conoidal, utilizando o elemento finito STRI3 como apresentado no capítulo anterior. Para solucionar as equações não-lineares de equilíbrio, o programa ABAQUS 6.11® combina processos de iteração e de incrementação do carregamento aplicado através do método de Newton-Raphson, e quando no problema há perda da capacidade de carga utiliza-se o método de Riks para obter a solução. 
O método de Riks é um método numérico que utiliza o procedimento de comprimento de arco no qual tanto os graus de liberdade a cada passo de aplicação do carregamento, quanto a magnitude de carregamento imposto à estrutura funcionam como incógnitas a resolver.

A seguir, determinou-se a trajetória de equilíbrio da casca conoidal frente ao carregamento transversal uniformemente distribuído na sua superfície a partir da relação entre o carregamento aplicado e os deslocamentos obtidos.

Primeiramente avaliou-se a influência da variação das condições de contorno da casca conoidal nas trajetórias não-lineares de equilíbrio, considerando nas análises o campo de deslocamento transversal, $w$, e observando a influência das formas das bordas curvas, que podem ser parabólicas, ou cilíndricas, nas trajetórias de equilíbrio não-lineares.

A partir desses resultados, obtiveram-se as cargas limites não-lineares comparando-as às cargas críticas obtidas com a análise linear. Ressalta-se que esta carga limite tem relação com o ponto de perda de estabilidade por ponto limite, com o primeiro ponto na trajetória nãolinear de equilíbrio a ter um recuo em sua capacidade de carga.

Verificou-se a influência da variação das magnitudes dos fatores de escala das imperfeições geométricas no comportamento dos conóides, as quais são utilizadas como condições iniciais para obtenção das análises não-lineares assumindo a forma de algum modo de flambagem. E enfim, avaliou-se a influência da variação das alturas das bordas curvas da casca conoidal parabólica, ou cilíndrica, nas trajetórias não-lineares de equilíbrio dos esforços de membrana e momentos internos.

\subsection{ANÁLISE PARAMÉTRICA DAS CONDIÇÕES DE CONTORNO}

A análise da influência das condições de contorno nos caminhos não-lineares de equilíbrio do campo de deslocamentos transversais, $w$, foi realizada avaliando a trajetória de equilíbrio do ponto P4 nas diferentes geometrias de cascas conoidais com bordas curvas parabólicas, Figuras 4.2 a 4.6. Nessas figuras, as retas horizontais tracejadas representam a carga crítica linear da casca conoidal obtidas no capítulo anterior a partir da solução do problema de autovalor.

São apresentadas na Figura 4.2 as trajetórias de equilíbrio não-lineares para o conóide de Geometria 1, o qual possui apenas a borda $\mathrm{H}_{2}$ curva, na forma parabólica, e as demais bordas 
$\mathrm{H}_{1}, \mathrm{R}_{1}$ e $\mathrm{R}_{2}$ retas, Figura 4.1. O ponto limite de carregamento para esta geometria não foi bem caracterizado quando se consideraram as condições de apoio de primeiro e segundo gêneros em todas as bordas da casca, Figuras 4.2 (a) e (b).

Figura 4.2- Análise paramétrica das condições de contorno no conóide de Geometria 1 (parabólico)

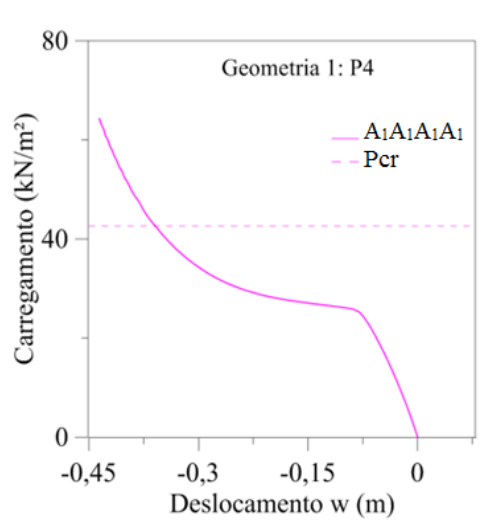

(a) $A_{1} A_{1} A_{1} A_{1}$

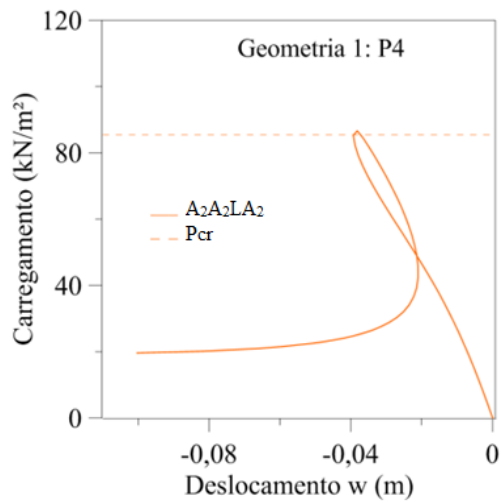

(d) $\mathrm{A}_{2} \mathrm{~A}_{2} \mathrm{LA}_{2}$

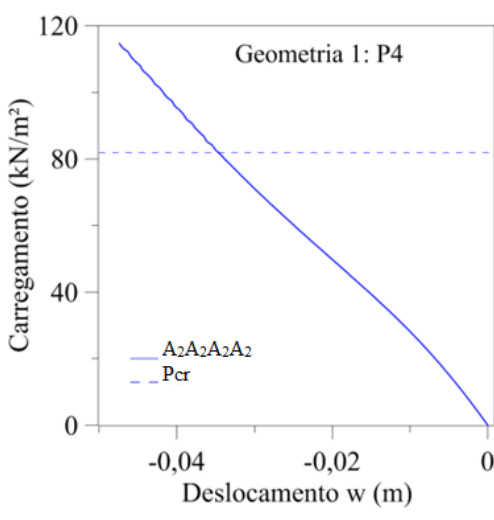

(b) $\mathrm{A}_{2} \mathrm{~A}_{2} \mathrm{~A}_{2} \mathrm{~A}_{2}$

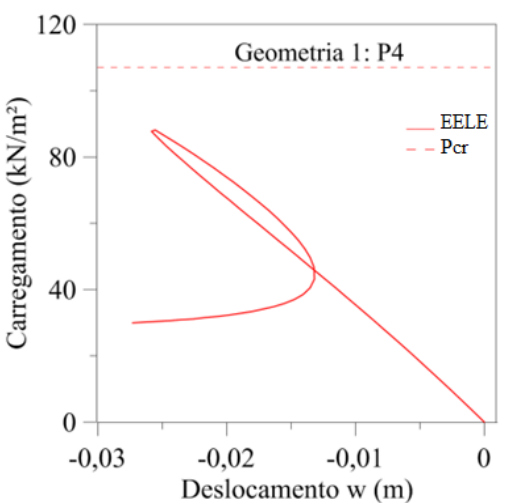

(e) EELE

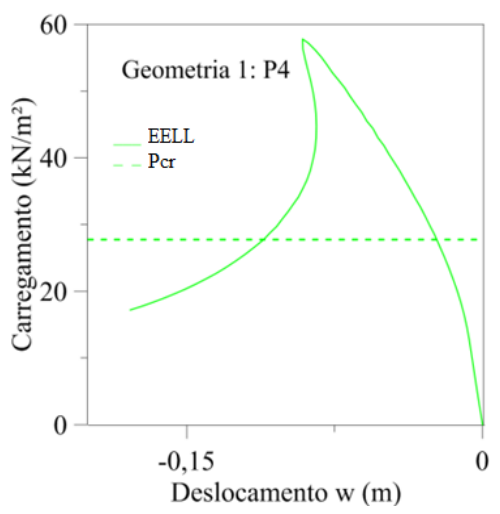

(c) EELL

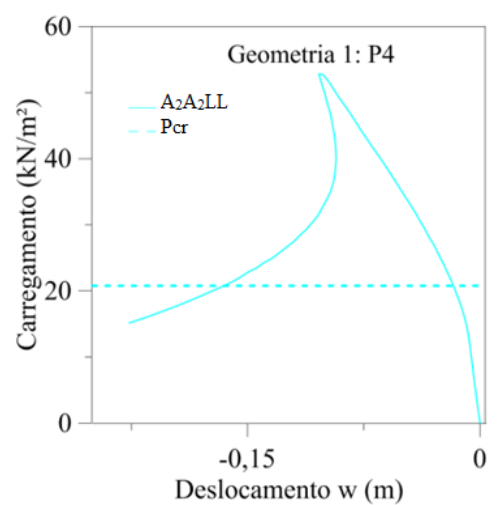

(f) $\mathrm{A}_{2} \mathrm{~A}_{2} \mathrm{LL}$

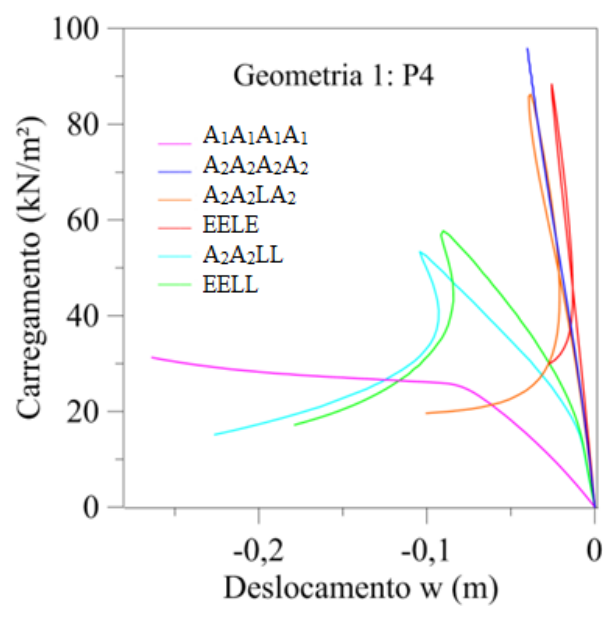

(g) Sobreposição das condições de apoio 
Verificou-se que as não linearidades influenciam os caminhos de equilíbrio não-lineares aumentando a capacidade de carga em relação à carga crítica linear, Figuras 4.2 (c), (d) e (f), ou diminuindo a carga limite em relação à carga crítica linear, Figura 4.2 (e). A sobreposição entre as condições de apoio está apresentada na Figura 4.2 (g) onde é possível observar a influência das diferentes condições de contorno nos caminhos de equilíbrio não-lineares desta geometria, sendo que para a condição de apoio EELE o conóide parabólico apresenta o maior ponto limite.

A Figura 4.3 apresenta as trajetórias não-lineares de equilíbrio do campo de deslocamentos transversais, $w$, para as cascas conoidais de Geometria 2 e de bordas curvas parabólicas. Verificou-se nesta figura que os pontos limites das trajetórias de equilíbrio não-lineares são bem definidos para esta geometria. A consideração das não-linearidades geométricas produziu uma diminuição da capacidade de carga em relação à carga crítica linear para as condições de contorno EELL, EELE e $\mathrm{A}_{2} \mathrm{~A}_{2} \mathrm{LA}_{2}$, Figuras 4.3 (c)-(e), e um aumento da capacidade de carga para as cascas conoidais com condição de contorno com todas as bordas apoiadas e com condição de apoio $\mathrm{A}_{2} \mathrm{~A}_{2} \mathrm{LL}$, como pode ser visualizado nas Figuras 4.3 (a), (b) e (f). $\mathrm{Na}$ sobreposição das condições de contorno, Figura 4.3 (g), observou-se que a condição de apoio $\mathrm{A}_{2} \mathrm{~A}_{2} \mathrm{~A}_{2} \mathrm{~A}_{2}$ conferiu a maior capacidade de carga ao conóide de bordas curvas parabólicas e de Geometria 2, sendo essa carga limite bem superior as demais obtidas.

Figura 4.3- Análise paramétrica das condições de contorno no conóide de Geometria 2 (parabólico)

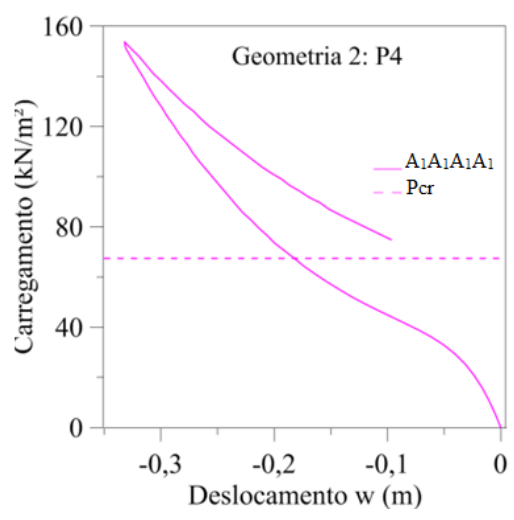

(a) $A_{1} A_{1} A_{1} A_{1}$

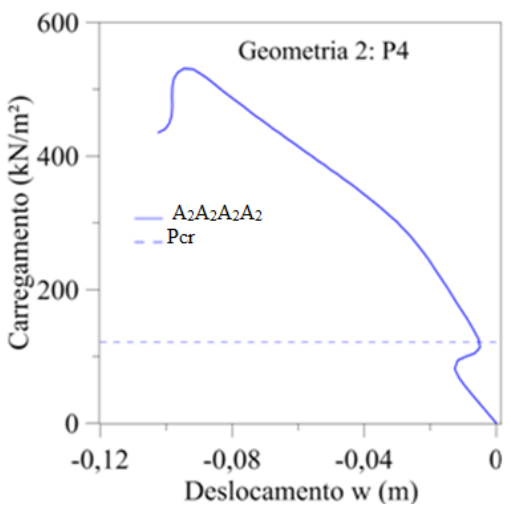

(b) $\mathrm{A}_{2} \mathrm{~A}_{2} \mathrm{~A}_{2} \mathrm{~A}_{2}$

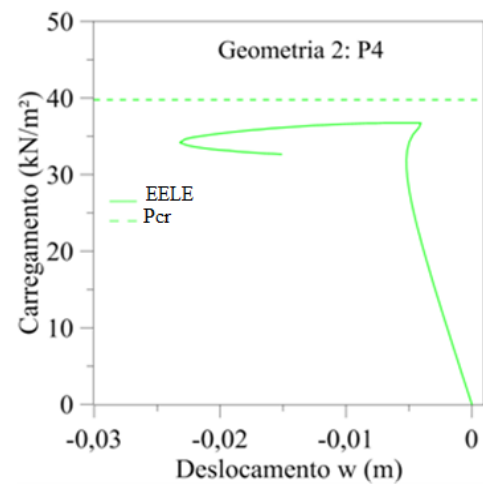

(c) EELL 


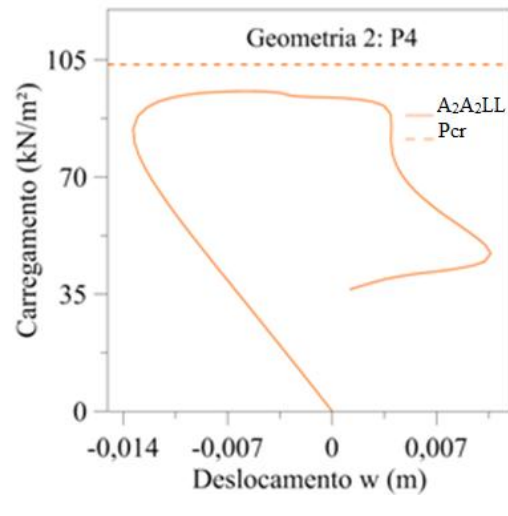

(d) $\mathrm{A}_{2} \mathrm{~A}_{2} \mathrm{LA}_{2}$

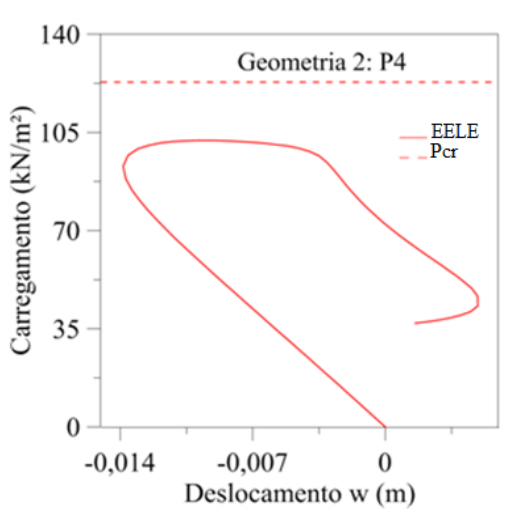

(e) EELE

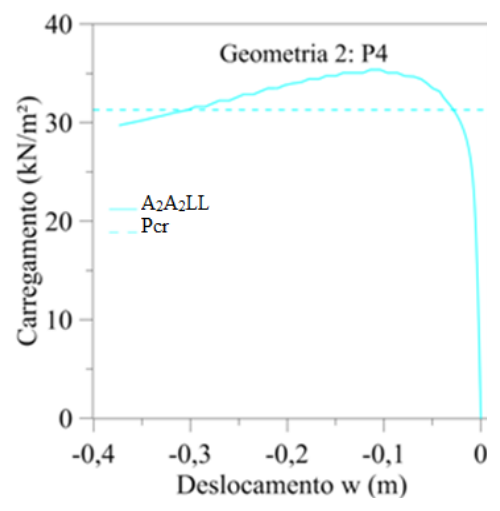

(f) $\mathrm{A}_{2} \mathrm{~A}_{2} \mathrm{LL}$

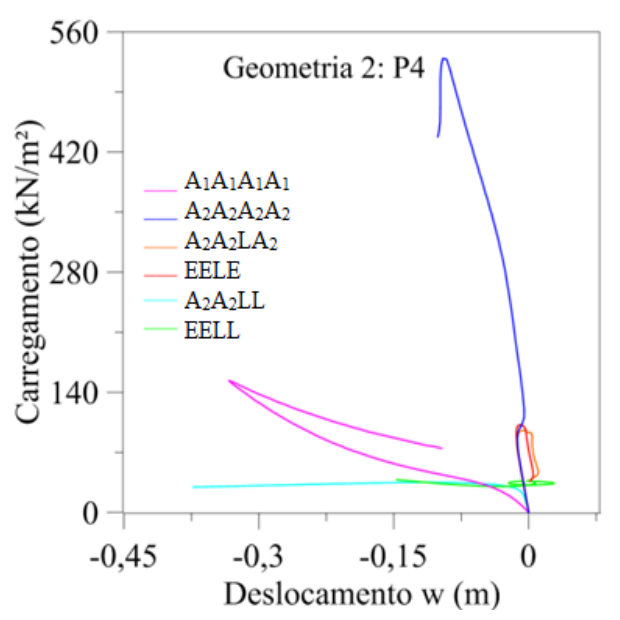

(g) Sobreposição das condições de apoio

O comportamento não-linear da casca parabólica de Geometria 3, a qual a borda com menor altura da curva representa metade da altura da curva de $\mathrm{H}_{2}$, pode ser analisado através dos caminhos não-lineares de equilíbrio do campo de deslocamentos transversais $w$, Figura 4.4.

A partir da Figura 4.4 observou-se o aumento na capacidade de carga da casca conoidal em comparação com as cargas críticas lineares nos conóides em todas as condições de contorno analisadas, Figuras 4.4 (a)-(d) e (f). A exceção é a condição de contorno EELE que apresentou redução da capacidade de carga do conóide, Figura 4.4 (e). Notou-se na sobreposição das condições de contorno, Figura $4.4(\mathrm{~g})$, as diferentes trajetórias não-lineares de equilíbrio de $w$ produzidas pela variação das condições de contorno, sendo que a maior capacidade de carga da casca conoidal parabólica de Geometria 3 foi para a condição de apoio $\mathrm{A}_{1} \mathrm{~A}_{1} \mathrm{~A}_{1} \mathrm{~A}_{1}$. Além disso, observou-se que as cascas com as condições de apoio $\mathrm{A}_{2} \mathrm{~A}_{2} \mathrm{LL}$ e EELL apresentaram um comportamento bastante semelhante nesta geometria. 
Figura 4.4- Análise paramétrica das condições de contorno no conóide de Geometria 3 (parabólico)

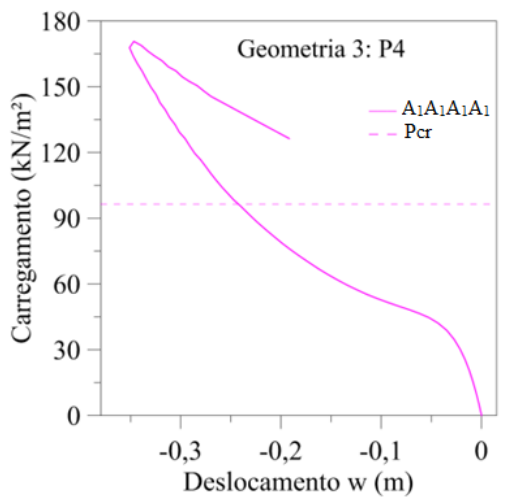

(a) $\mathrm{A}_{1} \mathrm{~A}_{1} \mathrm{~A}_{1} \mathrm{~A}_{1}$

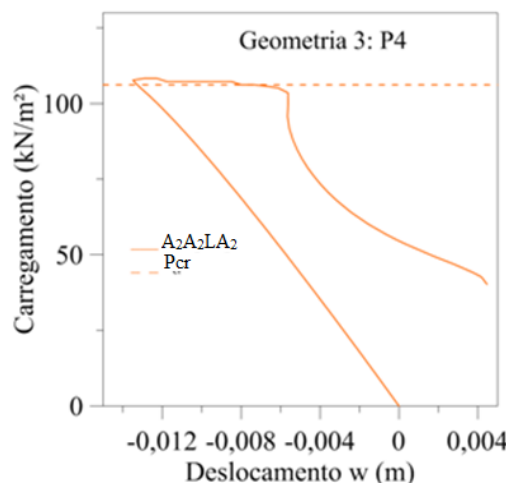

(d) $\mathrm{A}_{2} \mathrm{~A}_{2} \mathrm{LA}_{2}$

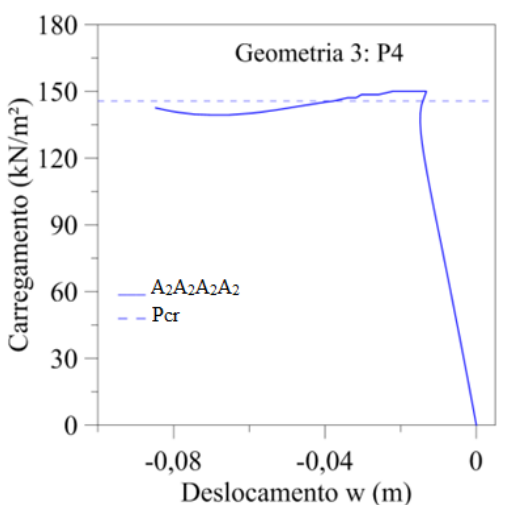

(b) $\mathrm{A}_{2} \mathrm{~A}_{2} \mathrm{~A}_{2} \mathrm{~A}_{2}$

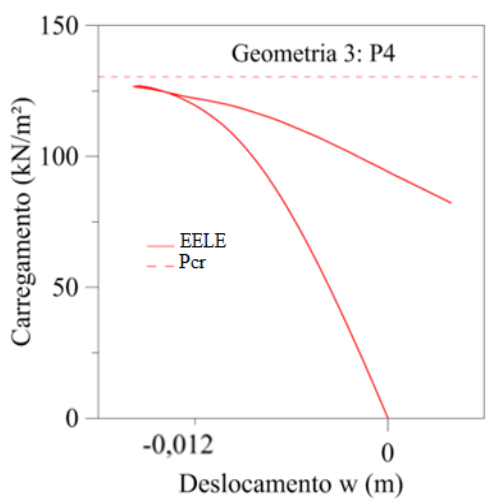

(e) EELE

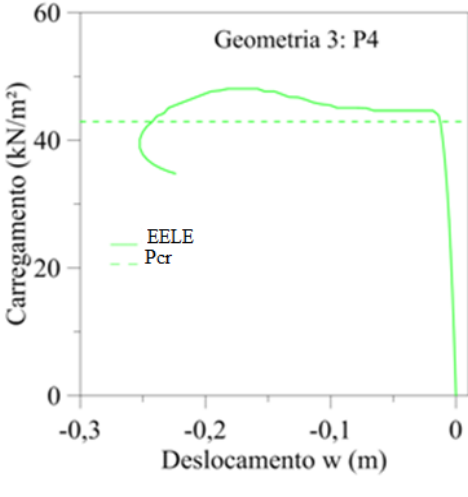

(c) EELL

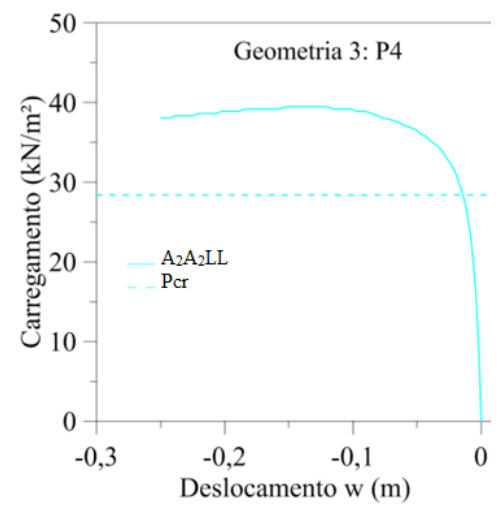

(f) $\mathrm{A}_{2} \mathrm{~A}_{2} \mathrm{LL}$

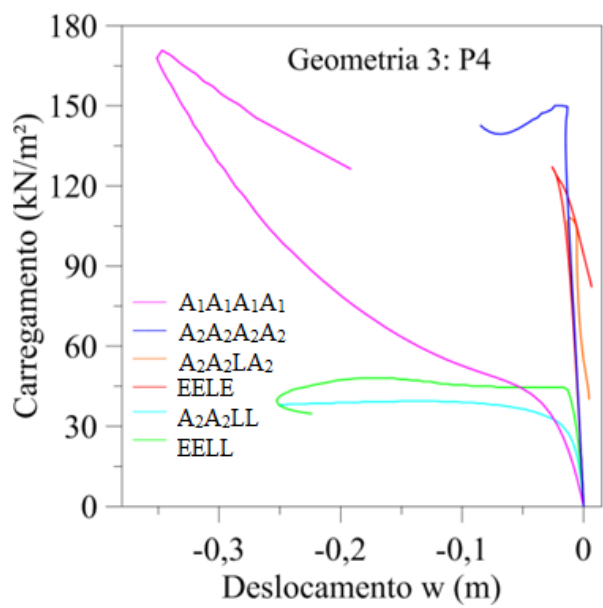

(g) Sobreposição das condições de apoio

A Figura 4.5 apresenta a influência da variação das condições de contorno no caminho nãolinear de equilíbrio dos deslocamentos $w$ para as cascas conoidais parabólicas de Geometria 4, que é um caso de painel parabólico, pois as bordas $\mathrm{H}_{1}$ e $\mathrm{H}_{2}$ têm a mesma altura. 
Figura 4.5- Análise paramétrica das condições de contorno no conóide de Geometria 4 (parabólico)

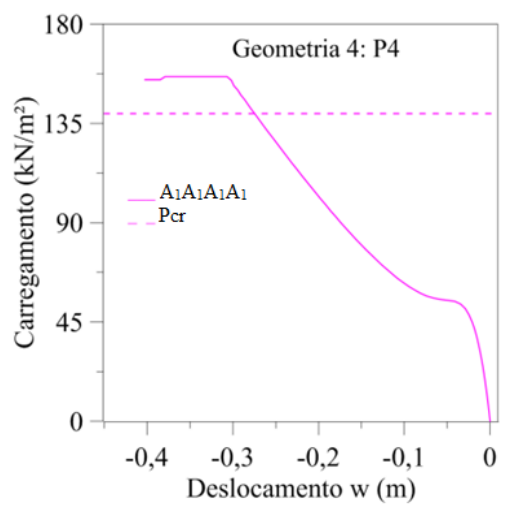

(a) $A_{1} A_{1} A_{1} A_{1}$

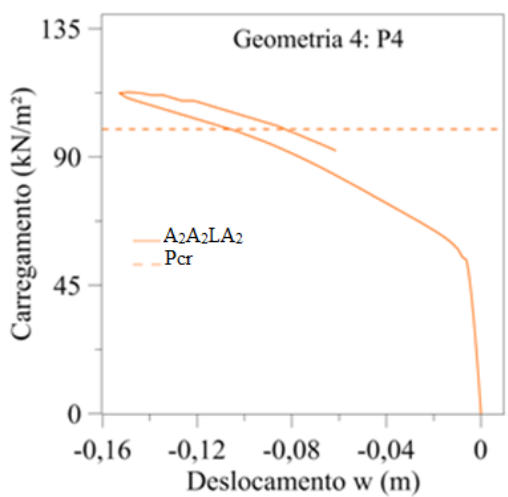

(d) $\mathrm{A}_{2} \mathrm{~A}_{2} \mathrm{LA}_{2}$

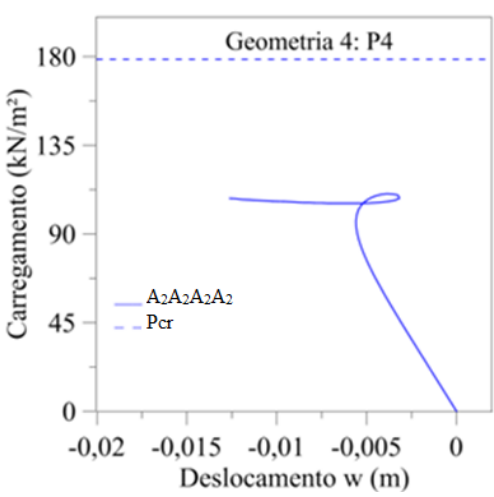

(b) $\mathrm{A}_{2} \mathrm{~A}_{2} \mathrm{~A}_{2} \mathrm{~A}_{2}$

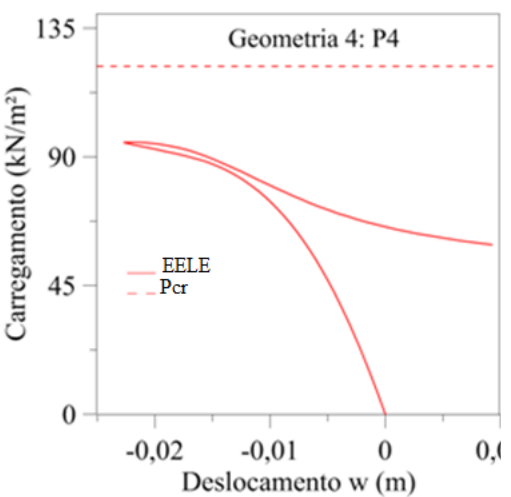

(e) EELE

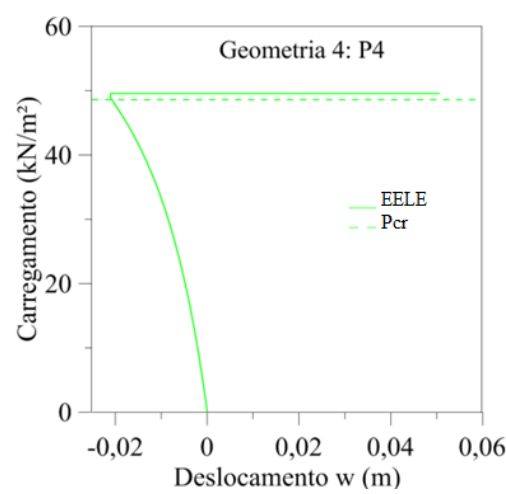

(c) EELL

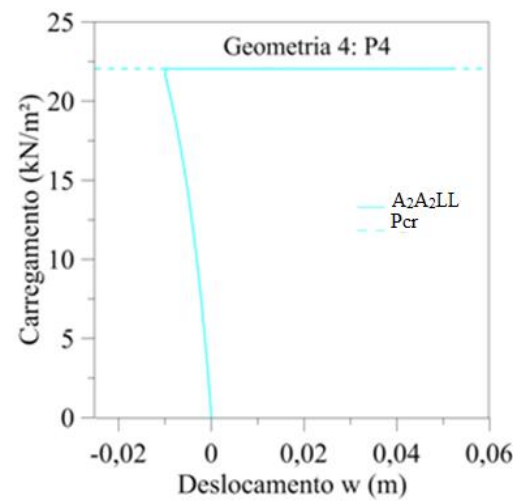

(f) $\mathrm{A}_{2} \mathrm{~A}_{2} \mathrm{LL}$

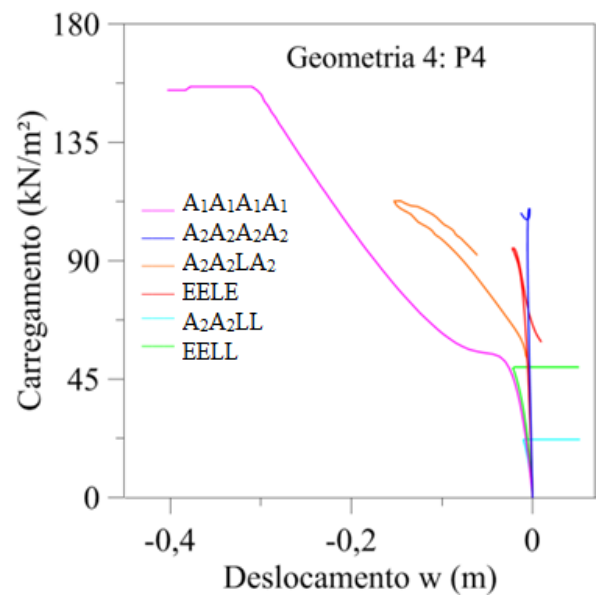

(g) Sobreposição das condições de apoio

Os caminhos de equilíbrio são não-lineares e sua capacidade de carga para a condição de apoio $\mathrm{A}_{2} \mathrm{~A}_{2} \mathrm{LL}$ convergiu em $22,0 \mathrm{kN} / \mathrm{m}^{2}$, o mesmo valor obtido para a carga crítica linear, como ilustra a Figura 4.5 (f), sendo esse caso a única coincidência registrada entre os vinte 
quatro casos abordados nesta dissertação. Assim como observado para as outras condições de contorno e de geometria, houve resultados cujas condições de contorno geraram cargas limites maiores do que a carga crítica linear, Figuras 4.5 (a), (c) e (d), bem como cargas limites menores que a resposta linear, Figuras 4.5 (b) e (e).

O caso apresentado na Figura 4.5 (b) do conóide de bordas curvas parabólicas apoiado em suas quatro bordas com apoios indeslocáveis, apresentou na análise linear a maior carga crítica de $178,6 \mathrm{kN} / \mathrm{m}^{2}$ diferentemente da carga limite não-linear com $110,4 \mathrm{kN} / \mathrm{m}^{2}$, levando a uma diferença de 39,19\% em relação à resposta da análise linear. Ressalta-se que na sobreposição das condições de contorno, Figura 4.5 (g), a casca com condição de apoio de primeiro gênero $A_{1} A_{1} A_{1} A_{1}$ possui a maior capacidade do conóide parabólico de Geometria 4, estando ainda, acima da análise linear.

Notou-se, ainda na Figura 4.5, que os conóides com as bordas $\mathrm{H}_{1}$ e $\mathrm{H}_{2}$ livres apresentaram uma região específica e bem definida no gráfico com grande deslocamento sem acréscimo de carga. Comportamento semelhante a um patamar de escoamento do material ao atingir o ponto limite de carregamento, indicando que o material não segue mais a lei de Hooke a partir deste ponto do gráfico.

Verificou-se que o comportamento não-linear da componente de deslocamento $w$ do conóide de bordas curvas parabólicas depende altamente da altura das bordas curvas adotadas na geometria e das condições de contorno a qual suas bordas estão submetidas. Quando o conóide com mesma condição de apoio foi avaliado alterando-se a geometria, produziram-se diferentes caminhos não-lineares de equilíbrio com variações distintas de capacidades de carregamento, como pode ser visualizado na Figura 4.6.

Verificou-se a partir da Figura 4.6 (a) que para a casca conoidal com condição de contorno $\mathrm{A}_{1} \mathrm{~A}_{1} \mathrm{~A}_{1} \mathrm{~A}_{1}$ as trajetórias de equilíbrio não-lineares são semelhantes, se diferenciando quanto a inclinação à esquerda das trajetórias, e com pontos bem definidos da capacidade da carga limite. A exceção é a Geometria 1 que apresenta uma inclinação maior que as demais geometrias e não há um ponto bem definido que caracteriza sua carga limite. Já para a casca com condição de apoio $\mathrm{A}_{2} \mathrm{~A}_{2} \mathrm{~A}_{2} \mathrm{~A}_{2}$, Figura 4.6 (b), a trajetória não-linear de equilíbrio para a casca de Geometria 1 é menos não-linear, quando comparada às demais trajetórias, sem a presença de um ponto limite para o carregamento. 
Figura 4.6- Análise paramétrica das geometrias para a mesma condição de contorno fixa (parabólico)

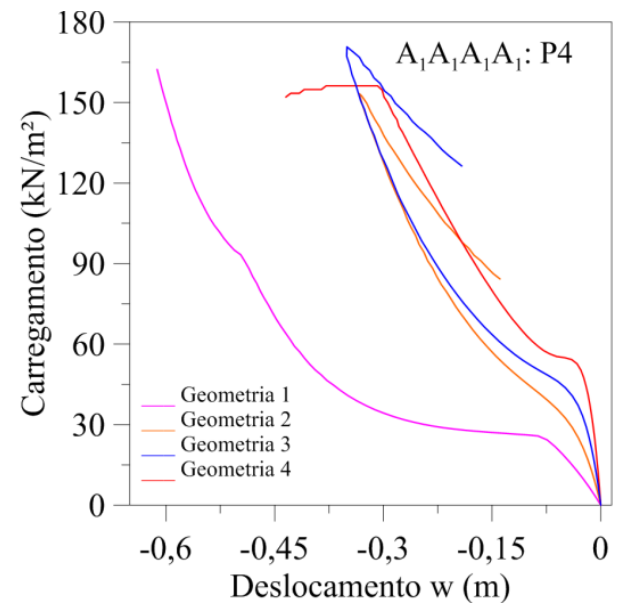

(a) $\mathrm{A}_{1} \mathrm{~A}_{1} \mathrm{~A}_{1} \mathrm{~A}_{1}$

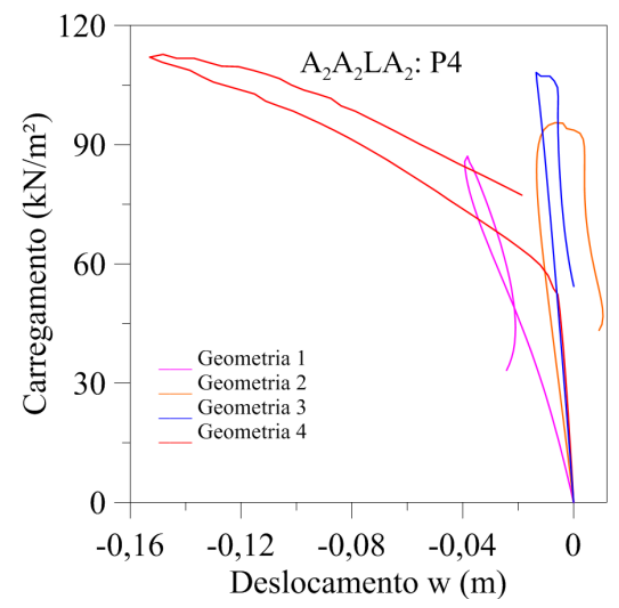

(c) $\mathrm{A}_{2} \mathrm{~A}_{2} \mathrm{LA}_{2}$

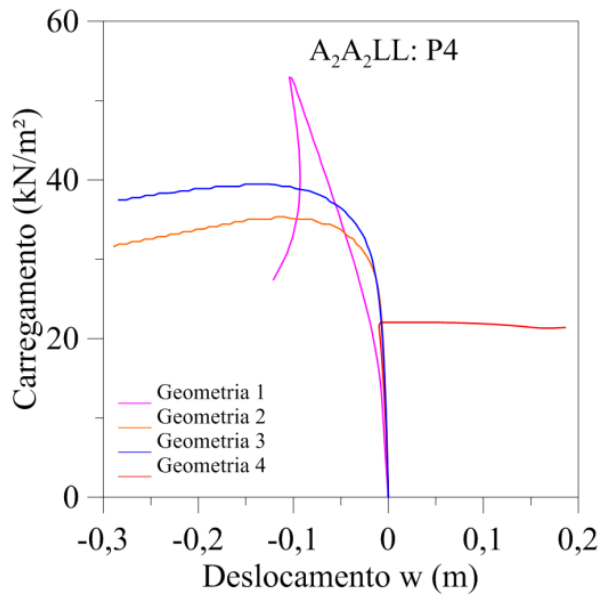

(e) $\mathrm{A}_{2} \mathrm{~A}_{2} \mathrm{LL}$

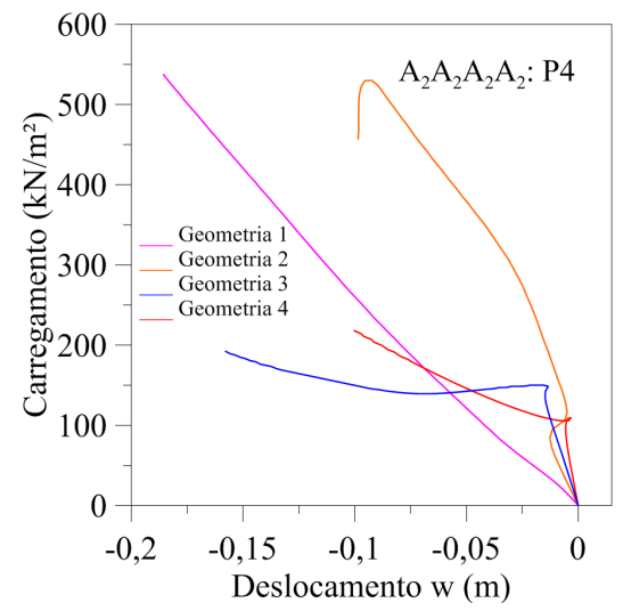

(b) $\mathrm{A}_{2} \mathrm{~A}_{2} \mathrm{~A}_{2} \mathrm{~A}_{2}$

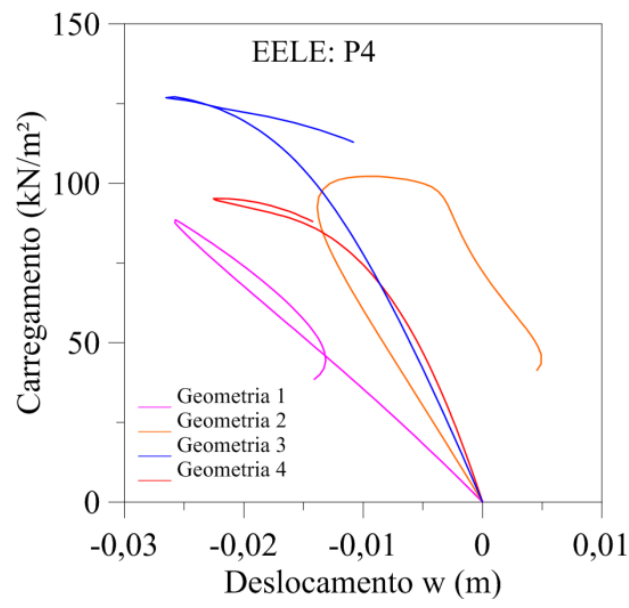

(d) EELE

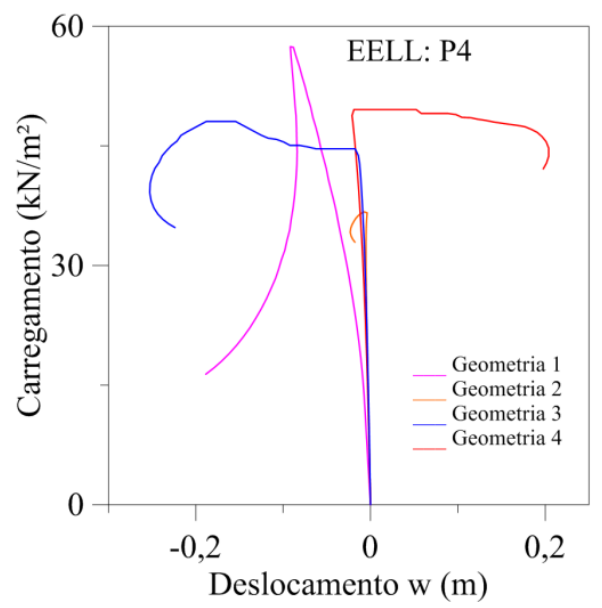

(f) EELL

Para as demais cascas conoidais apresentadas, Figuras 4.6 (c)-(f), notou-se que a trajetória de equilíbrio inicialmente é semelhante para os valores mais baixos de carregamento e, à medida 
que se incrementa o carregamento as trajetórias apresentam comportamentos variados com todas as curvas apresentando um limite de carregamento bem definido.

Figura 4.7- Análise paramétrica das geometrias para a mesma condição de contorno fixa (cilíndrico)

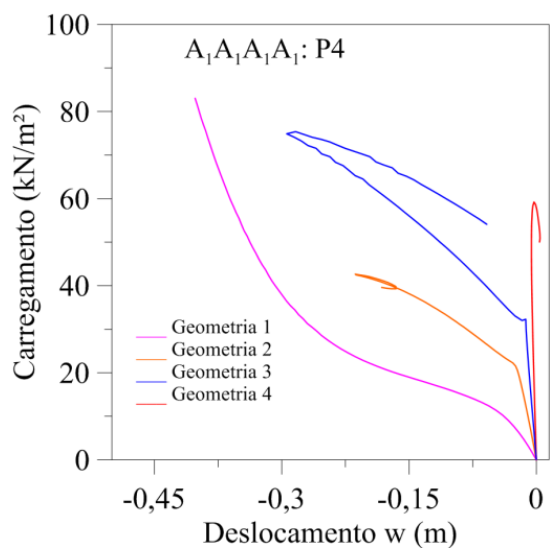

(a) Compatibilização $A_{1} A_{1} A_{1} A_{1}$

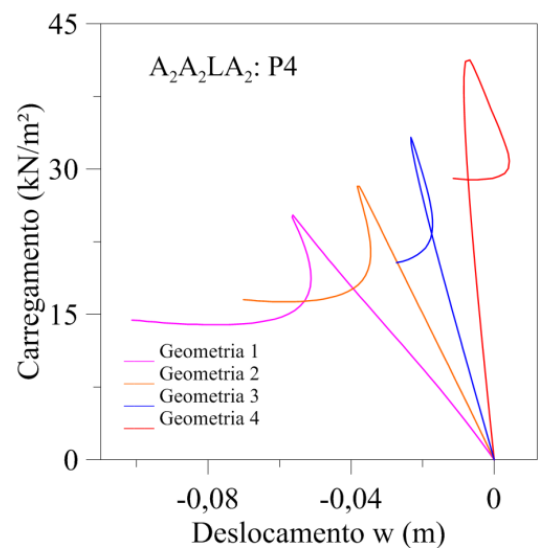

(c) Compatibilização $\mathrm{A}_{2} \mathrm{~A}_{2} \mathrm{LA}_{2}$

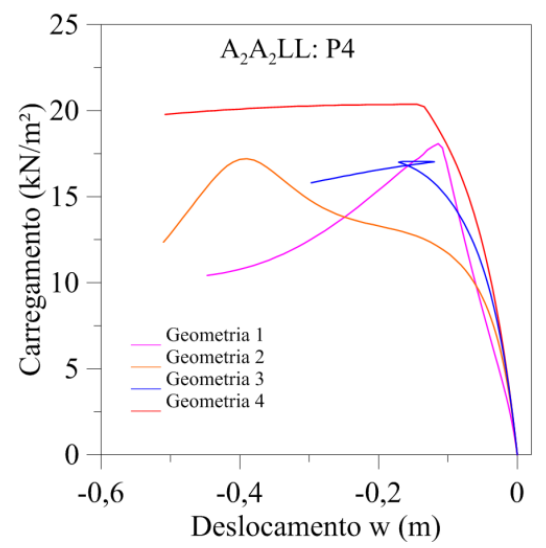

(e) Compatibilização $\mathrm{A}_{2} \mathrm{~A}_{2} \mathrm{LL}$

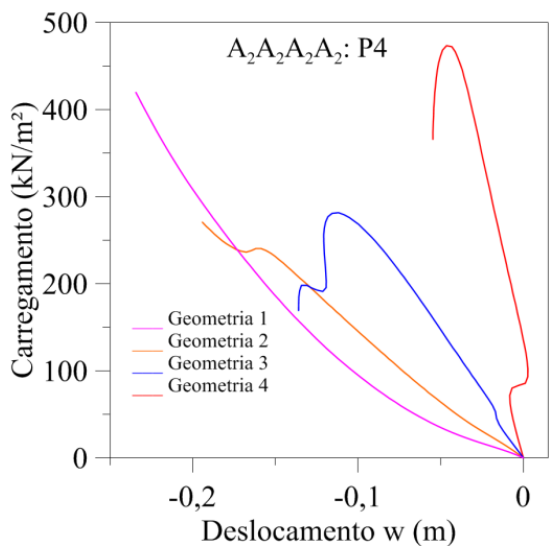

(b) Compatibilização $\mathrm{A}_{2} \mathrm{~A}_{2} \mathrm{~A}_{2} \mathrm{~A}_{2}$

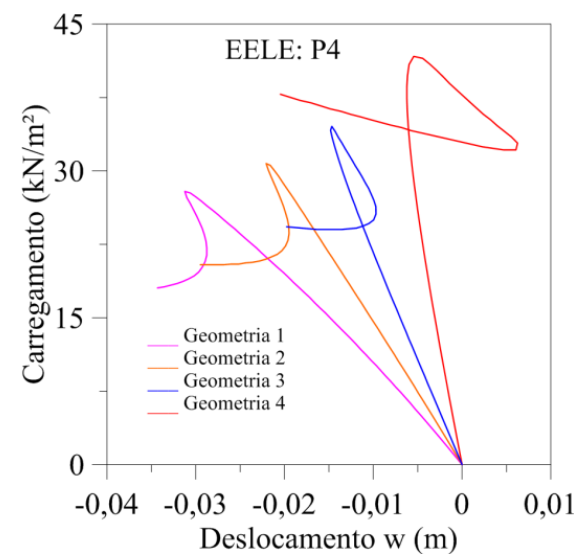

(d) Compatibilização EELE

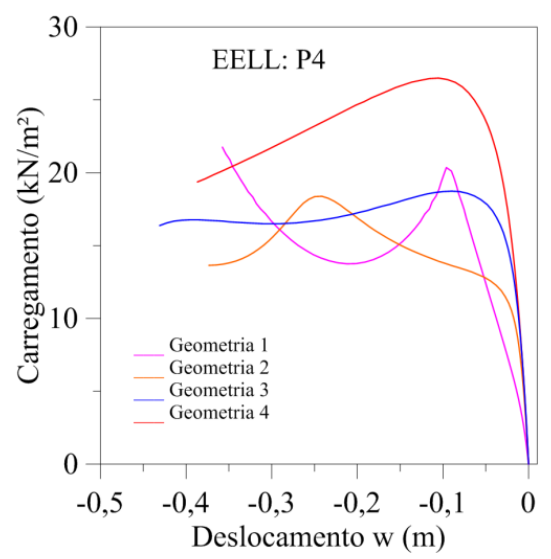

(f) Compatibilização EELL 
Considerando-se as cascas conoidais de bordas curvas cilíndricas, realizou-se o estudo da influência da variação da geometria e das condições de apoio nas trajetórias não-lineares do campo de deslocamento transversal $w$ (ponto P4) através da Figura 4.7.

Visualizou-se que o seu comportamento não-linear, assim como no caso parabólico, é altamente dependente da variação das alturas das bordas curvas e das condições de contorno. Percebeu-se nas sobreposições das trajetórias de equilíbrio apresentadas na Figura 4.7 que considerando a mesma condição de contorno, produziu-se diferentes caminhos não-lineares de equilíbrio e capacidades de carga nas Geometrias 1,2, 3 e 4, ora superiores, ora inferiores, à carga crítica linear registrada em uma mesma geometria. Observou-se nas Figuras 4.7 (a) e (b), que a carga limite não-linear não está bem caracterizada na trajetória não-linear de equilíbrio da Geometria 1, assim como observado anteriormente nos casos parabólicos de Geometria 1.

Por fim, descreve-se na Tabela 4.1 as cargas limites não-lineares $\left(\mathrm{P}_{\mathrm{nl}}\right)$ para diferentes condições de apoio e de geometrias. Esta carga limite estudada corresponde ao primeiro ponto na trajetória não-linear de equilíbrio a ter um recuo em sua capacidade de carga. Nos conóides de Geometria 1 com apoios de primeiro, ou de segundo, gêneros nas quatro bordas, não foi possível identificar uma carga limite não-linear, sendo sinalizados na tabela pelo símbolo *.

Em todas as condições de contorno foram encontradas geometrias nas quais os pontos limites são inferiores aos das cargas críticas da análise linear, estes casos foram destacados em vermelho na Tabela 4.1. Além disso, na Tabela 4.1 estão destacados em negrito os casos cujos resultados não-lineares encontram-se acima da carga crítica atingida pela análise linear. Isto indica que análise linear pode subestimar ou superestimar o comportamento não-linear dos conóides.

Verificaram-se, na Tabela 4.1, as altas capacidades portantes principalmente dos conóides com apoios de primeiro, ou segundo gêneros em todas as bordas. O módulo de elasticidade empregado nas análises leva a condição que o material trabalhe no regime elástico-linear, produzindo estas altas capacidades de carga. Verificou-se a necessidade de uma análise que leve em conta o comportamento não-linear do material constituinte dos conóides, ou seja, as não-linearidades físicas. Esta análise simultaneamente à análise das não-linearidades geométricas, consideradas no escopo deste trabalho, se torna uma tarefa mais trabalhosa, mas obtém cargas limites mais satisfatória à realidade do problema. 
Tabela 4.1- Carga limite não-linear $\left(\mathrm{P}_{\mathrm{nl}}\right)$ da casca conoidal para diferentes condições de apoio e de geometria $\left(\mathrm{kN} / \mathrm{m}^{2}\right)$

\begin{tabular}{|c|c|c|c|c|c|c|c|c|c|c|c|c|}
\hline \multirow{3}{*}{ 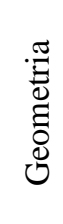 } & \multicolumn{12}{|c|}{ CA } \\
\hline & \multicolumn{2}{|c|}{$\mathrm{A}_{1} \mathrm{~A}_{1} \mathrm{~A}_{1} \mathrm{~A}_{1}$} & \multicolumn{2}{|c|}{$\mathrm{A}_{2} \mathrm{~A}_{2} \mathrm{~A}_{2} \mathrm{~A}_{2}$} & \multicolumn{2}{|c|}{$\mathrm{A}_{2} \mathrm{~A}_{2} \mathrm{LA}_{2}$} & \multicolumn{2}{|c|}{ EELE } & \multicolumn{2}{|c|}{$\mathrm{A}_{2} \mathrm{~A}_{2} \mathrm{LL}$} & \multicolumn{2}{|c|}{ EELL } \\
\hline & $\mathrm{P}_{\mathrm{cr}}$ & $\mathrm{P}_{\mathrm{nl}}$ & $\mathrm{P}_{\mathrm{cr}}$ & $\mathrm{P}_{\mathrm{nl}}$ & $\mathrm{P}_{\mathrm{cr}}$ & $\mathrm{P}_{\mathrm{nl}}$ & $\mathrm{P}_{\mathrm{cr}}$ & $\mathrm{P}_{\mathrm{nl}}$ & $\mathrm{P}_{\mathrm{cr}}$ & $\mathrm{P}_{\mathrm{nl}}$ & $\mathrm{P}_{\mathrm{cr}}$ & $\mathrm{P}_{\mathrm{nl}}$ \\
\hline \multicolumn{13}{|c|}{ Casca conoidal parabólica } \\
\hline 1 & 42,6 & * & 81,9 & * & 85,4 & 87,1 & 106,9 & 88,8 & 20,8 & 53,4 & 27,7 & 58,0 \\
\hline 2 & 67,4 & 154,4 & 121,5 & 531,2 & 103,6 & 95,6 & 122,9 & 102,0 & 31,3 & 35,4 & 39,8 & 36,8 \\
\hline 3 & 96,5 & 170,7 & 145,7 & 150,1 & 106,2 & 108,3 & 130,3 & 127,1 & 28,4 & 39,5 & 42,9 & 48,1 \\
\hline 4 & 139,5 & 156,2 & 178,6 & 110,4 & 99,7 & 112,7 & 121,7 & 95,3 & 22,0 & 22,0 & 48,6 & 49,5 \\
\hline \multicolumn{13}{|c|}{ Casca conoidal cilíndrica } \\
\hline 1 & 28,7 & * & 41,1 & * & 47,4 & 25,4 & 56,1 & 28,0 & 17,0 & 18,1 & 17,0 & 20,4 \\
\hline 2 & 44,1 & 42,6 & 58,2 & 240,9 & 52,8 & 28,5 & 62,6 & 30,9 & 20,0 & 17,2 & 23,0 & 18,4 \\
\hline 3 & 63,9 & 75,4 & 78,0 & 281,6 & 60,7 & 33,3 & 69,0 & 34,6 & 20,3 & 17,0 & 30,3 & 18,7 \\
\hline 4 & 99,1 & 59,2 & 116,9 & 474,6 & 73,1 & 41,4 & 79,0 & 41,8 & 21,9 & 20,4 & 38,7 & 26,5 \\
\hline
\end{tabular}

Percebeu-se que, dependendo da condição de apoio e da geometria, foram encontradas conóides com alta, ou baixa, capacidade de carga. O ponto limite onde ocorre um recuo de capacidade de carga não-linear, foi altamente dependente dos parâmetros geométricos e condições de apoio do conóide. Assim como na análise linear percebeu-se na Tabela 4.1 que os casos parabólicos apresentaram capacidades de carga superiores aos casos cilíndricos. A exceção é o apoio $\mathrm{A}_{2} \mathrm{~A}_{2} \mathrm{~A}_{2} \mathrm{~A}_{2}$, no qual as Geometrias 3 e 4 , com bordas curvas cilíndricas, apresentou superioridade da carga limite de $46,70 \%$ e de $76,74 \%$, respectivamente, em relação às Geometrias 3 e 4 com bordas curvas parabólicas.

Observou-se que os casos parabólicos e cilíndricos dos conóides com apoios $\mathrm{A}_{2} \mathrm{~A}_{2} \mathrm{~A}_{2} \mathrm{~A}_{2}$ obtiveram a resposta da carga limite não-linear superior à carga crítica linear, exceto o conóide de Geometria 4 e bordas curvas parabólicas, cuja carga limite não-linear representou $61,81 \%$ da carga crítica linear.

A partir da Tabela 4.1 notou-se que as maiores cargas limites para os conóides de bordas curvas cilíndricas, ou parabólicas, foram encontradas para condição de apoio $\mathrm{A}_{2} \mathrm{~A}_{2} \mathrm{~A}_{2} \mathrm{~A}_{2}$ sendo 
na Geometria 2 de bordas curvas parabólicas, com valor 10,66\% acima da maior carga limite do conóide de bordas curvas cilíndricas, registrada para a Geometria 4.

Nos conóides parabólicos de Geometria 3 e 4, as maiores cargas limites foram encontradas com a condição de apoio de primeiro gênero $A_{1} A_{1} A_{1} A_{1}$. Percebeu-se que em ambas as geometrias, as cascas obtiveram sua menor carga limite para os apoios indeslocáveis em suas bordas retas e livres em suas bordas curvas, $\mathrm{A}_{2} \mathrm{~A}_{2} \mathrm{LL}$, sendo que a menor carga limite dos casos parabólicos é para a Geometria 4, ainda com valor 22,73\% acima da menor carga limite dos casos cilíndricos, encontrada na Geometria 3, conforme apresentado na Tabela 4.1.

Com o apoio $\mathrm{A}_{2} \mathrm{~A}_{2} \mathrm{LL}$, a carga limite não-linear dos casos parabólicos foram superiores às cargas críticas lineares chegando ao valor de $61,05 \%$ maior para a Geometria 1. A exceção é a Geometria 4 que convergiu o resultado em $22,0 \mathrm{kN} / \mathrm{m}^{2}$, mesmo valor obtido para a carga crítica na análise linear. Ainda se observou para este apoio que, para o caso das bordas curvas cilíndricas, apenas a Geometria 1 teve resultado superior à carga crítica linear, estando 6,08\% acima.

No apoio com uma borda curva livre e as outras engastadas, EELE, as cargas críticas lineares foram superiores em todas as geometrias chegando a 50,64\% acima da resposta não-linear no conóide de Geometria 2 de bordas curvas cilíndricas e 21,69\% acima da resposta não-linear do conóide de Geometria 4 de bordas curvas parabólicas. A maior carga limite deste apoio foi encontrada no caso do conóide de bordas curvas parabólicas e Geometria 3 e no conóide de bordas cilíndricas, e Geometria 4, sendo que o conóide de Geometria 3 e bordas parabólicas tem carga limite $67,11 \%$ superior à Geometria 4 com bordas cilíndricas.

Adicionalmente, a partir destes resultados torna-se claro a importância da análise não-linear, pois a análise linear pode superestimar, ou subestimar, o comportamento não-linear da casca conoidal.

\subsection{INFLUENCIA DA FORMA DA BORDA CURVA}

Avalia-se nesta seção a influência da forma da borda curva, parabólica ou cilíndrica, na trajetória de equilíbrio não-linear da casca conoidal. Para isto, consideraram-se as cascas conoidais de Geometria 1 e 4 e a condição de contorno $\mathrm{A}_{2} \mathrm{~A}_{2} \mathrm{~A}_{2} \mathrm{~A}_{2}$. 
Na Figura 4.8 apresentam-se através dos pontos P1, P2, P3, P4 e P5 destacados na Figura 4.1, os caminhos não-lineares de equilíbrio dos conóides parabólicos e cilíndricos de Geometria 1 com apoios indeslocáveis em suas quatro bordas.

Figura 4.8- Trajetória não-linear de equilíbrio dos conóides de Geometria $1\left(\mathrm{~A}_{2} \mathrm{~A}_{2} \mathrm{~A}_{2} \mathrm{~A}_{2}\right.$ - parabólico $x$ cilíndrico)
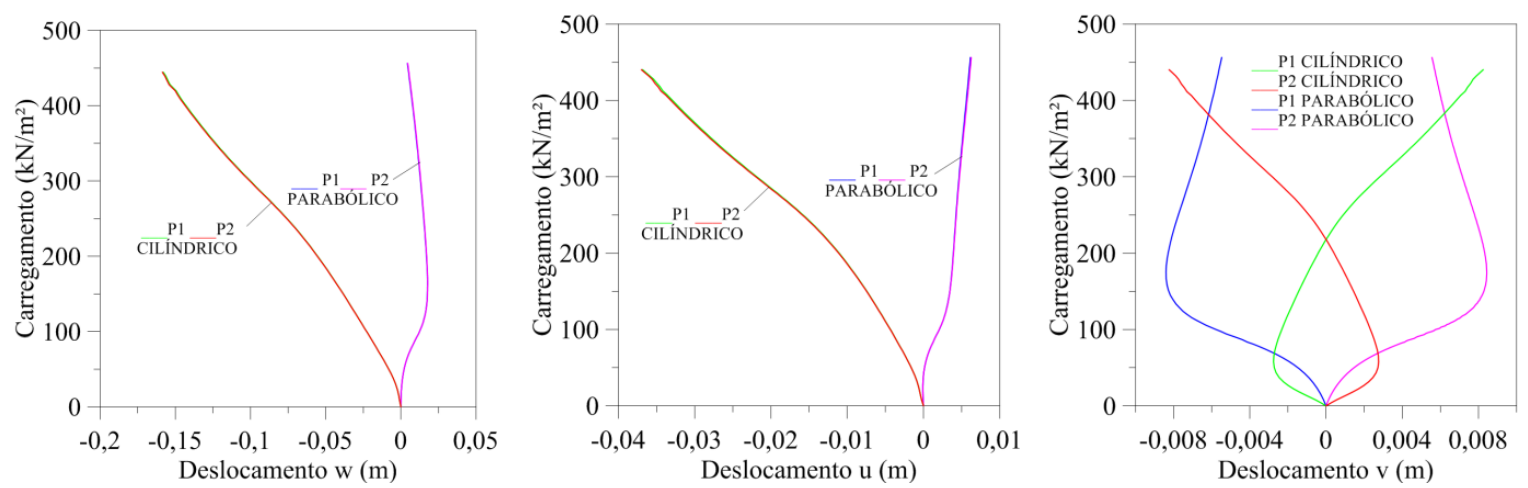

(a) P1 e P2
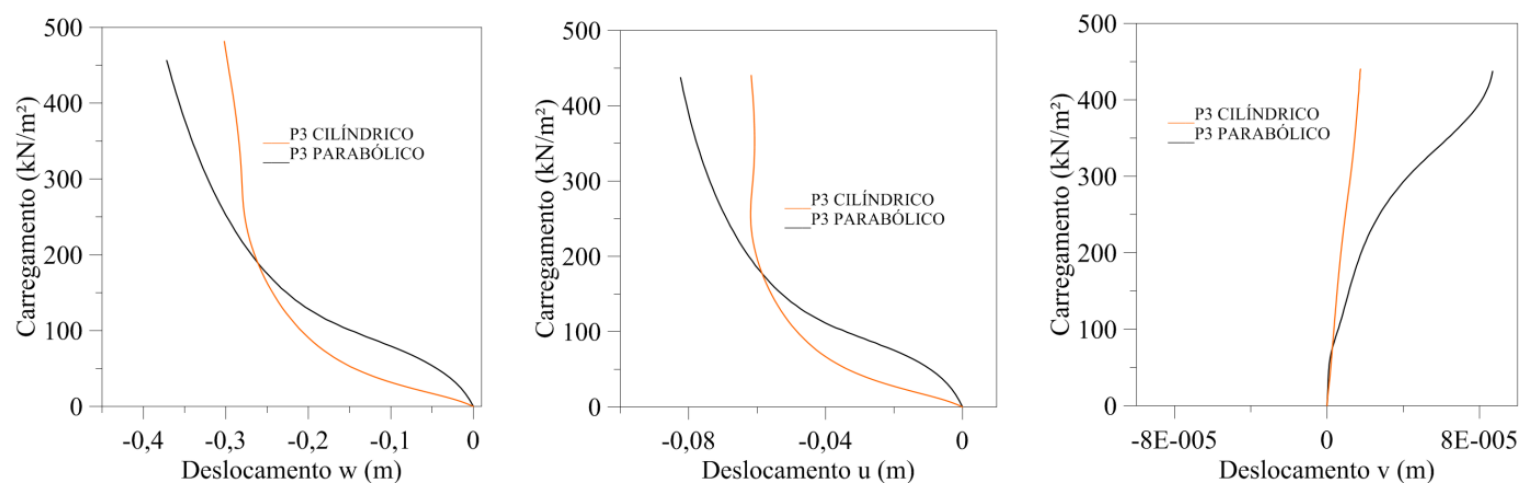

(b) P3
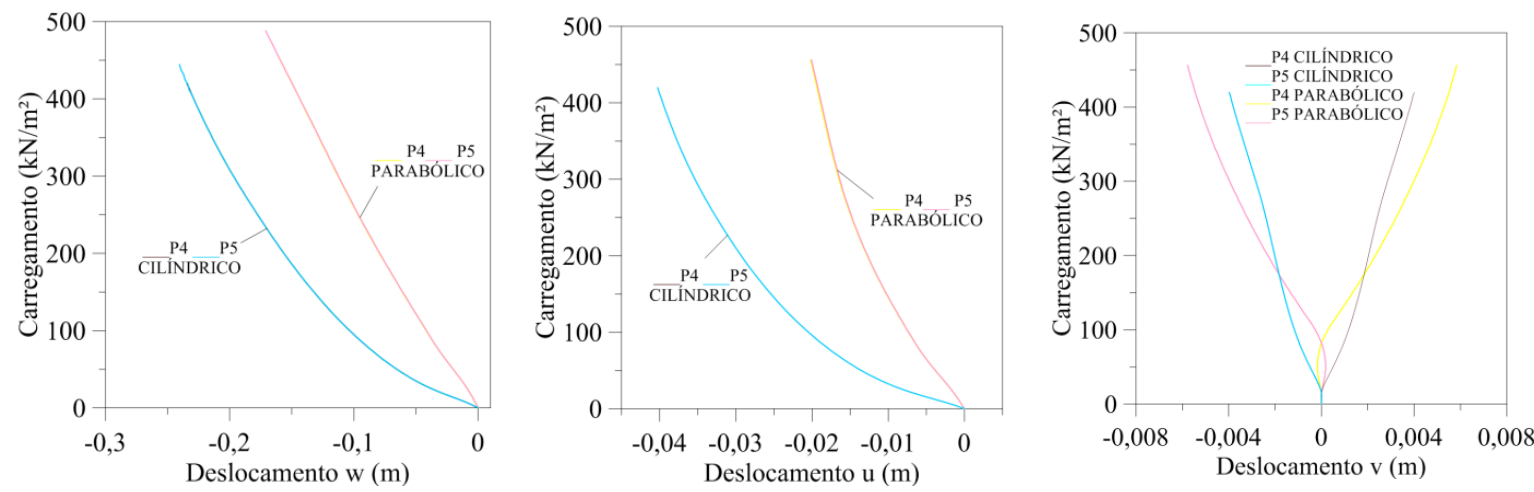

(c) P4 e P5 
Notou-se, na Figura 4.8, que a trajetória de equilíbrio não-linear da Geometria 1 não apresenta claramente um ponto com perda da capacidade de carga. Todos os deslocamentos possuem valores significativos com exceção do campo de deslocamento $v$ para o ponto P3, Figura 4.8 (b), localizado ao centro do conóide, no qual os valores são praticamente nulos. Destaca-se a superioridade da magnitude dos deslocamentos $w$ em relação aos demais deslocamentos em todos os pontos de observação.

Verificou-se na Figura 4.8 que nos pontos simétricos, posicionados em torno do eixo $x$, houve simetria nos campos de deslocamentos $u$ e $w$ como pode ser visualizado na sobreposição dos pontos próximos a borda $\mathrm{H}_{2}$ de maior altura curva (P1 e P2), Figura 4.8 (a), e também dos pontos próximos a borda $\mathrm{H}_{1}(\mathrm{P} 4$ e P5), Figura 4.8 (c).

As Figuras 4.9 a 4.11 ilustram as formas deformadas dos campos de deslocamento $w, u$ e $v$, respectivamente, em três pontos de observação denominados $\mathrm{M}_{1}, \mathrm{M}_{2}$ e $\mathrm{M}_{3}$ e posicionados ao longo das trajetórias não-lineares de equilíbrio de forma a verificar como as não-linearidades geométricas modificam as configurações dos deslocamentos $w, u$ e $v$.

As Figuras 4.9 e 4.10 corroboram na explicação da simetria dos campos de deslocamentos $w$ e $u$, respectivamente, em torno do eixo $x$ e ao longo da trajetória de equilíbrio não-linear. Esta simetria é permanente ao longo de toda trajetória não-linear de equilíbrio avaliada na Geometria 1.

Devido à diferença entre as altura das bordas $\mathrm{H}_{1}$ e $\mathrm{H}_{2}$ da Geometria 1, é identificado uma dependência da coordenada axial para descrever a forma de todos os campos de deslocamentos.

Ressalta-se que tanto no modelo parabólico quanto cilíndrico, há uma semelhança entre a composição modal que descreve o campo dos deslocamentos $u$, Figura 4.10, e o campo de deslocamentos $w$, Figura 4.9. Há três semi-ondas circunferenciais e simétricas em torno do eixo $x$, porém fortemente dependentes da coordena axial $x$.

Verificou-se no primeiro ponto de observação, $\mathrm{M}_{1}$, Figuras 4.9 (a) e 4.10 (a), que os deslocamentos foram maiores nas proximidades da borda $\mathrm{H}_{1} \mathrm{e}$, à medida que se incrementa $\mathrm{o}$ carregamento, as não-linearidades geométricas foram atuando e deslocaram o máximo dos campos de deslocamentos para uma região mais ao centro dos conóides, como ilustram as Figuras 4.9 (b) e (c) e 4.10 (b) e (c). 
Figura 4.9- Modos de deslocamentos $w$ ao longo das trajetórias não-lineares de equilíbrio da Geometria 1 submetida ao apoio $\mathrm{A}_{2} \mathrm{~A}_{2} \mathrm{~A}_{2} \mathrm{~A}_{2}$

Caso parabólico
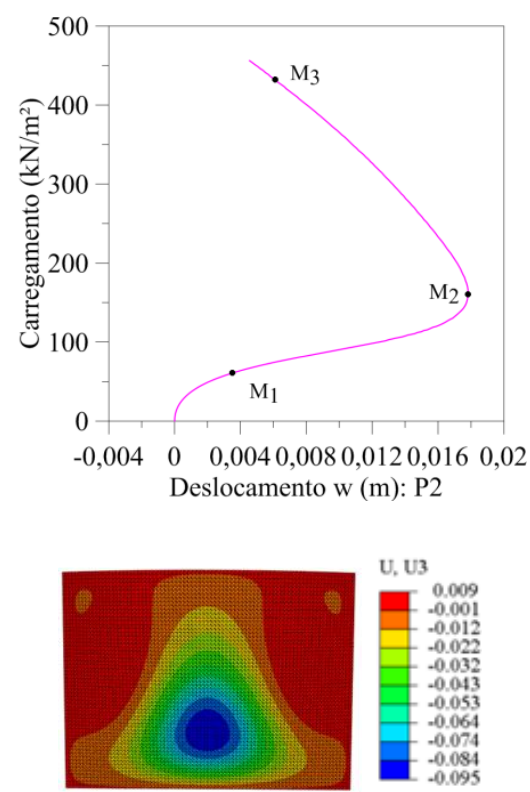

(b) $\mathrm{M}_{2}$

(a) $\mathrm{M}_{1}$

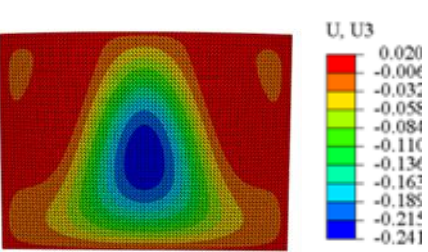

(c) $\mathrm{M}_{3}$

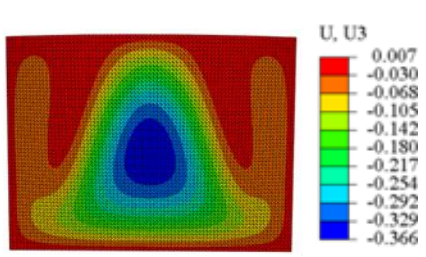

Caso cilíndrico
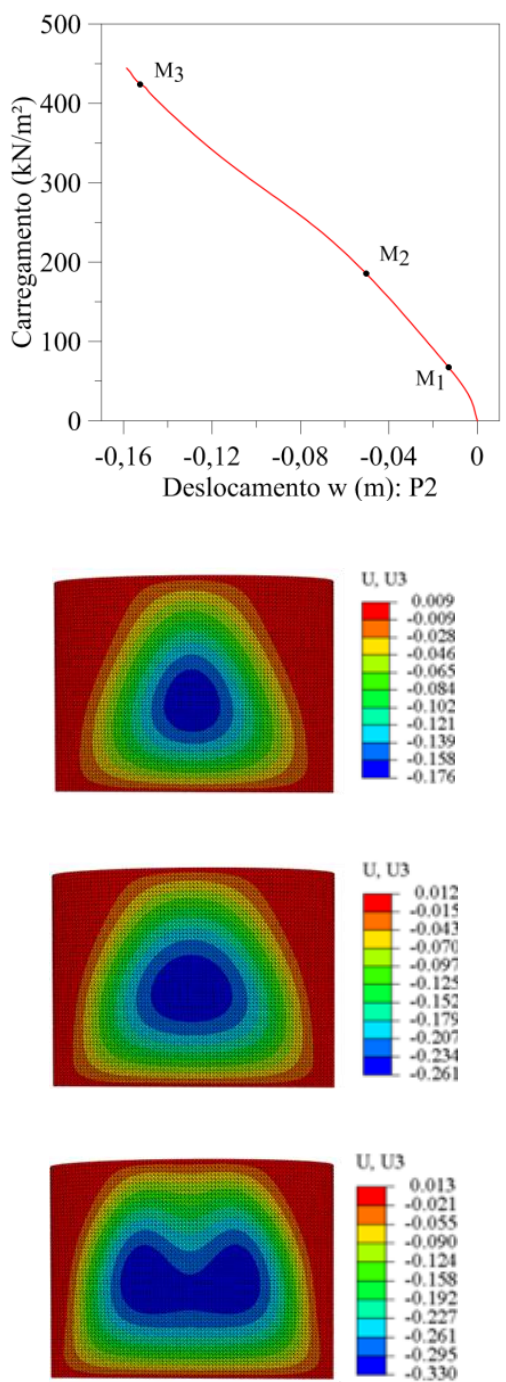

A partir das Figuras 4.9 (c) e 4.10 (c) observa-se que as formas deslocadas de $w$ e $u$, relativas ao ponto de amostragem $\mathrm{M}_{3}$, são alteradas no caso cilíndrico, indicando um forte acoplamento modal com modos superiores, com o máximo deslocamento dividindo-se em duas semi-ondas circunferenciais no lado próximo a borda de maior altura da curva. 
Figura 4.10- Modos de deslocamentos $u$ ao longo das trajetórias não-lineares de equilíbrio da Geometria 1 submetida ao apoio $\mathrm{A}_{2} \mathrm{~A}_{2} \mathrm{~A}_{2} \mathrm{~A}_{2}$

Caso parabólico
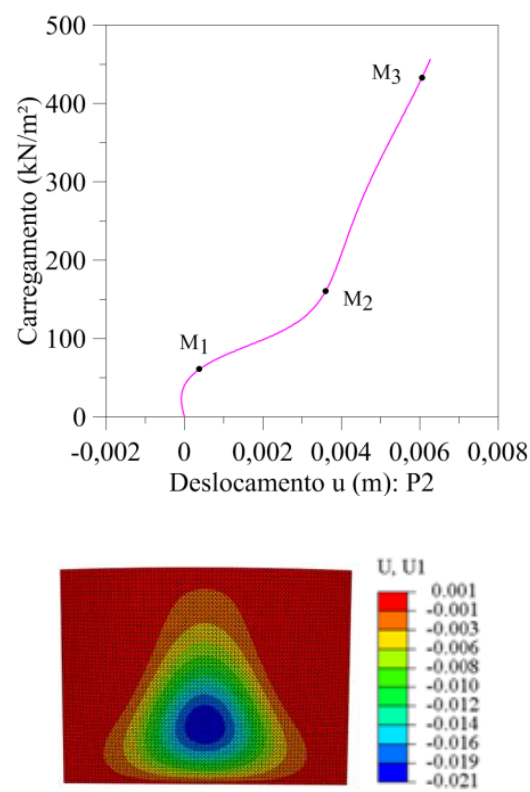

(b) $\mathrm{M}_{2}$

(a) $\mathrm{M}_{1}$

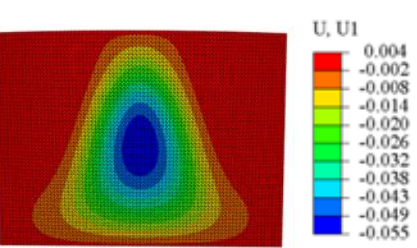

(c) $\mathrm{M}_{3}$
Caso cilíndrico
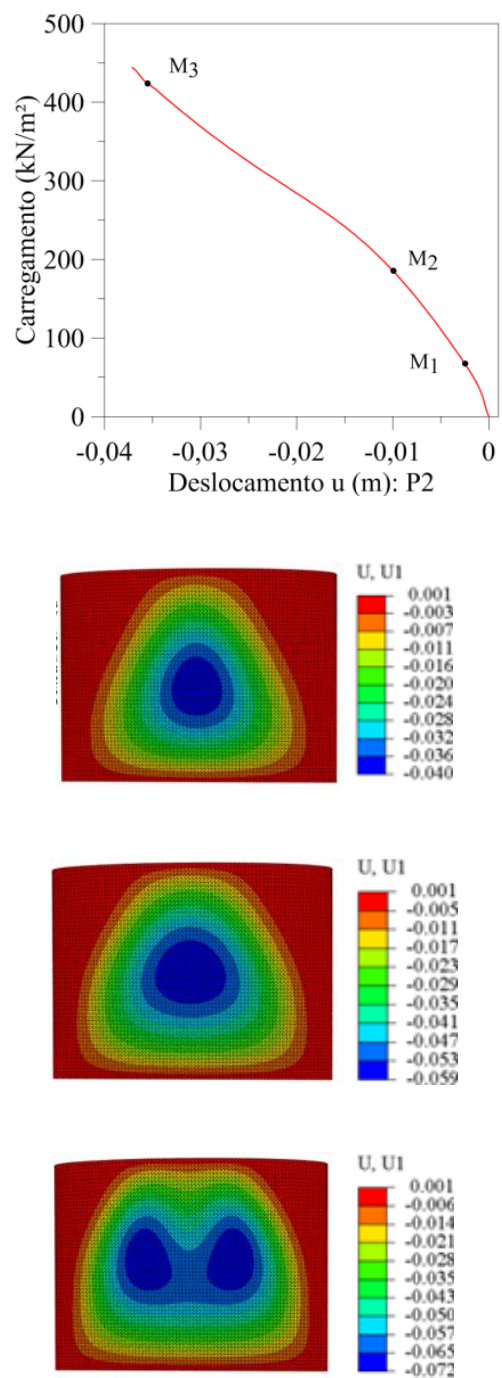

Na topologia da forma do campo de deslocamentos $v$ ao longo da trajetória de equilíbrio nãolinear da casca conoidal de Geometria 1 e com apoios $\mathrm{A}_{2} \mathrm{~A}_{2} \mathrm{~A}_{2} \mathrm{~A}_{2}$, Figura 4.11, identificou-se uma anti-simetria dos deslocamentos em torno do eixo $x$ com forte dependência da coordenada axial $x$, como observado nos pontos de amostragem próximos a borda $\mathrm{H}_{2}(\mathrm{P} 1 \mathrm{e}$ P2), Figura 4.8 (a), e também dos pontos de amostragem próximos a borda $\mathrm{H}_{1}$ (P4 e P5), Figura 4.8 (c). Notou-se ainda que os deslocamentos $v$ têm topologias semelhantes nos casos parabólicos e cilíndricos assumindo a forma de duas semi-ondas circunferenciais com antisimetria em torno do eixo axial $x$ no início da trajetória, Figura 4.11 (a), com o surgimento de outras semi-ondas para valores de cargas maiores, Figuras 4.11 (b) e (c), o que indica também um acoplamento de modos superiores ao decorrer da trajetória de equilíbrio. 
Figura 4.11- Modos de deslocamentos $v$ ao longo das trajetórias não-lineares de equilíbrio da Geometria 1 com apoio $\mathrm{A}_{2} \mathrm{~A}_{2} \mathrm{~A}_{2} \mathrm{~A}_{2}$

Caso parabólico
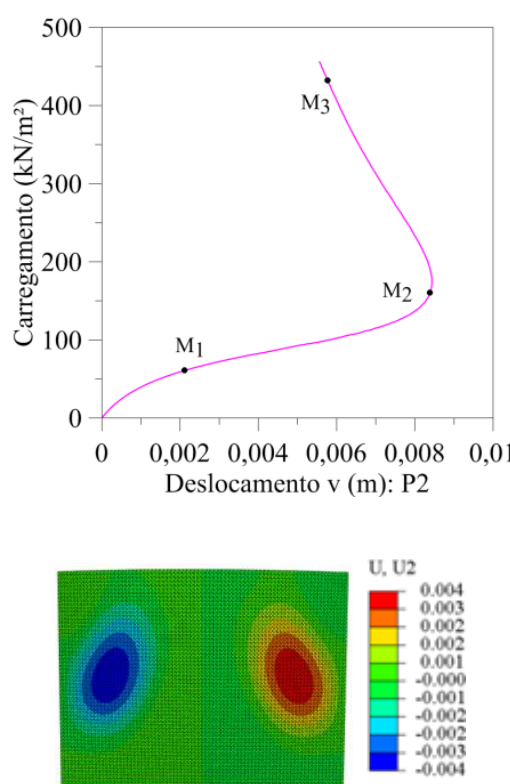

(b) $\mathrm{M}_{2}$

(c) $\mathrm{M}_{3}$

(a) $\mathrm{M}_{1}$
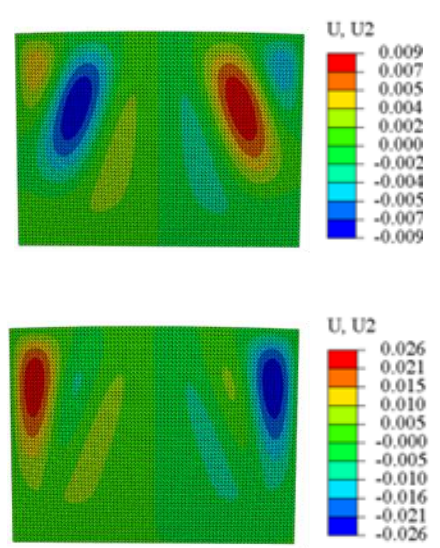

Caso cilíndrico
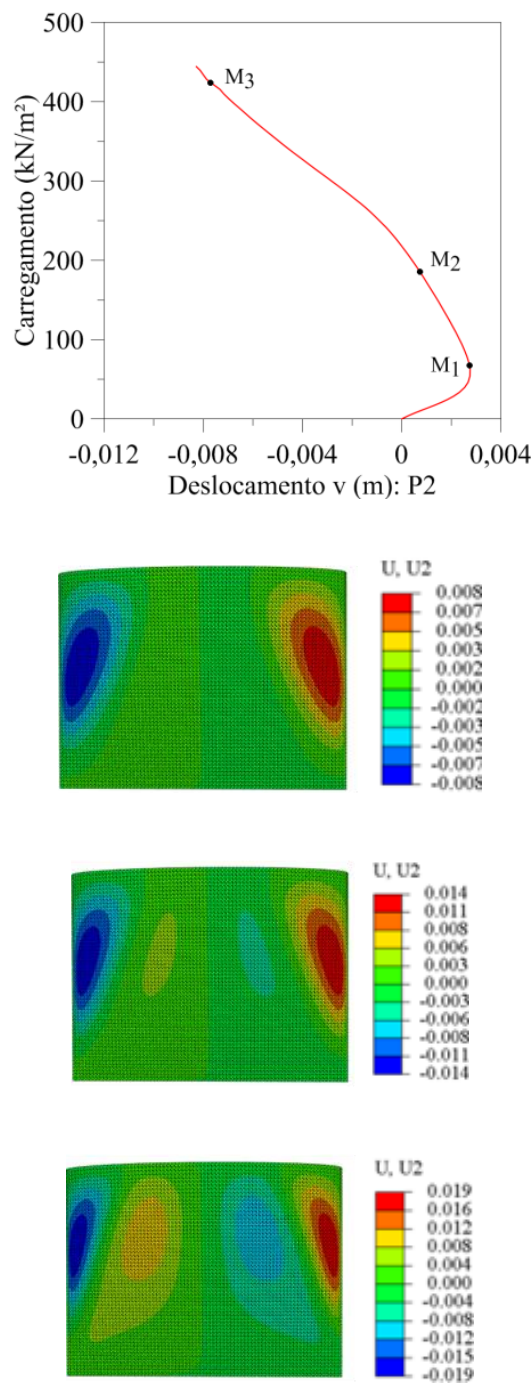

As trajetórias não-lineares de equilíbrio de um típico caso de painel de bordas curvas parabólicas, ou cilíndricas, formado pela Geometria 4, são apresentadas na Figura 4.12 considerando-se apoios indeslocáveis em suas quatro bordas. Para avaliar a influência da forma das bordas curvas dos conóides de Geometria 4 nas trajetórias de equilíbrio, foram utilizados os pontos de amostragem P1, P2, P3, P4 e P5 para os deslocamentos $u, v$ e $w$ e apresentados na Figura 4.1.

Observou-se na Figura 4.12, que o comportamento da casca conoidal com bordas cilíndricas é altamente não-linear quando comparado com a casca conoidal de bordas parabólicas. Notouse a partir das componentes dos campos de deslocamentos, tanto da geometria parabólica quanto cilíndrica, que a trajetória de equilíbrio apresenta claramente um ponto de perda da 
capacidade de carga e deslocamentos não nulos na maioria dos pontos de amostragem, com exceção os deslocamentos $u$ e $v$ no centro da casca conoidal, ponto P3. Destaca-se que as trajetórias de equilíbrio nos pontos de amostragem dos deslocamentos $w$ representam bem o comportamento dos conóides e sua magnitude apresenta superioridade em relação aos demais deslocamentos.

Figura 4.12- Trajetória não-linear de equilíbrio dos conóides de Geometria $4\left(\mathrm{~A}_{2} \mathrm{~A}_{2} \mathrm{~A}_{2} \mathrm{~A}_{2}\right.$ - parabólico $\mathrm{x}$ cilíndrico)
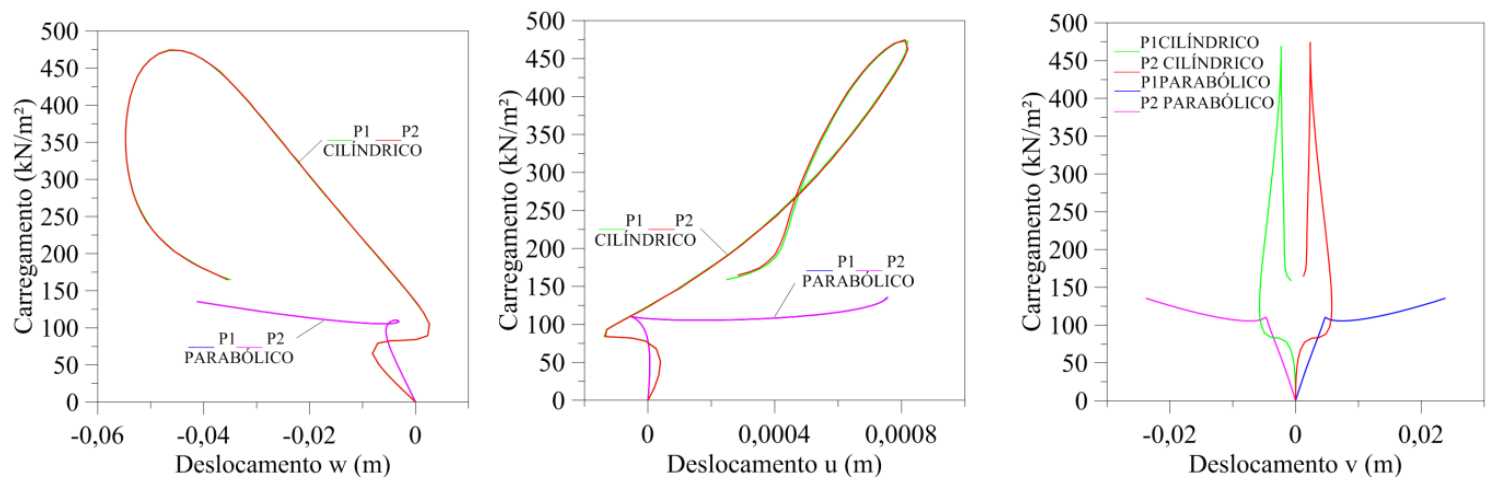

(a) P1 e P2
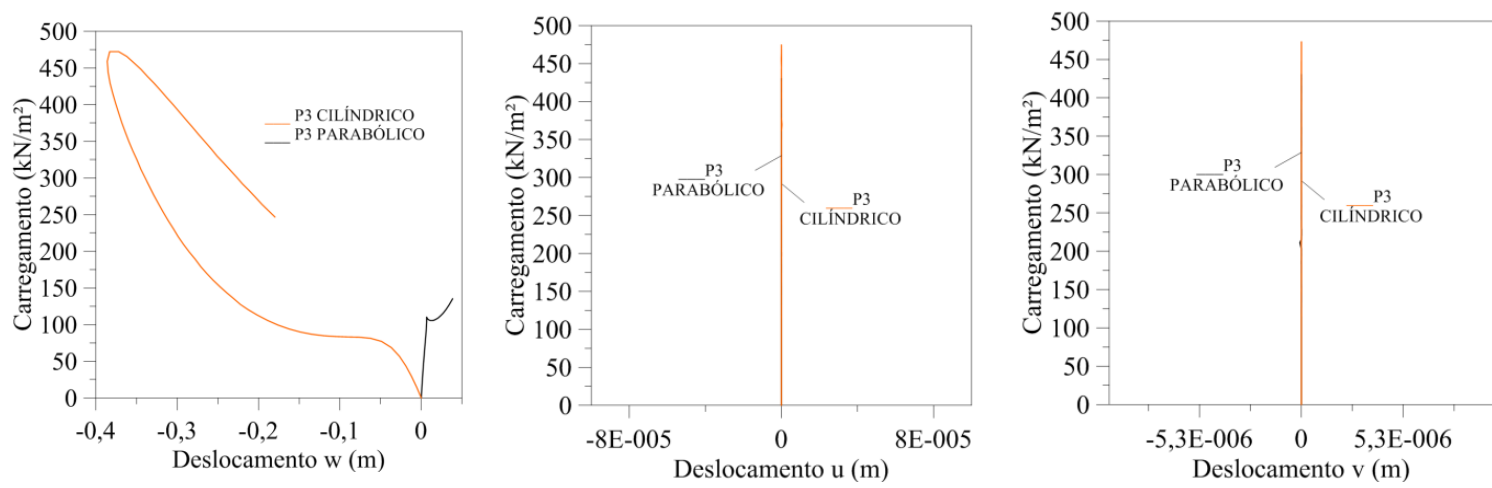

(b) P3
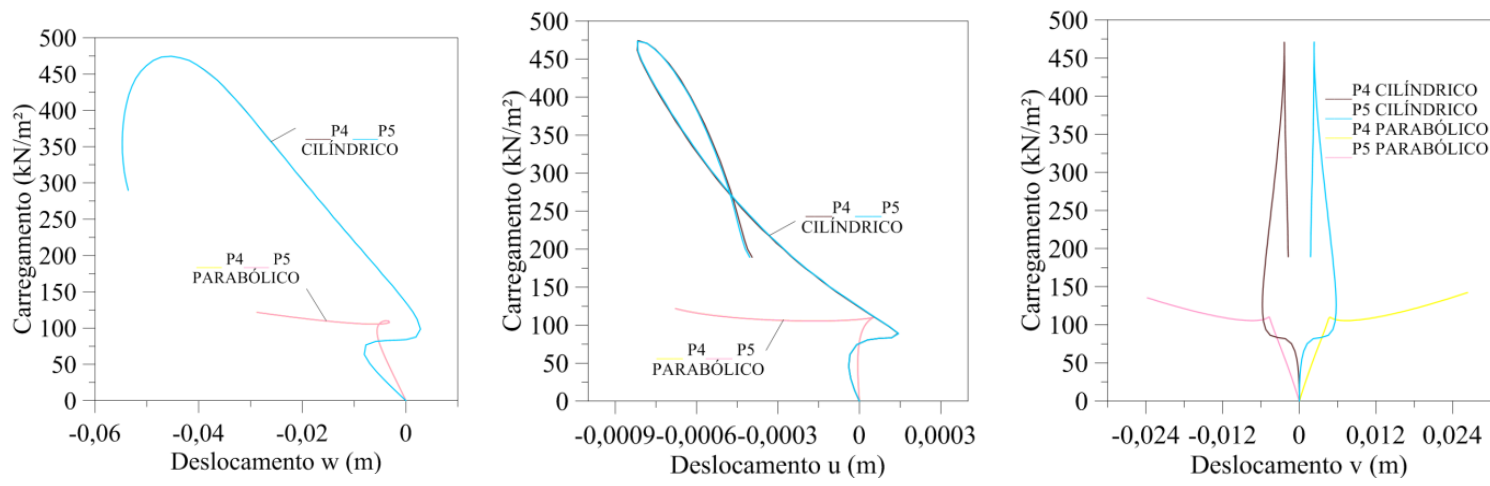

(c) P4 e P5 
São apresentadas nas Figuras 4.13 a 4.15, as formas deformadas dos campos de deslocamentos, amostrados em três pontos escolhidos ao longo das trajetórias não-lineares de equilíbrio, para ilustrar como as não-linearidades geométricas modificam os campos de deslocamentos $u, v$ e $w$, no início da trajetória, $\mathbf{M}_{1}$, no momento em que atinge o ponto limite, $\mathbf{M}_{2}$, e após o ponto limite, $\mathbf{M}_{3}$.

Figura 4.13- Modos de deslocamentos $w$ ao longo das trajetórias não-lineares de equilíbrio da Geometria 4 submetida ao apoio $\mathrm{A}_{2} \mathrm{~A}_{2} \mathrm{~A}_{2} \mathrm{~A}_{2}$

Caso parabólico

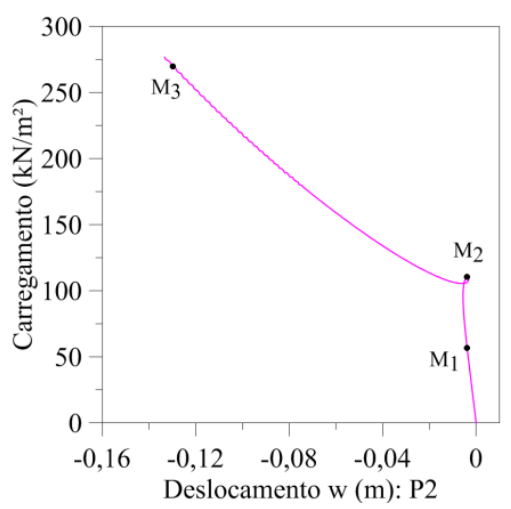

(a) $\mathrm{M}_{1}$

(b) $\mathrm{M}_{2}$

(c) $\mathrm{M}_{3}$
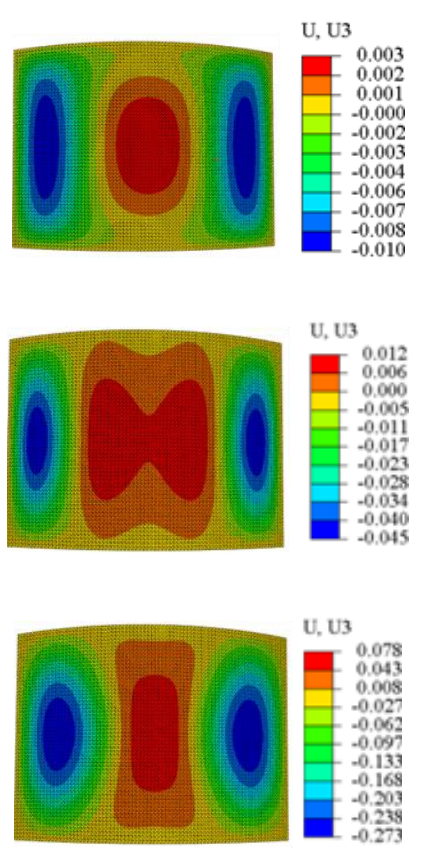
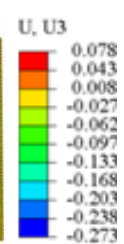

Caso cilíndrico
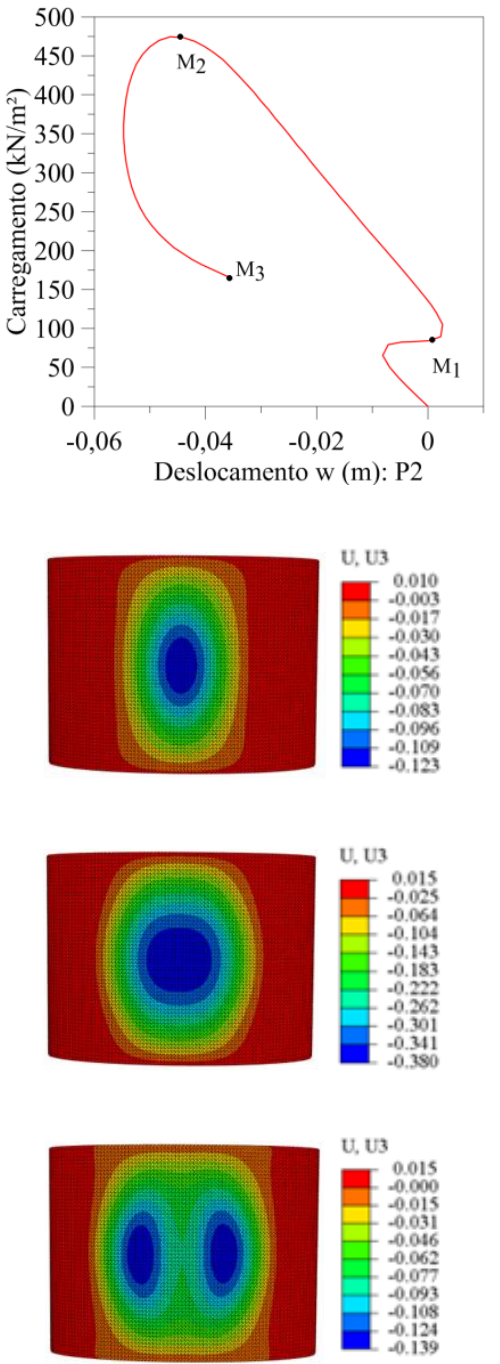

Devido à altura das bordas curvas serem iguais na Geometria 4 e o carregamento ser uniformemente distribuído ao longo da superfície dos conóides parabólicos e cilíndricos, observou-se na Figura 4.13, a simetria nos modos de deslocamento $w$ em torno do eixo $x$, com uma independência da coordenada axial. Estas simetrias são permanentes ao longo da trajetória de equilíbrio, o que pode ser visualizado a partir dos pontos $\mathrm{M}_{1}, \mathrm{M}_{2}$ e $\mathrm{M}_{3}$. Ao atingir 
a carga limite os modos $w$ não perdem a simetria na forma deslocada, o que pode ser verificado na Figura 4.12 ocorrendo a sobreposição dos pontos P1 e P2, Figura 4.12 (a), e também dos pontos P4 e P5, Figura 4.12 (c), em toda a trajetória de equilíbrio, além dos pontos P1 e P4 e P2 e P5 apresentarem os mesmos valores.

Notou-se a diferença entre as topologias parabólica e cilíndrica na Geometria 4 dividindo-se ao longo da trajetória em números diferentes de ondas circunferenciais. O caso cilíndrico iniciou a trajetória com três semi-ondas circunferenciais como ilustrado no ponto $\mathrm{M}_{1}$, Figura 4.13 (a), dividindo-se em quatro semi-ondas circunferenciais a medida que incrementou-se o carregamento, $\mathrm{M}_{2}$ e $\mathrm{M}_{3}$, Figuras 4.13 (b) e (c). Já a casca conoidal com bordas curvas parabólicas, iniciou a trajetória de equilíbrio, M1, com três semi-ondas circunferenciais, Figura 4.13 (a), dividindo-se em quatro máximos de semi-ondas ao atingir a carga limite, Figura 4.13 (b), voltando a apresentar três máximos de semi-ondas em $\mathrm{M}_{3}$, Figura 4.13 (c).

Além disso, observou-se uma diferença, entre as bordas curvas parabólicas e cilíndricas, para o campo de deslocamento $u$ da casca conoidal de Geometria 4. Apesar de manter os deslocamentos nulos no centro dos conóides, Figura 4.12 (b), o acoplamento modal que se desenvolve ao longo da trajetória de equilíbrio provocou uma divisão diferente no número de semi-ondas circunferenciais, como ilustram a Figuras 4.14 (a)-(c). Ainda, a partir da Figura 4.14, observou-se um comportamento simétrico na forma do campo de deslocamentos $u$ em torno do eixo $x$, sendo permanente ao longo de toda trajetória de equilíbrio, como pode ser visualizado através dos pontos $\mathrm{M}_{1}, \mathrm{M}_{2}$ e $\mathrm{M}_{3}$ da Figura 4.14 juntamente com a sobreposição dos pontos P1 e P2, Figura 4.12 (a), e dos pontos P4 e P5, Figura 4.12 (c).

Figura 4.14- Modos de deslocamentos $u$ ao longo das trajetórias não-lineares de equilíbrio da Geometria 4 submetida ao apoio $\mathrm{A}_{2} \mathrm{~A}_{2} \mathrm{~A}_{2} \mathrm{~A}_{2}$

Caso parabólico

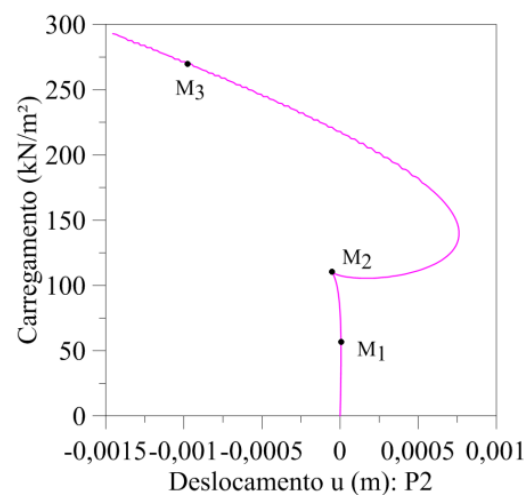

Caso cilíndrico

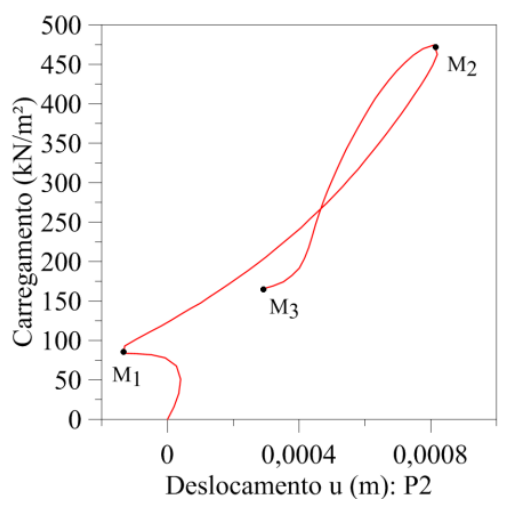


(a) $M_{1}$
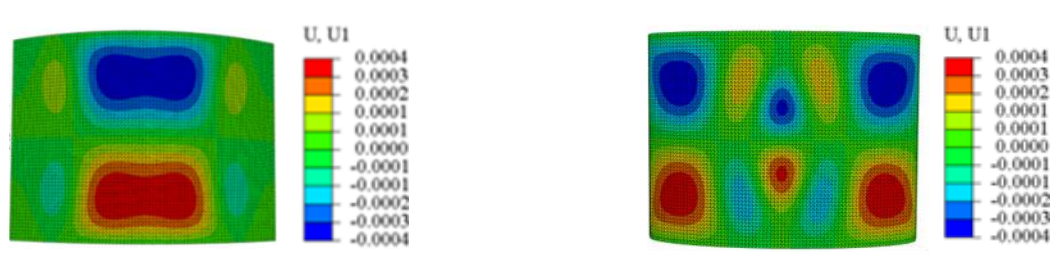

(b) $\mathrm{M}_{2}$
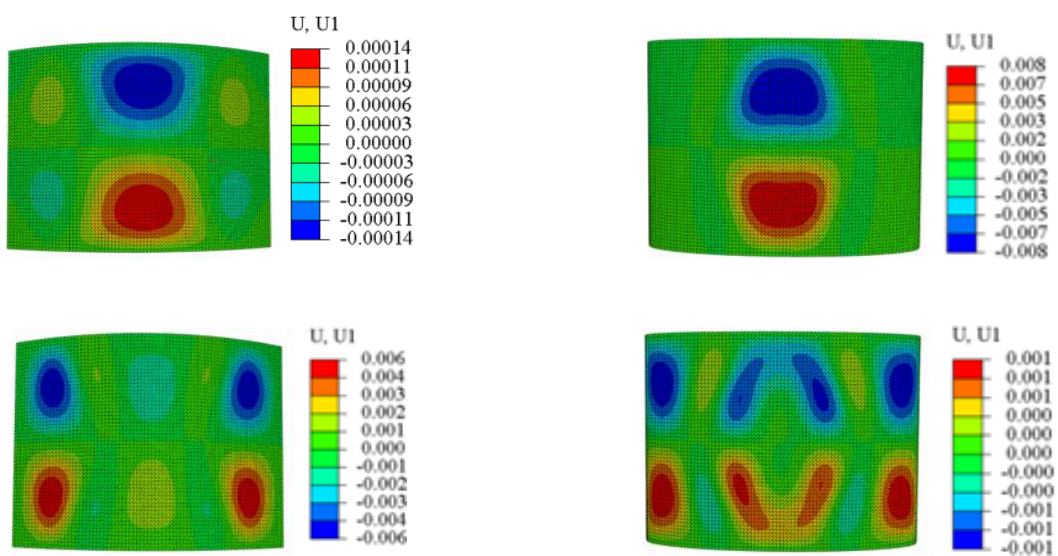

Quanto ao campo de deslocamentos $v$, Figura 4.15, notou-se a semelhança para esse campo de deslocamento entre os conóides de bordas parabólicas e cilíndricas de Geometria 4. Observou-se no início das trajetórias de equilíbrio, Figura 4.15 (a), duas semi-ondas circunferenciais anti-simétricas em torno do eixo axial $x$. Esta anti-simetria está presente ao longo da trajetória de equilíbrio estudada, o que pode ser visualizado através dos campos de deslocamentos $\mathrm{M}_{1}, \mathrm{M}_{2}$ e $\mathrm{M}_{3}$ da Figura 4.15 juntamente com a Figura 4.12. Verificou-se que os deslocamentos são nulos no centro, P3, dos dois casos de bordas curvas, e ainda, no decorrer da trajetória do conóide cilíndrico, houve o aparecimento de mais duas semi-ondas circunferenciais de pequena magnitude no centro, Figuras 4.15 (b) e (c).

Figura 4.15- Modos de deslocamentos $v$ ao longo das trajetórias não-lineares de equilíbrio da Geometria 4 submetida ao apoio $\mathrm{A}_{2} \mathrm{~A}_{2} \mathrm{~A}_{2} \mathrm{~A}_{2}$

Caso parabólico

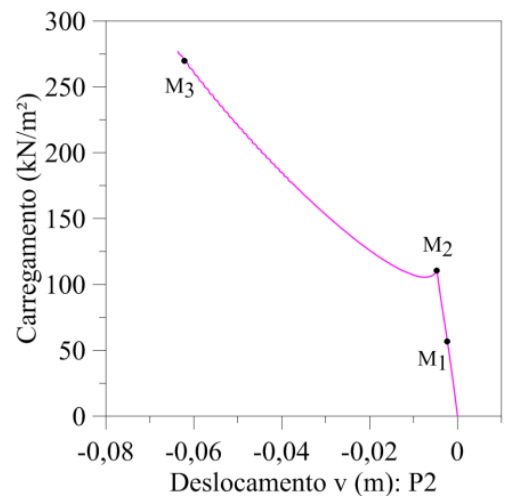

Caso cilíndrico

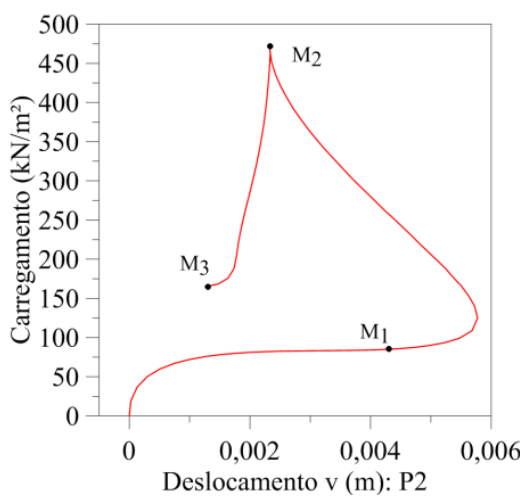


(a) $M_{1}$
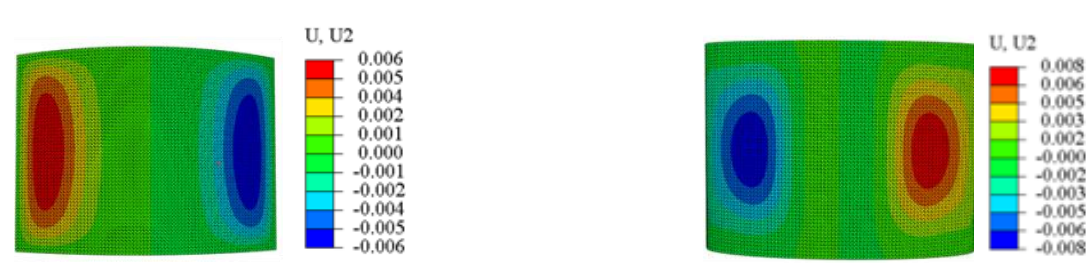

(b) $\mathrm{M}_{2}$
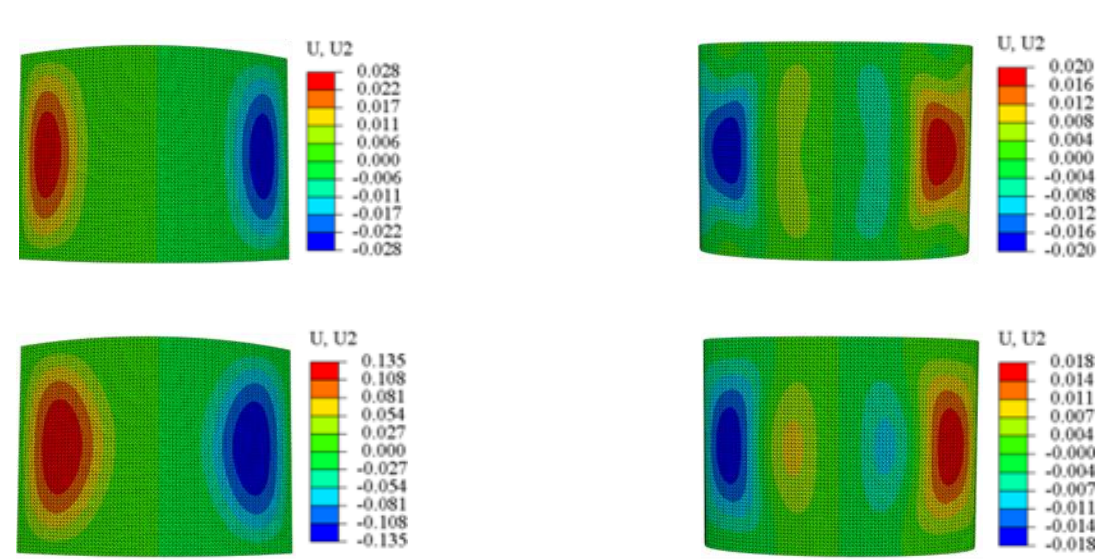

As geometrias submetidas ao apoio de segundo gênero em todas as bordas, com valores diferentes entre as alturas das bordas curvas, geraram semi-ondas circunferências fortemente dependentes da coordenada axial $x$. Quando as bordas curvas apresentam a mesma altura, ocorre uma independência das ondas circunferências da coordenada axial $x$.

Finalizando este item, nas Figuras 4.16 e 4.17, compararam-se as topologias dos modos de flambagem lineares e os modos dos campos de deslocamentos não-lineares na posição referente à carga limite, $\mathrm{M}_{2}$, tanto dos casos parabólicos quanto dos casos cilíndricos, pois para efetuar as análises não-lineares no programa ABAQUS 6.11® utilizam-se como perturbação inicial, porcentagens dos modos de flambagem do respectivo modelo. Verificouse que, mesmo utilizando-se os primeiros modos de flambagem lineares, as formas dos deslocamentos do conóide de Geometria 1, ou Geometria 4, percorrem caminhos não-lineares não apresentando coincidência com a forma do modo de flambagem ao atingir a carga limite, indicando-se grande influência das não-linearidades geométricas. 
Figura 4.16- Influência da variação das Geometrias na condição de contorno $\mathrm{A}_{2} \mathrm{~A}_{2} \mathrm{~A}_{2} \mathrm{~A}_{2}$ do conóide parabólico

$w$
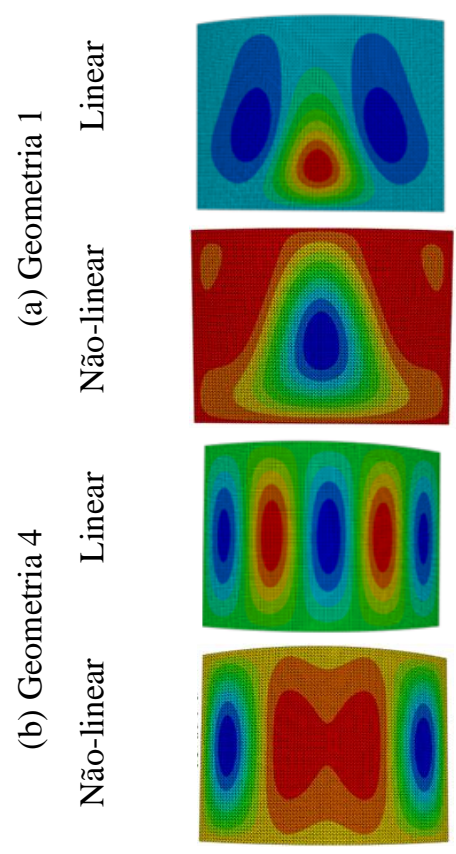

$v$
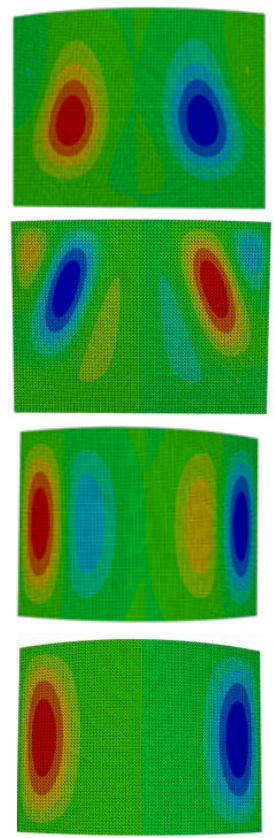

$u$
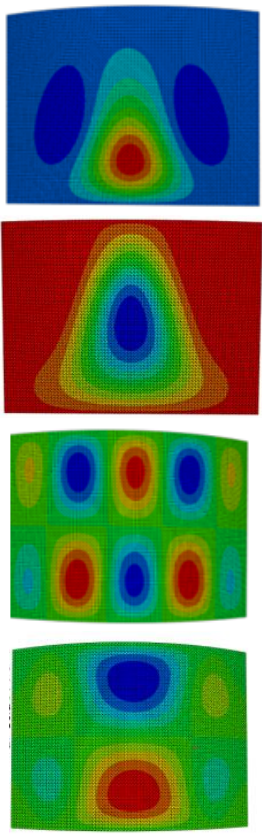

Figura 4.17- Modo de flambagem Influência da variação das Geometrias na condição de contorno $\mathrm{A}_{2} \mathrm{~A}_{2} \mathrm{~A}_{2} \mathrm{~A}_{2}$ do conóide cilíndrico

$w$
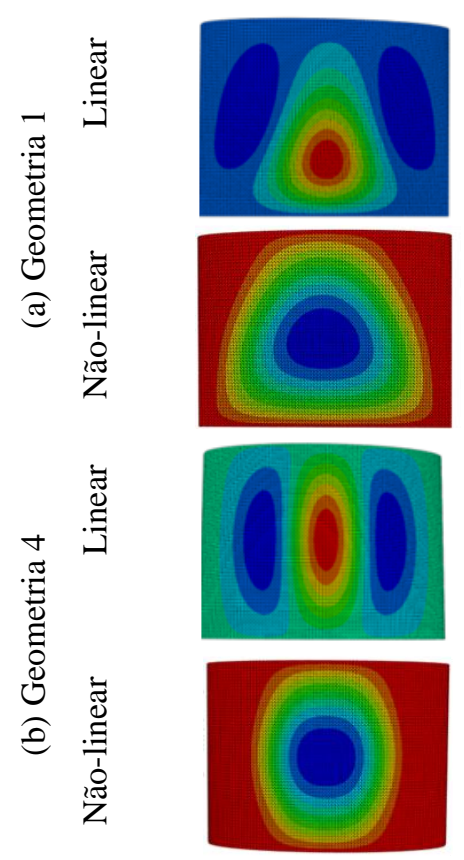

$v$
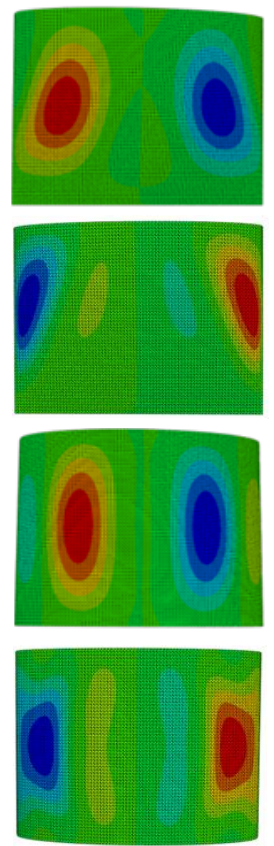

$u$
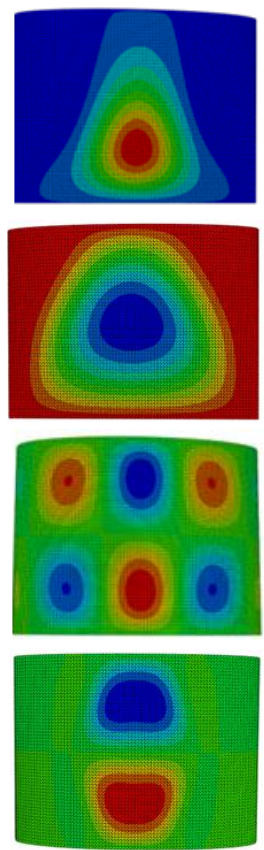


\subsection{INFLUÊNCIA DA IMPERFEIÇÃO GEOMÉTRICA INICIAL}

Imperfeições geométricas iniciais influenciam no comportamento das cascas conoidais e podem ser introduzidas por perturbações na geometria indeformada da casca. Essa perturbação pode assumir a forma de algum modo de flambagem e a magnitude do seu fator de escala influencia na resposta da trajetória de equilíbrio não-linear.

Com objetivo de avaliar a influência do fator de escala da perturbação nos resultados das trajetórias não-lineares de equilíbrio via MEF, nas Figuras 4.18 e 4.19 ilustram-se o estudo do fator de escala realizado nas Geometrias 1, 2, 3 e 4, considerando as bordas curvas parabólicas, ou cilíndricas, com apoios indeslocáveis em suas quatro bordas. Aplicaram-se imperfeições modais com a forma do primeiro modo de flambagem linear com magnitudes de $1 \%, 10 \%$ e $20 \%$ da espessura da casca conoidal.

Figura 4.18- Influência da imperfeição geométrica inicial (Modelo parabólico com apoios $\mathrm{A}_{2} \mathrm{~A}_{2} \mathrm{~A}_{2} \mathrm{~A}_{2}$ )
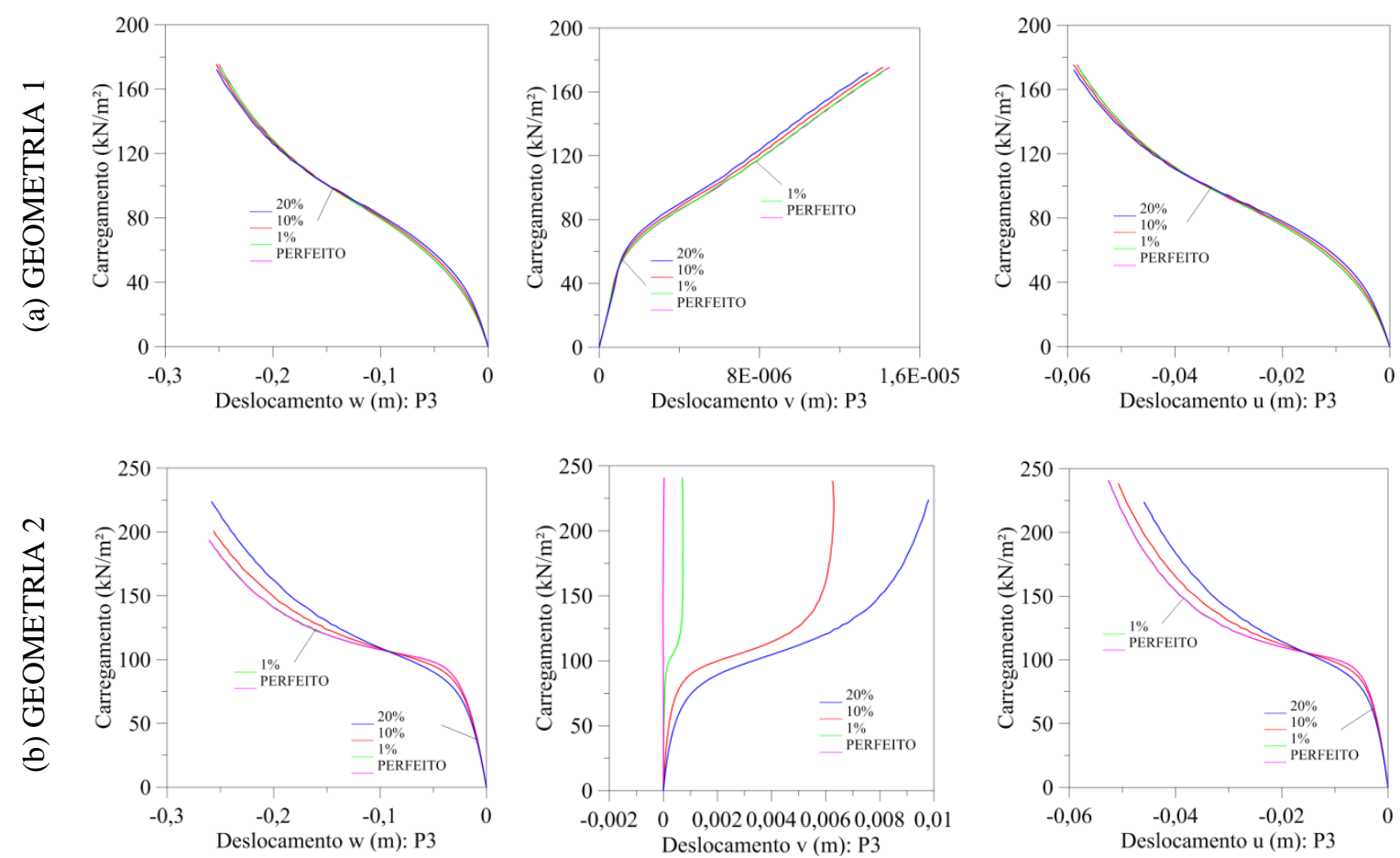

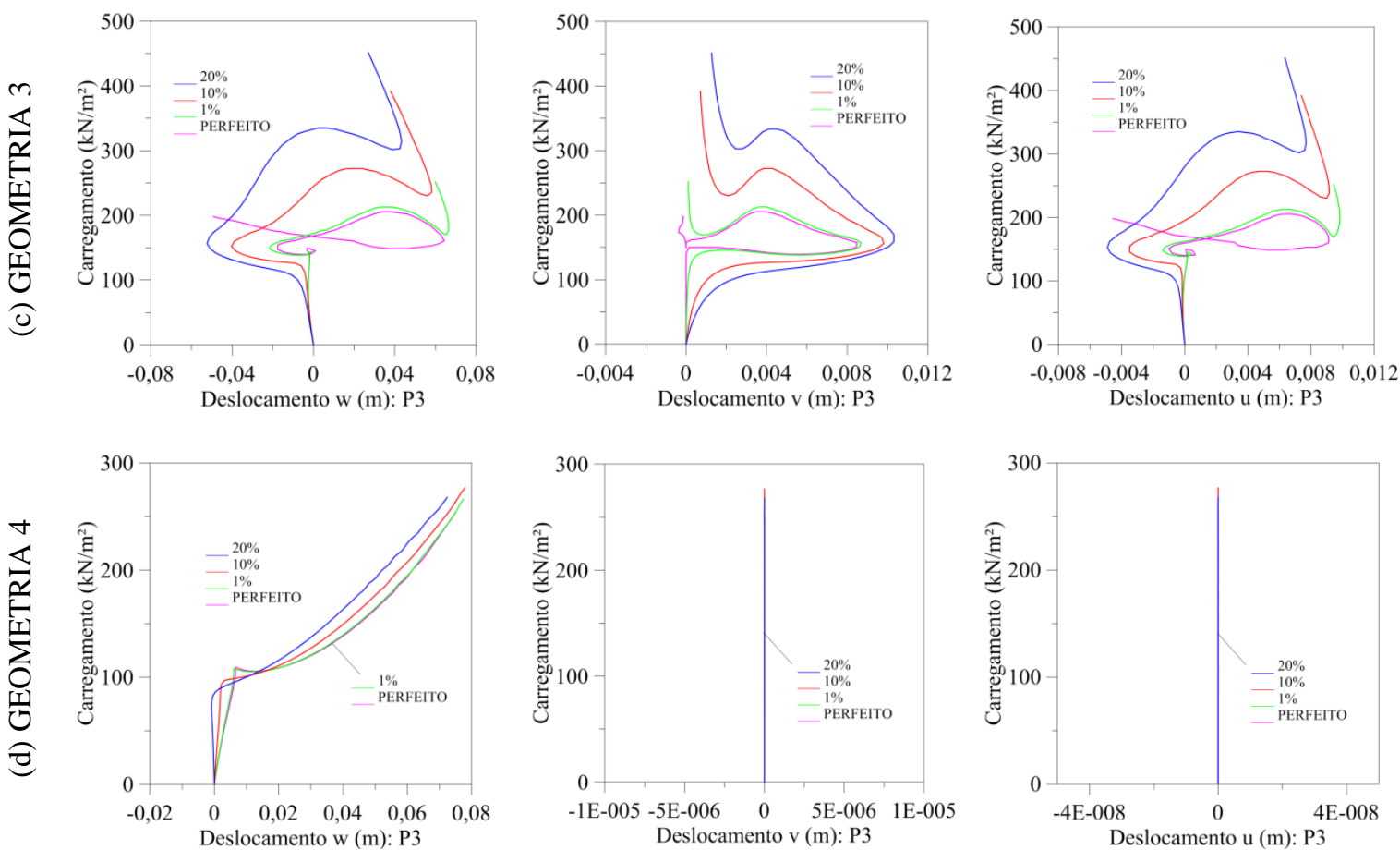

Figura 4.19- Influência da imperfeição geométrica inicial (Modelo cilíndrico com apoios $\mathrm{A}_{2} \mathrm{~A}_{2} \mathrm{~A}_{2} \mathrm{~A}_{2}$ )
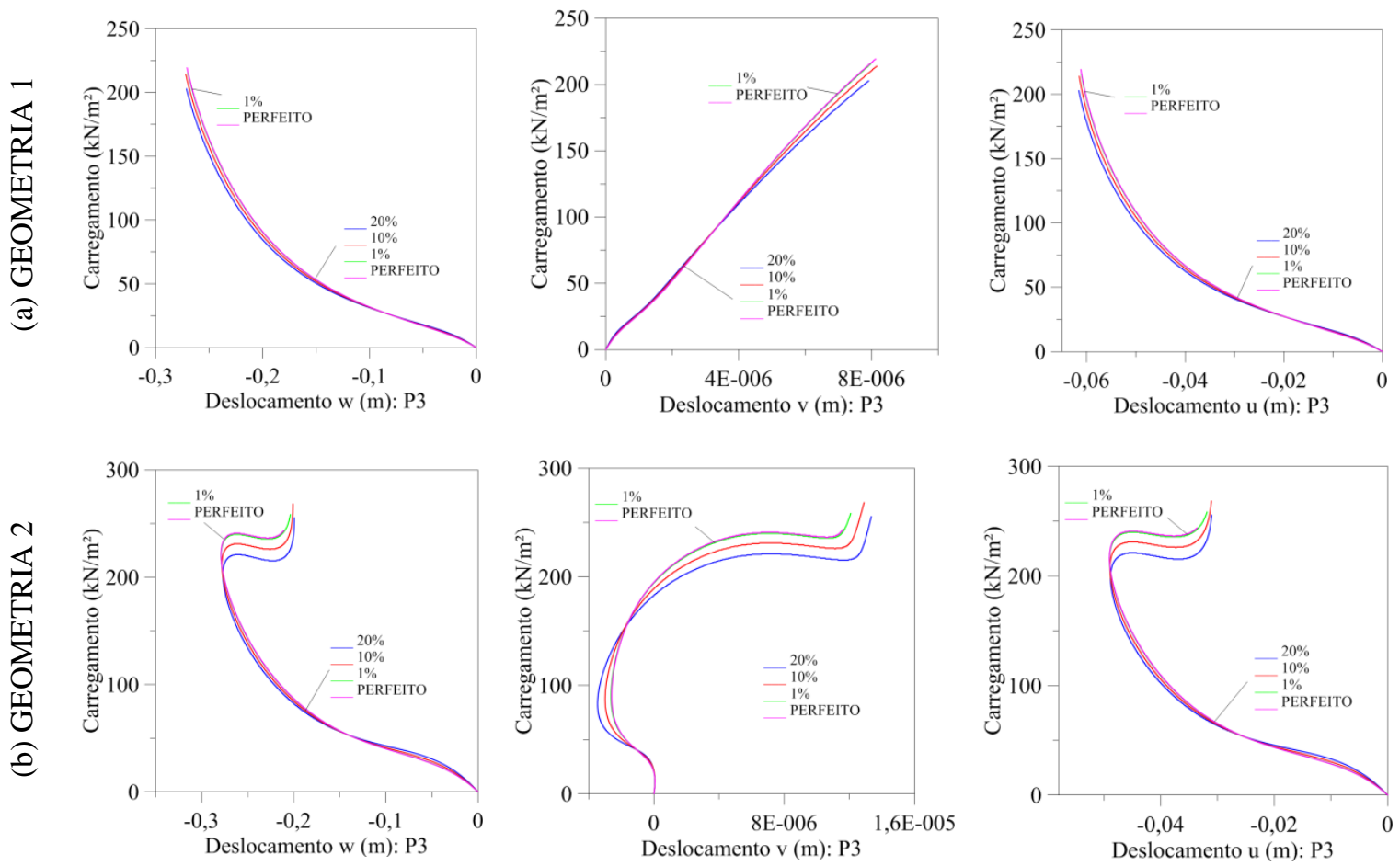

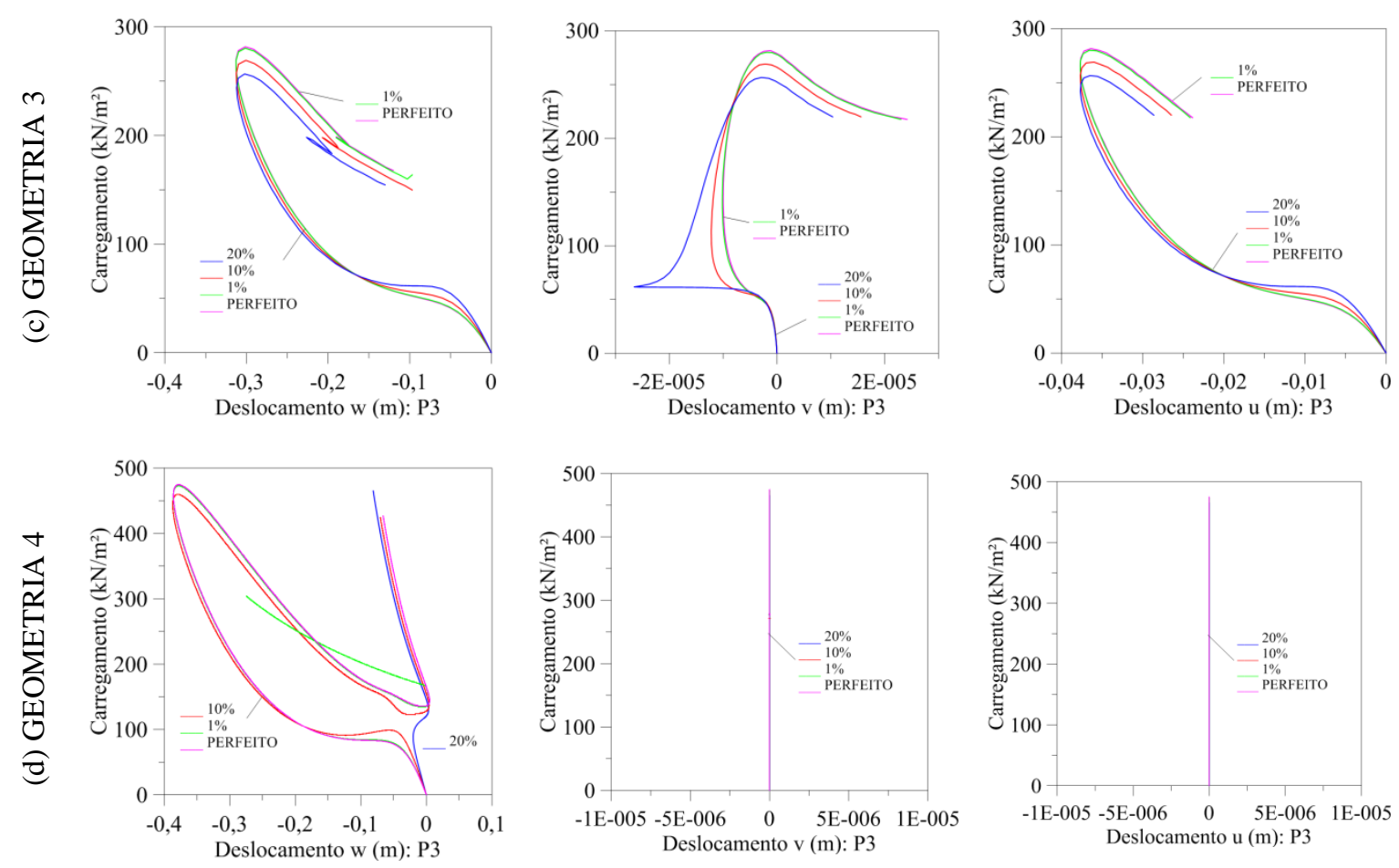

Os conóides de Geometria 1, Figuras 4.18 (a) e 4.19 (a), apresentaram pouca sensibilidade ao nível de imperfeição inicial com os resultados convergindo para a resposta do conóide perfeito. Na trajetória de equilíbrio do campo de deslocamento $w$, ponto P3 do conóide de Geometria 4 com bordas curvas cilíndricas, Figura 4.19 (d), verificou-se a influência da imperfeição geométrica para avaliar os resultados não-lineares, pois a aplicação de uma imperfeição geométrica de $20 \%$ da espessura gerou uma trajetória do deslocamento $w$ com um traçado diferente dos ouros níveis de imperfeições utilizadas. Já nas porcentagens de $10 \%$ e $1 \%$, as trajetórias de equilíbrio assemelham-se ao da casca considerada perfeita.

Nas Figuras 4.18 (b) e (c) e 4.19 (b) e (c), observou-se que os conóides de Geometrias 2 e 3 com bordas curvas parabólicas, ou cilíndricas, tem grande sensibilidade ao fator de escala nos deslocamentos $u, v$ e $w$ indicando forte interação do modo da imperfeição geométrica inicial no comportamento não-linear da casca conoidal.

\subsection{VARIAÇÃO DOS EFEITOS DE MEMBRANA E DE FLEXÃO AO LONGO DA TRAJETÓRIA DE EQUILÍBRIO}

Uma análise relevante para projetos de coberturas de grandes vãos em cascas conoidais é a variação dos esforços internos de membrana e das resultantes de flexão. Nesta seção, avaliou- 
se a influência da variação das alturas das bordas curvas parabólicas, ou cilíndricas, dos conóides na variação dos esforços de membrana e dos momentos internos, considerando as cascas conoidais de Geometria 1 e 4 com a condição de contorno $\mathrm{A}_{2} \mathrm{~A}_{2} \mathrm{~A}_{2} \mathrm{~A}_{2}$. Para este estudo utilizou-se o ponto de observação $\mathrm{P}_{3}$ localizado no centro dos conóides, além dos pontos de observação na trajetória de equilíbrio denominados $M_{1}, M_{2}$ e $M_{3}$ posicionados de forma a ilustrar os esforços na mesma coordenada de carregamento para as Geometrias 1 e 4.

Nas Figuras 4.20 e 4.21, são apresentadas as variações do momento de torção, $M_{x y}$, das cascas conoidais com bordas curvas parabólicas, ou cilíndricas, respectivamente.

Figura 4.20- Trajetória não-linear de $\mathrm{M}_{\mathrm{xy}}$ dos conóides parabólicos de condição de contorno $\mathrm{A}_{2} \mathrm{~A}_{2} \mathrm{~A}_{2} \mathrm{~A}_{2}$

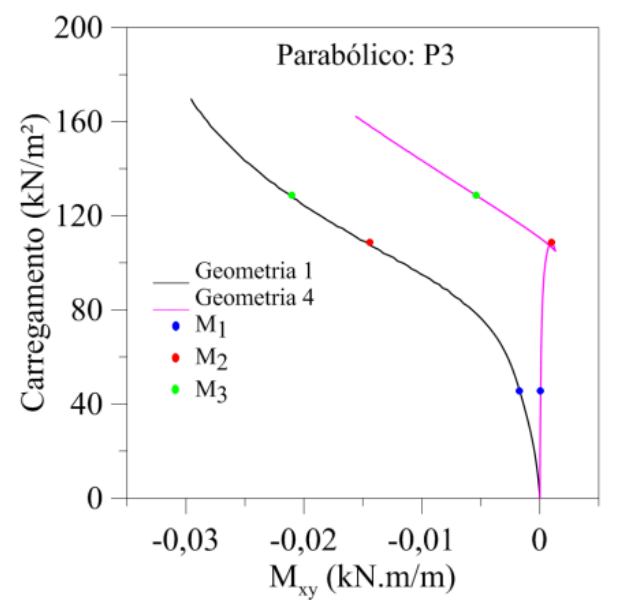

Geometria 1

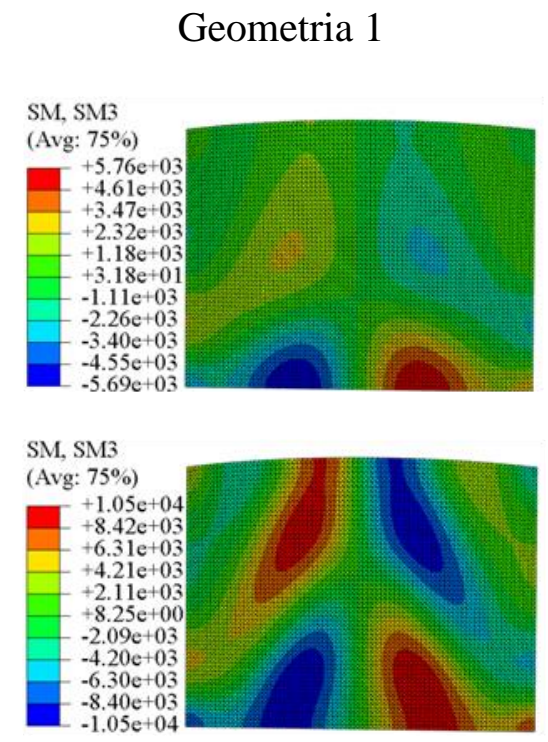

(b) $\mathrm{M}_{2}$

(a) $\mathrm{M}_{1}$

Geometria 4
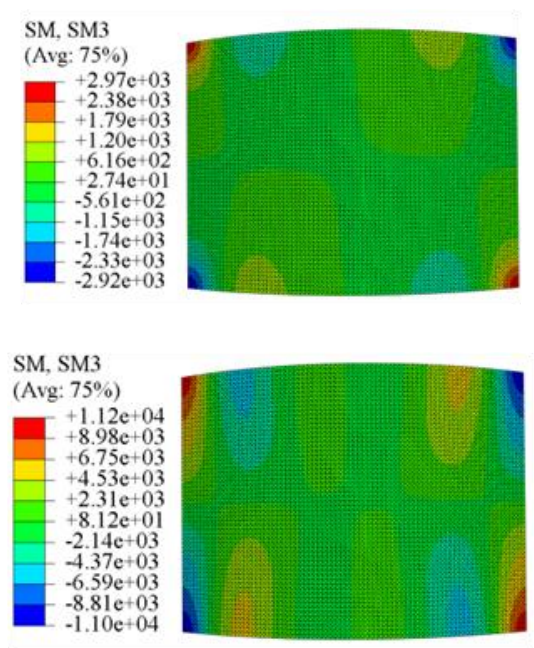
(c) $\mathrm{M}_{3}$
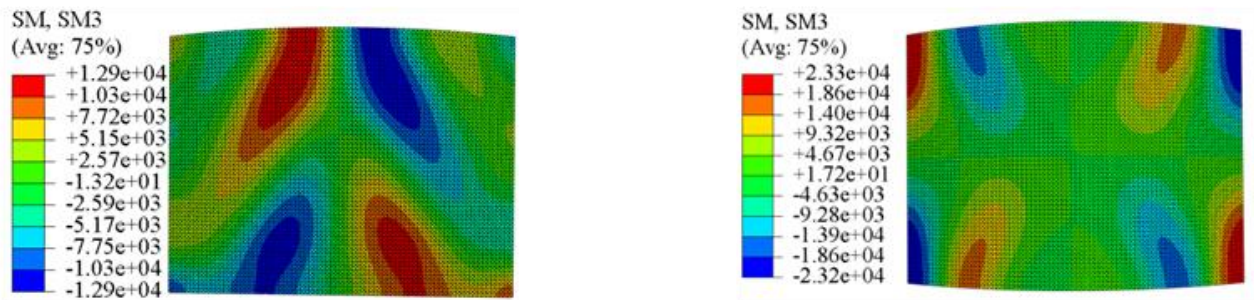

Figura 4.21- Trajetória não-linear de $\mathrm{M}_{\mathrm{xy}}$ do conóide cilíndrico de condição de contorno $\mathrm{A}_{2} \mathrm{~A}_{2} \mathrm{~A}_{2} \mathrm{~A}_{2}$

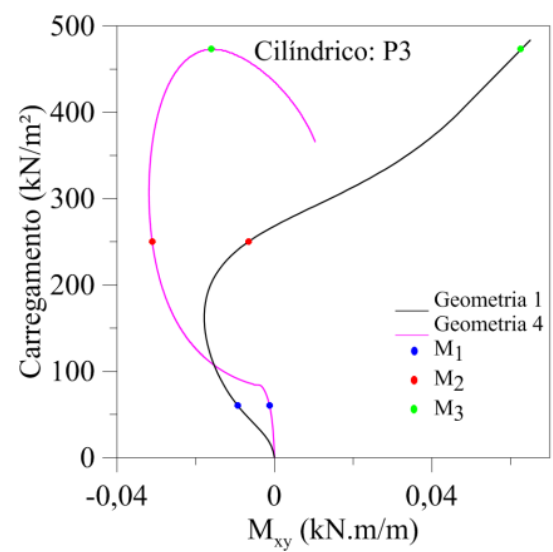

Geometria 1
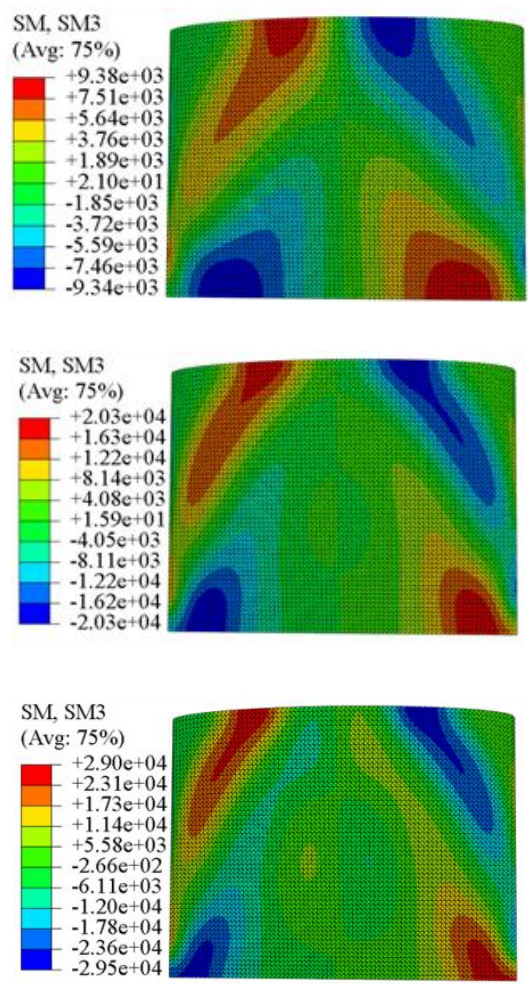

Geometria 4
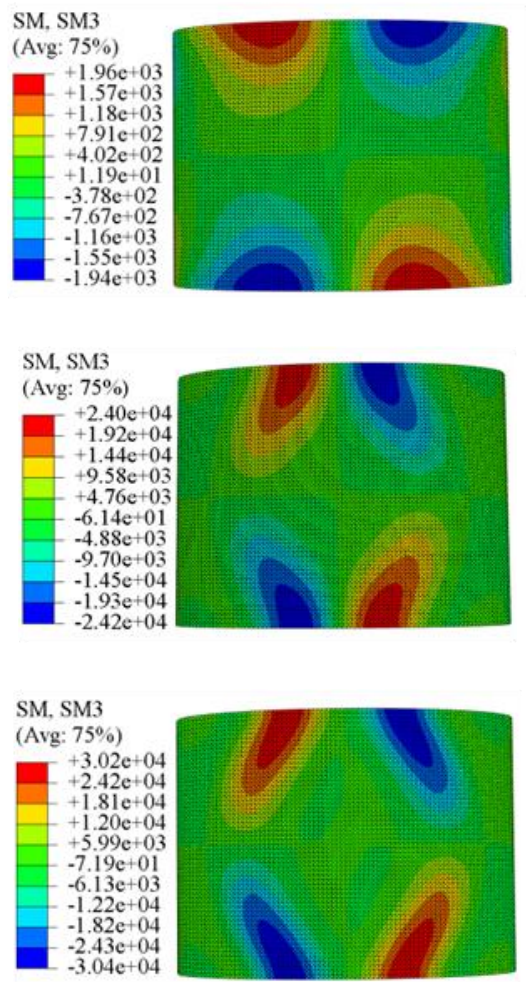

Observou-se que os momentos torçores, no início do carregamento, são distribuídos de forma praticamente uniforme na parte central das cascas conoidais, Figuras 4.20 (a) e 4.21 (a) e uma concentração de momentos torçores próxima as bordas curvas dos conóides. No caso do 
conóide parabólico de Geometria 1 os momentos torçores são de maior intensidade na borda de curva de menor altura no início do carregamento, $\mathrm{H}_{1}$. Porém, com o incremento de carga, esses valores de torçores adquirem intensidade na borda curva $\mathrm{H}_{2}$, com anti-simetria em torno do eixo $x$. Também observou-se no conóide de Geometria 4 uma anti-simetria na distribuição dos esforços torçores da casca em torno dos eixos $x$ e $y$, devido a igualdade entre as alturas das bordas curvas. Entretanto, a princípio, ocorreu uma pequena concentração desse esforço nas bordas curvas próxima aos cantos do conóide, aumentando esta concentração no decorrer da trajetória.

Nas trajetórias não-lineares dos momentos torçores dos conóides cilíndricos, Figura 4.21, observou-se que os momentos torçores se distribuem de forma anti-simétrica, em torno do eixo $x$, como apresentado para a casca conoidal parabólica, mas com a concentração de esforços torçores ocorrendo nas extremidades que possuem a borda curva. Além disso, percebeu-se que os momentos torçores internos atuantes nos conóides de Geometria 4, de bordas curvas cilíndricas, apresentaram valores mais altos que o conóide de Geometria 1 cilíndrico quando se incrementou o carregamento.

A partir das Figuras 4.20 e 4.21 observou-se que o incremento de carregamento provocou nos conóides de Geometria 1 maiores distribuições de momento torçor pela superfície do conóide devido à inclinação que surge entre as borda curvas.

Figura 4.22- Trajetória não-linear de $\mathrm{M}_{\mathrm{x}}$ do parabólico de condição de contorno $\mathrm{A}_{2} \mathrm{~A}_{2} \mathrm{~A}_{2} \mathrm{~A}_{2}$

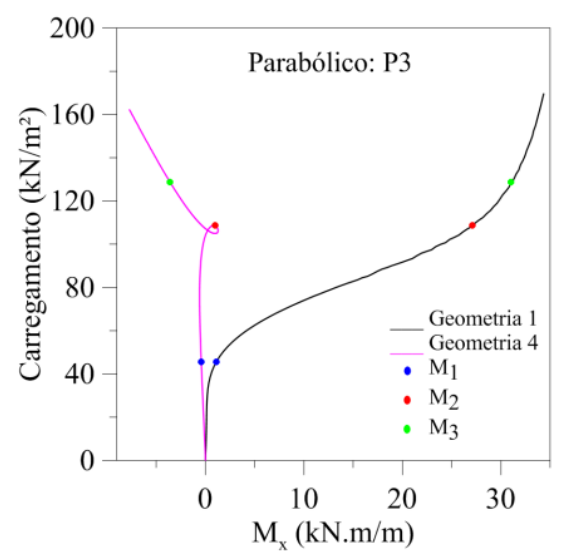


Geometria 1

(a) $\mathrm{M}_{1}$

(b) $\mathrm{M}_{2}$

(c) $\mathrm{M}_{3}$
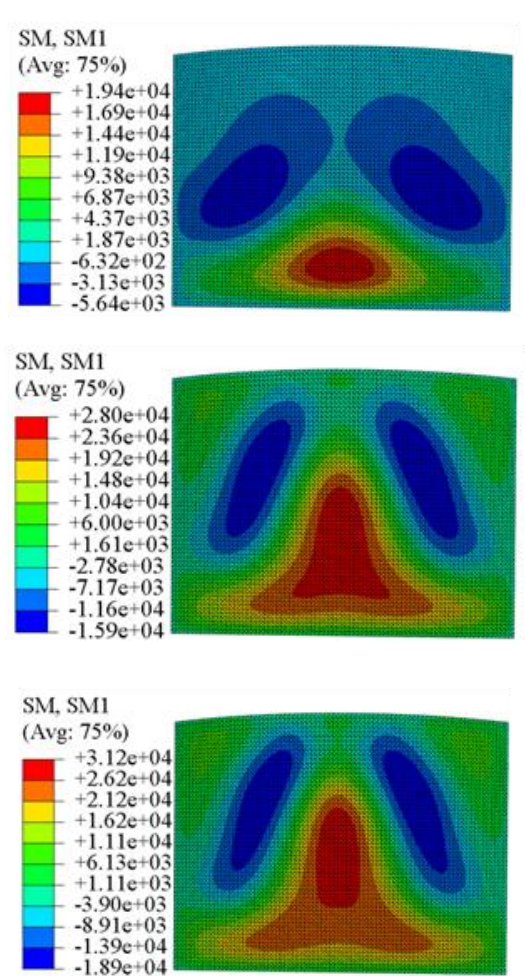

Geometria 4
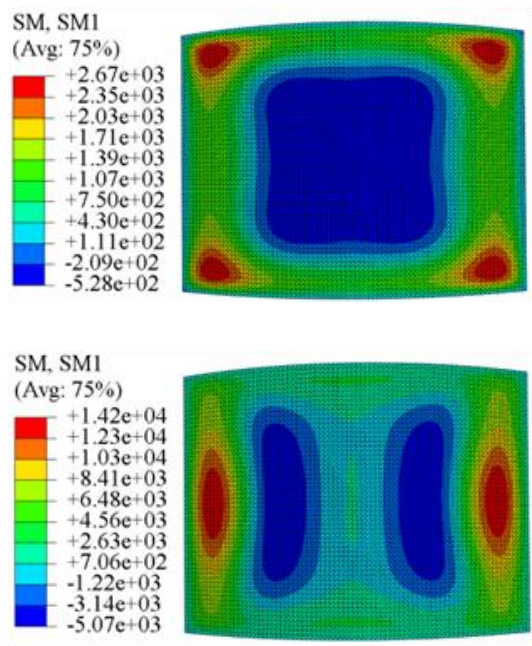

SM, SMI

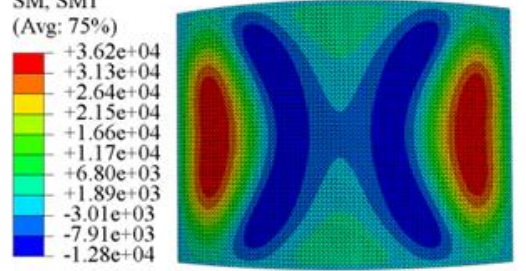

Apresentam-se nas Figuras 4.22 e 4.23 as trajetórias não-lineares das resultantes de momento fletor $M_{x}$ com o incremento do carregamento para os conóides parabólicos e cilíndricos. Observou-se que a distribuição do momento fletor $M_{x}$ é simétrica, em torno do eixo $x$, independentemente da geometria e da forma da borda curva. Porém, notou-se, na Figura 4.22, que na Geometria 1 há uma distribuição mais proporcional entre os momentos positivos e os momentos negativos ao longo da superfície do conóide quando comparada a Geometria 4, que apresenta uma predominância de momentos negativos com o incremento do carregamento. Já para o conóide cilíndrico, Figura 4.23, deve-se destacar que a Geometria 1, diferentemente do conóide parabólico, apresentou uma predominância dos momentos fletores positivos e para a Geometria 4 há uma distribuição proporcional entre valores positivos e negativos do momento fletor $M_{x}$. Ainda sobre a variação do momento fletor $M_{x}$ é importante destacar que, independentemente da forma da borda curva, nos conóides de Geometria 1 foi identificada uma assimetria, bem como simetria para as Geometrias 4, na distribuição ao longo do eixo $x$. 
Figura 4.23- Trajetória não-linear de $\mathrm{M}_{\mathrm{x}}$ do conóide cilíndrico de condição de contorno $\mathrm{A}_{2} \mathrm{~A}_{2} \mathrm{~A}_{2} \mathrm{~A}_{2}$

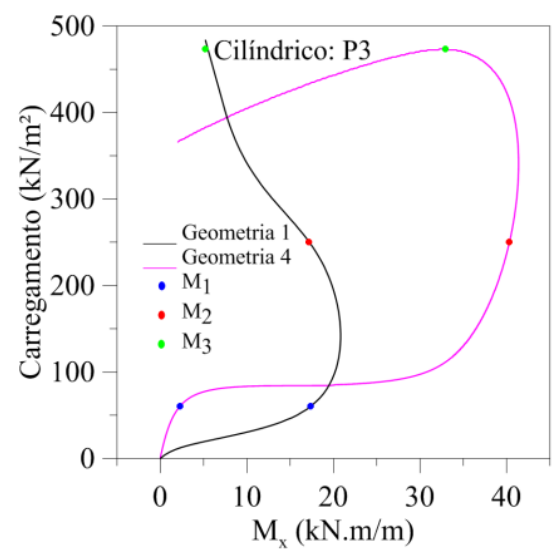

Geometria 1

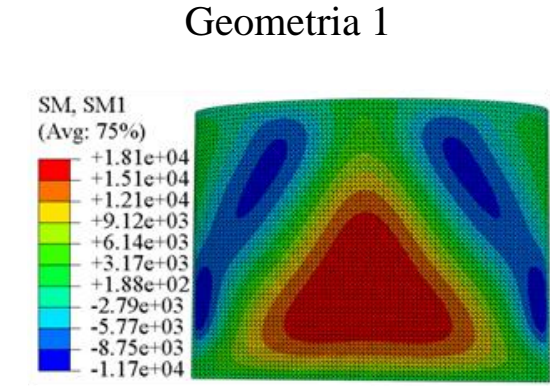

(b) $\mathrm{M}_{2}$

(c) $\mathrm{M}_{3}$

(a) $\mathrm{M}_{1}$
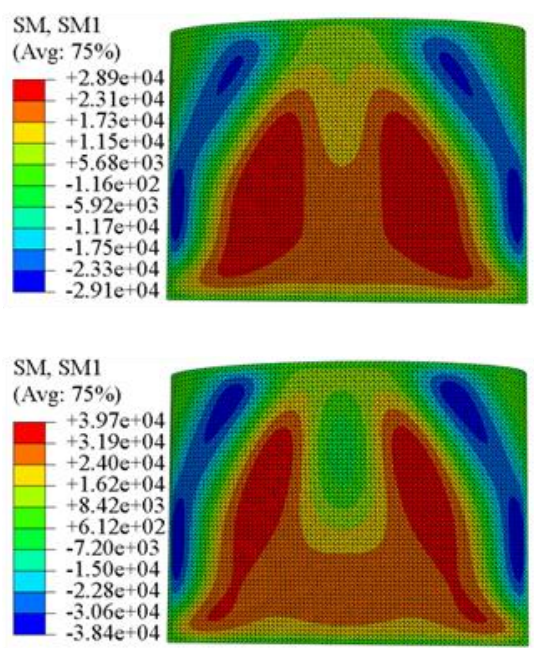

Geometria 4
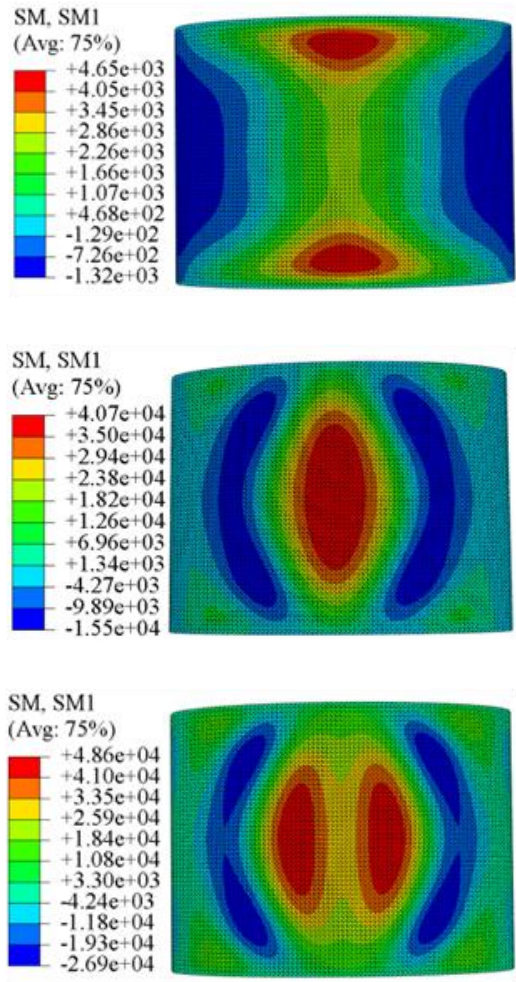

Nas Figuras 4.24 e 4.25, são apresentados os caminhos não-lineares das resultantes de flexão $M_{y}$ das cascas conoidais parabólicas e cilíndricas, respectivamente, ao longo do processo de carregamento transversal. A mesma observação sobre a distribuição do momento $M_{x}$ ao longo da superfície do conóide pode ser feita para a distribuição do momento fletor $M_{y}$, ou seja, há uma distribuição simétrica do momento fletor $M_{y}$ em torno do eixo $x$, independentemente da geometria e da forma da borda curva. Porém, notou-se, na Figura 4.24, que as Geometrias 1 e 4 apresentaram uma distribuição proporcional entre os momentos positivos e os momentos negativos. Essa distribuição proporcional de momentos positivos e negativos também se 
repetiu para conóide cilíndrico de Geometria 4. A exceção foi o conóide cilíndrico de Geometria 1 que teve a predominância de momentos positivos para os diferentes níveis de carregamento, como ilustra a Figura 4.25.

Figura 4.24- Trajetória não-linear de $\mathrm{M}_{\mathrm{y}}$ do conóide parabólico de condição de contorno $\mathrm{A}_{2} \mathrm{~A}_{2} \mathrm{~A}_{2} \mathrm{~A}_{2}$

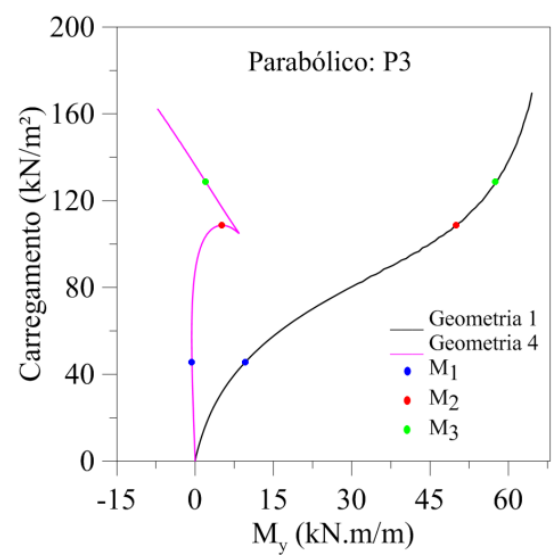

Geometria 1

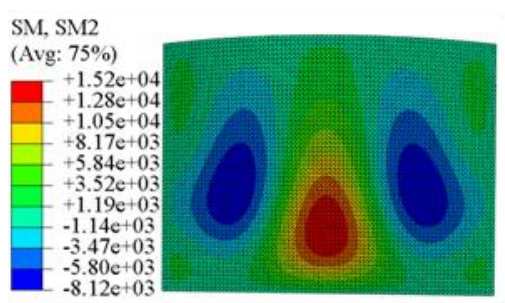

(b) $\mathrm{M}_{2}$

(c) $\mathrm{M}_{3}$

(a) $\mathrm{M}_{1}$
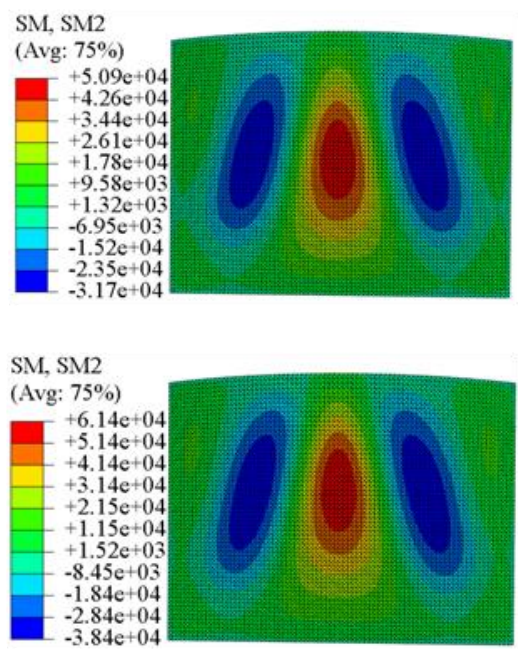

Geometria 4
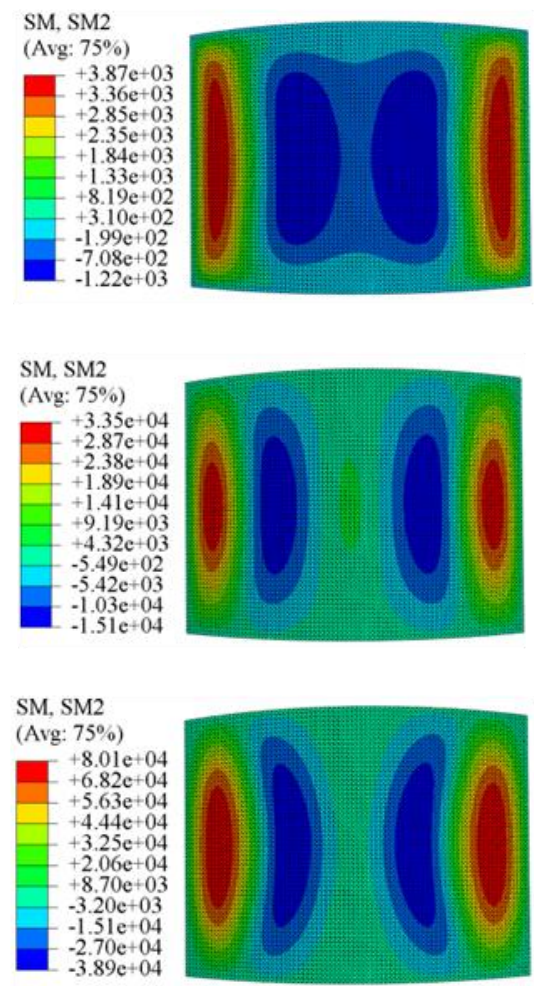
Figura 4.25- Trajetória não-linear de $\mathrm{M}_{\mathrm{y}}$ do conóide cilíndrico de condição de contorno $\mathrm{A}_{2} \mathrm{~A}_{2} \mathrm{~A}_{2} \mathrm{~A}_{2}$

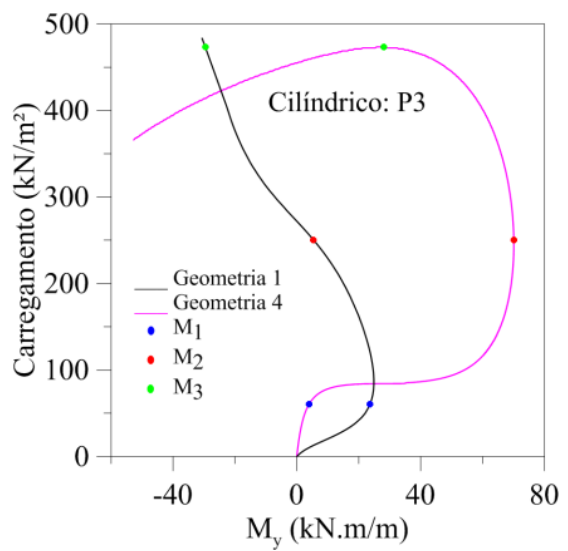

Geometria 1

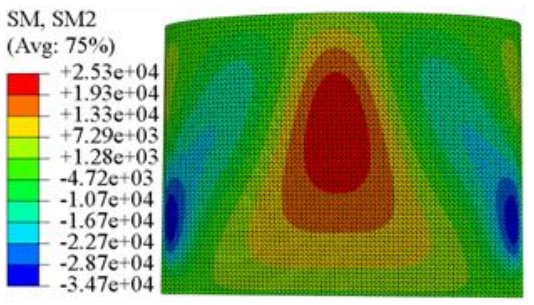

(b) $\mathrm{M}_{2}$

(c) $\mathrm{M}_{3}$

(a) $\mathrm{M}_{1}$

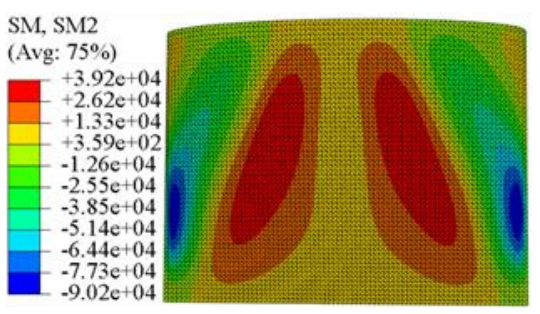

Geometria 4
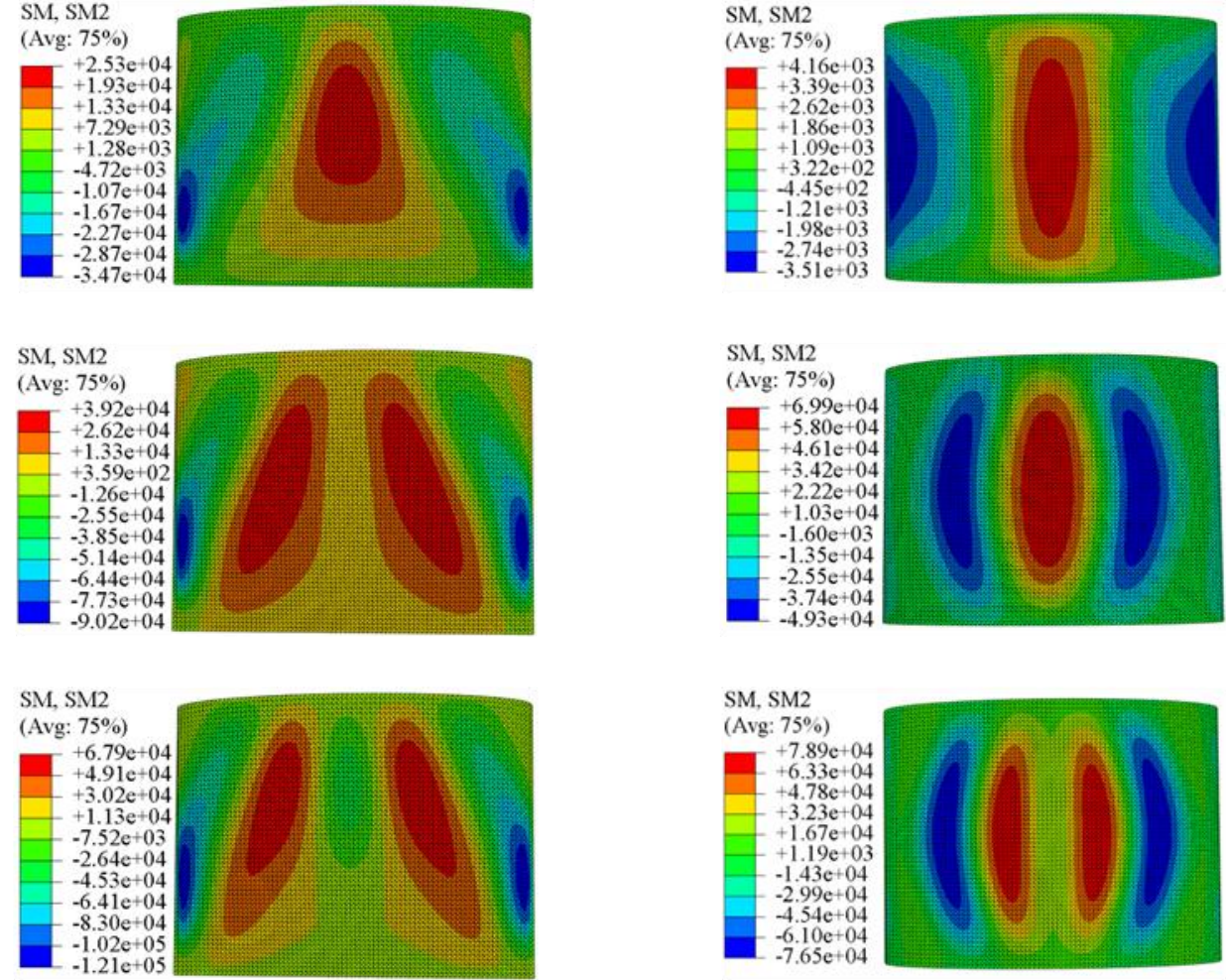

Além dos momentos internos, de flexão e de torção, os conóides analisados estão submetidos também a esforços de membrana gerando-se compressão, ou tração, e cisalhamento em pontos diferentes da superfície. Verificou-se a distribuição dos esforços normais e cisalhantes no plano ao longo da trajetória não-linear de equilíbrio das cascas conoidais parabólicas e cilíndricas através das Figuras 4.26 a 4.31. 
Figura 4.26- Trajetória não-linear de $\mathrm{N}_{\mathrm{x}}$ do conóide parabólico de condição de contorno $\mathrm{A}_{2} \mathrm{~A}_{2} \mathrm{~A}_{2} \mathrm{~A}_{2}$

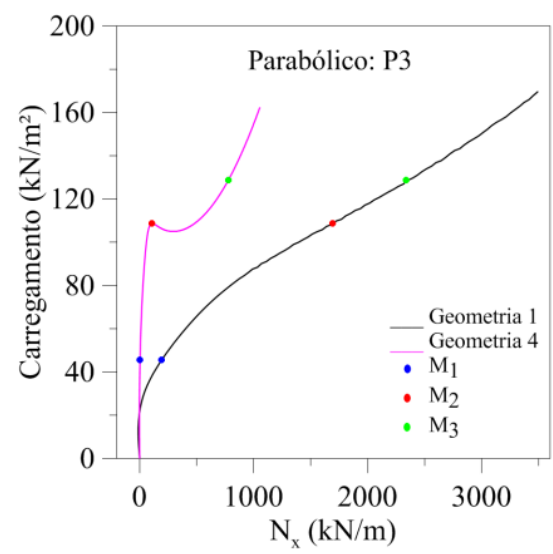

Geometria 1

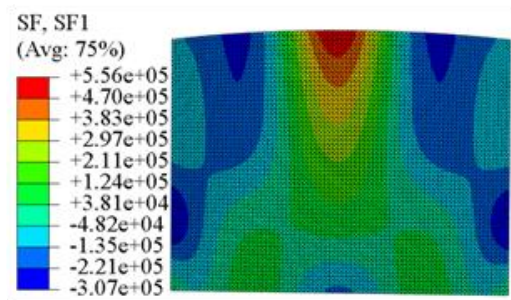

(b) $\mathrm{M}_{2}$

(c) $\mathrm{M}_{3}$

(a) $\mathrm{M}_{1}$
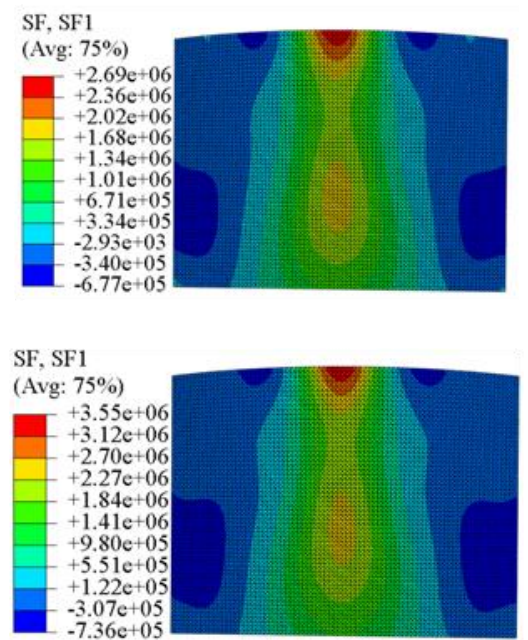

Geometria 4
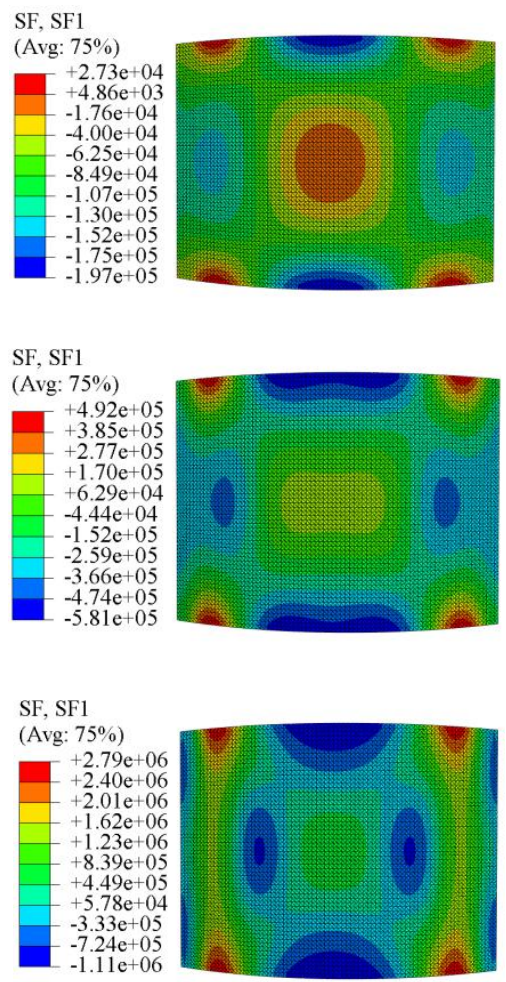

Nas trajetórias não-lineares dos esforços normais, $N_{x}$, visualizadas nas Figuras 4.26 e 4.27 para os conóides parabólicos e cilíndricos de Geometria 1, notou-se que estes esforços têm grandes magnitudes em várias regiões da casca e que as regiões das bordas retas são predominantemente comprimidas e pequenas regiões de tração nas proximidades das bordas curvas $\mathrm{H}_{2}$. Os esforços normais internos $N_{x}$ são, na maioria dos casos estudados, superiores na casca de Geometria 1. O esforço de membrana $\mathrm{N}_{\mathrm{x}}$ é simétrico em torno do eixo $\mathrm{x}$, independentemente da forma da borda curva ou da geometria do conóide 
Figura 4.27- Trajetória não-linear de $\mathrm{N}_{\mathrm{x}}$ do conóide cilíndrico de condição de contorno $\mathrm{A}_{2} \mathrm{~A}_{2} \mathrm{~A}_{2} \mathrm{~A}_{2}$

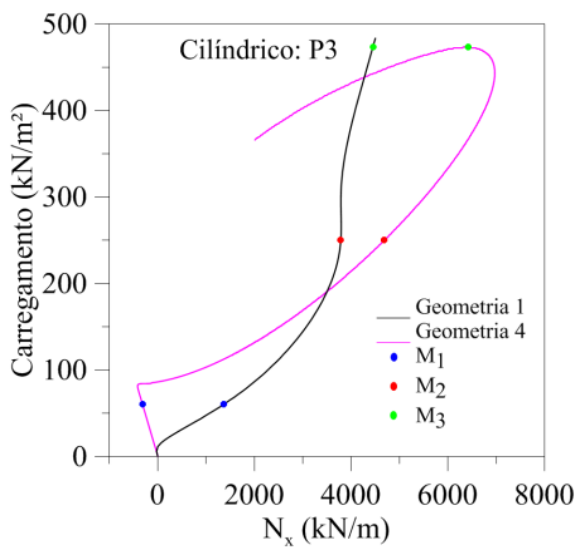

Geometria 1

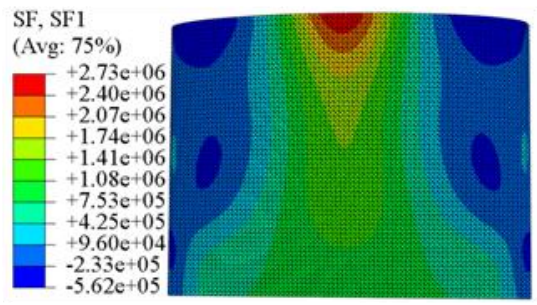

(b) $\mathrm{M}_{2}$

(c) $\mathrm{M}_{3}$
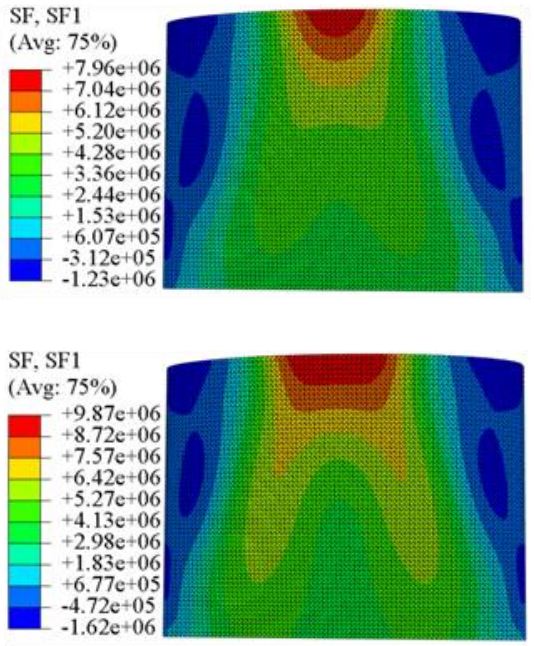

Geometria 4
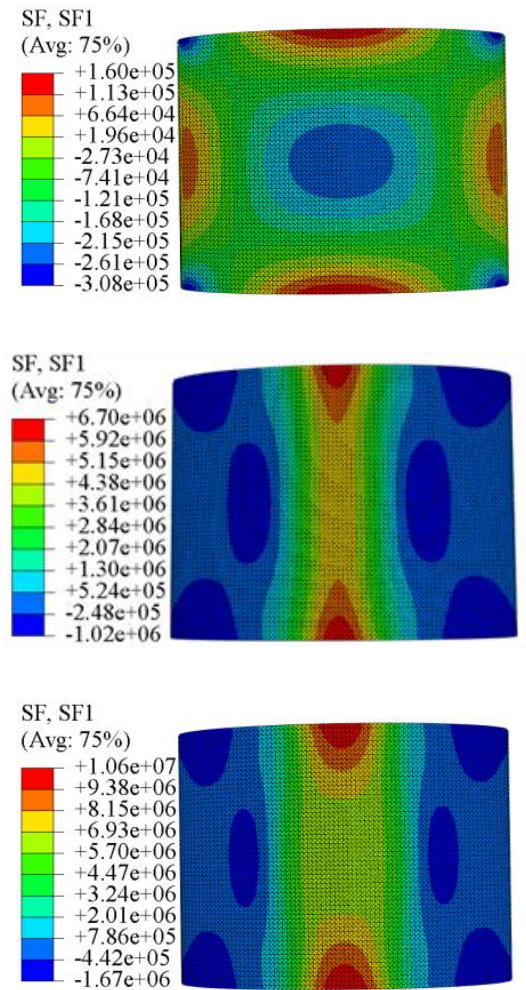

Já as trajetórias dos conóides de Geometria 4 são diferentes para os casos parabólicos e cilíndricos. No caso parabólico, a princípio, há pontos de tração e compressão nas das bordas curvas, tração na região central e compressão próxima às bordas retas com o incremento de carga surge compressão na região central. No caso cilíndrico, a princípio, há pontos de tração e compressão nas duas bordas curvas, compressão na região central e tração próxima às bordas retas. Com o incremento de carga surgiu compressão na região das bordas retas e tração nas duas bordas curvas, organizando-se em faixas paralelas ao eixo $x$. 
Figura 4.28- Trajetória não-linear de $\mathrm{N}_{\mathrm{y}}$ do conóide parabólico de condição de contorno $\mathrm{A}_{2} \mathrm{~A}_{2} \mathrm{~A}_{2} \mathrm{~A}_{2}$

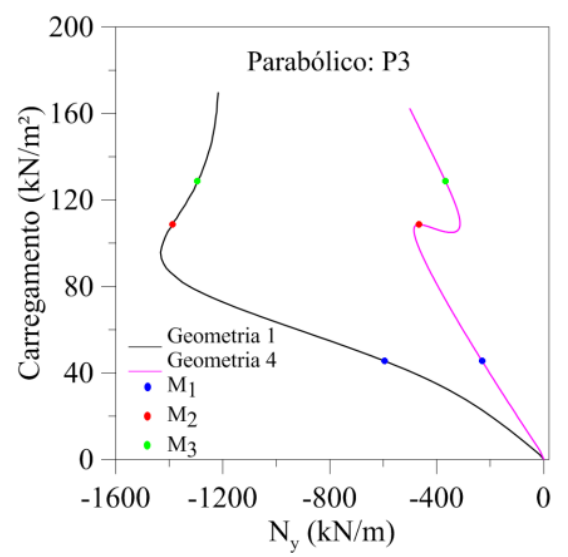

Geometria 1

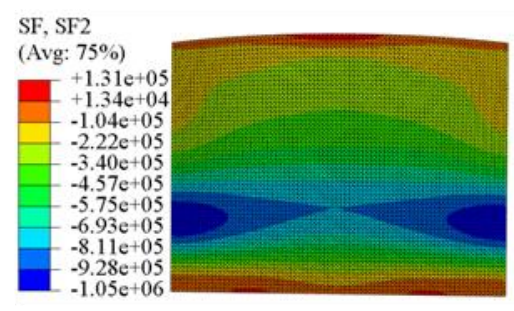

(b) $\mathrm{M}_{2}$

(c) $\mathrm{M}_{3}$
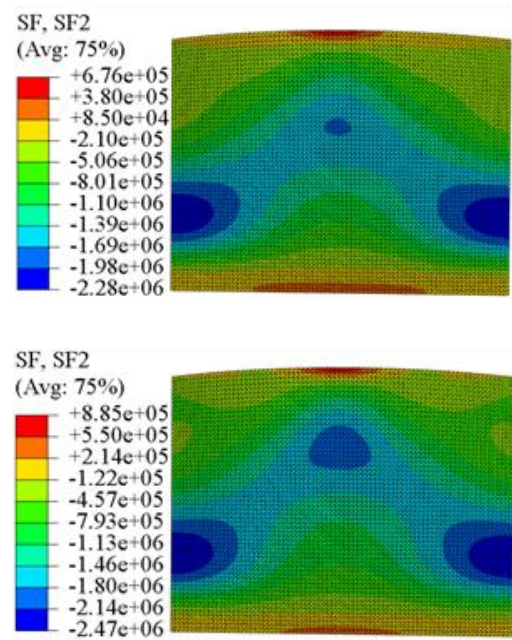

Geometria 4
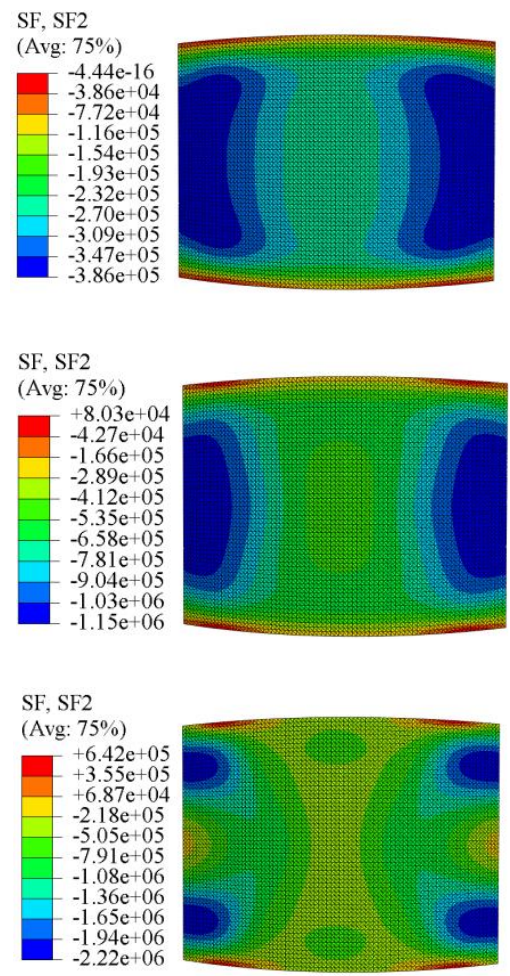

Outro esforço de membrana com trajetórias não-lineares de grandes magnitudes em várias regiões dos conóides são os esforços normais $N_{y}$, Figuras 4.28 e 4.29, nos quais a distribuição dos esforços internos $N_{y}$ é simétrica em torno do eixo $x$. Os conóides de Geometria 1 apresentaram comportamentos semelhantes tanto nos casos cilíndricos como nos parabólicos, Figuras 4.28 e 4.29, com faixas de compressão de uma borda reta a outra borda reta, além de tração, de menor concentração, nas bordas curvas. Já no conóide de Geometria 4 de bordas curvas parabólicas, Figura 4.28, identificou-se uma alta concentração de compressão junto aos apoios de bordas retas com pequena concentração de tração nas bordas curvas. No caso 
cilíndrico, Figura 4.29, observou-se uma alta concentração de compressão na parte central durante toda a trajetória de equilíbrio.

Figura 4.29- Trajetória não-linear de $\mathrm{N}_{\mathrm{y}}$ do conóide cilíndrico de condição de contorno $\mathrm{A}_{2} \mathrm{~A}_{2} \mathrm{~A}_{2} \mathrm{~A}_{2}$

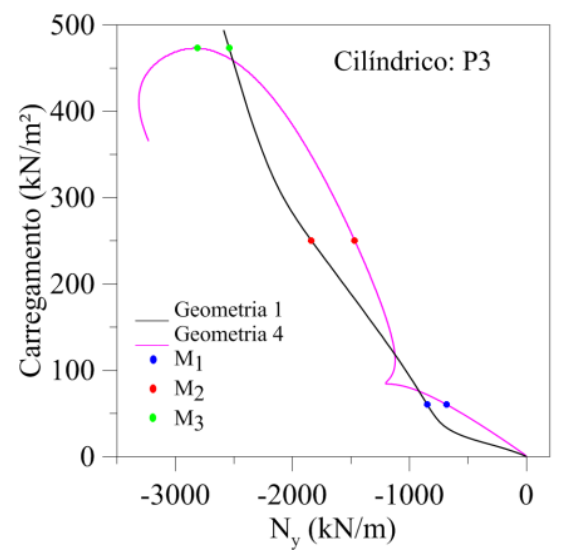

\section{Geometria 1}

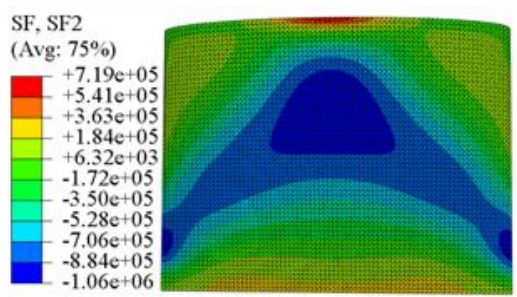

(b) $\mathrm{M}_{2}$

(a) $\mathrm{M}_{1}$

(c) $\mathrm{M}_{3}$
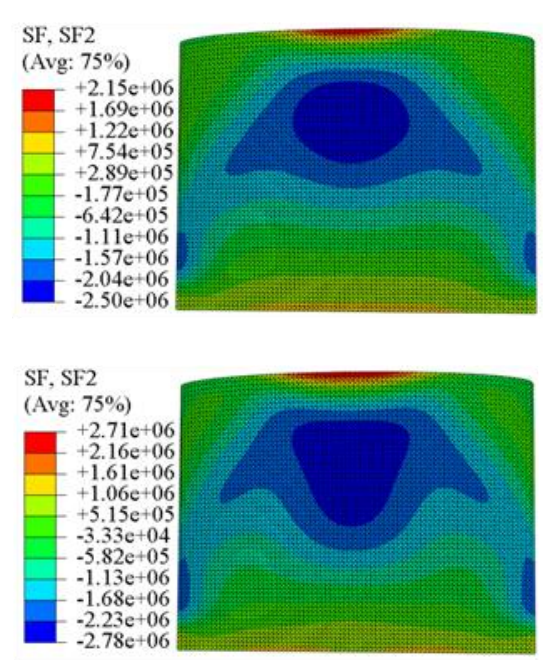

Geometria 4
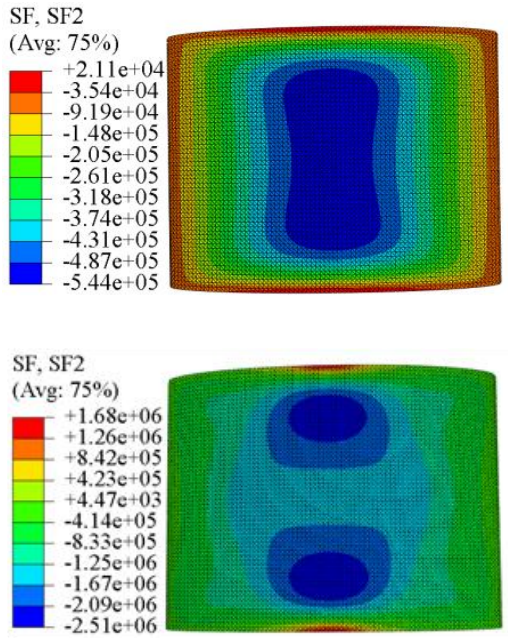

SF, SF2

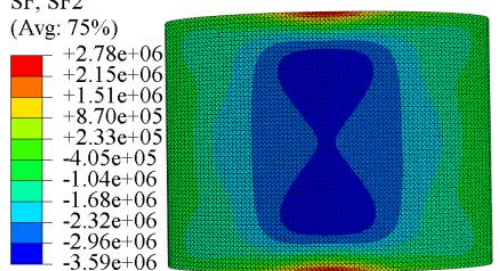

Nas Figuras 4.30 e 4.31 a seguir, podem ser visualizadas as distribuições dos esforços normais cisalhantes no plano, $N_{x y}$. Verificou-se que, no ponto estudado, suas magnitudes são inferiores aos demais esforços de membrana, mas há regiões de concentração desses esforços, como por exemplo, nas regiões próximas as bordas curvas. Observou-se também, como esperado, a distribuição anti-simétrica de esforços em relação ao eixo $x$. 
Figura 4.30- Trajetória não-linear de $\mathrm{N}_{\mathrm{xy}}$ do conóide parabólico de condição de contorno $\mathrm{A}_{2} \mathrm{~A}_{2} \mathrm{~A}_{2} \mathrm{~A}_{2}$

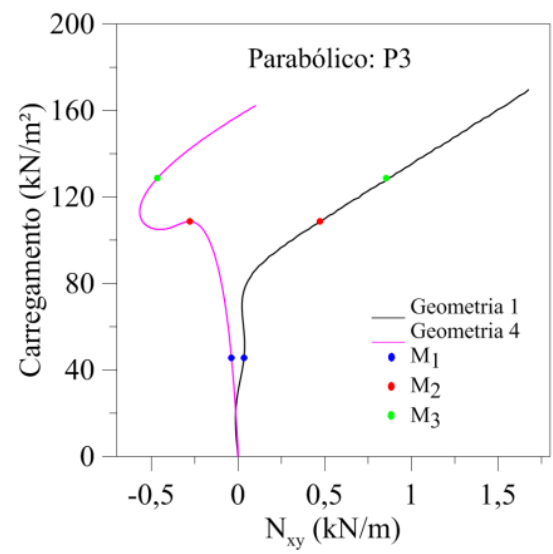

Geometria 1
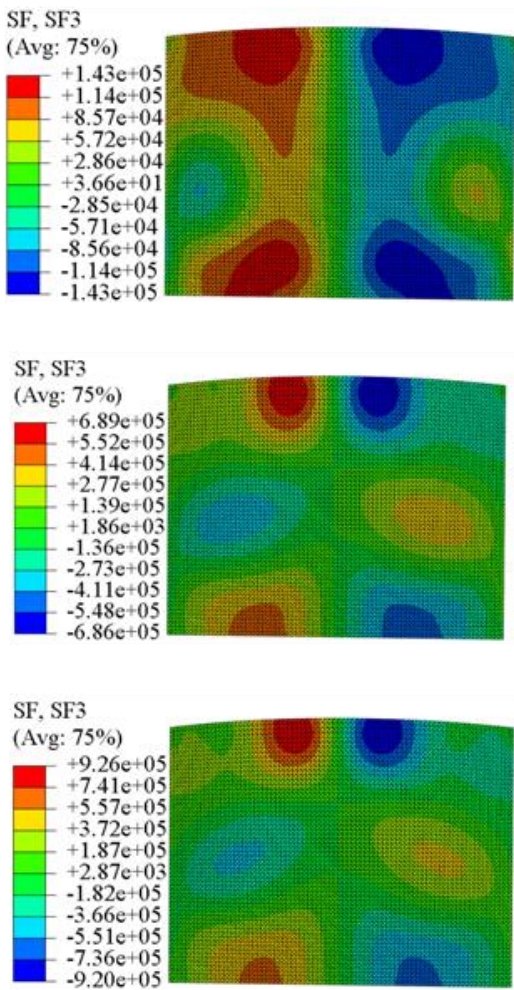

Geometria 4
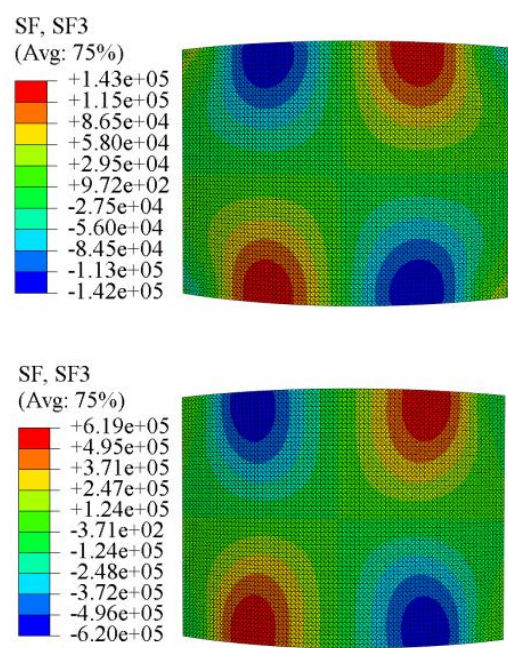

SF, SF3

(Avg: $75 \%$ )

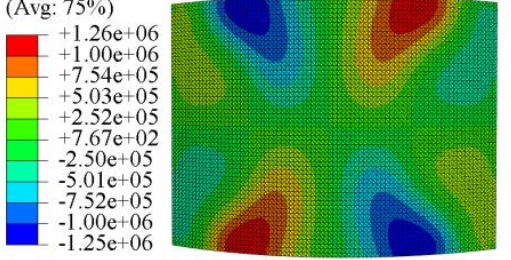


Figura 4.31- Trajetória não-linear de $\mathrm{N}_{\mathrm{xy}}$ do conóide cilíndrico de condição de contorno $\mathrm{A}_{2} \mathrm{~A}_{2} \mathrm{~A}_{2} \mathrm{~A}_{2}$

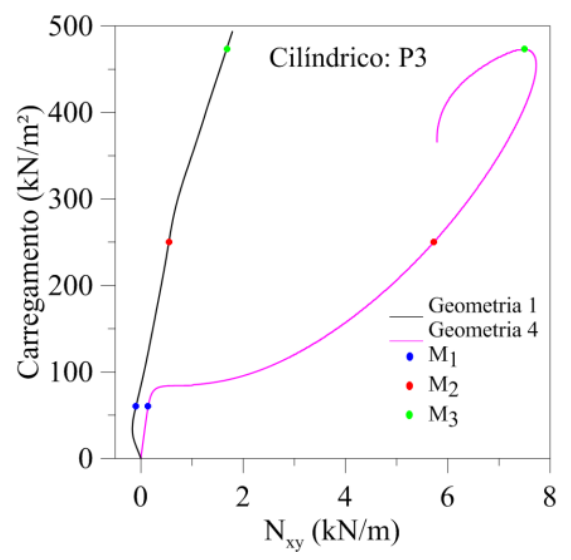

Geometria 1

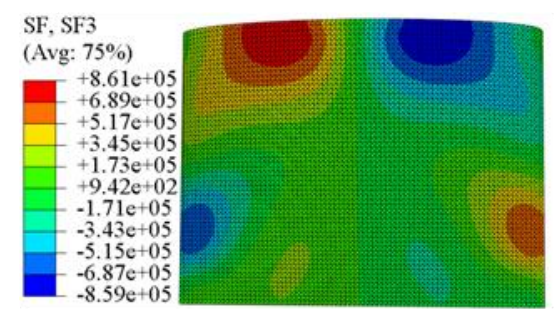

(b) $\mathrm{M}_{2}$

(c) $\mathrm{M}_{3}$

(a) $\mathrm{M}_{1}$

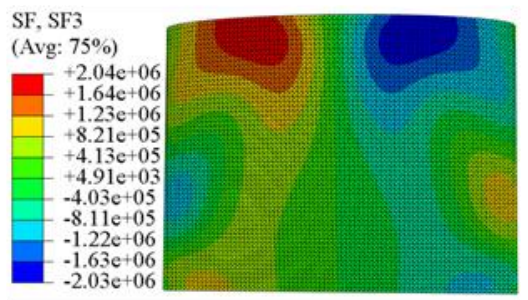

Geometria 4
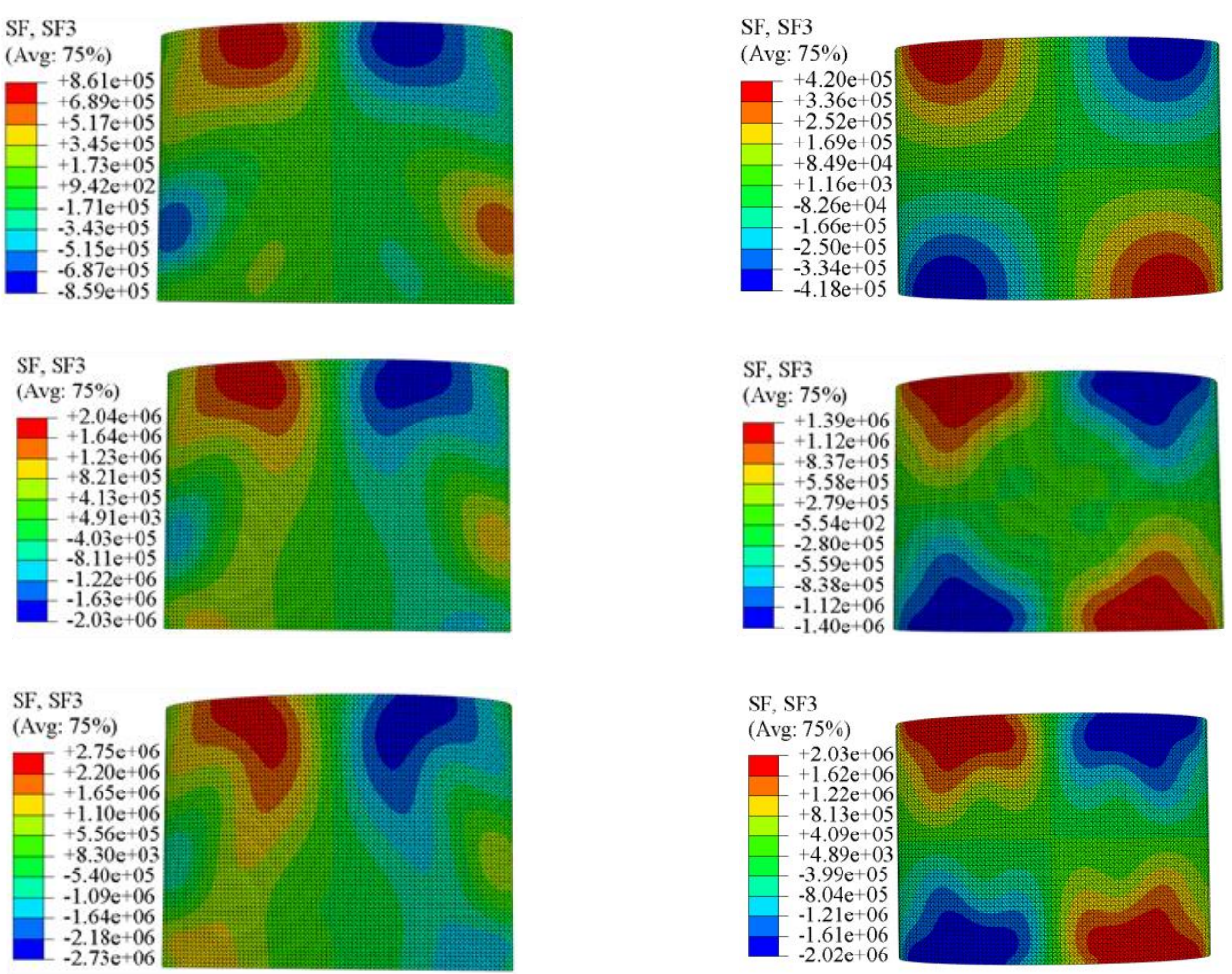

Por fim, notou-se nas formas das trajetórias dos esforços de membrana e das resultantes de flexão e de torção que a variação das alturas das bordas curvas das cascas conoidais apoiadas nas quatro bordas e a consideração das não-linearidades geométricas promoveram caminhos não-lineares diferenciados para os efeitos de membrana e de momentos. Verificaram-se no decorrer da trajetória que dependendo da geometria, as regiões comprimidas não estão necessariamente nos apoios, mas existem regiões com altas, ou baixas, concentrações de compressão, ou tração, bem como momentos positivos, ou negativos, cujas coordenadas deslocaram-se à medida que se incrementou carregamento ao sistema. Deve-se destacar que 
no ponto de observação, $\mathrm{P}_{3}$, em todos os conóides de Geometria 1 com condição de apoio $\mathrm{A}_{2} \mathrm{~A}_{2} \mathrm{~A}_{2} \mathrm{~A}_{2}$, independentemente da forma da borda curva, o carregamento transversal provocou maiores valores das resultantes de membrana e de momento no ponto de observação na trajetória de equilíbrio $\mathrm{M}_{1}$. 


\section{CAPÍTULO 5 \\ CONCLUSÕES}

Este capítulo apresenta as conclusões obtidas com a pesquisa sobre cascas conoidais abatidas. Levando-se em consideração as equações não-lineares de equilíbrio das cascas conoidais de bordas curvas parabólicas, ou cilíndricas, verificou-se que a presença de não-linearidades sugere grande influência no comportamento dos conóides. Isso ocorre principalmente na equação dos deslocamentos transversais com a presença de termos cúbicos. Os deslocamentos $u, v$ e $w$ aparecem em cada uma das equações de equilíbrio, sugerindo um forte acoplamento modal entre os campos de deslocamentos, além disso, percebeu-se a existência da função de forma $\bar{z}(x, y)$ e de suas derivadas indicando que o tipo de curva das bordas também influencia no comportamento do conóide.

Pela observação dos resultados da análise estática linear, percebeu-se que variando os parâmetros de geometria, condições de contorno e tipo de curva das bordas, obtiveram-se cargas críticas diferenciadas em cada caso sendo as topologias dos modos de flambagem afetadas alterando-se o número de semi-ondas e até mesmo suas disposições ao longo da superfície dos conóides. As magnitudes das componentes de deslocamentos transversais $w$ mostraram-se superiores às amplitudes dos campos de deslocamentos $u$ e $v$, e ainda observouse que simetria nas condições de contorno, ou na geometria, gerou simetria, ou anti-simetria, nos campos de deslocamentos em torno do eixo axial $x$. Porém, para as geometrias com valores da altura máxima das bordas curvas diferentes e apoios assimétricos com uma borda curva livre, a disposição das semi-ondas circunferenciais na forma deslocada é fortemente dependente da coordenada axial.

Com a análise analítica da complexidade das componentes dos campos de deslocamentos do modo de flambagem verificou-se a dificuldade para se desenvolver soluções analíticas para esse problema. Nas decomposições obtidas ocorreu à existência de modos complexos com a presença de outros modos de flambagem de configurações distintas em seus números de semiondas, para conseguir descrever o modo de flambagem obtido via MEF. A expansão modal decomposta proposta para os deslocamentos $w$ apresentou boa convergência em relação à 
resposta obtida via MEF, porém as decomposições obtidas para descrever os deslocamentos $v$ e $u$ divergiram em várias regiões da casca conoidal parabólica constituindo aproximações de menor precisão. Com isso, há necessidade de obtenção da solução modal que considere os acoplamentos e as interações modais que decorrem das não-linearidades geométricas presentes nas equações de equilíbrio através de técnicas analíticas para a obtenção consistente dessas expansões modais, como por exemplo, o método da perturbação.

Levando-se em consideração a análise paramétrica estática não-linear, percebeu-se que as não linearidades geométricas produziram trajetórias de equilíbrio com comportamentos altamente não-lineares tanto nos casos parabólicos como nos cilíndricos e essas trajetórias também se mostraram influenciadas pela geometria e condições de contorno avaliadas. Obtiveram-se cargas limites não-lineares com alta ou baixa, capacidades de carga em comparação às análises lineares das cargas críticas, o que deixa claro que a análise linear pode subestimar ou superestimar o comportamento não-linear das cascas conoidais não sendo recomendada sua adoção em análises de estruturas tipo conóides. Dessa forma, a consideração das nãolinearidades provenientes da geometria, abordadas nesta dissertação, tem crucial importância nos resultados.

Pela observação das topologias dos campos de deslocamentos, bem como dos esforços de membrana e momentos internos, ao longo das trajetórias de equilíbrio, percebeu-se que são influenciados pelas não-linearidades geométricas alterando-se ao longo da incrementação de carga. O que implica a grande importância da consideração das não-linearidades geométricas nos estudos das cascas conoidais.

Ainda há muito que avançar nos estudos das cascas conoidais e para melhor entendimento do comportamento não-linear, sugerem-se as seguintes abordagens para trabalhos futuros:

- análise estática e dinâmica de conóides considerando-se as não-linearidades físicas e geométricas, variando-se parâmetros de geometria e condições de contorno.

- estudo da influência das condições de contorno e da variação de parâmetros geométricos no comportamento dinâmico, comparando-se cascas conoidais de bordas curvas parabólicas, ou cilíndricas;

- $\quad$ análise estática e dinâmica não-linear de cascas conoidais submetidas a carregamento axial; 
- $\quad$ análise do acoplamento modal na perspectiva de se obter uma solução modal para descrever o campo de deslocamento e, com isso, obter uma análise analítica não-linear de cascas conoidais;

- $\quad$ análise estática e dinâmica da influência de aberturas presentes em diferentes posições na superfície dos conóides parabólicos e cilíndricos variando-se parâmetros de geometria. 


\section{REFERÊNCIAS}

ABAQUS 6.11. ABAQUS/CAE User's Manual. Dassault Systemes, USA, 2011.

ALIJANI, F.; AMABILI, M. Nonlinear vibrations of thick laminated circular cylindrical panels. Composite Structures, v. 96, p. 643-660, 2012.

ALMROTH, B. O.; BRUSH, D. O. Buckling of Bars, Plates and Shells. USA: McGraw-Hill Book Company, Inc, 1975.

AMABILI, M. Nonlinear vibrations of circular cylindrical panels. Journal of Sound and Vibration, v. 281, p. 509-535, 2004.

BANDYOPADHYAY, J. N.; CHAKRAVORTY, D.; SINHA, P. K. Finite element free vibration analysis os conoidal shells. Computers \& Structures, v. 56, n. 6, p. 975-978, 1995 BANDYOPADHYAY, J. N. A. GHOSH, B. Approximate bending analysis of conoidal shells using the Galerkin method. Computers e Structures, Great Britain, 36, n. 5, p. 801-805, 1990.

CAVALCANTI, L. V. Análise da estabilidade e vibrações de cascas conoidais abatidas. Dissertação (Mestrado em Engenharia Civil)- Pontifícia Universidade Católica do Rio de Janeiro. Rio de Janeiro, p. 154. 2015.

CHAKRAVORTY, D.; DAS, H. S. A finite element application in the analysis and design of point-supported composite conoidal shell roofs: suggesting selection guidelines. Departamento de Engenharia Civil, Univesidade de Jadavpur, Kolkata, Índia. 2009.

CRISFIELD, M. A. Non-linear finite element analysis os solids and structures. v. 1. John Wiley \& Sons Ltd. p. 234-238, England, 1991.

DEBONGNIE, J. F. Physical interpretation and generalization of Marguerre's shallow shell theory. Int J. Eng Sci. v. 17, p. 387-399, 1978.

DEL PRADO, Z. J. G. N.; GONÇALVES, P. B.; SILVA, F. M. A. Low-dimensional models for the nonlinear vibration analysis of cylindrical shells based on a perturbation procedure and proper orthogonal decomposition. Journal of Sound and Vibration, v. 315, p. 641-663, 2008. 
DINIS, H.; MEDRANO, R. H.; MEIRELLES, C. R. M. The application of finite element modeling in the design of reinforced concrete shell. Universidade Presbiteriana Mackenzie, Brasil. 2009

FGV. Torre Oscar Niemeyer: Galeria de fotos. Fundação Getúlio Vargas. Diponível em:< http://torre-oscar-niemeyer.fg v.br/galeria>. Acesso: 25/03/2016.

FONTES, R. Análise de casca de alvenaria cerâmica armada- Tipo parabolóide hiperbólico. Dissertação (Mestrado em Engenharia de Estruturas) - Escola de Engenharia da Universidade Federal de Minas Gerais. Minas Gerais, p. 121. 2005.

GONÇALVES, P. B.; SOARES, R. M. Buckling and nonlinear vibrations analysis of conoidal shells. In: 23rd ABCM International Congress of Mechanical Engineering, 2015, Rio de Janeiro, Brasil.

GONÇALVES, P. B.; SOARES, R. M.Análise numérica do comportamento não-linear estático e dinâmico de cascas conoidais. In: Proceedings of the 37th CILAMCE IBERIAN LATIN-AMERICAN CONGRESS ON COMPUTACIONAL METHODS IN ENGINEERING, 2016, Brasílial, 6-9 Novembro, 2016.

HANAI, J. B.; TEIXEIRA, P. W. G. N. Projeto e execução de coberturas em casca de concreto com forma de membrana pênsil invertida e seção tipo sanduíche. Cadernos de Engenharia de Estruturas, São Carlos, n. 19, p. 101-131, 2002.

ROSA, M. Igreja São Francisco de Assis. Disponível em:<http://www.belohorizonte.mg.gov. br/node/31084>. Acesso: 25/03/2016.

SASHOO, S. Dynamic characters of stiffened composite conoidal shell roofs with cutouts: design aids and selection guidelines. Hindawi Publishing Corporation Journal of Engineering, v. 2013, p. 18, 2013. ID 230120

SATTLER, H. A. R. Modelo de baixa dimensão para análise dinâmica de painel cilíndrico simplesmente apoiado. Dissertação de mestrado- PPG-GECON, Universidade Federal de Goiás, Goiânia, p. 75. 2015.

SILVA, F. M. A. Modelos de Dimensão Reduzida para Análise das Oscilações NãoLineares e Estabilidade de Cascas Cilíndricas. Tese (Doutorado em Engenharia Civil) Pontifícia Universidade Católica do Rio de Janeiro. Rio de Janeiro, p. 182. 2008.

STAVRIDIS, L. T. Dynamic analysis of shallow shells of rectangular base. Journal of Sound an Vibration, 861-882, sv981907, 1998. 
STRUCTURAE. Felix Candela: Biographical Information. International Database for Civil and Structural Engineering. Disponível em: 〈https://structurae.net/persons/felix-candela> Acesso: 25/03/2016

VISOTTO, I. Geração computacional de formas livres de estruturas em casca. Tese (Doutorado em Engenharia Mecânica)- Universidade Estadual de Campinas. Campinas, p. 195. 1993.

PLAZA, M. J. C. Eduardo Torroja Miret. Diccionario Biográfico Espanol. Real Academia de la Lengua Espanola (2011). Disponível em: <http://www.fundacioneduardotorroja.org/inde x.php/en/eduardo-torroja/biografia.html?showall=\&limitstart=>

ZIGONI, C. Eleições 2014: Congresso Nacional permanecerá desigual nos próximos 4 anos. Notícias do INESC. Disponível em:< http://www.inesc.org.br/noticias/noticias-doinesc/2014/outubro/eleicoes-2014-congresso-nacional-permanecera-desigual-nos-proximos-4anos> . Acesso: 24/05/2016. 